Ironies of Solidarity 


\section{Politics and Development in Contemporary Africa}

Published by one of the world's leading publishers on African issues, 'Politics and Development in Contemporary Africa' seeks to provide accessible but in-depth analysis of key contemporary issues affecting countries within the continent. Featuring a wealth of empirical material and case study detail, and focussing on a diverse range of subject matter - from conflict to gender, development to the environment - the series is a platform for scholars to present original and often provocative arguments. Selected titles in the series are published in association with the International African Institute.

\section{Editorial board}

Rita Abrahamsen (University of Ottawa); Morten Boas (Norwegian Institute of International Affairs); David Booth (Overseas Development Institute); Padraig Carmody (Trinity College Dublin); Neil Carrier (University of Bristol); Fantu Cheru (Leiden University); Kevin Dunn (Hobart and William Smith Colleges); Amanda Hammar (University of Copenhagen); Alcinda Honwana (Open University); Paul Jackson (University of Birmingham); Gabrielle Lynch (University of Warwick); Zachariah Mampilly (Vassar College); Henning Melber (Dag Hammarskjöld Foundation); Garth A. Myers (Trinity College Hartford Connecticut); Léonce Ndikumana (UMass Amherst); Cyril Obi (Social Science Research Council); Susan Parnell (University of Cape Town); Mareike Schomerus (Overseas Development Institute); Laura Seay (Morehouse College); Howard Stein (University of Michigan); Mats Utas (Uppsala University); Alex de Waal (Tufts University)

\section{Already published}

Mobility between Africa, Asia and Latin America: Economic Networks and Cultural Interactions, edited by Ute Röschenthaler and Alessandro Jedlowski

Agricultural Development in Rwanda: Authoritarianism, Markets and Spaces of Governance, Chris Huggins

Liberia's Female Veterans: War, Roles and Reintegration, Leena Vastapuu and Emmi Nieminen

Food Aid in Sudan: A History of Power, Politics and Profit, Susanne Jaspars

Kakuma Refugee Camp: Humanitarian Urbanism in Kenya's Accidental City, Bram J. Jansen 
Development Planning in South Africa: Provincial Policy and State Power in the Eastern Cape, John Reynolds

Uganda: The Dynamics of Neoliberal Transformation, Jörg Weigratz

AIDS in the Shadow of Biomedicine: Inside South Africa's Epidemic, Isak Niehaus

Infrastructure and Hybrid Governance in the Democratic Republic of Congo, edited by Kristof Titeca and Tom De Herdt

BRICS and Resistance in Africa: Contention, Assimilation and Co-optation, edited by Justin van der Merwe, Patrick Bond, and Nicola Dodd

Forthcoming titles

Entrepreneurs and SMEs in Rwanda: Conspicuous by their Absence, David Poole

Malawi: Economy, Society and Political Affairs, edited by Matthias Rompel and Reimer Gronemeyer

Undoing Coups: The African Union and Post-coup Intervention in Madagascar, Antonia Witt

Africa's Shadow Rise: China and the Mirage of African Economic Development, Padraig Carmody and Peter Kragelund

Contesting Africa's New Green Revolution: Biotechnology and Philanthrocapitalist Development in Ghana, Jacqueline Ignatova

Economic Diversification in Nigeria: Fractious Politics and an Economy Beyond Oil, Zainab Usman

The Politics of Fear in South Sudan: Generating Chaos, Creating Conflict, Daniel Akeck Thiong 


\section{About the author}

Erik Bähre is Associate Professor at the Institute of Cultural Anthropology and Development Sociology at Leiden University. He is the Principal Investigator of the ERC Consolidator Project 'Moralising Misfortune: A Comparative Anthropology of Commercial Insurance' and author of Money and Violence: Financial Self-Help Groups in a South African Township.

\section{Published in association with the International African Institute}

The principal aim of the International African Institute is to promote scholarly understanding of Africa, notably its changing societies, cultures and languages. Founded in 1926 and based in London, it supports a range of publications including the journal Africa.

www.internationalafricaninstitute.org 


\section{Ironies of Solidarity}

Insurance and Financialization of Kinship in South Africa

\section{Erik Bähre}


Ironies of Solidarity: Insurance and Financialization of Kinship in South Africa was first published in 2020 by Zed Books Ltd, The Foundry, I 7 Oval Way, London SEII ${ }_{5}$ RR, UK.

www.zedbooks.net

Copyright (c) Erik Bähre 2020

The right of Erik Bähre to be identified as the author of this work has been asserted by him in accordance with the Copyright, Designs and Patents Act, I 988

Typeset in Plantin by Swales and Willis Ltd, Exeter, Devon

Index by Rohan Bolton

Cover design by Burgess and Beech

Cover photo $\odot$ Joan Bardeletti / Panos Pictures

Printed and bound by the CPI Group Ltd (UK), Croydon, CRo 4 YY

All rights reserved. No part of this publication may be reproduced, stored in a retrieval system or transmitted in any form or by any means, electronic, mechanical, photocopying or otherwise, without the prior permission of Zed Books Ltd.

A catalogue record for this book is available from the British Library

ISBN $978-\mathrm{I}-78699-857-6 \mathrm{hb}$

ISBN 978-I-78699-858-3 pb

ISBN 978-I-78699-856-9 pdf

ISBN 978-I-78699-854-5 epub

ISBN 978-I-78699-8 55-2 mobi

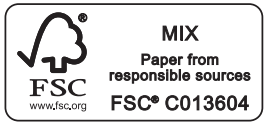


To the memory of Simnikiwe "Nana" Moyikwa/Dingile, I988-20I 5 



\section{Contents}

List of illustrations $\quad$ XI

Acknowledgements XIII

I. Introduction I

2. An ironic analysis $\quad$ I8

3. Hope and redistribution 39

4. Penetrating a new market 56

5. The Janus face of inclusion $8 \mathrm{I}$

6. The enchantment of abstract finance IOO

7. Transforming mutualities in business II9

8. Death as moral hazard I40

9. Conclusion: ironies of solidarity I65

$\begin{array}{ll}\text { Notes } & \text { I79 }\end{array}$

$\begin{array}{ll}\text { Bibliography } & \text { I } 90\end{array}$

Index 209 



\section{Illustrations}

\section{Figures}

6.I Threats to sustainability of insurance for the poor and lower middle classes (LSM I-5) according to actuaries (\%)

6.2 "In the eyes of members of low income households (LSM I-5), how trustworthy are ..."

6.3 Residents of Indawo Yoxolo and Tembani: "How trustworthy do you think are ..."

8. I Funerals: advantages taken

\section{Tables}

I.I Insurance uptake, Indawo Yoxolo and Tembani, Cape Town

4.I Survey response from actuaries on policies of the South African government: "The government has developed BEE policies which improve the insurance industry"

4.2 Survey response from actuaries on policies of the South African government: "The government has developed BEE policies which improve clients' access to insurance products"

4.3 Survey response from actuaries on policies of the South African government: "The National Health Insurance Scheme (NHIS) will make citizens depend on the state"

4.4 Survey response from actuaries on policies of the South African government: "The National Health Insurance Scheme (NHIS) is meant to ensure political support for the ANC"

7.I Schematic representation of identities and affiliations of taxi associations 



\section{Acknowledgements}

If it were not for insurance, this book would not have been written. And if it were not for how South African insurance companies expanded their markets, I could not have studied how insurance was related to democratization and became part of the everyday lives of people in the townships of Cape Town. My first research there took place in I995, a year after South Africa's landmark first democratic elections. At the time, insurance was virtually absent in the townships and people relied on neighbors, kin, and other social networks to overcome adversities. This changed dramatically over the next twenty years as insurance companies began developing products that targeted Africans. Today, insurance has become a very important and simultaneously discreet part of everyday life.

There is also a personal reason why the book would probably not have come into being if it had not been for insurance. When I was about to start fieldwork, I became very ill. It was my insurance that paid for the very expensive treatment. I doubt if I would have survived without insurance, but without a doubt the medical expenses would have financially crippled me and my family, with devastating consequences especially for my children. For that reason, I am grateful to people I have never met and never will meet. Despite not knowing one another, they helped me and my family overcome a life-threatening adversity. Acknowledging them might seem out of place. It is not about personal relations or social obligations. It is not even about charity, since my insurance consists of contractual obligations with a private company. But I am nonetheless grateful that this large-scale and abstract form of solidarity exists, that an insurance company makes this kind of solidarity possible, and that the state regulates it in such a way that money is made available to cure me and others.

My deep gratitude goes to the residents of Indawo Yoxolo, Tembani, and other townships in Cape Town - for our conversations, for inviting me to events, and for sharing important aspects of their lives with me. I especially value the insights they gave me into the less heroic and benevolent episodes of their lives - aspects that were not sanitized by a language of how things ideally should be, but that actually revealed how life really is. I greatly appreciate how people dealt 
with our differences, which are so deeply entrenched in South Africa's history. Over the years, their world became a part of my world, and changed the way I look at life. This enrichment goes far beyond this book. Edith Moyikwa and Vido Sam dedicated indispensable support during fieldwork. I am very grateful to Edith for taking care of my safety and for being a wonderful, patient, and fun teacher.

I thank Rob Thomson, for giving insights into basic actuarial knowledge. The Actuarial Society of South Africa and Actuaries Without Borders graciously assisted me in meeting actuaries and distributed the online survey among its members. I am grateful to actuaries and others working in South Africa's insurance sector for showing me the complex and sensitive political issues they face.

I thank my colleagues and staff at the Institute of Cultural Anthropology and Development Sociology at Leiden University for supporting my work and for our critical conversations about ethnography, economic anthropology, African Studies, and anthropology in general.

My deep appreciation goes to Antonádia Borges, João de Pina Cabral, Maghiel van Crevel, Tamás Csikós, Marleen Dekker, Ton Dietz, JanBart Gewald, Fabíola Gomes, Maia Green, Chris Hann, Keith Hart, Debora James, Don Kalb, Anouk de Koning, Sabine Luning, Marianne Maeckelbergh, Bettina Mahlert, Amade M'charek, Isak Niehaus, Peter Pels, Yolisa Pikie, Daivi Rodima-Taylor, Hadrien Saiag, Günther Schlee, Sylvia Terpe, Bonno Thoden van Velzen, Cees van der Waal, Jörg Wiegratz, and Ilana van Wyk. Our engaging and critical conversations contributed to shaping the ideas and methods of this study and helped define its boundaries. Often a very casual remark, over a drink or during a walk, had a profound impact.

This project received funding from: NWO, which allowed me to work at AMIDSt, now AISSR, at the University of Amsterdam; the ESRC, by taking part in Deborah James' LSE project on popular economies in South Africa; and the European Research Council (ERC) under the Horizon 2020 Research and Innovation Programme (Grant No. 682467).

My fellowship at the Netherlands Institute of Advanced Studies (NIAS) provided time to think, read, write, and have inspiring conversations with scholars working on similar issues, but from distinct disciplinary traditions. The animated conversations with Tazuko van Berkel and her thoughtful feedback on the manuscript galvanized the more philosophical take on solidarity and money.

Nikkie Buskermolen, Tim van de Meerendonk, Irene Moretti, Nikki Mulder, and Robert Ross carefully read an entire draft of the manuscript 
and offered insightful comments that helped me clarify my arguments and write a better book.

I thank Aaron Gundogan and Matthijs Kallenberg for assisting with the bibliography. I am grateful to Jill Haring for editing my English and helping navigate a language that will never completely feel like home.

I am grateful to the editors at the International Africa Institute and Zed Books for their critical and constructive comments throughout the publishing process, and the three anonymous reviewers who provided superb suggestions. I thank Stephanie Kitchen, managing editor, for ensuring a smooth publication process, Jonathan Hoare for copy-editing, and Rohan Bolton for indexing.

My deepest gratitude goes to Esther, Ruben, and Nina for adjusting their lives and giving me space to work during days and hours that are ideally reserved for family life, and for accepting the absence of their husband and father during fieldwork.

This book examines the ironies of solidarity in relation to kinship and dependency and shows how difficult solidarity can sometimes be. One might wonder if this analysis, and the central role of irony, took any inspiration from my own biography and family history. Rest assured: Of course not! 
Du kannst Dich zurückhalten von den Leiden der Welt, das ist Dir freigestellt und entspricht Deiner Natur, aber vielleicht ist gerade dieses Zurückhalten das einzige Leid, das Du vermeiden könntest.

You can withdraw from the suffering of the world, you have free permission to do so, and it is in accordance with your nature, but perhaps this very holding back is the one suffering you could have avoided.

Franz Kafka (writer and insurance employee, translation by Muirs) 


\section{$\mathbf{I}$}

\section{Introduction}

After apartheid ended in 1994, South African insurance companies quickly established specific departments to target the poor and lower middle classes. Some companies opened offices in the African and colored townships and hired local brokers from these areas. ${ }^{1}$ They visit people in their homes, approach them at taxi ranks and train stations, and give presentations at schools, police stations, medical centers, and even military bases. Insurance brokers set up their overhead projectors in staff rooms to describe their products and the benefits they bring. They mostly sell funeral insurance, along with other products such as endowment plans, retirement annuities, and policies that cover schooling costs for children or grandchildren. Twenty years ago, such presentations were unknown, but today they occur on a regular and frequent basis, to the point where it has become common for insurance brokers to present their products at local schools about once a month.

The insurance sector has always been strong in South Africa, with most companies headquartered in Cape Town. However, until I994, when the first democratic elections were held in the country, not much attention had been given to the relatively poor African population. Since then, insurance companies have created new policies that target poorer people and have expanded their infrastructure to include relatively poor clients. Most of these companies are of South African origin, like Liberty, Sanlam, and Momentum Group, all listed on the Johannesburg stock exchange. Old Mutual, despite being listed on the London stock exchange, is also regarded as South African because it was founded there in 1845 . The insurance market also includes international insurers such as Allianz (Datamonitor 20I0).

These efforts attracted millions of new South African clients, which led insurance companies to set their sights on the global market. They wanted to market the products, technologies, and services they had developed in South Africa to the rest of the continent and to emerging markets in the BRIC countries (Brazil, Russia, India, China). In an attempt to access these and other new markets, South Africa joined the bloc in $2010,{ }^{2}$ which then became BRICS.

In addition to commercial expectations, these new financial products for new markets were also politically motivated. When apartheid ended in 1994, Nelson Mandela became South Africa's first democratically 
elected president and the African National Congress (ANC), which was rooted in the struggle against apartheid, was voted into power. Along with the ANC's goal to overcome racial inequalities, they emphasized that for too long the financial sector had ignored Africans. They implemented a wide range of regulations in an attempt to make the financial sector racially inclusive. Financial companies were compelled to make a concerted effort to offer more and better financial services to the predominantly African population. Providing financial services to the poor and middle classes led to more aggressive marketing for insurance products. Insurance companies set up new subsidiaries to target this new market in Cape Town and across South Africa, and opened new offices in the townships where they could sell insurance products to the poor and African population. They sold insurance products in cooperation with local supermarkets, undertakers, and other stores and offices. Additionally, they established ties with singing groups, neighborhood associations, and many other groups and organizations through which they could sell their products.

The increasing presence of insurance in the townships of Cape Town became clearly visible through advertising. In Langa, one of the oldest African townships of Cape Town, I saw an advertisement for funeral insurance on the premises of a primary school. The advertisement consisted of the name and logo of the funeral insurer and said, "We've got zonke bonke," which roughly translates into "We've got something for everyone." Above the insurance advert was a second sign with the name of the primary school, which was a lot smaller, almost invisible compared with the insurance advert. It struck me that the funeral insurance advert was approximately twenty times the size of the name of the primary school. The jarring combination of funeral insurance and a children's school clearly shows how prominent funeral insurance had become. A survey I carried out in two Cape Town townships revealed that the marketing efforts of insurance companies were quite successful (more details on the survey later). Seventy-five percent of the respondents had at least one insurance policy, while some had up to nine. These were often funeral insurances, as well as Unemployment Insurance (UIF), medical insurance, pension funds, and credit insurance (see Table I.I). I wondered if the placard was reminding parents of their responsibilities towards their dependent children? How do these products realign relationships between parents and children?

The placards also made me consider the relationship between the state and the market. Does the size of the placards in any way represent the power and presence of the state and the market in townships like Langa? Is the state, here represented by the school, so small and 
nearly invisible vis-à-vis a market that is here represented by the insurance advert? Were residents submitted to market forces so powerful they were able to conquer schoolgrounds? Or, are there other, more subtle ways of understanding how financial products change the lives of their clients?

This book will carefully analyze why insurance companies started selling their products to people who live in extremely precarious and riskprone circumstances and how such marketing strategies were part of very specific relationships between the post-apartheid democratic state and the financial sector. The book explores why African clients living in the townships of Cape Town bought insurance products, how they became part of their ways of coping with uncertainties and social relations, and why they bought them even when they knew that insurance policies did not always help to overcome adversities. I will show how insurance policies sometimes exacerbate problems, aggravate insecurity, and intensify sometimes violent conflicts within communities and families.

The book will explain how these deep changes reflect the ironies of solidarity. Insurance can be understood as a form of solidarity in that people pool money in order to overcome adversity. It is a kind of mutual support, albeit at the center of a sophisticated financial market. Defining insurance as a kind of solidarity makes it possible to ask a new kind of question: When people buy insurance, how does this specific kind of solidarity affect other solidarities? How does it change solidarity among family and among neighbors? Does insurance complement or replace state-based solidarity such as welfare? How does the landscape of all forms of solidarity, each with its own specific responsibilities, entitlements, hierarchies, and boundaries, change when insurance enters the scene?

Irony is a way of using language, where you say one thing, but mean the exact opposite. During my first visit to South Africa in I995, I had a most ironic conversation in a car. My fellow passenger, a black activist, was bragging about how great South Africa was, complimenting its beautiful nature, excellent wine, great wild animals, etc. Then he proceeded to glorify the number of South Africans who die in traffic accidents, how it was the most racist and unequal country in the world, and that few cities could match Cape Town in terms of violence. I knew him well enough to understand he was being ironic. In this situation the irony was clear, but irony is often ambiguous and we are left wondering what is really meant.

The irony I find in solidarity refers to specific understandings of social change and problem solving. Solidarity is ironic in that it successfully offers care, protection, sharing, and help in times of adversity. 
Table 1.1 - Insurance uptake, Indawo Yoxolo and Tembani, Cape Town

\begin{tabular}{|l|l|}
\hline & $\begin{array}{l}\text { Respondents with at least one of these } \\
\text { policies (\%) }\end{array}$ \\
\hline Has an insurance policy & 75 \\
\hline Funeral policy & 63 \\
\hline Unemployment Insurance (UIF) & 44 \\
\hline Health insurance & 27 \\
\hline Pension fund & 24 \\
\hline Insurance for housing loan & 24 \\
\hline Provident fund & 16 \\
\hline Education policy & 8 \\
\hline Car insurance & 8 \\
\hline Disability insurance & 5 \\
\hline Insurance for furniture loan & 4 \\
\hline Investment fund & 4 \\
\hline
\end{tabular}

But it is exactly these solutions that simultaneously create conflicts, violence, inequalities, and exclusion. In this sense, its offer of solutions is ambiguous, leading people in a vicious cycle of looking for new solutions, which again lead to new problems. This dynamic is at the center of social change. This can be seen in funeral insurance, for example. While it covers expenses and care for the bereaved and avoids debt, it can simultaneously foment tensions where siblings accuse one another of profiting from the death of a parent. People purchase an insurance policy even though in the back of their minds, they doubt it will fulfill its promises. Thus, the irony of solidarity is that solutions and problems are intimately connected, or may be even the same thing. Sometimes what constitutes the solution and what constitutes the problem is ambiguous.

\section{Financialization in Africa}

Insurance in South Africa must be understood in the broader context of financialization in Africa as a whole. In this book, I define 
financialization as the process in which financial markets and financial products become increasingly central to an economy, meaning they become integrated into everyday life. ${ }^{3}$ For quite some time anthropologists have studied the increasing uptake of credit products in Africa. Since before the I980s, credit has become increasingly available and is marketed as a way to decrease poverty and invest in the future. Credit proponents argued that it would make business grow, would allow African companies to access previously unexplored markets, and that entrepreneurship would flourish. They expounded a win-win situation that, on the one hand, offered new business opportunities for banks and entrepreneurs, and on the other, alleviated poverty.

Several ethnographic studies revealed that credit in Africa had very different consequences from what financial service providers expected. Shipton's (1989, 2007, 2010) work with the Luo in Kenya shows how credit reshaped the kinship and clan relationships that were tied to land put up as collateral, which in turn led to conflicts. Other studies showed that credit did not always empower people, and in fact sometimes weakened citizenship rights by fomenting informality (Elyachar 2002, 2005), or by stimulating consumerist notions of wellbeing and respectability (James 20I4). While credit stimulated a consumer oriented middle class in Africa, dependency on it made the emerging African middle class vulnerable to new patronage relations and created new economic inequalities (Green 20I5; James 20I4; Shipton 2010). The credit made available by the advent of new digital technologies in Africa did not necessarily empower people either (Breckenridge 20I0, 20I4; Kusimba 2018). Instead, it became central to gendered kinship obligations (Kusimba 20I8; Kusimba et al. 20I8). In short, credit products had unforeseen consequences that were, ironically, the exact opposite of what its advocates expected.

The fact that insurance is a different kind of financial service than credit raises the question as to what extent insurance has different consequences. For example, credit requires clients to put up collateral that the bank can use when payments are missed. Insurance, on the other hand, does not require collateral. Clients that buy an insurance product make regular payments and when a specific adversity occurs, they or their dependents must prove they are entitled to specific benefits. Does this difference, as well as other specificities of insurance, matter? Insurance requires specific social and institutional arrangements, which suggests that there are specific concerns and moralities about how insurance affects everyday life. The relations and ideologies of insurance, different than those of credit, are explored ethnographically in this book. Does the financialization of insurance lead to specific 
moral concerns? Does it shape kinship in particular ways? Does it lead to specific market and state configurations that have consequences for social justice? The financialization of insurance has only recently received attention in African studies, partly because it is a relatively new phenomenon. Healthcare finance in Africa is increasingly financed by public expenditures, money mobilized in community-based organizations, and private insurance companies. Only recently have medical anthropologists pointed out the need for an anthropological research agenda on health insurance in the Global South (Dao and Nichter 20I6; Dao and Mulligan 20I6). ${ }^{4}$

Defining insurance as a form of solidarity creates wide-ranging implications for what it brings to everyday life, how it relates to the politics of the state as well as the politics of kinship, and how it relates to people's dreams and anxieties about the future. Hence, the financialization of insurance can only be understood by carefully examining how insurance functions as a kind of solidarity, and what happens when insurance and solidarity are situated within the market.

In order to understand what this kind of solidarity does and what its impact is, one needs to examine it in relation to other solidarities. Insurance does not operate in isolation and cannot be understood as separate from other forms of solidarity. Therefore, one needs to understand how insurance relates to the state that defines solidarity based on citizenship and how it supports people accordingly. Additionally, one needs to understand how insurance influences and changes other forms of solidarity that are based on neighborhood relations, such as burial societies. Finally, insurance solidarity affects kinship networks because it offers new forms of care and creates new suspicions about people that use insurance to exploit family members.

These changes can only be fully understood by examining the irony of solidarity where care and support inevitably creates tensions. These tensions are inherent to establishing the boundaries of care (inclusion and exclusion) and the illiberal aspect of solidarity (degrees of conformity to hierarchies and procedures). Irony manifests itself differently in all kinds of solidarity, from kinship to neighborhood relations, the state, insurance, and so on. Each has its own form of care and each is charged with specific ways of creating solidarity boundaries and specific configurations of conformity. The solidarity found in insurance seemingly offers an escape from tension, thus making it a liberating force. However, this liberation is only partial because people continue caring for each other using multiple forms of solidarity, and because insurance produces its own particular cruelties by defining boundaries that curtail people's individual freedoms. 
This approach to the financialization of insurance has important consequences for understanding how ironies push socio-economic change, for conceptualizing the intimate encounters with global financial markets, and for theorizing care and conflict in solidarity.

\section{Caught in the counter-discourse}

South Africa is an extremely unequal and violent place, and social scientists have tried to find economic explanations for this. Key studies have argued that these high levels of inequality and violence are due to the rise of neoliberalism, pointing to the economic and ontological insecurities that neoliberalism and financialization brought to the country. Bond concludes that "South Africa can be considered an ally of global finance with, first, support for neoliberal global governance no matter its failure to deliver" (Bond 20I4, 454; see also Bond 2000). Cheru (200I) finds an "ascendancy of neoliberalism in South Africa" and argues that underneath a seemingly progressive social policy to decrease poverty and inequality lies an aggressive neoliberal strategy. Comaroff and Comaroff (200I) argue that there is a rising culture of neoliberalism in South Africa with the triumph of the free market leading to new forms of violence and new kinds of identity politics (see also Comaroff and Comaroff I999, 2000). Miraftab (2004) writes that rising global neoliberalization paralyzed South Africa's local governments and led to problems in waste collection. Naomi Klein's (2008) influential The Shock Doctrine states that South Africa's inequality and violence was caused by its quick adoption of neoliberalism in the I990s, leading to a "democracy born in chains," the chains being neoliberalism. Ferguson (2007, 2015) identifies neoliberalism in South Africa as a central cause in the rise of welfare payments to the poor and as a primary force behind the political debates about a universal basic income (Ferguson 2007, 20I5). According to James (2014), the increased uptake of credit and the indebtedness of the South African middle and working classes is driven by neoliberalism and state policy intended to liberalize the South African economy. In fact, rising neoliberalism, and financialization as an expression of neoliberalism, have become such prevalent explanations for the inequality, violence, and everything else that occurs in South Africa that it might seem ridiculous to challenge this causality. ${ }^{5}$

At the same time, there are reasons to question the causality between financialization and neoliberalism in South Africa, as well as the argument that inequality and violence are a result of South Africa's embrace 
of neoliberalism. This is not to deny the existence of neoliberalism and its relationship to financialization. Krippner (2OII) carefully explores this historical relationship in Capitalizing on Crisis. The book offers a detailed account of the rise of financialization in the United States by placing it in the specific historical context of market liberalization. She convincingly demonstrates that after World War II economic growth was driven by a Keynesian approach of political control over the market. At that time, the market was not regarded as something that could operate freely, but rather, in line with Polanyi's understanding, something that had to be actively shaped so it would benefit society and secure peace. This Keynesian approach to markets, Krippner shows, led to tensions in the US when the economic boom ended and was followed by a recession in the late I 960 s and I970s. There was no political agreement on how to restructure the US economy and how best to shape the market politically. The response to the dilemma was to deregulate the economy, specifically financial markets, by eliminating interest rate ceilings and other such strategies. Deregulation was regarded as a technical reaction to depoliticize the crisis and momentarily deal with the political impasse on how to steer the economy. Financialization thus meant that "the market could do the choosing in deciding which sectors to favour in the distribution of capital, sparing policymakers this unpalatable task" (Krippner 20II, I42).

The question is whether liberalization of the economy was as central to South Africa's political economy as it was in the US, as well as many other countries across the globe. Or does the South African political context of financialization have its own specificities that require us to think of other explanations for financialization, as well as the high levels of inequality and violence? As I will show in this book, financialization in South Africa was strongly connected to the end of apartheid and the establishment of an inclusive democracy. In South Africa, financialization was part of government policies that intended to overcome racism and racial inequalities. It was part of a political dynamic that forced the financial sector to embrace democracy and become racially inclusive by selling insurance policies to the predominantly poor African population. Financialization in South Africa was not the result of "letting the market do the choosing," as in the United States. On the contrary, in South Africa it was part of a nation-wide political project that subjected the market to racial inclusion. I will show how this specific political history matters in the explanations for what finance does in everyday life.

To begin with, neoliberalism was not central to South Africa's political economy, especially not in the I990s when insurance companies started 
marketing their products to the African population. It is relevant here that after the global financial crisis of 2007 , the South African government was internationally praised for successfully keeping financial markets in check and under control. Before the crisis, South Africa had controlled the market by maintaining exceptionally high interest rates that made credit less attractive; trading credit default swaps, which was at the heart of the financial crisis of 2007 , was not allowed on the Johannesburg stock exchange; and unlike banks in other parts of the world, South African banks had minimal exposure to the subprime loans that collapsed in 2007 (Zerbst 20I I; Mail and Guardian 2008). Trevor Manuel, who was South African minister of finance from 1996 to 2009, highlighted the importance of the state having control over the economy in his Annual Budget Speech. In 2009, Manuel explicitly drew on Polanyi when he spoke against a "utopian faith in self-regulation," arguing forcefully in favor of the state playing a major role in the regulation of markets (Manuel 2009, 3). ${ }^{6}$ It is thus overly simplistic to argue that neoliberalism drove financialization in South Africa.

Several anthropologists have debated that "the concept of neoliberalism has become an obstacle for the anthropological understanding of the twenty-first century" (Eriksen et al. 20I 5; see also Ganti 20I4). This seems to be the case in South Africa. Anthropology has made valuable contributions by criticizing assumptions about the universality of orthodox economic theory, and has problematized the insistence on methodological individualism. Anthropological studies have revealed that if we are to understand what markets and other economic arrangements are about, it is vital to see their role in social networks, varying ideologies, and institutional settings. While scrutinizing neoliberalism is highly valuable and has led to fascinating studies and insights, it has also become part of a counter-discourse that - just like orthodox economics is in danger of defining its own universalities. Neoliberalism has become the center of this universalizing counter-discourse that implies that there once existed a harmonious and caring pre-neoliberal world.

Maurer (2006, I7) argues along similar lines when he writes about " $[\mathrm{t}]$ he telling of the tale and the criticism of the tale." He characterizes the anthropological study of money as a tale that revolves around three recurring themes: the embeddedness of the economy, money as special purpose money, and people's engagement in multiple monetary repertoires. Without denying the value of these debates, Maurer (2006) urges anthropology to theorize economic issues in a new conceptual language that makes it possible to focus on other themes and issues.

A defining characteristic of the counter-discourse that is prominent in anthropology is that the malign aspects of community and other 
social categories are blamed on abstractions. In economic anthropology, these can be abstract invocations of neoliberalism that are seen as the source of conflicts and inequalities expressed in the social domain. Other abstractions that can be held responsible are economic symbols such as GDP, the Gini index, or many others. They can be taken as so powerful that they supposedly govern everyday life and cause inequality and violence. Such a theoretical approach to economic abstraction can cause anthropologists to insufficiently develop dimensions of violence or inequality that are not caused by abstract forces (see also Bähre 20I5). The English language reinforces this connotation of abstraction. Used one way, abstraction can refer to a general quality or idea outside of specific realities like, for example, when we refer to abstract art. However, used another way, abstraction can refer to the disruptive act of taking away, of theft - for example, when we talk about the abstraction of resources. ${ }^{7}$ This counter-discourse can be formulated as described below. ${ }^{8}$

We use ethnography to try to understand human interdependencies; how hierarchies, identities, and power dynamics work on an intimate level; and how these are part of larger changes on the national or global level. These studies reveal immoralities such as human suffering, exclusion, and dehumanizing processes, and help understand their dynamics within communities, kinship relations, and other forms of solidarity. We try to understand why these immoralities occur within the interactions we study. Why is it that solidarity and belonging, which are so fundamental to humanity, are permeated with suffering, inequalities, and conflict? Why is it that people are excluded in such harsh ways, and how do immoralities occur? Why are some people's rights violated and marginalized? Why do these immoralities exist or come about, and why are they so difficult to change? The explanations to these questions tend to blame the abstract, that which takes place outside the everyday encounters that we study in fieldwork, and that we recognize as fundamental to humanity. The causes are largely found outside the everyday lived realities that we study. Explanations are sought within the abstract notions of power in economic theory, which promotes an unrealistic and ideological vision of society in its methodological individualism. At the moment, at least in economic anthropology, neoliberalism and rational choice theory are prominent abstractions that are considered responsible for the immorality we encounter in fieldwork.

When we cast blame on the abstract and the invisible we engage in a sort of purification ritual. By this I mean that when fieldwork 
reveals that sociality is permeated with immoralities, when we see suffering in communities and in other encounters, and we attribute it to abstractions, we construct a notion of sociality that would be moral if it were not "contaminated" by these abstractions. This notion implies that socialities and solidarities are harmonious and fair, and that the immorality revealed by fieldwork does not originate from the people being studied. This leads to the question: Does not such a counter-discourse reproduce the same problem it tries to refute? The counter-discourse of attributing immorality to abstractions runs the risk of becoming its own universality.

I share Maurer's (2008) concern that anthropologists and activists tend to celebrate the personal and social aspects of finance and money while being overly skeptical of the abstract and calculative characteristics of money: " $[\mathrm{I}] \mathrm{n}$ trying to recuperate a social economy of a personal money ... we cast aside the unanticipated potential (and, indeed, the necessity) of abstract, calculative agencies and impersonal institutions and money" (Maurer 2008, 77). When neoliberalism is defined as the fundamental cause of financialization, violence, and inequality in South Africa, then abstraction is equated with violence and power. This allows the social and personal aspects of the economy to then be conceptualized as the solution, or at least a welcome counter-force. However, if we are more careful in making this conceptual cluster of finance, neoliberalism, abstraction, and (neo-Foucauldian) power, a new conceptual space can be created to suggest new explanations and develop a new theoretical language. Not automatically "blaming" neoliberalism allows identifying other ways of explaining how and why financialization unfolds in South Africa. With this in mind, I argue that irony, not neoliberalism, should take center stage. Irony offers a more nuanced view because it reveals how people experience and deal with simultaneously oppressive and liberating aspects of abstraction and depersonalization. Irony means that people socialize money, which is basically a Zelizerian approach to money, but with limitations and sometimes at social costs. I will show in the next chapters how an ironic approach to financialization means observing how socializing money can lead to suffering and violence.

"Blaming" abstract forces such as neoliberalism risks reifying the idea that solidarity and reciprocity are harmonious and dignified, especially when the intimate realm is not "contaminated" by cruel external economic and political forces. It often leads academics and activists who promote alternative economies based on solidarity to a certain nostalgia that tries to regain human dignity by carving out a niche that is separate 
from global financial markets by, for example, creating networks based on bartering or gift exchanges rather than money. In this context, Hart's $(2004,2010,2015)$ notion of the human economy is very relevant. Hart calls for the humanization of the economy but he does not do this by celebrating a non-monetized, social economy. He (see also Maurer 2008) states that abstraction and monetization are not necessarily the antithesis to social justice. Instead of socializing the economy, Hart argues for transforming global and abstract economic dynamics by humanizing and democratizing, though not necessarily socializing, them. Hart thus suggests that the abstract and non-social aspects of the economy can contribute to a human economy (Hart 2004, 20IO, 2015).

What does this mean for the study of insurance in a context of high economic and racial inequality? What do we gain, in intellectual terms, when we look at solidarity as an ironic process that rests on social and abstract qualities? What light does such an approach shed on morality and sociality, and the extreme levels of conflict and violence in South Africa?

\section{Cape Town: city of hope?}

Cape Town can be a wonderful city, but not for everyone. Cape Town is part of the Western Cape Province, which has the highest murder rate in the country. ${ }^{9}$ Cape Town has recently been ranked as the twentieth most violent city in the world. ${ }^{10}$ The townships where the respondents live and where new insurance products are being marketed are part of the Cape Flats, where most of the approximately four million Capetonians live. Crime is concentrated in the Cape Flats townships of Khayelitsha, Gugulethu, Nyanga, and Mitchells Plain (Manaliyo 20I4, 597). CrimeStats South Africa makes an annual top ten list of precincts with the most reported crimes based on statistics from the South African police. Here too, the Cape Flats come out very unfavorably. In 20I4, six out of ten precincts with the highest murder rates in South Africa were in the Cape Flats. In the same year, seven of the ten precincts with the highest number of attempted murders in South Africa were also in the Cape Flats. ${ }^{11}$

Cape Town is a city of extremes and the uneven distribution of wealth is painfully palpable. Homes worth over two million US dollars are not unusual on the slopes of Table Mountain, which attract a national and international elite. Seen from Clifton, the stunning views of the sea and Robben Islands, where Nelson Mandela had been 
imprisoned, are now a cultural heritage site and tourist destination. Only 20 kilometers down the road from the affluent suburb Constantia are the Cape Flats where increasingly more people live in makeshift houses constructed from corrugated iron sheets and pieces of wood, and where several families are forced to share a single toilet. The inequality in Cape Town may not be an exception in South Africa, but the layout of the city makes it particularly visible. ${ }^{12}$

Violence and inequalities still permeate South African society today, more than twenty years after the first democratic elections of I994. Desmond Tutu described democratic South Africa as "the rainbow nation," and pleaded for an inclusion that respected diversity. In his inauguration speech as the first democratically elected president of South Africa, Nelson Mandela formulated the following aspirations for the future:

The time for the healing of the wounds has come.

The moment to bridge the chasms that divide us has come.

The time to build is upon us.

We have, at last, achieved our political emancipation. We pledge ourselves to liberate all our people from the continuing bondage of poverty, deprivation, suffering, gender and other discrimination. ${ }^{13}$

However, hope for the future was followed by disappointment. Desmond Tutu said that it was a disgrace that twenty years into democracy people were still going to bed hungry. He criticized the ANC government for being worse than the apartheid state because it placed economic interests above human rights. ${ }^{14}$ Anti-apartheid activist and anthropologist Mamphela Ramphele (2OI2) pointed out that economic inequality worsened under democracy and that democracy had given rise to a small elite of "tenderpreneurs" (Ramphele 20I2, 7): "We are now in the early stages of a dangerous kleptocracy. A culture of impunity is taking root at every level in government" (Ramphele 20I 2, 8).

Disappointment and anger found their way into South Africa's popular culture. The four members of the music group Dookoom (Isaac Mutant, Human Waste, spooky, and Whatgwann) write aggressive and bitter noise rap from Heinz Park, an impoverished community in the Cape Flats. Songs like "Larney jou poes" (slang for "hey boss, you cunt" ${ }^{15}$ ) are ironic and cynical approaches to exploitation and suffering. Dookoom appropriates the filth and horror of everyday life in the Cape Flats and wears it as a badge of honor. Below are excerpts of an interview with members of Dookoom: 
Interviewer: $\quad$ Your artist profile description on Soundcloud reads, DOOKOOM, KAK [Afrikaans for shit] STIRVY, CAPE TOWN SEWERS, South Africa. Could you elaborate on the use of the words "stirvy" and "Cape Town sewers" and why you chose to describe your page as such?

Human Waste: I guess it's a metaphor. "Kak stirvy" means we're very fancy. We don't use single-ply toilet paper. Sewers are rotten filthy places full of human waste and discarded rubbish.

Interviewer: What do you have to say to people who think that you are too angry?

Human Waste: JOU POES [Afrikaans for "you cunt"]!!! [laughs] How can you not be angry though? How angry is angry enough? You have to be living in a bubble of privilege or just delusional not to be angry. There's so much fucked up shit going on in South Africa and the world. People think anger is "negative." They get more outraged when you say "poes" than at the situation that caused you to say "poes." Anger is actually a very positive thing, it helps enable change. ${ }^{16}$

Human Waste and the other members of Dookoom express their anger at being discarded like feces in a sewage, as far removed from privilege as possible. In another interview, Dookoom member Isaac Mutant expressed his disappointment in the promises of democracy: "So fuck the rainbow nation, my broe [my brother]; it's a fucking farce." 17

It is within this context of lost hope that insurance companies are trying to sell insurance to predominantly poor Africans. Insurance companies sell policies to people who see their future as bleak and grim by promising to deter adversities and mitigate risks. This raises questions about how financialization features in people's aspiration for the future, and their disappointment in the rainbow nation. To what extent do insurance products alleviate social injustices, especially those that are caused by violence and inequalities? Or does financialization in the end reproduce certain social injustices, or even create new ones?

Ethnographies on South African cities have shown how people try to make ends meet in hostile urban environments, and how they try to maintain their dignity while being confronted with economic conditions and racist identity politics that put humanity under pressure. 
Africans in urban areas set up a wide range of networks that provide some economic, social, and even emotional security. Burial societies and other financial mutuals are established among migrant men and among neighboring women (Bähre 2007). Migrant women also set up singing groups as a way to establish new forms of belonging and to help support their families (James I999). Post-apartheid cities are sites for producing new social identities and lifestyles that are charged with power dynamics (Bank 20II; James 20I4). How does the financialization of insurance change these urban networks and the economic, social, and emotional security that they provide? What happens to the networks of insurance brokers, taxi owners, shop owners, and undertakers?

\section{Outline and arguments}

In the next chapter I discuss different approaches to irony that help to make sense of financialization. I explore the irony in the gift and the idea of using a framework for non-monetized societies for understanding solidarity in a financial market. I then discuss three distinct approaches that offer valuable insights into the relationship between irony, rationality, and solidarity and that help to understand financialization. The end of this chapter presents how irony was central to the methodological approach of this study.

In Chapter 3 I argue why and how insurance is part of an ontology of redistribution. To understand financialization along with the ongoing violence and inequality in South Africa, one needs to examine the emergence of a developing state based on social democratic principles. This implies both that neoliberalism is an insufficient vantage point and that casting blame on neoliberalism is beside the point. The fact of the matter is that people's understanding of economy, including their desires and anxieties that surround wealth, is determined by redistribution. Redistribution is in fact at the heart of the post-apartheid state (welfare, development aid, taxation). It is accomplished through a state-controlled market (insurance, Black Economic Empowerment criteria), imagined in a theology (neo-Pentecostal churches), and conducted within kinship and neighborhood networks. Understanding post-apartheid political economy requires examining the interdependencies between these forms of redistribution.

Chapter 4 examines how the insurance sector developed products for a new market of people that had hitherto been unrecognized as citizens. It examines the double meaning of abstraction, where money is abstracted 
from clients and insurance is based on abstract representations of everyday social reality. The chapter explores how actuarial knowledge and practices and marketing techniques rely on different forms of abstraction that include very specific definitions of risks and costs and involve market segmentation strategies that classify potential consumers. While the chapter looks at technical aspects like actuarial expertise, it also shows how these abstraction techniques are both moral and ideological, and capable of hiding some of the social injustices involved in selling insurance to this particular market.

Chapter 5 examines the relationship between insurance companies and their clients, which revolves primarily around selling policies and handling claims. Key to this relationship is the reliance of insurance companies on abstraction and sociality, anonymous bureaucracies, and personal networks. This particular combination of abstraction and sociality reveals that inclusion in insurance is Janus-faced. For making sales, insurance companies rely heavily and even exploitatively on social networks. However, when it comes to resolving claims, more often than not insurance companies revert to bureaucracy. Clients sometimes find themselves in Kafkaesque bureaucracies that de facto exclude them from insurance.

The central question in Chapter 6 is, why do people living in the townships of Cape Town buy insurance policies when there are clearly so many bad experiences and abstract contributions to human suffering? To answer that, I argue that insurance promises an escape from oftentimes cruel neighborhood solidarity and helps them rearrange kinship relations. Insurance companies wrongly assume that African clients prefer sociality and community, which they highlight in their marketing policies. Clients in reality are attracted to abstract and anonymous bureaucracy. I will show how the enchantment of abstract financial products can be understood by carefully examining the Weberian term stahlhartes Gehäuse. I argue that the irony of this German term was lost when translated into English as "iron cage." But going back to the original German expression can shed light on the enchantment of abstract finance offered through large-scale bureaucracies. The term stahlhartes Gehäuse clarifies why people want to leave the cooperative world of burial societies and this Weberian concept sheds light on how insurance helps people to renegotiate anxiety arousing solidarities and kinship obligations.

Chapter 7 offers a close account of how insurance was part of the transformation of solidarity in the taxi industry. It explores how different forms of solidarity (based on commercial insurance and migrant labor stories) coexist and create new inequalities. Over the past fifteen 
years, the South African government has used commercial insurance to "rationalize" the taxi industry and break up one of the most powerful forms of solidarity in Cape Town. The strategy to pacify the sector by creating an industry composed of individual taxi entrepreneurs with individual debts and individual insurance policies failed. The result instead was that taxi associations and their leaders were empowered and consequently became more violent.

Chapter 8 looks at how insurance examines the morality that surrounds death. It does so by carefully analyzing rumors and accounts that involve insurance murder, and by comparing funeral insurance with neighborhood-organized burial societies. Because insurance is abstract and invisible, it offers space for fantasy, a clean slate on which social tensions can be projected. Nonetheless, projecting these social tensions and concerns on insurance does not mean they are caused by insurance. The abstraction of insurance and insurance contracts creates opportunities for projecting kinship concerns. This becomes particularly salient in the cosmological, economic, and social uncertainties that surround death. Death draws out and amplifies the tensions found in kinship ties, and hence the abstraction and monetary value of insurance allows for speculations.

The conclusion suggests ways to further conceptualize financialization as an ironic process. I reflect on how irony drives social change, and that distinguishing between morality and rationality is not the way to understand economic change. Instead, we must recognize how ironies are fundamental to social and institutional arrangements that involve money, as well as the moralities that are part of the economy. How is it that certain ironies can go fairly unnoticed at one point, and then at another point take center stage, forcing people to think of new solutions that inevitably give birth to new problems? Financialization is best understood from the vantage point of irony regarding multiple solidarities, the social and abstract, and the personal and impersonal dynamics of economics. In order to understand financialization one needs to examine how solidarities produce specific forms of exclusion and hierarchies, each defining and negotiating rights and obligations. The conclusion also suggests ways for examining how ironies are shaped by desires for freedom and independence both politically and personally, and by the need for connectedness and belonging in a wide range of interdependent solidarities, followed by possible consequences for methods of anthropological inquiry. 


\section{2 \\ An ironic analysis}

\section{Conflicts in the gift}

In order to understand insurance as a form of solidarity, it is important to look at Mauss' study of gifts in "archaic societies" (Mauss 1925), although he is far from the first to come to mind. The insurance products that this book examines are at the center of global financial markets and are sold in a context of complex national politics in the townships of a large metropole. These financial products and the context in which they are sold bear little resemblance to the mwali armshells that are part of the kula exchange of the Trobriand Islanders, neither are insurance contracts imbued with the spirit of Hau that binds giver and receiver in Maori society. Yet Mauss' analysis of the gift is highly relevant to an understanding of insurance products if one places his work within its historical context and recognizes the attention he gives to discord.

The historical context of The Gift (Mauss I 925) was a few years after the Great War and the Russian Revolution. This context together with Mauss' personal involvement in French socialist initiatives led him to examine the morality of an economy, which was very important to him (Fournier 2006). Mauss believed strongly in the cooperative movement to which he actively contributed, but had an ambivalent view on the Russian Revolution. Although he shared many socialist ideals, he fiercely criticized the Bolshevik Revolution for its attempt to enforce rights through violence, for destroying the economy, and for waging a revolution against the interest of the proletariat (Fournier 2006, I99-200). Instead of foreseeing a purely socialist economy, he was in favor of a mixed economy that preserved the market and currency and was "a mixture of capitalism, statism, administrative socialism, free collectivities, and individualism" (quoted in Fournier 2006, 203).

The ideals and activist aspirations of Mauss are clearly stated in his introduction to The Gift $(1925,5)$ where he writes about the crisis in law and economic organization that seems to refer to the horrific violence and suffering of his time, not least, the Bolshevik Revolution and the Great War. Without being nostalgic, it seems Mauss was hoping to find different laws and economic organizations that made up society. The Gift examines how people are able to create collectivities, share, and connect to one another. His essays moreover show how the 
gift is a "total prestation," which means that the gift is at the same time a political, religious, legal, and social act that is at the center of a moral universe.

What makes The Gift particularly interesting and relevant for the study of insurance is that Mauss goes beyond the gift being harmonious, peaceful, and constructive. On several occasions he shows the disharmonious and destructive side of gift-giving, $\mathrm{He}$ does so by pointing out that the German word for Gift has a double meaning of both gift and poison. Mauss points out that the gift becoming poison is fundamental in Germanic folklore: "The Rhine Gold is fatal to the man who wins it, the cup of Hagen is disastrous to the winner who drinks of it; numerous tales and legends of this kind, Germanic and Celtic, still haunt our imaginations" (Mauss I925, 62). He explores how this duality is also found in the Hindu classical period where a gift must be given and must be accepted, but it is at the same time dangerous to accept a gift that puts the recipient in a subordinate and dependent relation to the giver. He describes a situation where great gifts were refused with the following explanation: "Oh King, to receive from kings is honey at first but ends as poison" (quoted in Mauss I925, 58). Throughout the book Mauss refers to myths and situations where gifts are connected to violent deaths, sometimes as a sanction that enforces gift-giving, and at other times as a consequence of receiving a dangerous gift. One of the most remarkable examples is found in the conclusion and is based on Thurnwald's description of a Melanesian feast that suddenly turns into a battle. It is worth quoting in full:
Buleau, a chief, had invited Bobal, another chief, and his people to a feast which was probably to be the first in a long series. Dances were performed all night long. By morning everyone was excited by the sleepless night of song and dance. On a remark made by Buleau one of Bobal's men killed him; and the troop of men massacred and pillaged and ran off with the women of the village. "Buleau and Bobal were more friends than rivals," they said to Thurnwald. We all have experience of events like this. (Mauss I925, 80)

Here Bobal's gift is a massacre in that he reciprocates the feast by killing the host, pillaging the village, and running off with the women. It is significant that Mauss uses the word "we" in his comment at the end, "We all have experience of events like this." He infers that violence found in friendships constituted through gift-giving is not exceptional or "archaic," but is inherent to all of us as humans. We all indeed have experienced that hospitality and gifts can be reciprocated with destruction, 
or where the sense of superiority provided by the act of giving a gift leads the giver to overstep boundaries, which can be met with aggression. ${ }^{1}$ Mauss concludes The Gift with an attempt to "extend these observations to our own societies" (1925, 83). Although Mauss was an active supporter of cooperative movements and collectivities that could promote a socialist agenda, The Gift shows that he was certainly not blind to the irony found in gift-giving and solidarity, which could be extremely aggressive and even violent.

The aggressive side of gift-giving is also found in Marilyn Strathern's The Gender of the Gift (I988), where she juxtaposed the economy of gifts and the economy of markets and commodities in Melanesian society. Her analysis demonstrates that reciprocity and gifts are charged with power, coercion, and social tensions and are fundamental to the shaping of personhood (Strathern I988). It is important to highlight that her analysis thus situates power within personal relations and within the gift-giving. Strathern does not attribute power or coercion within the gift to the abstractions of global markets. ${ }^{2}$

Can this approach to the gift as a deeply ambivalent expression of care and conflict shed light on gift-giving in a capitalist society like South Africa? In my earlier research in the townships of Cape Town I examined financial mutuals (Bähre 2007) where neighboring women, and sometimes also men, would form groups of typically ten people. They met once a month to give money to one of the members and, in the process, lavished extensive praise on the recipient, telling her she was like a daughter or mother, that she made the giver proud, and that she could ask for help in any situation. The sociable and caring aspects of these gift-giving relations were salient, and recipients of the gifts of money were sometimes visibly moved. At these meetings, members expressed the importance of being respectable and how they would help one another lead respectable and caring lives. All the members of the financial mutual I had joined bought something special with the money they received. One woman bought a secondhand television and she told us she would think of us and of how much we cared for her every time she watched TV. When it was my turn to cash in, I used the money to make a down payment on a handmade carpet that would be sent to the Netherlands. But unfortunately, I never received the carpet and thus wasted my money. The women in our financial mutual had clearly made better choices than I had.

Through gift-giving, members of these financial mutuals tried to build respectability and humanity in a place of economic insecurity that came from living in one of the world's most unequal and racially divided countries, where people are constantly worried about "becoming 
a statistic" of violence, as a friend of mine said, and where volatile kinship relations were experienced every day. These groups worked as a safe harbor in a community that was dominated by mafia-style organizations (Bähre 2007). Gift-giving and financial mutuals helped members feel cared for, meet social obligations towards children and other kin, and lead respectable lives. The organizations had names like "Let's hold each other" (Masibambane), and when members presented money to a recipient, they emphasized that although they could not give much, it came straight from the heart.

Like Mauss and Strathern, I also saw the aggressive and powerhungry side of gift-giving. Financial mutuals were often charged with rivalry where members held sway over others by overpowering them with gifts that could not be reciprocated. I saw one woman receive money and presents worth more than six times her monthly wage as a cleaner at the hospital. After she received these gifts, she became ill, causing rumors and suspicions to circulate about members having bewitched her (Bähre 2007, I4I-I66). On another occasion a shopkeeper told me how she helped her hungry and desperately poor neighbor. She had some meat that had gone bad and could not be sold anymore. Initially, she tried giving it to her dogs, but they refused to eat it. So she gave the rotten meat to her neighbor who was so desperate she ate it. This became a great source of amusement to the shop owner and other neighbors. When the poor neighbor who had eaten the rotten meat died a short time later, probably due to an AIDS related disease, the neighbors were reluctant to collect money for her funeral and behaved very inappropriately at the wakes, which left many feeling guilty about how badly they had treated her (Bähre 2007, 85-II3). This shows how the relations of care in financial mutuals and giftgiving in general are profoundly ambivalent, and how gifts contained both constructive and destructive forces. Gift-giving revealed that violence and aggression could be at home in personal relationships and ingrained in solidarity among neighbors. Hence, violence and aggression, just like care and compassion, were inherent to solidarity (Bähre 2015). Could market insurance and its less personal obligations and abstract products solve this problem?

\section{Solidarity in the market}

This book shows that one of the key reasons people in South Africa purchase insurance policies is to alleviate, mitigate, and possibly even escape the violence, aggression, and inequality that ensues from gift-giving and 
solidarity systems. Many see abstract financial products as the solution to violence and inequality, even though it also simultaneously creates its own violent and aggressive dynamics.

Insurance is situated rather awkwardly in the conceptual landscape of economic anthropology. Insurance, especially when it is provided for by financial corporations, breaks free of the dichotomies that have permeated economic anthropology for most of the twentieth century, such as gift versus commodity, reciprocity versus market exchange, and economies that produce solidarity versus those that erode solidarity (Bloch and Parry I989; see also Maurer 2006, 2008). Insurance is a type of solidarity that establishes a relationship between the insured and the insurer that typically, or at least ideally, lasts for many years, but which is positioned at the heart of global financial markets. It is a kind of solidarity that, in many ways, is far removed from the type anthropologists usually study, which focuses on personal networks based on reciprocity and on systems outside the financial markets, like cashless economies, alternative currency initiatives, or sharing economy movements. Anthropological studies became particularly important in understanding these forms of solidarity after the global economic crisis of $2007 . .^{3}$

Even though commercial insurance does not immediately provide a warm fuzzy feeling, it is worth considering as a kind of solidarity where people contribute to a collective in order to compensate a specific person's loss. It is a form of solidarity even when clients and insurance sector employees talk about the lack of morality in the process. On one hand, insurance companies accuse clients of cheating when given the opportunity, and of creating moral hazards by taking additional risks because they have insurance. One the other hand, insurance clients complain about their terrible experiences with insurance bureaucracy, how the policies they purchased do not deliver as expected, or how they feel cheated by an insurance agent. Nonetheless, commercial insurance unites people's interests and helps them overcome adversities collectively. Therefore, this tricky position of straddling the dualities that have been fundamental to twentieth-century economic anthropology makes commercial insurance particularly interesting, and is possibly the reason it is largely unexplored.

It can be said that commercial insurance is a form of redistribution, in that money is collected in a centrally administered fund from which clients are compensated. ${ }^{4}$ In contrast, anthropological theory has typically examined redistribution as a political system. Polanyi (I944) argued that redistribution was characteristic to pre-market societies, and was an economy that allowed chiefship, feudalism, and aristocratic families 
to gain political power over people. Sahlins' interest was mainly in how reciprocity-based societies made the evolutionary step to redistribution and other forms of political centricity (Sahlins I972, 209-2 I0).

An important change since Polanyi and Sahlins is that redistribution has also been recognized in contemporary societies and in the politics of the nation-state. Roitman (2005) examined how redistribution in the Chad Basin of Africa is central to the state's political control and to notions of citizenship. Hann (2009) shows how redistribution has been crucial to Chinese government politics since I949 and how it has affected social relationships and moral communities. Alexander (2009) draws on Polanyi's concept of redistribution to examine government welfare practices and ideologies in the UK and its consequences for citizenship. These are just some of many interesting and valuable studies that have corrected the view that redistribution only helps us understand the politics of societies without markets. ${ }^{5}$ However, this leaves us with the connection between redistribution and political control. The next step is to examine redistribution inside markets and to let go of assumptions about the relationship between types of exchange (reciprocity, redistribution, market exchange) and organizational forms (kinship, political structures, markets). Bloch and Parry (I989) brilliantly deconstructed the binaries founded on reciprocity and market exchange. They propose studying short-term cycles of exchange that serve self-interests and are by their very nature fragile, as opposed to long-term cycles of exchange that serve to maintain social order. What needs to happen next is to include redistribution in the analysis of what Bloch and Parry call transactional systems. This means that instead of "only" deconstructing a binary (reciprocity-market) we need to deconstruct a ternary founded on reciprocity, market exchange, and redistribution. What makes commercial insurance theoretically challenging is that it is market and solidarity and redistribution and long-term cycles of exchange and anonymous institutions and abstract calculations. The fact that insurance does not fit in the counter-discourse of economic anthropology is exactly why it is worth studying.

In order to understand markets, it is vital to examine how they are interdependent with rights and obligations within kinships, neighborhood support networks, and churches, as well as in the care provided by the state. This is done by situating commercial insurance in wider transactional systems. ${ }^{6}$ It is impossible to fully grasp financial products such as insurance without understanding reciprocity within kinships and other solidarities. Similarly, in a global economy, we cannot fully grasp the economics of kinship and communities without understanding financial products and services. 
There are two technical developments that are particularly relevant to insurance. First is the development of actuarial knowledge that, since the end of the nineteenth century, has enabled calculating risks and setting up new kinds of collectivities such as the welfare state and insurance. This raises a whole gamut of questions regarding the interdependency between these new forms of insurance and the insurance organized through personal networks. How do insurance products relate to preexisting support networks operating among kin, neighbors, and other identities? How does this technology lead to shifting moral discourses about responsibility, entitlements, and the legitimacy of different forms of solidarity? ${ }^{7}$ Second is the development of new marketing strategies and new infrastructures that allow selling relatively small and inexpensive insurance products to poor and lower-middle-class people living in the townships of Cape Town. These products raise questions of how to market to previously neglected consumers who often have no fixed employment that provides insurance, who are more likely to be illiterate, and who, at least according to insurance company employees, have a different culture. How does the development of products, marketing strategies, and other organizational aspects construct these consumers? What are the experiences of insurance clients and their social networks with these technological and symbolic constructions? ${ }^{\text {? }}$

\section{Irony in rationality and solidarity}

An ironist can say one thing and mean the opposite, but one cannot always be completely sure if someone is being ironic. Irony thus creates doubt about the presence of a contradiction: Are someone's words or actions to be taken literally, or do they signify the opposite? Irony means that language and other forms of social action are charged with irreconcilable contradictions. ${ }^{9}$

Irony offers a fruitful perspective on the workings of the abstract and socializing aspects of financialization and solidarity. Irony means that financialization both overpowers and empowers, and that solidarity is a source of both care and violence. These ironies are overlooked when the abstract dimensions of economy are understood as oppressive, and the social as warm and caring. It is important to recognize how abstraction and sociality produce both benevolence and malevolence. This allows for a better understanding of how violence and care can be closely connected, and even produce one another. The irony of solidarity means that people and societies help mitigate and overcome adversities, while simultaneously producing new forms of exclusion and suffering. 
Rorty (1989) offers valuable epistemological and moral insights into ironies that create important avenues for understanding insurance and its relationship to other forms of solidarity. His work Contingency, Irony, and Solidarity was primarily intended to elucidate how private and public goods are formed and related. It was his approach to irony and solidarity that inspired the title of this book because it helped me make sense of the contradictory ethnographic evidence on how people talk about, experience, and shape insurance. It helped me understand insurance as a kind of solidarity that was simultaneously caring and oppressive, inclusive and exclusive, and how the social and abstract characteristics of insurance played a key role in people's understanding of what insurance was about.

The starting point of Rorty's pragmatic philosophy is far removed from ethnographic realities I encountered in Cape Town. Rorty is concerned with epistemological questions regarding objectivity and morality. He argues that the distinction between objectivity and morality is temporal and contingent. He not only questions the idea that objectivity and morality are separate, he also rejects the claim that morality is universal and extraneous to people, their languages, and ways of understanding the world. Instead of looking for objectivity we need to strive for understanding and truth and this requires morality, the connection being that morality enables seeing the world in a new way, for example by "suddenly" recognizing people as fellow human beings. Rorty contends that we need to recognize that morality is contingent and at the same time not resort to a kind of relativism that makes morality meaningless and impossible to uphold or express. This irony, recognizing that morality is contingent and simultaneously pointing out how crucial morality is for our understanding of the world, leads Rorty to explore the private-public divide. Publicly, one needs to uphold a certain morality and this morality is expressed through ever-expanding forms of solidarity. Privately, one needs to be aware of the contingency of morality and that the vocabulary through which the world is conceptualized is never final and needs to be open for change. This requires a degree of reflexivity about one's own place in the shaping of morality and understanding; in order for moralities to be important in public life one has to be reflexive in private. This means that Rorty acknowledges that moralities are shaped by specific communities and societies and recognizes the contingency of those important to us.

Rorty's intention is to explore how ironies shape the ways we understand the world, shape solidarity and drive social change. He outlines a liberal utopia where people have debates that are guided by deep-seated moralities and convictions, while being aware of the contingency of the 
language that shapes these debates and offers thoughts, metaphors, and ideas. This reflexivity means that when people debate their moralities and state their convictions, they are aware that they do so as members of a particular community with contingent convictions.

Thus, Rorty acknowledges the contingency of knowledge and morality and points out the importance of reflexivity, but at the same time that this does not lead to nihilism. He instead advocates a pragmatic approach by asking which languages, metaphors, and contradictions both reveal as well as hide our understanding of society and ways to solve problems. He argues that ironies will not be resolved but will eventually be cast aside and deemed irrelevant, and in this process a new language that offers new ways of understanding the world emerges. He discusses important contributions in the literature that show how a new language allows seeing phenomena in a new light, defining new kinds of problems, thinking of new solutions for these newly defined problems, and of course, creating different ironies.

The language of Rorty's pragmatic philosophy often resonated with fieldwork encounters and conversations where people talked about their experience with insurance. This is, among others, because insurance is always a collective where people pool money by making monthly payment, which in turns entitles them to very specific benefits in times of adversity. This inevitably creates tensions between collective and private interests that can never be fully resolved. In my research, I heard numerous accounts that depicted this ironic process. Several Cape Town residents reported that they continued taking out insurance policies despite often having bad personal experiences and hearing the many stories circulating about people being cheated by the insurance sector. This was puzzling. Why did they persist in doing something that they knew would cost a substantial amount of money, would possibly not help when faced with adversity, and in some cases even worsen their situation? I argue that in order to answer this question it is vital to examine the irony inherent to situational ambiguity. The irony here is found in the contradictory forces that make up solidarity. This is apparent when insurance both alleviates and creates risks; when instead of helping people overcome adversities, it becomes an adversity; when instead of being used to support one another collectively, it becomes detrimental to mutual support; when clients living in the townships of Cape Town decide to buy it to solve problems between kin and within communities, but instead add new problems to these relationships.

To explore the relationship between rationality and irony it is worth reviewing Evans-Pritchard's work on Zande thought. Evans-Pritchard ([1937] 1976) showed the rationality of Zande beliefs in witchcraft, 
magic, and oracles. He famously wrote: "Is Zande thought so different from ours that we can only describe their speech and actions without comprehending them, or is it essentially like our own thought expressed in an idiom with which we are unaccustomed?" (Evans-Pritchard I976, 4).

One of Evans-Pritchard's major contributions was showing how rationality is the outcome of specific contexts and ironies. One of these ironies is that the Zande are able to reconcile natural explanations for misfortune - the first spear, with magical explanations for misfortune the second spear: "The attribution of misfortune to witchcraft does not exclude what we call its real causes but is superimposed on them and gives to social events their moral value" (Evans-Pritchard I976, 25).

The irony of Zande thought is that "scientific" and "magical" explanations support one another in explaining misfortune: "Azande do not perceive the contradiction as we perceive it," Evans-Pritchard $(1976,4)$ explained. Another irony is related to the identification of witches. The Azande believe that witchcraft is a physical trait that is transmitted by unilinear descent - from father to son and from mother to daughter. At the same time, the Azande believe that the mother of a female witch or the father of a male witch does not have to be a witch. Evans-Pritchard explores this contradiction and shows how it is not problematic in the eyes of the Azande. Evans-Pritchard also describes how the Azande treat conflicting messages from the oracles that give information about the causes of misfortune. He shows how skepticism and belief in the oracles go together and actually reinforce the power of the oracles: "No one believes that the oracle is nonsense, but everyone thinks that for some particular reason in this particular case the particular poison used is in error in respect to himself" (Evans-Pritchard I976, I63).

The most perceptible irony in Evans-Pritchard's ethnography is when he tries to unmask the witchdoctor, Bögwözu. With the help of his servant, Kamanga, Bögwözu will perform surgery on a boy to remove witchcraft poison - a black substance - from his belly using a poultice that Bögwözu had made. Evans-Pritchard discovers a piece of charcoal hidden in the poultice and secretly takes it out before the surgery takes place. Thus, at the end of the surgery when Bögwözu presents the cloth with no "poison," he is exposed as a fraud. Afterwards, Evans-Pritchard confronts both Bögwözu and Kamanga. He writes: "I told them that I had removed the charcoal from the poultice, and asked Bögwözu to explain how it had got there. For a few moments he pretended incredulity ... but ... he made no further difficulty about admitting the imposture" (Evans-Pritchard 1976, I03-104). EvansPritchard writes that the magical surgery Bögwözu was to perform was nothing more than a trick. 
Nonetheless, Kamanga's faith was only temporarily shaken by the unmasking, and he quickly restored his faith through what EvansPritchard called secondary elaboration:

Two points emerge clearly from it. The first is that people not only know that witch-doctors can produce objects from the bodies of their patients by fraud, but also that they are aware of the kind of fraud they employ. The second point is that this knowledge does not conflict with great faith in witch-doctors, because it is believed that a considerable number of them do actually produce remarkable cures through their traffic with witches. (Evans-Pritchard 1976, 107)

The irony of Evans-Pritchard's attempt to unmask Zande belief is that it exposes his own rationality by exploring how notions of rationality are anchored in specific institutional and social relations. Rationality is contextual and socially embedded. It deals with the ironies of everyday life as much for the Azande as for actuaries working for South African insurance companies and African clients living in the townships of Cape Town. ${ }^{10}$ Rationality matters in the choices that clients make when faced with life and death situations or when trying to overcome adversities. Like Evans-Pritchard, I approach rationality as something that is context-dependent and part of specific institutional and social arrangements. The reasoning behind how insurance is shaped and used is also charged with contradictions and ironies, similar to those inherent to solidarity. In order to understand insurance, it is pivotal to explore these ironies and find out how people live with them, and at which points the irony of situations becomes uncomfortable and motivates people to make different decisions and change the way they do things.

Now let us move from Zande thought in the first half of the twentieth century to the rationality approach that predominates the second half of the twentieth century: rational choice theory (RCT). The premise of RCT is that to understand society, we must examine the individual decisions that people make. According to RCT, people make choices that have the best possible outcomes, meaning those that provide the greatest utility or happiness for the decision-makers. It is a universal theory used to explain why people vote for certain political parties, buy particular products, and deal with nuclear threats (Amadae 20I6). The irony in RCT is that it denies that rationality is contextual despite having been developed in a very specific political-economic context where it had to address explicit political and moral issues. In Cold War America, RCT held that the "self-interested, strategic rational actor became the central figure around which the re-examination of traditional Enlightenment 
themes and problems of government was based" (Amadae 2003, 3). RCT played a central role in the post-World War II defense against communism, including communist authoritarian and collective ideology. The moral principle of RCT was to defend society against these ideologies and promote a free society with the virtues of liberalism and a free market democracy.

The organizations that disseminated RCT, like the RAND Corporation and the Ford Foundation, were primarily academic, but political and military as well (Amadae 2003). RCT was developed as a value-free notion of human action to address the specific moral and political issues that revolved around the Cold War. The RAND Corporation played a central role in this:

It is no exaggeration to say that virtually all the roads to rational choice theory lead from RAND ... a quintessential American Cold War institution, and in turn to the Cold War Motives that underlay much of the impetus propagating rational choice theory. (Amadae 2003, I I)

The RAND Corporation was founded in 1948 by the Douglas Aircraft Company "to connect military planning with research and development decisions." 11 One of its aims was to develop models that predicted behavior and to use them to prevent the escalation of the Cold War into a nuclear war: "The relationship of military-organized science to democracy was perhaps the issue most fraught with controversy in the immediate post-war period" (Mirowski 2005, 95). RAND adherents include more than thirty Nobel Prize laureates, particularly in economics, and influential public servants, such as former US Secretary of Defense Donald Rumsfeld. ${ }^{12}$

The so-called prisoner's dilemma was originally developed at the RAND Corporation in I950 by Flood and Dresher (Poundstone 1992) and became the central expression of rational choice theory and the standard for game theory. One of the premises of game theory is to examine whether people cooperate or not and how this relates to individual and collective outcomes. ${ }^{13}$ The prisoner's dilemma experiment creates a conflict between rewards for both the individual and the common good (Poundstone 1992, 8-9). It assumes that two members of a criminal gang are arrested and imprisoned, locked up in solitary confinement where they cannot communicate with each other. The prosecutors do not have enough evidence to convict either of the two prisoners and so they offer a reduced sentence in exchange for information that incriminates the other prisoner. If both prisoners betray each other, they are both sentenced to two years in prison. If prisoner 
A betrays $B, A$ will be free and $B$ will get three years, and vice versa. If both prisoners remain silent, they will each serve one year in prison for a lesser charge.

The irony of the experiment is related to assumptions regarding the importance of social and institutional contexts in decision-making. One assumption is that the two prisoners have strongly shared morals about loyalty and trust because they are both gang members. It is implicitly assumed that both are guilty and that they both know they are guilty. The experiment assumes that the two gang members committed the crime together and that they are equally responsible for what happened. In the end, after both confess and all the evidence is collected, both get the same prison sentence. Referring to the experiment's formal protocol, the experiment involved two people, but the actual description incorporated a host of people and institutions that included prosecutors and a fair and efficient state apparatus. The experiment assumed very specific and, one might say, unusual circumstances: social assumptions about how fellow gang members relate to one another; moral assumptions of extreme loyalty between gangsters and the reliability of state institutions; situational assumptions where both prisoners acknowledged that they as individuals were responsible for what happened; and institutional assumptions in the expectations of a punitive context in which the experiment is set. ${ }^{14}$

The irony found in the prisoner's dilemma and in RCT approaches in general is that contexts do not matter. RCT developed a detailed and sophisticated logic based on the principles of profit maximization, self-interest, consistency, and the belief that rationality is universal and therefore not bound to contexts, not even the academic context that produced it (Herfeld 2013). Or, as Amadae (2003, 252) formulated: "Rational choice theory itself evinces no historical awareness, even of its own evolution as a science discipline."

Logic and rationality, including that produced as RCT, is contextual, one might even say emic, while appearing to address similar themes (see Table 2.I). The similarity between Zande thought, RCT, and the prisoner's dilemma is that they are structured around "the other" who one cannot fully know or trust, and who therefore marks or challenges the boundaries of solidarity: the Zande witch, the RCT communist, and the gang member in the prisoner's dilemma. These three very different approaches all address specific fears that are mostly related to death: death and disease among the Azande, death by nuclear war and collective ideologies in RCT, and the social death of imprisonment in the prisoner's dilemma. These rationalities smoothly incorporate ironies. The Zande ironies are assimilated through the first and second spear 
Table 2.1 - Ironies in rationalities

\begin{tabular}{|l|l|l|l|}
\hline & Azande thought & RCT thought & Prisoner's dilemma \\
\hline The other & The witch & The communist & The gang member \\
\hline The fear & $\begin{array}{l}\text { Death and } \\
\text { disease }\end{array}$ & $\begin{array}{l}\text { Nuclear war and } \\
\text { ideologies of } \\
\text { collectivity }\end{array}$ & $\begin{array}{l}\text { Social death (betrayal, } \\
\text { solitary confinement, } \\
\text { prison sentence) }\end{array}$ \\
\hline $\begin{array}{l}\text { Thecondary } \\
\text { elaboration; first } \\
\text { and second } \\
\text { spear; witchcraft } \\
\text { inherited and } \\
\text { discovered }\end{array}$ & $\begin{array}{l}\text { RCT became the } \\
\text { collective ideology } \\
\text { in post-war US; fear } \\
\text { was the starting } \\
\text { point of the analysis } \\
\text { of cooperation }\end{array}$ & $\begin{array}{l}\text { Individual choice } \\
\text { explained within } \\
\text { the context of a } \\
\text { well-functioning and } \\
\text { reliable collective } \\
\text { (the state's judiciary } \\
\text { system) }\end{array}$ \\
\hline
\end{tabular}

and secondary elaboration. RCT irony is found in its insistence on individual rationality and its denial of being central to a collective political ideology. The irony of the prisoner's dilemma is that it offers a theory of society based on individual behavior by assuming that a reliable collective state apparatus already exists. ${ }^{15}$

Thus, if there is something universal about rationality, it is that it deals with the ironies of everyday life that form around the boundaries of solidarity. Hence, how do ironies charge the financialization of insurance? How do the insurance clients in the townships of Cape Town navigate the ironic forces in their lives and deal with their complex social relations? Why, for example, are funeral insurance policies so popular among people who often already have informal funeral insurance arrangements through burial societies, and who often have or hear about bad experiences with insurance companies? In order to understand the financialization of insurance, it is important to examine people's expectations, their definitions of problems and solutions, and how these are part of specific social and institutional contexts.

I use irony to, like Rorty, move away from distinguishing between the moral and the rational. My focus on irony is not meant to embrace nihilism and cynicism, as in "nothing works." Instead, my intention is to generate insights that are based on compassion and show how irony offers insights into what is or becomes uncomfortable, where things are not as coherent and solid as some like it to be. Irony offers insights into the cracks and ambiguity of economic language and practice, suggesting that there might be something else at stake, and shows why people are ready for change, even if it means creating new problems. 


\section{Irony in method}

Rorty's approach to morality provides an epistemological foundation for anthropological research. ${ }^{16}$ If our understanding of the world is characterized by contingency, irony, and solidarity, then our ways of doing research and our methods should enable and reflect that. If contingency characterizes our conceptualization of the world, then our methods should facilitate the discovery of contingent events, which means the methods themselves need to embrace contingency by being open to surprises and other serendipities, for example. ${ }^{17}$ The methods would reveal how people try to resolve contradictions and ironies, and how they are sometimes successful. They would show that some ironies become less relevant albeit unresolved, and how contingencies in events and languages lead to new moralities, again riddled with ironies and contradictions.

The foundational method of cultural anthropology as developed by Malinowski identified the ironies of everyday life, but this was only revealed much later. In Argonauts of the Western Pacific Malinwoski (I922) presented a method that suited an anti-ironic and functionalist view of society. His method is anti-ironic because there is no space for contradictions, tensions, or ambiguities in a functionalist analysis of society. Participant observation, according to Malinowski, was meant to reveal how different elements of society contributed to the functioning of society and culture. He used a metaphor of the body to explain how fieldwork methods and the analysis of society converge. Participant observation started with discovering what he called the skeleton of society, defined as the rules and regularities that shaped society. This was followed by studying people's ambitions, statuses, and vanities, described as the flesh and blood of society. Finally, participant observation revealed people's feelings and internal dialogues, which referred to the third element of the spirit (Malinowski I922):

Their whole tribal tradition, the whole structure of their society, are embodied in the most elusive of all materials; the human being. (Malinowski [1922] I983, II)

The irony of Malinowksi's ethnographic approach was only revealed posthumously, after the publication of A Diary in the Strict Sense of the Term (Malinowski 1967). In the diary Malinowski expresses his hidden desires, frustrations, anger, lust, and disgust. These are aspects of society and ethnographic research that were kept out of sight, but they 
were also strongly tied to Malinowski's body metaphor. But unlike his functionalist theory of the connection between body and society, these experiences are disruptive and unsettling:

I watched the muscles of her back, her figure, her legs, and the beauty of the body so hidden to us, whites, fascinated me. Probably even with my own wife I'll never have the opportunity to observe the play of back muscles for as long as with this little animal. At moments I was sorry I was not a savage and could not possess this pretty girl. In Kaulaka I looked around, noting things to photograph. Then walked to the beach, admiring the body of a very handsome boy who was walking ahead of me. Taking into account a certain residue of homosexuality in human nature, the cult of the beauty of the human body corresponds to the definition given by Stendhal. (Malinowski [1967] I989, 255-256)

Here, the way in which the body is described does not align itself with a functionalist interpretation of society, nor with what might be considered functional in the academic world where Malinowski was so successful. The diary shows that doing ethnographic research using a metaphor of the body also revealed possibly unwanted desires and disharmonious aspects of society. Thus, the irony was that the body was central to the way in which Malinowski separated his findings and interpretations into two parts: a palpable, functionalistic, and public literature; and a disharmonious concealed diary.

Evans-Pritchard ([1937] I976) used the methods of participant observation and ethnography to explicitly address the contradictions and ironies of Zande thought, but maintained the idea of social structure. Although Zande belief in witchcraft was full of contradictions, it was stable and rational, at least in the eyes of the Zande, because it was firmly anchored in institutions that complemented one another. According to Evans-Pritchard, institutional changes had to precede changing Zande rationality. He argued that institutional changes were produced by forces outside Zande society. He makes no mention of internal forces that could lead to change.

According to Gluckman, and the Manchester School in general, anthropological research must focus on specific and unusual events. ${ }^{18}$ "The atypicality of the events was of primary interest, most especially those that expressed conflict and crisis or threw into relief the social and political tensions that were conceived as being at the heart of everyday life" (Kapferer 2015, 2). Instead of assuming that the structure of a society could be unveiled by studying typical events, Gluckman focused on the unusual ones because they could reveal the 
transformative potentials of society. His seminal Analysis of a Social Situation in Modern Zululand (Gluckman I940) refers to an atypical event and gives a detailed account of the relationships between headmen, chiefs, bridge-constructors, missionaries, the Mahlabatini office staff, traders, agents, the district surgeon, the anthropologist, and so on, "[a]ltogether about twenty-four Europeans and about four hundred Zulu" (Gluckman I940, I 53). Gluckman maintained that participant observation was about discovering the transformative potential of events by carefully analyzing the tensions that were inherent to new forms of cooperation:

The innovation of Gluckman and the Manchester School was to make the event of crisis, the event of vital conflictual intensity, a primary focus of anthropological attention. Moreover, the critical event atypical but not necessarily exceptional - was switched from being of secondary importance in anthropological ethnography (of "the exception proves the rule" kind) to being of primary methodological worth (a site of potential), calling for more thorough investigation of its ethnographic realities. (Kapferer 20I 5,3 )

It is well established that this methodological approach was fundamental to the Manchester School and its predecessor, the Rhodes-Livingstone Institute. It also inspired Mitchell's analysis of the Kalela Dance in Rhodesia (Mitchell 1956, I). Mitchell used what we now would call a "mixed methods approach" that included observations, analyses of song texts, interviews, and statistical data collection. He found that the "tribal" Kalela Dance was an expression of industrial production in the Copperbelt that was intimately intertwined with labor migration and urban relations, including with Europeans (Mitchell I956). These fragilities have had equal importance in Kapferer's work on social relations and rituals and in his development of a constructivist approach to events that resonates with the philosophy of Deleuze and Guattari (Kapferer 2007, 2015). ${ }^{19}$

In short, this means that detailed studies of events are not necessarily illustrations of larger social processes, but rather that larger social processes unfold within specific events. Contradictions, tensions, and conflicts should not be treated as exceptional or as outliers with little relevance, but as fundamental to both social stability and social change. In order to understand ironies, one inevitably has to be reflexive of the positionality of the researchers and their relationship to, or participation in, events. Methods are not neutral territory, but are contingent on the academic worlds that produce them and the social dynamics that people study. 
This was embarrassingly clear to me in my own field work, where I could not completely escape the irony of doing research among people living in extremely precarious situations, while I enjoyed the luxuries offered by one of the world's wealthiest cities.

I carried out my fieldwork in the townships of Cape Town, mostly in Indawo Yoxolo, Khayelitsha, and Crossroads, but also in other predominantly Xhosa-speaking townships. Given the characteristics of the topic (commercial insurance) and the place (the Cape Flats), my fieldwork was conducted within a fragmented social network. Initially, I mostly interviewed people who wanted to tell me about their problems with insurance companies, which often led to conversations with their relatives, neighbors, or other people in their social network. I also interviewed people living in the Cape Flats who were professionally involved in insurance, such as sales agents, brokers, and undertakers, or who participated in associations that had marketing interests for insurance companies, such as burial societies and taxi associations.

For safety reasons, I stayed in the mostly white suburbs of Cape Town and Stellenbosch, rather than in the townships. From these affluent areas I took a car to the Cape Flats to meet Edith Moyikwa or Mandisa Kuju who assisted me during the research with translations, interpretations, and safety issues. At the end of the day, after having listened to how people came to grips with their financial products, poverty, conflicts within families or associations, and the ever-present anxiety about violence, I would drive back to the suburbs to work on my fieldwork notes or meet friends for sushi. I sometimes had Sunday lunch at one of the nearby opulent wine estates.

Furthermore, I did research among actuaries and others involved in the development, marketing, and management of insurance for African clients. These professionals were primarily white male South Africans in their thirties and forties. Most were actuaries but some had different educational backgrounds such as medicine or business administration. I interviewed them in office buildings situated in the business districts of Cape Town and Johannesburg, in nearby cafés, at insurance-related events, and occasionally at the university or via Skype. Our conversations were about people that were referred to in the abstract as an abbreviation that indicated a specific consumer profile, or as a statistic with calculable risks. Sometimes the "abbreviations" were present as the servers at our table, but they were not part of our conversation. In some situations, I felt like a broker of sorts myself, a kind of translator between the world of actuaries and their clients, talking about people who seemed so distant, even though they lived only ten minutes away 
and were busy cleaning the houses of the professionals I was talking to, taking care of their children and maintaining their gardens.

This irony of talking in abstract and distant ways about people who were actually so close, sometimes present, is fertile ground for reflecting on what ethnographic and statistical evidence reveal and simultaneously conceal. Instead of simply concluding that some disciplines rely rather blindly on statistical data, maybe it would be more constructive to consider how to combine ethnography with statistics. Today, descriptive statistics are virtually absent in economic anthropology. But it is worth exploring how to bring statistical evidence into ethnographic research. Perhaps there are ways of including statistical analysis without misrepresenting social life and without statistics turning into structural and symbolic violence, and without downgrading ethnographic evidence into vignettes that support statistical evidence. ${ }^{20}$ In order to understand how the social and abstract dynamics of money and economics work in general, it is valuable to incorporate methods that correspond to both realities and not celebrate the social over the abstract. In this book, I include descriptive statistics in order to achieve a better understanding of the connections between social and abstract economic dimensions and the ironies they produce. Methods like statistics make room for particular abstractions and thus can help provide important insights. As I will show, these abstractions are not only of interest to marketers and actuaries, but are also important for understanding why people living in the townships of Cape Town experience insurance policies.

I created a neighborhood survey that elicited experiences and opinions related to insurance, risks, and reciprocity. The survey questions were based on ideas and insights developed during fieldwork, which were then used for a neighborhood survey in 2005 and 2006, mainly conducted by my research assistant, Edith. We tested a few questionnaires together, after which I modified them to add clarity and remove ambiguities. Because Edith had been working with me since I997, she was well aware of what anthropological research was about and how to conduct interviews. Initially, she did the survey on her own, but after she was robbed at gunpoint while traveling to people's houses for interviews, she was accompanied by her husband Vido for safety reasons. The interviews took place in the homes of the respondents, and to ensure employed people were included, the questionnaire was done mostly on the weekends or in the evenings. A total of I IO interviews were carried out in the neighborhoods of Indawo Yoxolo and Tembani.

Indawo Yoxolo, where I had been carrying out fieldwork since I997, ${ }^{21}$ began as a squatter camp and in the mid-I990s became part 
of the National Reconstruction and Development Plan (RDP). A small part of Indawo Yoxolo is still a squatter camp but more people live in subsidized one-room houses with a pre-paid electricity meter, a water tap, and a toilet. Unemployment is very high in Indawo Yoxolo and the people that have jobs typically earn a minimum wage as cleaners, domestic workers, or security guards. Nonetheless, the respondents in Indawo Yoxolo had an average of I.8 insurance policies each. Tembani, in contrast, is a relatively wealthy part of the township of Khayelitsha. Residents are often civil servants, nurses, police-officers, and other professionals who live in two- or three-bedroom houses, sometimes with a garage and a car. Some residents are fairly successful business owners who run a shop or own a few taxis. On average, respondents from Tembani had 3.2 insurance policies each. By focusing the survey on these two areas it was possible to gain some insight into the relationship between commercial insurance, neighborhood relations, and poverty.

I also developed an online survey for actuaries which was sent out in November 20I I. To do this, I had help from Actuaries Without Borders and the survey link was sent by email by the Actuarial Society of South Africa to its approximately six hundred members. Seventy-nine actuaries responded and shared their opinions and experiences regarding the insurance sector, how national political changes affected the sector, the development of products for poorer clients, and other questions related to the market.

These key methods, along with the analysis of policy papers and other documents, debates on (social) media, participant observation at several events, and time spent with people in casual conversations produced several case studies. Some of them involved only a few people and took place during a relatively short period. Others involved prolonged political struggles spanning several decades. Using multiple methods and integrating them into case studies proved very fruitful for understanding the ironies of solidarity. The case studies revealed the incongruences between what people say and what they do, and clarified how people involved in events and places have different narratives. They brought to light how the world views of predominantly white professionals in the insurance sector informed the insurance policies that changed the lives of clients living on the Cape Flats. But most importantly, they offered insights into how irony was an important motor of social change and how, simultaneously, social change produced its own ironies.

Mixed methods also helped to bring out the ironies of solidarity, particularly by combining the two surveys with more standard anthropology methods. The reason for this might be because surveys as a method are more abstract in that they provide less room for sociality, 
i.e. the impersonal relationship between researcher and respondents. They offer no space for the complexities and richness of people's narratives that encapsulate some of the abstract forces that are so crucial to the nexus of solidarity and insurance. Thus, it is possible that ironies produced by the abstract and social dynamics of economy can be better identified by using methods that inherently represent and produce abstraction and sociality. Moreover, the results of the neighborhood and online surveys at times differed greatly. In the neighborhood survey, I asked respondents how they experienced insurance. Then, in the online survey, I asked actuaries how they thought their clients experienced insurance, challenging them to reflect on what insurance looked like from the perspective of poor African clients. The responses of the actuaries were often very different and even diametrically opposed to the answers from the neighborhood survey. The difference between these survey results is what led me to explore the ironies of solidarity in greater detail. 


\section{3 \\ Hope and redistribution}

\section{Introduction: from labor to redistribution}

Marketing insurance to predominantly poor and lower-middle-class Africans was part of a major shift in South Africa's political economy, which was marked by the end of apartheid in I994. During and before apartheid, South Africa's political economy was based on racial exclusion and subjugation through the control of land and labor. After I994, its political economy veered towards redistribution, which was done through large-scale institutions that defined entitlements according to citizenship. This shift from the politics of labor and land to the politics of redistribution was fundamental to the realignment of social and institutional relationships, the articulation of inequalities and conflicts, and people's hopes and anxieties about the future. In fact, redistribution is more important for understanding the financialization of insurance than the rise of global neoliberalism.

This shift carries implications that go beyond politics and can be viewed as an ontological change. It changed ways of being and notions of the self as constituted by relations with others. It became a guiding principle expressed in economic languages, practices, and realities. ${ }^{1}$ Therefore, these changes are not only about changing power relations in a democratic South Africa and the redistribution of new resources. They are also about new forms of intersubjectivity and the explanations people give for why some have become very wealthy while so many others continue to live in poverty and insecurity in the new South Africa. The shift is ontological because it leads to new types of conflicts and new explanations for these conflicts. People's experiences changed after 1994 and consequently, the explanations for these experiences also changed. Redistribution, both real and imagined, became central to the language people used to understand what happened to them. In this chapter I will define this ontology of redistribution and show how insurance was part of it, at least for the predominantly poor African clients living in the townships of Cape Town. An ontology of redistribution helps us to understand how people see the world, identify problems and solutions that they encounter in everyday life, and how struggles are defined. ${ }^{2}$ The reason for approaching this from an ontological point of view is because of what Mol calls the politics of what: 
"What is the reality that takes shape and that various people come to live with?" (Mol 20I4, 2).

To understand the rise of an ontology of redistribution it is relevant to first examine some of the key features of apartheid political economy and how they affected the lives of Africans who now live in the townships of Cape Town.

The control of land and labor was the essential cause of racial inequalities during apartheid (1948-1994), as well as during colonialism and the Union of South Africa. Africans were not allowed to live in most of South Africa. They were only allowed to inhabit the so-called Homelands or Bantustans, which were basically rural labor reserves for specified ethnic groups. For the Xhosa people these were the Transkei and Ciskei Bantustans in what is now the Eastern Cape. Bantustans comprised only small parts of South Africa, and the Africans who lived outside these designated areas were forcefully removed by taking away their land and livelihood. A few, mostly male, Africans were allowed to leave the Bantustans to work temporarily in South Africa's mines, industrial areas, and cities. However, as soon as their employment contract ended, they were forced to return to their Bantustans. ${ }^{3}$ It was nearly impossible for African women to leave the Bantustans to work or to join their husbands. Froneman, who was Chairman of the Bantu Affairs Commission and Deputy Minister, made it clear that he did not want African women and children outside the Bantustans. In 1969, he stated in the House of Assembly that South Africa "must not be burdened with superfluous appendages such as wives, children and dependents who could not provide service" (Cock I980, 245). ${ }^{4}$

Cape Town had other racist policies in addition to the national apartheid laws, which made Cape Town into a city for whites and coloreds only and were intended to "phase Africans out of the Western Cape" (Goldin I987, 87). Only a small group of Africans, almost all Xhosa, were granted "section Io rights" 5 allowing them to live in Cape Town permanently in the specially designated townships of Langa, Nyanga, and Guguletu. The remaining African populations of Cape Town were labeled and treated as migrants having only temporary rights to live and work in Cape Town. When their employment ended, they had to return to Ciskei or Transkei. These so-called migrants had to live in the same designated townships, but were confined to "migrant hostels," a term that concealed the terrible conditions under which they were forced to live, sharing rooms and even beds (see Ramphele I993). When I visited the hostels in Langa and Nyanga for the first time in I995, I was appalled at the horrible living conditions. The hostels were overcrowded 
and poorly maintained, cooking facilities were not functioning properly, and sanitation did not work, forcing people to live in the stench of urine.

Africans who lived in Cape Town without section Io rights or a temporary pass were considered illegal migrants. They lived in shacks on plots where Africans with section Io rights lived - so-called "backyard shacks" - or moved into the migrant hostels. Some lived illegally in garden sheds belonging to white employers, while working as domestics, nannies, or gardeners. Others found shelter in shacks on the barren land of the Cape Flats, or even on rooftops. Illegal migrants lived in constant fear of being caught by the police, being imprisoned, and being deported to the Bantustans (Ross 1999, I I4-I43; Ramphele I989, I991). ${ }^{6}$

Racial discrimination and the control of land and labor had tremendous and well-documented consequences for kinships and household relationships. Apartheid legislation forced African men to live apart from their families and created an impoverished economy in the Bantustans, which also had far-reaching implications for intergenerational and gender relations. Families were split apart and children grew up in different households. ${ }^{7}$ Migrant labor placed fatherhood and masculinity in general under pressure and defined it as a man's ability to financially support his family. African women, even more so than men, could not generate income unless they lived in the city illegally. This meant that they were forced to depend on migrant men for survival, which often led to highly unequal and exploitative relations. ${ }^{8}$ As land, cattle, and decent incomes from wage labor became scarce, the reproduction of kinship through the maintenance of a household, marriage, or inheritance became increasingly fragile. The destruction of households and kinships led to volatile relations, especially between men and women and different generations. This volatility is one of the key consequences of the political economy of apartheid and its racial control of land and labor. ${ }^{9}$

Thus, we can see that racism, during and before apartheid, and the politics of subjugating people by controlling land and labor had widespread consequences for households, kinships, and neighborhood relationships in Cape Town. It is in this context that apartheid ended in 1994, leaving a new democratically elected government to deal with the inequalities it inherited and to include Africans as South African citizens. Next, I will show how large-scale redistribution became pivotal to democratization and citizenship for all South Africans, and explore how this relates to the experience of Africans living in Cape Town. Although many of racial inequalities still persist, the end of apartheid led to new experiences with the state that produced new explanations for why 
some people benefited from democracy while many others remained poor. I will show how insurance was part of these new experiences with the economy.

\section{Service delivery and community conflict}

The breakdown of apartheid led to rapid urbanization, especially in the I980s when increasing numbers of people left the Bantustans for Cape Town. ${ }^{10}$ Many of them moved into shacks in informal settlements spread across the Cape Flats. They had no sanitation, electricity, schools, medical services, or other infrastructure. Shacks were typically built close together, meaning fires could easily spread, especially in the cold, wet Cape Town winters when paraffin stoves were used for heating. When there were fires, the fire brigade sometimes could not reach the shack settlements to extinguish them because there were no roads, leaving many people homeless, injured, and even dead. A woman told me how a paraffin heater had set her shack on fire and burned her sleeping grandchild to death.

When the ANC won the national elections in 1994, it set out to improve these living conditions by redistributing development resources. It created policies to redistribute land to the African poor; to increase their access to water, sanitation, and electricity; to provide basic housing; to improve health and education; and a wide range of other strategies (ANC 1994; Bähre 2007; De Wet 1996). Housing for the poor, including the delivery of related utilities such as water, sanitation, electricity, and roads, was one of the main features of post-apartheid development (Huchzermeyer 200I). ${ }^{11}$ The 1996 government census showed that 72 percent of black South Africans had no running water, as opposed to 4 percent of white South Africans (Nnadozie 20I3). These projects intended to improve people's living conditions and strengthen active citizenship. By including residents in the decision-making process, these policies would strengthen democratization at the community level (ANC I994, I I9-I35; Bähre 2007, 5I-8I; Niksic 2004).

Indawo Yoxolo was one of the squatter camps that received development resources. In the early I990s, Indawo Yoxolo consisted of approximately a hundred precarious shacks built on the sand and among the bushes of the Cape Flats. From the I99os onwards, the government, in cooperation with the private sector, demarcated plots and built roads, a sewage system, and electricity networks. The plots often contained a small one-room house called a "matchbox house" because of its small size, or an "RDP house" referring to the National Reconstruction and 
Development Program that built many of these houses. ${ }^{12}$ Later, Indawo Yoxolo was given a police station, schools, and a small hospital that offered basic medical services.

For the Xhosa residents of Indawo Yoxolo, the new democratic government manifested itself most concretely through the resources that came with service delivery and the involvement of the residents in these projects. The residents learned how to get on the waiting list for a plot with an RDP house, and how to get a job with one of the construction companies that built the roads, sewage systems, electricity grids, and RDP houses. They tried to find ways to influence community participation in development policies and in the allocation of plots and temporary jobs.

In Indawo Yoxolo, as in other parts of South Africa, community participation and grassroots democratization gave rise to a group of violent brokers. These brokers were residents of Indawo Yoxolo who claimed to democratically represent the community, a claim that was challenged by other residents. Their opponents called them the Big Five, after South Africa's five most dangerous wild animals: the lion, elephant, buffalo, leopard, and rhinoceros.

By 1997, the Big Five had taken nearly full control over Indawo Yoxolo. Within two years they had become powerful brokers negotiating between development organizations (municipal organizations, government departments, NGOs, construction companies, etc.) and residents hoping to own a plot of land with an $\mathrm{I} 8 \mathrm{~m}^{2} \mathrm{RDP}$ house that had a water tap, a toilet, and a prepaid electricity meter. Getting a plot or a job meant bribing the Big Five, who intimidated residents and fiercely attacked anyone that publically spoke out against them in an attempt to end the corruption (Bähre 2007).

Not many Indawo Yoxolo residents went to the government agencies, construction companies, or local ANC branch to try to change this situation. The ones who did gave detailed accounts of how Big Five members demanded bribes, illegally sold plots to people who were not entitled to them, and sold already occupied houses after throwing the owner's belongings out on the street. In a hearing organized by the provincial branch of the ANC, residents testified that the Big Five intimidated them by holding them at gunpoint and other forms of violence, and relayed several cases of assault.

One evening, the leader of these opposition residents was walking down the street near his home when he was approached by one of the Big Five members who took out a gun and shot him through the head, killing him instantly. In the following days, Big Five members shot several other people in the area who had criticized them publicly, 
and threatened to kill others, among them my research assistant, Edith. The violence was very effective and the Big Five kept their control over Indawo Yoxolo and the redistribution of the resources made available through service delivery (Bähre 2007, 5I-84).

Service delivery led to many, often violent, community protests throughout the country and Indawo Yoxolo was no exception (see among others Jain 20I0). These tensions continued over the years, and in 2009 they were addressed by president Zuma when he spoke at a national meeting on service delivery:

[B] urning down libraries, torching people's houses, and looting spaza shops do not build a strong nation. It does not solve our legitimate problems. It is not a foundation upon which we can collectively build a bright future for our children. ${ }^{13}$

For the residents of Indawo Yoxolo, democracy was characterized by the redistribution of government resources by a local mafia. Largescale redistribution of resources and democratization defined the relationships they had with their neighbors, NGOs, and local and provincial politics.

\section{Black Economic Empowerment and racial tensions}

Another important strategy to target racial inequality was Black Economic Empowerment (BEE). The ANC government developed a wide range of policies and legislation that forced companies and organizations to employ more black people at all levels, including at senior levels. BEE was intended to increase the share of black corporate ownership, and to make sure that tenders were awarded more often to black-owned companies, even when they did not yet have the expertise that the white-owned companies had built up during the apartheid era. ${ }^{14}$ The South African government used BEE and its successors to try to gain a firm grip on South African businesses. It was enforced in state and parastatal organizations, and the government pressured private sector companies to adopt similar policies. Private companies that did not make systematic efforts to overcome racial inequality could be excluded from doing business with the government, would not obtain government grants and funding, and would be withheld industrial licenses (Arya and Bassi 2011, 683).

Many Xhosa residents living in the Cape Flats had high entrepreneurial expectations of BEE. They did not think a regular job was 
feasible, or that an insecure job as a cleaner or security guard could provide a better future. Thus, many tried to set up BEE businesses and compete for government tenders. Especially after 2000, people often told me about their aspirations to start a business. It seemed that everybody wanted to become a businessperson of some kind, despite having little notion about what that entailed. I had many conversations with people who did not know what a business plan was, but wanted me to help them write one because they had heard that it was essential to starting a business.

Government tenders attracted massive interest once BEE criteria were established. For example, in 2006 the Cape Town city council published a request for tender for cleaning a fairly small public library. The library had regular cleaners, but twice a year it needed what they called "deep cleaning." This meant washing hard-to-reach windows, waxing the floors, and cleaning the carpets and upholstered furniture with special chemicals. This was a small job that would probably take three cleaners two days of work. The tender process meant interested companies had to visit the library and submit a bid. These visits were registered in a book provided by the city council, and then the company representatives were given a short tour through the library to explain the work to be done. When the day came for the visits, the librarians and civil servant responsible for organizing the tender were overwhelmed when approximately three hundred people representing three hundred cleaning companies arrived to inspect the library and compete for the tender. Many were not even able to enter the small library and had to wait outside on the street, trying to find out what was happening inside. Because everyone had to register their names and company details in the book, and the librarians were only able to give tours to a few dozen people at a time, the interested parties were forced to wait for hours.

Many of the visitors that day had just recently started a cleaning company and hoped that BEE policy had created an opportunity for them. Additionally, the city council had established criteria for Historically Disadvantaged Individuals, or the HDI criteria, which many of the three hundred companies probably met, but nevertheless had little chance of winning the contract. The intense competition was punctuated by the fact that many companies did not seem to know how to write a proper bid, nor did they have the necessary equipment, personnel, or skills. The head librarian had little confidence in the BEE companies and wanted the contract to be awarded to the company that had done the deep cleaning in the past. That, however, was a white-owned company, which aroused suspicions that the Afrikaans head librarian was racist and resisted transformation. The white-owned company had also 
submitted a bid, which the city council rejected because the company did not meet HDI criteria. Eventually, the city council decided to redo the entire tendering process, this time in a more orderly way. One of the civil servants working on this case told Zanele, one of the competing entrepreneurs: "If you want to receive business in the future you have to vote for us [ANC]. I will make sure that the head librarian will not create any nonsense."

Every year there are thousands, if not tens of thousands of procurements in South Africa, and many more companies hoping that democratization and BEE policy has created new income prospects. However, most people think BEE policies and HDI criteria have not created substantial opportunities, and seem to benefit only a relatively small group of wealthy "tenderpreneurs" sometimes called the "black diamonds" (Ramphele 20I2; Ponte et al. 2007; Southall 2007).

The boundaries between the real and imagined wealth of democratic redistribution were apparently quite blurred. Zanele, for example, had purchased cleaning equipment such as a floor polishing machine and professional vacuum cleaners, in addition to a pickup truck to transport the equipment and cleaning staff to different sites. The city council had published another request for tender to clean a government building in the city center and Zanele decided to submit a bid. Her decision immediately led to an argument with a colored woman who also owned a cleaning company and who had won this tender in the past. According to Zanele, the woman intimidated her and said that she had better not compete with her, saying she knew where Zanele lived and that she would kill her if she persisted. Zanele made it clear that she would not be intimidated and that she would try to get the tender.

However, it soon became clear that the woman's threat was serious. Zanele was sleeping at home when for some reason she woke up in the middle of the night. She was thirsty and got out of bed to drink some water. When she returned to the bedroom she saw her husband still fast asleep, but she noticed that her pillow was ripped apart and that there were feathers all over the bed. Zanele woke her husband, asking "What happened to my pillow?" He had no idea. Then they noticed a tiny hole in the corrugated iron roof, just above the pillow. They searched the pillow and the mattress and found a bullet. They were convinced that the colored woman who had threatened to kill her had either climbed up on the roof and shot at her, or that she had hired someone to kill her. If Zanele had not gotten out of bed for a drink who knows, maybe the ancestors were protecting her - she would have been dead. Zanele was shocked at how she and her husband had narrowly escaped death. 
It is a fact that people sometimes use violence, and even kill, to guarantee their business (see also Bähre 2007, 5 I-8I; Bähre 20I4). At the same time, however, what are the odds that someone had climbed onto a corrugated iron roof without being heard, and then shot a bullet through the roof to hit exactly where Zanele's head would have been had she not gotten up for some water? Zanele's account can be interpreted as a collective fantasy that Thoden van Velzen defined as "the intermediaries or the gateways to a society's jouissance, that knot of anguish and sensuous pleasures that lies behind religious or other public discourse and speculation" (Thoden van Velzen I995, 730). ${ }^{15}$ Zanele's account conveys desires and anxieties about future prosperity as well as fear of racial violence. These desires and anxieties revolve around the new political economy of large-scale resource redistribution that is part of democratization and the transformation of racial hierarchies.

\section{Social grants and gencrational strain}

Social grants have existed in South Africa since the beginning of the twentieth century, but Africans were rarely entitled to them. ${ }^{16}$ Thus, democratization brought major changes to the availability of social grants in that all South Africans were made eligible for them, irrespective of race. Moreover, after the I994 elections, the government set up several new types of social grants. Today, there are social grants in the form of cash for food relief, child support, foster care, care-dependency, and old age. This had a significant impact on South African society, both for the recipients and for the national economy. In the ten years between 1997 and 2007 the number of beneficiaries almost tripled. In 2003, 30 percent of South African households received at least one grant (Holmes 20I4). In 2006, the Minister of Finance, Trevor Manuel, said in his annual budget speech that social grants had become "the fastest-growing category of government expenditure since 200I, and now amounts to R70 billion [almost USD 7 billion in 2006] a year, about 3.4 percent of gross domestic product." ${ }^{17}$ One year later, the number of grant beneficiaries far exceeded the number of people that paid income taxes. By 20I3, almost half of South African households received at least one grant (Holmes 20I4).

During fieldwork I saw firsthand how social workers encouraged people to apply for grants. They emphasized job insecurity and carefully hinted at the risk of HIV infection. ${ }^{18}$ They told their clients that the future was uncertain and that there was no guarantee as to how much longer the government would continue providing social grants. 
Even people with well-paying jobs were sometimes urged to apply for disability grants, just to be sure. ${ }^{19}$

Most social grants are given to parents and grandparents. ${ }^{20}$ Many young African men and women, especially those with little formal education, depend on their parents and grandparents who receive these grants. ${ }^{21}$ Because jobs are hard to find, it is the disabled, sick, and elderly in many South African households who generate income, and not the young men and women in the prime of their lives.

Veliswa, for example, is well into her eighties and lives in Ezibeleni, a township of Queenstown in the Eastern Cape. I met Veliswa for the first time in 1997. She lived with her husband in a small house with a vegetable garden in the back. She had no children or grandchildren living with her, although those in the neighborhood would occasionally visit them and join them for a meal. Ten years later, Veliswa's situation was very different. Her husband had died and her sole income was her old age grant provided by the state. Now she had five teenage grandchildren living with her for months, even years, at a time. None of them contributed financially to the household. Some of Veliswa's children would occasionally send her money for taking care of the children, but it was very little. Veliswa enjoyed the company of her grandchildren, but she also made it clear that it was very difficult to run a household and feed six people on a small social grant. ${ }^{22}$

People expressed concern that social grants would result in moral degeneration. Many men and women argued that unemployment was due to laziness or other forms of immorality. ${ }^{23}$ Despite ample evidence that jobs were extremely hard to find, especially for those with little formal education, people complained that their children, particularly young men, were too lazy to look for work, finding it all too comfortable to live off their grant-receiving parents or grandparents. Sometimes these accusations were quite harsh. For example, when I asked Dorothy how her nephew was doing, her response was startling. Her nephew, who had lived with Dorothy for some time, had AIDS and had moved to the Eastern Cape to die among family. She went on a rant about how lazy her nephew was: "He was too lazy to get out of bed, too lazy to do any chores around the house, and too lazy to look for a job." When I suggested that he was maybe too sick to do this, she denied it vehemently. According to her, he was lazy and used AIDS as an excuse.

When it came to girls, women in particular were worried that their daughters would get pregnant in order to be eligible for a child maintenance grant. Mothers expressed their concerns that these social grants increased teenage pregnancies and promoted unprotected sex, and lamented the girls' ignorance about child-rearing and the costs of living. 
One woman told me about an argument she had with her daughter of fourteen. The girl, who already had a child, threatened her mother saying that she would have more children so she could leave her parental home and live on child maintenance grants provided by the state. These concerns contrasted sharply with the actual number of pregnancies. Since the turn of the millennium, teenage pregnancies in Cape Town, as well as the rest of South Africa, have declined due to the increased use of contraceptives (Mkhwanazi 20IO; 20I4, see also Makiwane et al. 2006). These moral concerns need to be viewed in the context of the cultural practice of lobola, or bridewealth, which strictly regulates parental rights. ${ }^{24}$ Such conflicts reveal a mother's anxiety about an irresponsible daughter who readily has sex for money, and how social grants make it more difficult for parents to control their daughters' reproductive capacities.

Because of the high occurrence of HIV/AIDS in South Africa, grants to help the poor take care of orphans are desperately needed. However, these also lead to social tensions within families and between generations. Sipho and his brother lived with their parents in the Eastern Cape. When Sipho was still young, not yet a teenager, his father died. The brothers stayed with their mother, but before long she too became ill from AIDS and her health deteriorated rapidly. The siblings took care of their mother as best they could, and were also helped by their grandmother who lived a few streets away. They spent a lot of time with their grandmother, who usually cooked dinner for them. When their mother eventually died, they moved in with her. This left their parental home vacant, which was then sold by their father's brother who lived in the same town. This uncle took the money from selling the house and officially adopted Sipho and his brother, making him the beneficiary of a child maintenance grant called the Foster Care Grant. Therefore, in practice it was the grandmother who took care of the boys, but she received no financial compensation.

When other relatives became aware of this situation, many were angry. They thought it was unfair that the uncle refused to take care of his nephews after he legally adopted them, while still receiving the child maintenance grant and taking the money from selling his brother's house. Soon after, the grandmother also became ill and died of AIDS. Sipho and his brother had to move in with their uncle, which was horrible for them. Sipho recalled the humiliation he and his brother had to endure during dinner when they were forced to stand and watch their uncle, aunt, and cousins eat while they received nothing. They often went days without food were beaten severely. Sipho felt treated like a slave. 
Nobuhle, a relative on Sipho's mother's side, lived in Cape Town and during a visit to the village she heard about the situation. She decided to take Sipho with her to Cape Town, which was a tremendous relief to the boy. Her decision, however, fueled gossip within the family. Many wondered what happened with the child maintenance grant, and some suspected she had taken Sipho for the money. When Nobuhle heard about these rumors she was furious because the uncle was still the legal foster parent of both children, and she received no money at all. She had taken Sipho into her home to stop the abuse and because she liked having Sipho in the house; he was pleasant company and helped with chores.

Unfortunately, things became worse when Nobuhle suddenly had to be hospitalized. There were two cars parked in front of Nobuhle's house and because of the emergency situation they had not been moved to the garage. Sipho knew it would not be safe to leave the cars on the street and decided to park them in the garage himself. He did not have a driver's license, but he had seen people driving and thought it could not be too difficult. However, when he tried to move one car into the garage he crashed into the wall between the garage and the living room. He panicked and made matters worse by reversing into the other car, causing even more damage. Embarrassed and afraid of the repercussions, Sipho immediately ran away. Sipho only dared to contact his family again some time later, and their relationship is now slightly better, although he does not live with them anymore. Through all of this, Sipho's uncle remained his legal guardian and continued receiving the child maintenance grant.

This shows how important the redistribution of government grants has become, and its impact on kinship relations cannot be emphasized enough. Even when the amount of money that the government redistributed was quite small, it became part of conflicts within families. Redistribution of child maintenance grants became central to conflicts between parents and teenage daughters, fueling fears of teenage pregnancy even though teenage pregnancies were actually decreasing due to increased use of contraceptives. Redistribution of government grants also lead to other generational tensions. Unemployed young men and women depend on grandparents and end up sitting at home with few job prospects; families are concerned about members claiming foster care grants for children without actually taking care of them, causing prolonged conflicts to emerge. For many South Africans, this is what the post-apartheid economy looks and feels like in everyday life. Thus, when analyzing the redistribution of government grants in light of kinship relations, the ironies of solidarity become clear. These grants were 
a pivotal part of democratization and confirmed that citizenship rights were for all South Africans, irrespective of race. Solidarity on a national level made it easier for poor people to survive, making it a little bit easier for kin to help one another and strengthen kinship solidarity. But ironically, kinship solidarity also led to tensions and sometimes conflicts that highlighted how government redistribution was seen to stimulate immoral practices such as teenage pregnancy, laziness, and even child abuse.

\section{Praying for redistribution}

The growth of prosperity churches has caused redistribution to also become part of South Africa's religious landscape. ${ }^{25}$ A neighborhood survey that I carried out in Indawo Yoxolo revealed that increasing numbers of people are not affiliated to a church, while 40 percent of the respondents stated they were not affiliated to any religion at all. The survey also showed that prosperity churches have become more prominent, with approximately I 8 percent of the respondents saying they belonged to the Universal Church of the Kingdom of God (UCKG), the Apostolic Faith Mission, the Assemblies of God, and other similar prosperity churches. ${ }^{26}$

Prosperity churches are hierarchically organized and teach that financial success can be achieved through fervent prayers and generous donations. Their doctrines are strongly connected to their members' ambitions for a middle-class lifestyle of consumption (Helgesson 2006; James 20I4, 20I-226; Van Wyk 20I4). Furthermore, membership at a prosperity church confers middle-class distinction. "You know, it is all about standards," a member of a prosperity church told me. She had previously belonged to an independent African church with strong ties to her neighborhood in Indawo Yoxolo that emphasized the importance of kinship support and integrated ancestral beliefs in its sermons. But her financial situation had improved and she said she no longer wanted to be part of the "happy clappers," using a common derogatory expression for members of independent churches that practice extensive singing and clapping during sermons. Middle-class aspirations and the individualism that prosperity churches promote are apparent on the webpage of the Assemblies of God, ${ }^{27}$ which looks more like the homepage of a lifestyle magazine than a church. The page depicts a highly stylized living room - a consumerist's dream. It shows a leather designer chair that seats only one person, a large television, a bookcase, and an iPod on an expensive-looking designer table. Clicking on 
these consumer items reveals brief information about the Assemblies of God, such as an address and photographs. Clicking on "Contact Us" causes window blinds to appear, creating an even stronger image of how religion is an avenue to consumerist dreams of privacy and individualization. The only substantial links on the South African Assemblies of God website are about large-scale redistribution: one for donating money to the church, and another for learning how to access social development resources.

The redistribution of money and other forms of wealth features very prominently in these fast-growing prosperity churches. They propagate that if people make large donations to the church and pray fervently, God will guarantee they become wealthy. During fieldwork, I attended the Universal Church of the Kingdom of God (UCKG). While the African independent churches are typically located in people's houses in the townships, this church was in an abandoned factory hall in Woodstock, a suburban and industrial area near the city center.

The UCKG opened its first branch in Cape Town in 1997, and by 2007 it had expanded to thirty branches. The denomination originated in Brazil, and the different branches are headed by Brazilian pastors. They preach in English and sometimes Portuguese, in which case they are assisted by translators. One of the key points of the sermons is the promise of the tremendous wealth awaiting the congregation, typically a big house and a luxury car, most likely a BMW. The pastors teach that this wealth is ready and waiting, but that something is blocking it and preventing it from reaching the members. They say only God can "unblock" the wealth, meaning members must get God's attention. The way to do that is to donate as much money as possible and to pray fervently, even aggressively, insisting on a moment of God's attention to unblock the riches.

Men and women, many of them living in poverty, donate hundreds of rand during the services. The pastors spur the congregation into competing with one another to see who can donate the most, particularly during the church's Campaign of Israel. During this campaign, the pastors tell members to write their prayers on a piece of paper with the promise that they will be collected and taken to Israel to be closer to God. To make sure that God listens to their prayers, members have to donate as much money as they can put together. This is the only way to guarantee the release of wealth.

Miriam lived in Cape Town's township of Khayelitsha and had been a member of the UCKG in the past. Initially, she had been attracted to how the church tried to fight evil and its promises of wealth. With some embarrassment, she told me about how she took part in the Campaign 
of Israel. Urged by the pastor, she sold everything she had except the clothes she was wearing, and then gave all the money to the church to make sure her prayers reached God. Her sister, who was having an affair with the pastor, had done exactly the same. But half a year later when no riches appeared, both were upset and left the church. Miriam was still angry with her sister for having secretly kept a set of clothing for herself. She told her sister: "Why did you not tell me that you did not sell everything? Then I would have also kept an extra set of clothing for myself." She felt cheated by both her sister and the church. When I met Miriam, she had found employment as a cleaner. The pastor had left South Africa without telling anyone, and her sister had found a lowpaying job picking grapes on a vineyard in the Western Cape.

Assistance between UCKG members is limited to saying prayers. The church discourages other forms of mutual support, whether financial or helping find a job or run a household. It opposes traditional kinship relations by making its members renounce rituals that tie them to their ancestors (see also Van Wyk 20I4), which are fundamental to mutual kinship obligations such as funerals, rituals for ancestors involving the sacrifice of cattle, and the initiation of boys into manhood. These kinship obligations become marginalized when people stop taking part in the events. Indeed, this may be one of the things that draws people to these churches. Mutual obligations, after all, rarely offer prosperity, while the idea of religious riches through large-scale redistribution offers hope.

Van Wyk (20I4) gives a detailed analysis of the UCKG in Durban, South Africa. She argues that, although the UCKG is a global organization, it is too one-dimensional to be a neoliberal phenomenon. She concludes that the success of the church lies in its orientation towards local spirit beliefs and in its dealings with very specific local social situations. The church "portrayed a world in which liberation and spiritual redemption were perpetually deferred, where the individual was alone in the most basic of senses, and where God was not swayed by emotions but by contractual obligations" (Van Wyk 20I4, 235).

Prosperity churches are about fighting personal demons, establishing a contractual relationship with God, and stepping away from reciprocal relations between neighbors and kin. Their theology identifies the cruelty in reciprocal relationships, which despite offering care and support, can turn into demonic and exploitative relationships that prevent a blessed and prosperous life. The ontology of large-scale redistribution here means the miraculous accumulation of wealth - miraculous in that the amount of wealth is enormous and that it can be accumulated almost instantly. This form of religious redistribution reveals that 
members of congregations expect to be successful in life by following the spiritual and social guidelines established by the church. They believe that a strategy to get wealth from God is more feasible than looking for prosperity through the labor market or social networks among kin and neighbors. While the way these churches propagate wealth suggests a specific ontology of large-scale redistribution, it also ironically reveals that the solution creates its own forms of cruelty.

\section{Tense redistribution}

For many living in the Cape Flats and elsewhere in South Africa, the political economy of a liberated South Africa revolved around largescale redistribution. Freedom from apartheid meant a momentous shift from a racist political economy that controlled land and labor, to a political economy where citizenship, liberation, and prosperity were achieved through redistribution in entrepreneurship, state institutions, and a new theology of prosperity churches. Redistribution is now fundamental to understanding why some people achieve success while others remain poor, and helps explain the care, inequalities, and tensions that exist in relationships among neighbors, communities, and kin. Even when redistribution was only a promise, it still had real social and moral consequences that enabled new forms of care and help, but also led to conflicts within and between communities. Kinship relations were realigned, especially in terms of gerontocratic and gendered rights and responsibilities. Redistribution is key to people's experiences and interpretations related to the inequalities and conflicts that permeate South Africa today.

The South African scenario forces us to rethink classifying economic practices as either driven by the state or by the market. Following Guyer (1995), I would argue that people experience a plurality of economic and financial regimes. In South Africa, redistribution plays a central role in this plurality because it is not confined to the politics of kinship, kingship, or statehood. It is also the ontological lens through which people understand the workings of labor markets and how entrepreneurial opportunities arise, as well as how social relations become central to acquiring or hindering wealth. This means that redistribution is simultaneously part of the market and beyond the market, and that the distinction between market and state is not so central to people's ontology of wealth and what it means for their sense of being, especially in relation to kinship and its gendered and generational dependencies. 
Thus, scrutinizing the sociality of these forms of large-scale redistribution captures the post-apartheid economy more fully than studying the primacy of the (neoliberal) market or by analyzing the distinction between market and non-market exchanges. What becomes clear is that specific social relations are crucial for people's understanding of who they are and what the future might look like. There is a strong and yet apprehensive connection between accumulating wealth and investing it in social relations; in the calculations that connect categories of material value, spiritual practices, personhood, and how people are given value. What is striking is how central different forms of large-scale redistribution have become to this ontology of wealth. Social grants, development aid, Black Economic Empowerment, and supernatural sources of wealth are all understood in terms of how they affect the tensions inherent to accumulation and sociality. It is within this specific context that insurance is marketed to the African population and, just like these other forms of redistribution, the ontology of wealth becomes visible in the moral evaluation of potential relations. 


\section{Penetrating a new market}

\section{Introduction: classifying risks and clients}

Sibusiso Sitjo was a soft-spoken man in his twenties who lived with his parents in the township of Guguletu. Sibusiso worked for a broker who sold insurance policies while his parents ran a funeral business. Initially, Sibusiso worked in the broker's office in the center of Cape Town making phone calls to potential customers, but soon the company changed its sales techniques and Sibusiso and his colleagues were sent out to sell policies in African neighborhoods.

We had rallies. All the personnel from the branches would join in such a rally; it was a road trip. You go into virgin territory and receive a bonus when you conquer the virgin territory. I went to two road trips, to Somerset and George ... We had to test the territory and we worked as a team. We were dropped off in the area and went door to door selling policies ... The atmosphere was nice, it was a nice competition.

Sibusiso also sold policies to his neighbors in Guguletu, and his mother helped him sell to church congregants - though not from the church he and his family attended. He was worried that selling insurance to fellow church members would damage his reputation and possibly harm the family business. After six months, Sibusiso resigned because he earned too little. He was also embarrassed about the stories he had to tell in order to make his sales. "I had to make people afraid of the future," he told me. Fear was not a marketing strategy that Sibusiso wanted to use.

This chapter examines how insurance companies developed a market for poor and lower-middle-class Africans living in the townships of Cape Town, and focuses on how markets were established politically and economically. Applbaum convincingly argued that the notion of markets being self-evident and natural is an ideology, which is demystified by revealing how marketing hinges on power relations and cultural practices (Applbaum 2004). Applbaum's approach is fundamentally different from Chan's approach to the marketing of insurance in China (Chan 20I2). Chan's premise is that culture affects economic practices like marketing. She analyzes how national cultures create opportunities as well as obstacles for marketing life insurance, and 
places insurance at the crossroads of Western and Chinse culture, each with a different market logic.

I approach insurance marketing from the perspective of classification. Insurance companies classify risks, costs, and potential populations for which they develop specific products, services, and infrastructures. How are these classifications, which are so crucial to understanding risks and envisioning markets, determined? Where and how are classifications symbolically constructed through language, and what are their political and social consequences? Since Durkheim and Mauss published "Primitive Classifications" (I90I-I902), anthropologists have tried to understand how classifications come about, how they are pivotal to the way we see and experience the world, and how they play a fundamental role in our actions. Classifications are never mere reflections of technical or natural phenomena, but always imply cultural, linguistic, and social temporalities (see also Douglas and Wildavsky I983; Leach I964; Needham I979; Strathern 2000). Thus, classifications are crucial to understanding how sales agents like Sibusiso find themselves in the uncomfortable position of having to make people afraid of the future.

Classification is at the heart of defining the risks for which insurance policies are intended to compensate and by doing so it introduces moralities (Maurer 2005, I 5I-I 52). Classifications are primarily shaped by statistical techniques that are mastered by actuaries. It would be impossible for insurance companies to establish insurance schemes if they did not statistically classify the risks potential customers are exposed to, or the risks of particular events occurring. A wide range of statistical knowledge enables assessing possible risks as well as what to charge individual clients to cover those risks. Ewald (I99I, 2002) and De Swaan (I996) have pointed out that it only became possible to cover risks collectively, or one might add, bureaucratically, with the advancement of actuarial science in the nineteenth century. Without actuarial knowledge it is not possible to calculate premiums or compensations for specific perils.

Classifications are also important for creating new consumer markets. South African insurance companies want to know who their potential clients are, what kind of lifestyles they have or desire, and what kinds of products and services they want and can afford. Thus, like other companies across the globe, insurance companies create so-called market segments to "conquer" a new market. This means "they model or classify the world in accordance with a model of their own making in order to carry out the goal of expanding product purchase globally" (Applbaum 2004, 9I). Statistical methods are essential to market segmentation because marketers are interested in substantial subsets of consumers, not individual consumers (Applbaum 2004). 
Statistical methods are also essential to marketing insurance because they are the foundation of the actuarial knowledge that enables insurance products to be developed. When advanced actuarial techniques were first used in the nineteenth century, it became possible to establish large-scale insurance arrangements. These new arrangements were used by companies and state welfare programs and engendered new ways of seeing the future. ${ }^{1}$

According to Hacking (I990), the increased use of statistical techniques meant that people's perception of the future became less determined. He argued that statistical techniques were part of classifying the world in a different way. For statistical techniques to work,

[c]ategories had to be invented into which people could conveniently fall in order to be counted. The systematic collection of data about people has affected not only the ways in which we conceive of a society, but also the way in which we describe our neighbor. It has profoundly transformed what we choose to do, who we try to be, and what we think of ourselves. (Hacking I990, 3)

Ewald (I99I, 2002) reasoned along similar lines when he identified how nineteenth-century actuarial science - the statistical knowledge that is used to calculate risks - gave rise to what he called a "precautionary principle." A consequence of using actuarial statistics to define and classify risks was the ability to predict the future. These predictions were not made at individual levels, but at aggregate ones based on population averages. This allowed thinking and implementing measures to prevent unwanted events. In other words, actuarial knowledge made it possible to take precautions in the present with a view towards the future. Ewald (I99I, 2002) believed that this had revolutionary consequences for the provision of welfare. Instead of allocating welfare based on the principle of blame, for example, by distinguishing the deserving from the undeserving poor, welfare would become an expression of the precautionary principle. Therefore, welfare would be offered as a safeguard against future misfortune (Ewald I991, 2002; see also De Swaan I996).

Another example of how statistical categories and procedures can lead to new views of the future was proposed by Hart (2004). He points out that statistical distributions can represent political philosophies and societal values. The bell curve represents democratic values: it represents an equilibrium, with a tendency towards the center, where median, mean, and mode coincide to suggest stability. This offers a particular perspective that is both technical and moral with regard to issues like 
the distribution of income throughout populations or life expectancy. On the other hand, Hart argues that the power law is radically different because it is not modeled after equilibrium and does not consider the average to be meaningful. Instead, it represents exponential growth and high levels of volatility. According to Hart, this shows that statistical techniques are moral discourses that help shape societal concerns by offering a language to express problems and solutions. This raises the question of the importance of statistics and categories in South Africa's expanding insurance world.

I will now explore how risks, costs, and marketing classifications were established and how that impacted marketing insurance to the African population. I will examine how classifications reveal the positionality of the insurance sector in South African society, as well as how future risks and profits are envisioned.

\section{Negotiating ISM and FSM markets}

The Living Standard Measure (LSM) and Financial Service Measurement (FSM) are important tools for establishing new financial markets in South Africa in that they identify potential clients, especially those who are relatively poor and African. LSM ranks consumers on a scale from I to IO, with I roughly representing the poorest and IO the wealthiest. LSM does not, however, reflect only wealth. It measures a wide range of variables that include modes of transport; uptake of financial products and services; ownership of electronic items; consumption of chocolate, alcohol, clothing, and hygiene products; and many more. It checks for components such as swimming pools, computers, iPads, as well as the use of radio, TV, internet, and other media. Additionally, LSM records gender, age, race, income, education, and residential address. ${ }^{2}$

The LSM classification tool was first developed by the World Bank's Development Research Group in I980 (Chander et al. I980). The aim was to gather specific data on the living conditions of households in developing countries and use it to create a benchmark for monitoring progress. The effectiveness of various policies was thus measured in terms of ownership, access to the market economy, and the use of consumer products. The LSM ranking became particularly important under Alden Claussen (Mahon 2010, I74), a former commercial banker who became president of the World Bank in I98 I. During his mandate, the bank invested in an extensive data set that contained detailed statistics on consumption in developing countries, and LSM was used for 
assessing policies on health care, structural adjustment programs, welfare, income inequality, and many other core development concerns. Over the past thirty years, the World Bank has used LSM data for hundreds of working papers, articles, policy papers, and other publications on development. ${ }^{3}$ It produced over thirty LSM-related publications on South Africa alone. ${ }^{4}$

In I989, Jacky Galpin, an actuary at the University of the Witwatersrand in Johannesburg and a member of the South African Statistics Council, adapted the LSM ranking for the South African market. ${ }^{5}$ Since then, the South African Advertising Research Foundation (SAARF) has carried out a yearly survey that generates LSM data used by consumer research bureaus, supermarkets, universities, development organizations, and government agencies. ${ }^{6}$ This widespread application of LSM classifications allows institutions with quite disparate ideologies, such as the state, development organizations, and financial companies, to have a common technical language for discussing their different interests. LSM rankings are used to gauge both the potential of new markets and development goals; to talk about both profit and poverty alleviation; and to both confront and elude racial and economic inequalities in South Africa.

SAARF translated LSM data into ten different South African consumer profiles, identified as LSM I through LSM го. The statistical information in the dataset was then used to establish ideal consumer types. Additionally, the politics of financial inclusion, which were so crucial to democratization and overcoming the racial inequalities of apartheid, were identified in these LSM categories. From the I990s onwards, the inclusion of Africans was achieved by marketing for LSM I -5 categories, which included over twenty million people, or almost half of the country's population ( 44.3 percent).

These profiles established by SAARF conceal the racial aspect of market segmentation behind an abstract acronym, but then reveal racial profiles in their explanations. The typical LSM I is identified as living in a traditional hut in a rural or small urban area, and as having an average household income of $\mathrm{R}_{1}, 363$ per month. ${ }^{7} \mathrm{LSM}$ I types make very little use of financial or other services, with the possible exception of a so-called Mzansi bank account. They listen to radio stations in African languages (unspecified), and their social activities are limited to singing. However, the top category targeted by marketing for African inclusion is LSM 5. The people in this category are identified as typically male, between 15 and 50 years old, having some high-school education and a monthly household income of R4,I65. LSM 5 types usually live in a small urban or rural area with access to electricity, piped water, and 
a communal or outdoor toilet. Their houses have a TV, a hi-fi or radio set, a stove, and a refrigerator. They listen to radio stations that broadcast in African languages and to commercial stations that are mostly in English. They watch TV and read a daily newspaper. LMS $5 \mathrm{~s}$ also have a Mzansi bank account and their social activities include baking, going to night clubs, attending gatherings, buying lottery tickets, and ordering a take-away meal at least once a month. ${ }^{8}$

LSM typology is rather ambiguous in that it makes no explicit references to race and only addresses economic equality indirectly when referring to household income and consumer behavior. Yet, at the same time, LSM ascertains that race matters when it refers to Mzansi bank accounts. These bank accounts were established in 2004 as part of the Financial Sector Charter that made financial services available to the poor. "Mzansi" is the Xhosa word for "south" and refers to South Africa being the southernmost country on the continent. The use of a Xhosa word emphasizes the overlap of racial and economic inequalities in South Africa. The description of a typical LSM I listening to the radio in an African language is a racial reference in that it excludes English and Afrikaans, which are predominantly spoken by white and colored South Africans. Furthermore, the description of a typical LSM I living in a traditional hut refers to a "rondavel," a round hut with walls made of local materials such as stones, sand, or soil mixed with cow dung, and covered by a thatched roof. ${ }^{9}$ Even the reference to singing alludes to the overlap of race and class. Singing is associated with the extraordinary and internationally renowned gospel tradition found typically in the African independent churches that have strong ties with the community, but which are frowned upon by the men and women that frequent the prosperity churches.

LSM categories attempt to de-politicize concerns about race and economic inequality in South Africa by offering a language that is apparently neutral and more suitable for negotiations between government agencies, civil society organizations, and the financial sector. At the same time, LSM typologies reveal that financialization and markets cannot avoid racial and economic inequalities. Yet, LSM is a language that, at least temporarily, suspends tensions over highly contested racial and economic transformations. ${ }^{10}$

In 2002, a South African NGO called FinScope launched the FSM, a means that includes more financial information than the LSM, especially regarding the financial behavior of relatively poor people. FSM is also a market segmentation tool that gauges financial penetration, attitudes towards money, physical access to banks, and connectedness and optimism. FSM classifies people on a scale from I to 8, FSM I 
being those least familiar with financial products and services, and FSM 8 being the "fully banked." FinScope conducts an annual survey that generates a detailed FSM for South African banks, insurance companies, and development agencies (Porteous 2003).

The FinScope survey was organized by FinMark, a Johannesburg non-profit trust. FinMark received financial support from South Africa's financial sector as well as a $\mathrm{GBP}_{5}$ million donation from the UK Department for International Development (DFID) (Barlow $2003,2)$. Marketing agencies, financial companies, and development organizations could now share a language and classification system that, to some, apparently reconciled profit with poverty reduction. ${ }^{11}$ FinScope has a very clear position on this. They point out that financial markets "work for the poor" and enable them to store and transfer money safely, provide loan facilities that are cheaper than informal credit, offer insurance that makes them less vulnerable to adversities, and offer credit for business purposes (Porteous 2003).

However, bringing together marketing interests and poverty alleviation in FSM is not without problems. The first issue is accessing FSM data, which is only allowed to companies that co-finance the survey. These companies protect the information to prevent other firms from profiting from it without contributing to the survey costs. However, since the expenses are partly paid for with public money from the UK, requests to see the data were also submitted to DFID. Even so, DFID does not honor these requests, saying that it is FinMark's prerogative to decide who can have access to the information. Thus, the interests of FSM's participating commercial companies keep the data from others who might want to use it for development purposes. FinMark does produce a limited number of summaries that highlight particular results. However, these summaries offer little if any information on the execution of the survey or the analysis of the results.

The FSM survey includes questions that are particularly important for the development of the insurance market in South Africa. It asks respondents about their use of formal financial institutions, and whether or not they participate in informal financial arrangements such as burial societies and savings and credit groups that are usually organized between neighbors. Some questions address behavior, such as the use of specific services and products, while others address perceptions, such as those regarding debt, savings, insurance, and financial institutions in general. Personal motives are also examined. Respondents are asked about their reasons for participating in particular informal financial arrangements with questions about attempts to save money, to use the groups to provide for their family, or to participate in them 
for the purpose of socializing. ${ }^{12}$ This information is useful for market expansion in that it forges new relationships between formal financial institutions and informal financial arrangements. How these informal financial arrangements are used for marketing will be explored in the next chapter in greater detail.

The FSM survey also contains eleven psychographic statements where respondents are asked things like whether they "hate owing money" or if they "know quite a bit about money." Other questions address their perception of risk by asking, for example, the likelihood of the main wage earner dying, of the respondents losing their jobs, or of their property being destroyed by a flood. A consequence of these types of questions is that it reminds the poor of their vulnerability and forces them to expose it very explicitly. At the same time, FSM data offers a specific morality on how marketing and development can go hand in hand, suggesting that there is no tension between these very disparate goals or the institutions - especially government and banking - that represent these goals.

The data produced by FSM is technical in that it relies on complex statistical procedures for collecting and processing consumer information. Applbaum (2004, 9I-IO2) points out how important spatial metaphors are for defining new markets, to which I would add that sexuality and gender are equally important. FSM uses a sexualized language similar to what the sales agent Sibusiso Sitjo used when he described selling policies as "conquering virgin territory." For example, one of FSM's four central measures, the "take-up of a comprehensive list of financial services, both formal and informal," is categorized as "financial penetration" (FinScope 2004, introduction). They also used the term "segment penetration," later even developing a Financial Penetration Index (Melzer and Smith 2004, I 5-I7; FinScope 2004). We should not forget that the individuals referred to here as "financial virgins" waiting to be conquered and penetrated live in a country that is hard hit by HIV/AIDS, and where sexual violence is rampant (see Jewkes and Abrahams 2002). This language not only presents a sexualized discourse on finance, but also a gendered one. It implies that the market and its clients are female and the financial sector represents its male conquerors. Consequently, the marketing metaphors naturalize a hierarchy of active male businesses on one hand, and passive female clients on the other. Thus, financial development is presented through aggressive, sexually charged metaphors in a country where sexual violence is widespread.

Over the years, LSM and FSM classifications became the primary standards for describing a new market for insurance products. 
However, because the data is gathered and managed in a closed, cooperative arrangement between business and development agencies, it is not possible for others to examine the methods used to collect the survey material or how the results are analyzed. This is quite unfortunate, since this data that is so crucial to development raises several questions.

During my fieldwork, it became clear that most people did not make the kind of distinctions that were central to the survey. For example, the survey distinguishes between funeral policies, life insurance, and endowments, while the people that I had conversations with usually thought of them as one and the same product that provided support after someone died. FSM data could also be influenced by moral concerns, especially those related to death and funerals. As I will show later, there was a widespread concern that receiving money from an insurance company after someone died could be construed as incentive to harm others. This caused respondents that were sensitive to this issue to be reluctant to inform other household members about their policies. FSM does not seem to take this into account, meaning their tally of policies per household can be underreported.

Knowing that data collection results are influenced by the query practices employed, it is essential to know how FSM obtains data. The summaries they currently make available reveal nothing about data collection. They do not inform the identity of the surveyors, how they were trained and paid, or the kind of relationship they had with the respondents. Neither do they say how non-response cases are dealt with or how other statistical problems are addressed. This information is important when dealing with highly sensitive topics like money and finance, which not only impinge on the complex social and institutional relations in which every individual is embroiled, but also directly affect survival itself, particularly for the poor (see among others Bähre 2007; Bloch and Parry 1989; Hart et al. 2010; Maurer 2006; Simmel [1900] I990).

During my research in Cape Town, two situations taught me about the survey practices employed by others. When my research assistant, Edith, interviewed a woman for a questionnaire, the woman quickly became impatient. After only a few questions, she expressed doubts about Edith's professionality. She told Edith that this was not the first time she had participated in a survey, and that the other researcher had been much better because they had only asked her to provide a few personal details like age, address, and type of job. Once those questions were answered, she was told: "Ach, we know each other, we are all the same. I can complete the rest on my own." The respondent said she thought Edith lacked research skills because she asked too many questions. ${ }^{13}$ During another survey, the respondent told us in a similar 
fashion that she had already been interviewed before, in a very short survey. All she had been asked to provide was her name and address. Then, a few weeks later, a man arrived at her house with a parcel. "This is for you," he said. "You won it for giving all the right answers in the survey." The woman accepted the parcel, which contained condoms, an HIV/AIDS prevention pamphlet, and a T-shirt with a text that encouraged safe sex. An interview that had the appearance of a survey to help classify the target population for a HIV prevention campaign turned out to be a lottery in which respondents unknowingly participated.

As long as FSM survey procedures and practices cannot be examined, it is impossible to assess the reliability of their data, even when the survey is carried out by a reputable organization like FinMark. Nevertheless, FSM data is used for developing new insurance products, identifying new markets, alleviating poverty, and overcoming racial inequalities. While LSM and FSM are important symbolic representations that offer a common ground for diverse interests and for solving many social injustices, they simultaneously reveal the difficulties of making these changes in that they inevitably reproduce the same problems, particularly regarding race, economic inequality, and sexual metaphors. LSM and FSM terminology eases the tensions between insurance companies, commercial interests, and government development goals, while ironically revealing the social and symbolic reproduction of these same divisions and injustices.

\section{Precarious relations between market and state}

The government's political agenda to decrease racial and economic inequality through financial inclusion affected the insurance sector. The experiences of actuaries are particularly important to understand, since they are at the forefront of defining risks and developing new policies for new markets. Thus, because of their central role, it is highly relevant to analyze how they experience the politics of inclusion. In order to examine this, we must look at how actuaries and others working in the insurance sector deal with LSM and FSM categories, how they perceive the relationship between the insurance sector and the post-apartheid state, and their ideas and strategies for marketing to African clients. How do actuaries see post-apartheid changes and how do they work within the new political environment?

The actuaries working with the LSM $\mathrm{I}-5$ market tend to fall into a certain typology of their own. They are typically male white South Africans in their forties, with degrees from the University of Stellenbosch, 
University of Cape Town, or the University of the Witwatersrand. Some actuaries felt that they were part of a new era. One told me plainly: "Now is our time. We're young and we do not have the burden of history like the older people working here. We have to make something of this country." The Actuarial Society of South Africa (ASSA) saw the need to make the actuarial profession more inclusive. In 2000, ASSA established Actuaries on the Move to stimulate diversity in the profession and include mentoring and training programs to bring in more black actuaries. In 2005, the Association of South African Black Actuarial Professionals (ASABA) was founded. ${ }^{14}$ Between 2006 and 2016, the number of African actuaries has grown from twenty-eight to eighty-two. The total number of South African actuaries more than doubled during that period, meaning the percentage of African actuaries went from 4 percent to just under 6 percent. ${ }^{15}$

One of the forces behind the overhaul of actuarial science in South Africa was that many in the field felt personally responsible to contribute to the future of their country. Another was the pressure exerted by the government on insurers and actuaries. The FSM and LSM classifications that were so central to post-apartheid politics opened up a discourse in two opposite directions. On one hand, they unified the development and marketing worlds, but on the other hand they gave rise to tensions. The fact that government agencies, development organizations, marketing companies, and financial institutions now use the same classifications does not preclude friction from occurring over their meaning, which further emphasizes the changes taking place in the relationship between the financial worlds and the post-apartheid democracy of South Africa.

Liberation from apartheid included liberation from the racial classifications that characterized the apartheid state and market, and defined markets and risk. An actuary who had worked for an insurance company explained how delicate racial categories had become in the post-apartheid era:

Race is a no-go area publicly, it is too sensitive. Instead we present demographics, unemployment categories, and of course this strongly correlates with race, except when it comes to the black elite. Risk is allowed to be a poverty thing, but not a race thing.

LSM and FSM classifications are considered politically neutral categories and can therefore be used to define citizenship rights and marketing strategies. The Economic Development and Labor Council (NEDLAC), established in 1995, played a crucial role in defining the 
rights of stakeholders - owners, employees, and clients - in financial companies. NEDLAC became a dialogue forum representing the new relations between a democratically chosen government and private and semi-public institutions in the country, such as business enterprises, civil communities, and labor unions. In 2002, NEDLAC established the Financial Sector Charter, which came into effect in $2004 \cdot{ }^{16}$ The charter was dedicated to:

actively promoting a transformed, vibrant, and globally competitive financial sector that reflects the demographics of South Africa and contributes to the establishment of an equitable society by effectively providing accessible financial services to black people and by directing investment into targeted sectors of the economy.

The charter used LSM classifications to define targets for human resources and procurement and ownership, as well as to provide effective access to financial services, including specified insurance products. The charter stipulated that by 2008 , 80 percent of LSM I -5 would have access to financial transaction products and services, while "a percentage (to be settled with the life insurance industry) of LSM I-5 households have effective access to life insurance products and services" (Financial Sector Charter p. 9). ${ }^{17}$

Although both the state and the financial sector use LSM classifications to define particular targets, and even though some of these targets collaborate with the state and the financial sector, the process is not exempt from concerns. A common view in the world of insurance is that the ANC's approach to financial inclusion fostered

Table 4.1 - Survey response from actuaries on policies of the South African government: "The government has developed BEE policies which improve the insurance industry"

\begin{tabular}{|l|l|l|}
\hline Answer & $\begin{array}{l}\text { No. of respondents } \\
(\mathrm{n}=6 \mathrm{I})\end{array}$ & \% of respondents \\
\hline Strongly disagree & I 5 & 25 \\
\hline Disagree & I9 & $3 \mathrm{I}$ \\
\hline Neutral & 24 & 39 \\
\hline Agree & 3 & 5 \\
\hline Strongly agree & 0 & 0 \\
\hline
\end{tabular}


Table 4.2 - Survey response from actuaries on policies of the South African government: "The government has developed BEE policies which improve clients' access to insurance products"

\begin{tabular}{|l|l|l|}
\hline Answer & $\begin{array}{l}\text { No. of respondents } \\
(\mathrm{n}=6 \mathrm{I})\end{array}$ & \% of respondents \\
\hline Strongly disagree & $\mathrm{I} 2$ & 20 \\
\hline Disagree & 23 & 38 \\
\hline Neutral & $\mathrm{I} 4$ & 23 \\
\hline Agree & $\mathrm{I} 2$ & 20 \\
\hline Strongly agree & 0 & 0 \\
\hline
\end{tabular}

a neopatrimonial state. Only 5 percent of the actuaries who participated in my online survey agreed that the government's BEE policies improved the insurance industry.

Moreover, only a minority ( 20 percent) felt that the government's BEE policies provided their clients with better access to insurance products. In short, actuaries considered BEE financial policies to be bad for business and bad for clients.

Some actually believe that the ANC undermined the viability of the insurance sector. The industry not only felt pressured into adopting business models and strategies that might not be profitable, but also felt threatened by a wide range of government initiatives such as plans to establish a national funeral insurance, a National Social Security Fund (NSSF), ${ }^{18}$ and particularly the National Health Insurance Scheme (NHIS), also called National Health Insurance (NHI).

A subject of debate from the moment of democratization was implementing NHI as a nationwide health insurance program that would improve the quality of and access to medical aid (Botha and Hendricks 2008). In 2009, the minister of health established an advisory committee with a mandate "to advise the Minister on policy and legislation development and the implementation plan for the National Health Insurance system." The government envisioned NHI as being complementary to the health insurance that companies offer. It was to be funded by a prepayment-based system and was expected to generate improved and universal health care based on social solidarity. ${ }^{19}$

Many people working in the insurance industry were concerned about this development. The chief medical officer of a large insurance company shared his concern with me that NHI would decrease the 
quality of treatments. It would force medical doctors to work for lower wages because they would be paid per household rather than per treatment. This would be a deterrent for doctors to work in impoverished areas where patients were in much more need of medical aid. In fact, in $20 \mathrm{I} 2$, it proved difficult to recruit doctors to a pilot program established by the South African health minister in ten districts. The few doctors who did agree to work in the program were embarrassed about the poor medical services they delivered. Lack of funding, facilities, and medication meant they could only provide basic nursing services rather than full physician care (Malan 20I6). In 20I7, the Health Department released an NHI white paper that outlined "how government will become the single buyer of health services for all South Africans from both public and private medical providers through a mandatory NHI scheme" (González 20I7).

The chief medical officer made it clear that there was a clash between the government and insurance companies:

There is no partnership with the government ... The government puts pressure on us and this is one of the reasons for taking HIV clauses out of policies. The government wants to make it possible for HIV positive people to take a home bond, but people will only be eligible for loans when they can take out insurance. The government does not want to contribute to these costs.

Marius, a respectable and well-known insurance consultant, also felt that the sector's relationship with the government was hostile. When I initially introduced myself to him as a researcher, his response was very reserved and cautious. A year later, after we had met a few times, he became more open and relaxed and explained why he was initially reluctant to talk to me:

We have very bad experiences with researchers. They do research and are paid well by the government. You know that they will never criticize government and only criticize the industry. A woman once told me: "I am an independent researcher doing consultancy work for the government." [We both had a laugh before Marius went on.] The government is too socialistic. They have a socialist worldview, a view on people that is wrong. They develop ideas and policies that are not in line with human behavior. Let me give you an example. They want to establish a flat rate for health insurance [everyone pays the same premium]. The result is that only older people will take out 
insurance, not the young. Young people will take out a policy that pays a lump sum whenever they have to go to the hospital. This is not strictly health coverage, but young people use it as such. It's not really allowed, but it happens a lot because proper health insurance is much more expensive for them.

The fact that Marius had associated me as a researcher with being part of the government explained his reservations. He only became more open when it was clear to him that I had no affiliation to the South African government, nor was my research commissioned by them. Marius went on to criticize the government for not understanding people's behavior. According to Marius, government policy makers and politicians have strong socialist ideas that focus on communities and groups. They are unaware of the rational principles that underlie human behavior, which guide what insurance companies do:

We [insurance sector] have to deal with real people. They [politicians] all have their degree from Sussex ... They claim to have socialist ideas and claim to know how poor people think and what they want. But they are wrong. I subscribe to Marx when it comes to health. I don't think that health is a commodity. The government is trying to set up a health scheme for all employed people. But this system will lead to reduced funding for state hospitals and will increase the gap between the unemployed and the workers. The result is that the state absolves itself from social responsibilities. They turn health into a commodity.

According to Marius, the socialist ideas of the politicians are wrong and he identifies an irony in their application. Socialism is wrong because it does not take rationality into account, and the irony is that when these socialists' ideas are carried out in practice they transform health into a commodity. Thus, it is the market that protects the interests of the people, while it is the state that commodifies health. The market can ensure that the premiums of employed wealthier clients subsidize the health costs of the unemployed. The state's plans, according to Marius and others working in the insurance sector, weaken solidarity and obstruct welfare development by creating a division between insurance for the employed and insurance for the unemployed. The government's irrationality and socialist ideology also undercuts the value of the data it collects, which insurance companies could use for their calculations. Marius stated that, "Government statistics are notoriously unreliable. They are being manipulated for political reasons, I am certain of that." 
Especially during Mbeki's administration from I999 to 2008, actuaries treated HIV-related data with utmost suspicion. Mbeki refused to accept scientific evidence that HIV is responsible for AIDS and he refused to acknowledge the dramatic spread of the disease. ${ }^{20}$ There were recurrent rumors that medical personnel were not allowed to mention HIV in medical records, or even on the death certificates, of AIDS victims. It is said that to circumvent this dangerous omission, hospital nurses devised an informal system to notify each other of the HIV status of their patients, so they could provide the proper treatment and ensure their own protection. If a patient was suspected of having AIDS, they would put a blue flowerpot on his or her bedside table, while all other patients had different colored flowerpots. The very existence of rumors that the state was trying to conceal the occurrence of AIDS undermined the reliability of government statistics even further and underscored the irrationality of government policy.

Actuaries and others in the insurance sector had much more confidence in the statistics provided by SAARF and FinMark, even if they had little insight into how exactly the data was collected. Additionally, insurance companies could refer to their own information on risk and client characteristics, which they shared with other companies. I was frequently told that all members of the South African Actuarial Society pooled their data into aggregate data sets, which helped them develop risk profiles on the spread of HIV in South Africa.

The survey that I carried out with members of the South African Actuarial Society in 20II reflected their limited confidence in the state's ability to develop NHI. Most respondents feared NHI would make citizens dependent on the government and that it was deliberately being used to ensure political support for the ANC.

Table 4.3 - Survey response from actuaries on policies of the South African government: "The National Health Insurance Scheme (NHIS) will make citizens depend on the state"

\begin{tabular}{|l|l|l|}
\hline Answer & $\begin{array}{l}\text { No. of respondents } \\
(\mathrm{n}=62)\end{array}$ & \% of respondents \\
\hline Strongly disagree & I & 2 \\
\hline Disagree & I I & I8 \\
\hline Neutral & 3 & 5 \\
\hline Agree & 3 I & 50 \\
\hline Strongly agree & I6 & 26 \\
\hline
\end{tabular}


Table 4.4 - Survey response from actuaries on policies of the South African government: "The National Health Insurance Scheme (NHIS) is meant to ensure political support for the ANC"

\begin{tabular}{|l|l|l|}
\hline Answer & $\begin{array}{l}\text { No. of respondents } \\
(\mathrm{n}=62)\end{array}$ & $\%$ of respondents \\
\hline Strongly disagree & I & 2 \\
\hline Disagree & I I & I8 \\
\hline Neutral & I5 & 24 \\
\hline Agree & I9 & 3 I \\
\hline Strongly agree & I6 & 26 \\
\hline
\end{tabular}

The relationship between insurance companies and the government was quite tense. Actuaries felt that the plans for a national health insurance would result in neopatrimonialism. It would make South Africans, especially the poor, dependent on the state for medical care, and the state could then exploit them for electoral purposes. During election time, ANC politicians did in fact emphasize that government programs depended on the people's political support, and they threatened to withdraw funding or stop development projects if people did not vote for the ANC (Bähre 2005; Hull and James 20I2; James 20I I; Niehaus 2006). Many in the sector viewed the politics of inclusion as a threat, and were concerned that insurance companies would be forced to offer products that did not benefit the poor.

The tensions between the state and the market played out in a shared discourse and language that enabled formulating common goals. The government adopted the LSM and FSM categories that the industry had developed for marketing purposes, and used them for formulating their own agenda of financial inclusion to overcome racial and economic inequalities. Additionally, the government and the insurance sector reached an understanding that financial products had to be made available to LSM I-5 markets. Thus, both sides avoided making explicit references to class and race, and agreed that welfare, especially healthcare, must be provided for the previously excluded and predominantly poor and lower-middle-class Africans.

However, this did not assuage the concerns of many actuaries that the government was ignoring the principles of rational choice and the behavior of "real people" by relying on false socialist and communitarian ideologies, thus obstructing social development and strengthening its 
grip on the electorate. In the end, insurance companies would have to pay the price of financial inclusion.

\section{Defining risk and price}

When I started this study, I expected actuaries to be extremely concerned about the risks of the LSM I-5 market. Was it possible to meet both the political and the commercial objectives of financial inclusion? South Africans, particularly the poor, face tremendous risks. People living in the townships of Cape Town and other LSM I -5 clients live in frequent danger of being robbed, murdered, assaulted, or raped. Thus, marketing to LSM I -5 clients meant insurance companies had to address those risks, which are intimately connected to poverty, inequality, and violence in contemporary South Africa. Additionally, although HIV/AIDS is prevalent at all levels of society, expanding the insurance market means assuming those risks as well. In 20I 5 , I 9 percent of the adult population in South Africa was HIV positive. Despite retroviral drugs being more easily available, there were I 80,000 AIDSrelated deaths in $2015 .{ }^{21}$ It is not hard to imagine how difficult this makes it for companies to sell other types of health insurance. AIDS causes mortality rates to increase, sick clients might lose their jobs and claim unemployment benefits, and sick clients might not be able to meet their financial obligations and thus have to call on their credit insurance. Apart from the health implications, I expected AIDS to have far-reaching actuarial implications. Albeit not necessarily the poorest who are most at risk from HIV infection, money and financial dependency does matter when it comes to people's sexual behavior (Bähre 2002; Niehaus and Jonsson 2005).

Although the LSM and FSM categories are important symbolic representations of a new market, and statistics about risks such as HIV are very important for developing products and services, everyday practices in the LSM I-5 market are more haphazard. Actuaries told me that sometimes, in order to establish this new market, they had to rely on their gut feeling or professional habitus. Statistics were initially either unavailable, irrelevant, or unreliable. In addition to the time it took to set up a sound dataset, statistics seemed to play a minor role in business strategies. In 2005, an actuary working for a large South African insurance company explained to me that the LSM I-5 market was still uncharted territory. The company he worked for had only recently begun to explore what he called the lower end of the market, 
and therefore it was still accumulating client data. He explained the manner in which he developed products for the LSM I-5 market:

\begin{abstract}
Without client data it is difficult to assess the risks to which new clients are exposed. That weakens our ability to estimate the cost of implementation and administration and the potential size of the market. What I do is to look at similar policies from other insurance companies and copy their pricing and policy conditions. We then put the product on the market and we closely monitor the product. If it proves to be unprofitable for some reason or another, we take the policy out of the market and try something else.
\end{abstract}

Such hit-and-miss strategies were a far cry from the models he was taught at university, and from the procedures in better-established markets. To limit HIV-related risks, insurance companies set up exclusionary clauses. One way to do this was to refuse insurance policies, including life and credit insurance, to clients that tested HIV positive. But in 2005 , the same actuary explained to me that such HIV testing posed a problem:

People have different patterns of behavior and my company relies on traditional forms of risk management. But these cannot be applied to the lower end of the market ... When we wanted to test a client's HIV status, [we would ask them to come in for a test, but often] they would simply not show up. The upper end of the market does go for a test, but workers don't. They need to take a half day off and are afraid to find out that they are HIV positive. Testing is also expensive for us, making it a big obstacle for this market. According to my calculations it was possible to issue a life insurance policy without HIV testing and have a sufficient contingency reserve. But at the time it was difficult to get approval from my superiors for these kinds of policies.

The fact that HIV testing was expensive and time-consuming for the insurance company was compensated by increasing monthly premiums. Testing was also bad for business because it deterred clients who were unwilling to be tested or afraid to find out if they were HIV positive. Fraud was an additional problem, when clients sent someone other than themselves to do the test. For these reasons, in 2005, insurance companies changed their policies so that instead of making HIV an exclusionary clause, they priced for it. One insurance company did this by increasing the premium for their life insurance by Io percent annually. This increase was a cheaper and more effective way to 
deal with the risks of selling life insurance to the LSM I-5. In 2007, insurance companies agreed to stop HIV exclusionary clauses for life insurance altogether.

In addition to price increases to address the high mortality rates, insurers also revised policy conditions. For example, they excluded early deaths from the coverage, and death was only covered if the client had the policy for six to twenty-four months. Insurers also took increasing liberties in revising policy conditions and premium rates after the policies had already been issued. Raising premiums, changing policy conditions, and withdrawing policies were important tools for containing the risks encountered in this new market of relatively vulnerable and poor clients for which there was only sparse aggregate data. Another strategy was overpricing. Actuaries explained to me that when the risks were not clear, insurance companies sold the policies at relatively high prices to ensure that no money would be lost. They said that this was possible because the South African market was not very competitive. Overpricing meant not losing business while still dealing with the unknown risks of the LSM I-5 market. Another strategy was to make unemployment an exclusionary clause. Testing for HIV and other life-threatening conditions was expensive and unreliable and made it difficult to develop the LSM I-5 market. So instead, they forced clients to include several people in one life insurance policy, and used employment as a selection criteria. An insurer explained to me:

There is the anti-selection risk. People with HIV search for an insurer because they are infected. So the company is more likely to get sick people than healthy people. The way to deal with this is to take a whole group or population ... We also ask several questions about health and you have to add all your parents to the policy, not only the ones that are ill. We also try to sell policies via employers. That means that the basic requirement for the policy is that one has a job, which provides us with a certain probability of health.

"Risk is our business" was a common response when I asked about how poverty, illness, and violence made it more difficult to sell insurance to the LSM I-5 market. It was clear that risks were not a problem as long as they could be calculated. Calculating the risks enabled pricing them, or in other words, establishing the premium clients had to pay to cover the risks. Additionally, insurers adopted strategies such as overpricing, changing policy conditions after policies were purchased, excluding unemployed clients, and offering policies to groups of clients. But these types of measures can have far-reaching consequences for 
clients. How insurance companies define and manage risks can mean that the risks faced by LSM I-5 clients are not covered. Consequently, the ability of insurance companies to mitigate the risks to which the poor are exposed decreases. The strategies insurance companies resort to might make sense from a business perspective; however, they might not provide the expected benefits for LSM ${ }_{-}-5$ clients in that many of the risks of their everyday lives are excluded.

The implications of these insurance strategies and how they affect the risks of LSM I-5 clients become even more apparent when examining what insurance companies call costs. For insurers, LSM I-5 risks could be managed through well-established actuarial techniques; however, insurance for the LSM $\mathrm{I}_{-5} 5$ costs proved to be a much bigger issue.

LSM I-5 clients, I was told, are relatively expensive because they can only afford small policies. This makes operational costs for the LSM I-5 market high. It is expensive to administer policies, run a bureaucracy, and establish an infrastructure for clients who can only afford to pay a small premium every month, sometimes not more than a few rand. LSM I-5 clients were also more likely to cancel policies than wealthier clients, which meant that insurance companies had to do bureaucratic work without receiving premiums. Operational costs posed the main obstacle for LSM I-5 inclusion, and for the insurance companies, this was much more problematic than risks.

A closer look shows that what insurance companies call operational costs is directly related to what clients living in the townships of Cape Town experience as risks. This makes it especially important to carefully examine the meaning of actuarial definitions and practices in everyday life. The best way for insurance companies to make a profit in the LSM I-5 market is to cut operational costs. However, this is no simple matter. The costs are deeply intertwined with the risks that come with being poor in South Africa. The problems encountered by insurance companies in their attempts to cut operational costs suggest that insurance is not really able to cover the risks of their clients. The high operational costs are directly related to poverty, inequality, and common adversities such as unemployment, disease, crime, violence, and responsibility for destitute kin. These are the types of risks that prevent LSM I -5 clients from being able to afford more than a small policy with limited coverage, and it is because of these risks that these same clients are more likely to cancel their policies, thus increasing operational costs and reducing insurer revenue.

What insurance companies refer to as operational costs are really a function of the risks to which potential LSM I-5 clients are exposed. If insurers were able to manage operational costs, they could more easily 
explore and develop a tremendous potential global market that includes other African countries and emerging markets such as Brazil, India, and China. Reducing operational costs, therefore, became central to exploring markets in the Global South. The next chapter will analyze how insurers limit operational costs for the LSM I-5 market, and what the resulting consequences mean for brokers, clients, and the networks of people living in Cape Town townships.

\section{Symbols as violence, symbols of protection}

Douglas (1966) offered indispensable insight into the important role played by social categories in signaling dangers and threats to society. Classification creates a social and moral order. Although categories and systems of classification might seem neutral and self-evident, they are not, especially when it comes to insurance. The classifications that insurance companies use for identifying risks and marketing opportunities are not mere technical representations of the world: they are central to people's understanding of the moral and social threats to society. ${ }^{22}$ As Maurer found when examining actuarial knowledge in Islamic banking: "The measure of the man taken by the actuary is always-already both statistical and moral (and gendered)" (Maurer 2005 , I 5I). In South African classification, race must be included as an additional category of actuarial practices that bring together statistics and morality.

LSM and FSM are powerful symbols that provide a terrain on which to negotiate, agree, and disagree. Their language uses abstractions that create a comfortable distance from everyday realities like racial and economic inequality. Uncomfortable terms such as poverty, racial exclusion, and suffering are substituted by acronyms and numbers that make up the LSM I-5 market. There is a violence in the abstraction of LSM and FSM in that it creates space for dehumanization (see also Comaroff and Comaroff I999; Sayer 1987). They could be seen as contributing to what Galtung (I969) called structural violence that makes it difficult for people to survive. LSM and FSM classifications leave little room for the everyday concerns of LSM I-5 people and their experiences of poverty, inequality, and many other forms of marginalization.

Research methods can also become forms of symbolic violence. In The Weight of the World (Bourdieu et al. 2002) Bourdieu argues that we need to establish new ways of representing and understanding poverty and suffering. The contributions to this volume offer a wide range 
of examples on how to represent the everyday experiences of marginalization and exclusion, and how very personal stories actually reveal major social and political transformations. Particularly inspiring is Bourdieu's concluding chapter on understanding (Bourdieu 2002). He makes a strong case against methods that reproduce stereotypes and reinforce dominant discourses. Instead of research translating and understanding, Bourdieu argues that it becomes a form of domination by enforcing classification language and systems. Thus, in the end, researchers reproduce the same inequalities they examine (Bourdieu 2002).

An analysis of LSM and FSM practices identifies several of these forms of power attained through classifications. One is the aggressive sexual language that is common in marketing and expresses control over new markets, which sales people like Sibusiso have to adopt. Another is the distinction made between risks and operational costs, which on one hand, serves actuarial goals, and on the other, obscures the direct correlation between costs and the risks of everyday life in the LSM I-5 market. Finally, the way LSM and FSM segments people, and the way marketing creates the expectation that it is possible for people to move up the LSM and FSM ladder obscure the everyday experiences of people living on the margins of one of the world's most unequal and violent societies.

My conversations with actuaries and others working in the insurance sector also revealed a sense of lack of control. There is a constant concern that the ANC government will take away business and use LSM and FSM data to justify it. They worry about politicians who fail to understand the rational behavior of consumers. They are unsure whether LSM and FSM data provide a good representation of the South African population, seeing as there is no way of scrutinizing the methodology, the operationalization of the studies, or the research practices used to collect the data. To some extent actuaries realize that they have to develop policies through trial and error, and that LSM and FSM data provides only limited insights into new markets. Occasionally, LSM and FSM classifications are not quite relevant to everyday practices and experiences, making the definition of risk and costs much more important when making insurance policies.

Classifications of consumers, risks, and costs are not only about power. It seems that the psychological dimension of classifications is equally important. The actuaries and other professionals in the insurance sector that work with LSM and FSM categories are part of South African society. Their dream of a rainbow nation has also been shattered, and wealthy, well-educated white South Africans are concerned about the political and economic instability of the country. Notwithstanding their privileged position, insurance professionals are 
worried about violence. I vividly remember the conversations where they told me about their fear of becoming a statistic. For some time, "becoming a statistic" was a euphemism used to refer to becoming a victim of a violent crime. Parents sometimes told me that their children had recurring nightmares about violent burglaries at home or shootings that took place at school. The privilege of being part of a white elite living in a relatively safe environment, driving from a highly secured home or gated community to a highly secured office building is not sufficient protection against these fears. ${ }^{23}$ Even I sometimes had violent dreams during my fieldwork in South Africa. When I described one of these dreams to friends living in a white suburb of Cape Town, their response was quite revealing. I had dreamt that a friend of mine tried to stab and kill me with a knife. I managed to wrest the knife out of his hand, but in the struggle I stabbed him instead, and he bled to death. I expected my friends to share the horror I had felt when I woke up. But instead, one of them replied, "But Erik, this is a very good dream. You won the fight!"

The predominantly white and privileged elite also have fears of violence that are very real, and they see protecting themselves against potential attackers as vital. These fears are often associated with the poor Africans they engage with on a daily basis. The elite drive by the townships and squatter camps along the highways on their way to work and back, so they have some indication of their living circumstances. They interact with the LSM I-5 they employ as domestic workers or gardeners, or have brief encounters with the security guard at the entrance of their gated community. They exchange a few words and some money with LSM I-5 when they park their car on the street to go shopping or dine at a restaurant. Actuaries and others working in the insurance sector are concerned about the inequalities and violence in South Africa, which are sources of anxiety.

Devereux (I967) used Freud's psychoanalytical approach to show how methodological choices can suppress the anxieties of fieldwork and create an emotional distance. Devereux called this "isolation defense" (Devereux 1967, 83). Research methods and techniques are not necessarily used because they produce specific insights and understanding, but because they protect the researcher from the anxieties that are inherent to fieldwork. According to Devereux, objectivity and cultural relativism are isolation defenses when they are used to create an emotional boundary between the researcher and fieldwork experiences. Hastrup (1993, I995) argued that the way researchers construct hard facts can externalize pain, suffering, and disorder. When researchers distinguish hard facts from soft facts they create a hierarchy where hard 
facts are superior. Hastrup argues against this type of hierarchy and encourages investing in experiences and imagination that enable understanding what suffering is about.

Likewise, the LSM and FSM classifications can function as isolation defenses. The acronyms can shield actuaries and others working in the insurance sector against the anxieties provoked by the everyday suffering they see in South Africa. LSM and FSM classifications can be symbolic defenses, not unlike the electric fences and security gates that protect their houses and office buildings. Furthermore, in an ironic twist, LSM and FSM categories are attractive psychologically because they actually fail to represent suffering. This failure of representation is part of the appeal of LSM and FSM that makes professional engagements with the poor more palatable. Conversations and discussions about policy implications and actuarial strategies using LSM and FSM PowerPoints and documents can keep the anxieties of everyday life in South Africa at bay. In the end, they become symbols of not knowing, of covering up the anxieties that the rap group Dookoom expressed poetically as distancing oneself from people who live uncomfortably close. 


\section{5 \\ The Janus face of inclusion}

\section{Introduction: ambiguous inclusion}

A major concern for the LSM I-5 market, at least from the perspective of insurance companies, has been high operational costs. Poorer people could only afford relatively small premiums and actuaries reported that most of it went to covering administrative and bureaucratic expenses, and that only a relatively small amount of it actually covered the insured risk. Therefore, in order to successfully explore the LSM I-5 market, insurance companies had to find ways of reducing operational costs. This was key to making insurance both affordable for the poor and profitable for the companies.

A large part of the operational costs were the salaries and/or commissions and bonuses designated to insurance brokers. Typically, a broker's commission was 85 percent of an annual insurance premium. This meant that the first ten months of premium that a client paid went to the broker, and only after that would client payments go toward other operational costs (offices, administrative systems, banking costs, legal compliance, etc.) or toward covering the risks that comprised the insurance policy. An additional problem was that African clients living in the townships of Cape Town were more likely to discontinue their policies. While wealthier clients could afford to pay premiums for long periods, poorer clients were more likely to encounter financial setbacks that inevitably made it more difficult for them to pay for the insurance intended to mitigate some of the risks and adversities they faced.

This chapter is about how insurance companies attempted to limit operational costs in order to make insurance more affordable, and the consequences of these strategies. It shows how insurance companies reviewed and changed the remuneration of insurance agents, and how this affected the positions of brokers in their areas of operation. It shows how insurance companies also tried to work through intermediary organizations, which they expected would lower operational costs and give them the advantage of a more diverse clientele, thus decreasing insurer risks.

The way to gain insight into these stratagems is to examine how clients, brokers, and others involved in selling insurance or handling claims deal with them. How does limiting operational costs to make 
insurance more affordable play out in the lives of people living in the townships of Cape Town? How does it affect insurance clients and employees? What happens to social and institutional relationships in a neighborhood when insurance enters the scene? The position of brokers and other people and organizations that intermediate between large insurance companies and the everyday lived worlds of their clients is vital to understanding the redistributive character of insurance. They are in a position that allows them to navigate bureaucracies and social networks, and translate risks and cost strategies into everyday practice. How do brokers and other intermediaries steer between the insurance world and their clients? How do brokers and other intermediaries present the services and products offered by insurance to clients, and to what extent do they provide access to communities and risk mitigation of insurance?

In this chapter, I argue that Janus, the two-faced Roman god of gates and doors, of opening and closing, captures the ironic experiences of brokers, intermediary organizations, and clients in the insurance world. These ambiguities are most evident in the way social networks are used to procure access, albeit unevenly, in their experiences with Kafkaesque bureaucratic procedures, and in the difficulties people have to surmount the contradictions that are produced when risks are translated into the seemingly neutral language of operational costs.

\section{Wretched brokers}

A broker's income is typically based on commission. This posed a problem when insurers began targeting the $\mathrm{LSM}_{\mathrm{I}-5}$ market, because clients living in townships like Indawo Yoxolo were much more likely to cancel policies than wealthier clients living in Cape Town's affluent suburbs. The reason for canceling a policy was often due to inability to afford the monthly premium. But clients also told me that they sometimes canceled a policy because they had never wanted it in the first place. They felt pressured into buying a policy because of the social connection they had with the broker. An insurance client living in Khayelitsha told me that she found it difficult to turn down a broker because she knew him personally: "I met the broker through church and he came to see me. I bought a policy that I did not really need so I canceled it after a few months." Some clients intentionally provided false or canceled banking information, so as not to turn down the broker and still avoid buying the policy. However, these practices only served to damage the broker's income and increase operational costs. 
Consequently, in order to rein in increasing costs, insurance companies reviewed their commissions system in 2005 , alleging that too many policies were being canceled and administration costs for small policies were too high. The outcome of this review was to extend broker commissions over a longer period of up to several years. In other words, broker fees now depended on how long clients payed for insurance premiums. When clients canceled a policy within a relatively short time, the brokers would either receive much smaller commissions or none at all.

This change put pressure on brokers, which they in turn transferred to clients. One broker told me that in order to make a living he lied to prospective clients about the policies, the risks that they covered, and the conditions for making claims. An illiterate client in Indawo Yoxolo experienced the consequences of the pressure placed on brokers: "I thought I had bought a comprehensive health policy. The broker told me that an ambulance would pick me up at home, even when I had a simple cough. But when I was sick it turned out that I had bought a funeral policy."

High risks of unemployment and life-threatening diseases such as HIV and tuberculosis, the financial burden of being forced to care for destitute kin, and the soaring violence in the townships of Cape Town were additional reasons why poor clients frequently canceled their policies. As Caplovitz (I967) showed more than forty years ago, the poor always pay more, a problem that is not limited to the costs of credit and debt. Consequently, operational costs, in this case meaning payments to brokers, had to be factored into client risks. Although these were not risks directly related to what the insurance was intended to cover, they were nonetheless fundamental to providing the insurance.

Bantu's experience as a broker reveals the Janus-faced characteristics of translating risks into costs. He told me he had been lured by an insurance company recruiter into selling policies when he was living in East London and working as a hotel manager. The recruiter told Bantu that as a broker he could earn $\mathrm{R}_{\mathrm{I} 2,000}$ a month, a significant improvement from his hotel manager salary of $\mathrm{R}_{5}, 000$, and buy himself a good car. Tired of his job and attracted by the new prospects, he quit at the hotel and signed a contract with the insurance company. The contract stipulated that Bantu would receive five months of training. The first three months would be spent in full-time training, during which he would receive a salary of $\mathrm{R}_{5}, 000$. After that, he would start selling policies and earning commissions. To compensate for his inexperience, he would be paid $R_{2,500}$ in the fourth month and $R_{I}, 500$ in the fifth month. Once the training period was completed, his income would depend fully on 
commissions. The contract required Bantu to work for the insurance company for at least one year. If he quit before the year was over, he would be forced to repay the RI9,000 paid during the five months of training. Bantu was told that this clause had been added to prevent brokers from switching to a competitor after the company had invested in providing them with broker skills.

After completing the full-time training period, Bantu attended a company barbecue, which was his first opportunity to meet other sales representatives in the region. Given the high salary he was expecting to earn, he had assumed there would be luxury cars parked in the driveway, and was surprised to see old, rusty ones instead. Even the top salesman's car was modest, not much better than the one Bantu owned at the time. This encounter made him wonder whether his future would be as rosy as he had been told. His suspicions were confirmed once he started selling policies. It became clear that he would not make RI 2,000 a month. Instead, he was earning no more than $\mathrm{R}_{5}, 000$, about the same as he had earned as a hotel manager. A few of his colleagues earned up to RI 2,000 a month, but most earned far less. This caused Bantu anxiety and stress during the weekly meetings with management:

We would meet and the manager would show [on the board] how many policies everyone had sold, and the top salesman would be praised and treated as a role model. But during these meetings it also became clear that some colleagues had not sold a single policy. I really felt sorry for them as they had no income. Sometimes a colleague would come to me and ask me: "Can you please lend me some money?"You know they have a family to feed and no income, but you are also hesitant to give money. Are you ever going to get it back?

Bantu's colleagues that were earning no commission were unable to leave the company and look for another job because they would have had to repay the RI9,000. The costs that insurance companies tried to limit had translated into financial risk factors for the brokers, who ended up doing unpaid labor for the insurance company. Not only were commissions much lower than Bantu had expected, but his new job meant that he was burdened by all kinds of other expenses. He had to pay for his own car and gas, as well as his mobile phone calls. The costs of small gifts for his clients, such as pens and T-shirts with the insurance company's logo, or a takeaway meal from Kentucky Fried Chicken for people who attended his sales meetings, were paid from a fund that was managed and owned by the insurance company. The contributions to the fund were supposedly voluntary, but in practice management 
coerced brokers into making contributions, which were automatically deducted from the broker's salaries.

These kinds of financial risks and pressures were not the only drawbacks. Bantu and other brokers I met complained vehemently about the unexpected social pressures the job required. Because of being forced to aggressively mobilize his social network to sell policies, Bantu targeted his neighbors in East London and members of his church, and attended as many funerals as he could. Visibly embarrassed about trying to sell policies at funeral services, Bantu confided: "I would sit down with the bereaved and the neighbors and say things like: 'Is it not terribly sad to die and leave your family with nothing except the worry about how to pay for the funeral? A funeral insurance really takes this burden away from you.' Then I would hand them a brochure and try to meet them again later."

In return, Bantu's clients asked him for all kinds of favors: "You know how our people are. They think you are making a lot of money on them and that you take advantage. Therefore, you have to help them, otherwise your reputation goes down the drain." He received phone calls from clients asking for favors such as: "Could you take my child to school? I don't have money for transport," or "Could you come and pick me up and take me to the shop in town? I need to buy some groceries." He spent half his day driving people around and helping them with financial problems, such as difficulties with bank accounts or insurance companies. Most of the time these favors had nothing to do with his work. But if he refused to help, he thought his neighbors and clients would start gossiping about him, which would make it very difficult to sell policies. He told me that he was growing tired of these requests.

Near the end of his one-year contract, Bantu's car broke down. Because he had no money to repair it, he became less mobile and sold fewer policies. After exactly one year as an insurance broker, not a day longer, he quit his job. Even though he had no other employment prospect, he was desperate to get out of the insurance industry. Soon after quitting, he left his hometown of East London and moved to Cape Town, where he hoped for better employment opportunities. He was somewhat relieved to leave behind his neighbors, friends, fellow church members, and former clients because his reputation as a financial expert had become a burden. People continuously asked him for help in sorting out financial problems, expected him to write letters or make phone calls to financial organizations, and even wanted him to accompany them to a bank or insurance company. He had become their financial expert and general gofer, and gave no regard to the fact that he no longer worked for the insurance company. 
Once in Cape Town, Bantu started a small church in the living room of his small shack in Indawo Yoxolo. Starting a church did not require capital, and made the most of Bantu's excellent social skills and organizational talent, as well as his ability to collect money under very unusual circumstances. One year later I met Bantu again, who was now working as the manager of a large canteen at a training institute. $\mathrm{He}$ enjoyed his job, earned a decent salary, was making plans to marry his new girlfriend, and was certain he would never again work for the insurance industry.

Some of the actuaries and others working in the insurance industry were aware of broker tendencies to sometimes be dishonest when selling policies, and knew that it was easy to withhold information or lie about policy conditions to people that had little formal education. In their efforts to make money, insurance representatives could become very pushy, and many feared that such incidents would ultimately give the industry a bad reputation. The vulnerability of broker income resulted from measures employed by insurance companies to limit operational costs and make new insurance products affordable as well as profitable. Yet, although these measures limited the risks for insurance companies, they transferred them to brokers. The underlying problem here is that the income vulnerability imposed by the commission system, particularly when selling policies to Africans, was never addressed. Brokers were caught in the contradictions that occurred when risks were redefined as costs, and when social networks became difficult to mobilize successfully.

\section{“Outsourcing” to the community}

It is a global practice for insurance companies to rely on employers, unions, and other intermediaries involved in the world of formal and long-term employment. However, when selling policies to relatively poor people that have neither formal nor steady employment, insurance companies must look for alternatives. To limit operational costs and anti-selection risks, South African insurance companies cooperate with other organizations and intermediary groups and rely on group schemes (Thomson and Posel 2002). This is where the Janus faces of insurance reveal themselves.

Interviews with actuaries and others working in the insurance industry, as well as with residents of Indawo Yoxolo and Tembani, revealed that insurance companies were interested in working with a wide range of organizations such as churches, funeral undertakers, burial societies, 
soccer fan clubs, and singing groups. Insurance agents also encouraged residents to establish their own insurance groups, in the hope that access to their services would be enhanced.

A successful cooperation occurred between the insurance company African Life (which today is owned by SANLAM), and the Zion Christian Church (ZCC). The ZCC is probably South Africa's largest church denomination, with I, IOO congregations spread across the country. It has a strong leadership and focuses on the boundaries between insiders and outsiders, which are identified by ways of dressing and other social conventions. Members are not allowed to speak with outsiders about the church and are required to follow strict disciplinary rules about clothing, abstention from alcohol, and participation in meetings and other church events (see Comaroff I985; Kiernan 1974; Müller 20II).

For a long time, each ZCC congregation had its own burial society. This, however, presented limitations for ZCC members that moved to another congregation in South Africa, often in search of employment, because they had to start anew with the burial society of that new branch. This was also inconvenient in that rules differed between congregations, and joining a new one required a waiting period, meaning claims could only be submitted after premiums had been paid for half a year. Moreover, some ZCC branches had no burial society at all, and others had burial societies that functioned poorly. Therefore, the prospect of a common national funeral scheme for all ZCC congregations appeared to offer considerable benefits to members, and to strengthen hierarchies in this centrally led church. ${ }^{1}$

The national ZCC funeral scheme was established in 1989 in partnership with African Life, and was limited to members only. Over the years, this initiative led to the development of the Kganya Group, a company made responsible for running the scheme and taking care of administration and payments. Soon a wide range of additional financial services was developed and sold to ZCC members, such as the Kganya Card Account in the First National Bank, which is exclusively for ZCC members.

In 2006, a committee of one of the ZCC's congregations collected a monthly insurance premium of $\mathrm{R} 23$, which was deposited into the bank account of Kganya Group. Each ZCC branch took care of their own bookkeeping and helped organize wakes and funeral services. A ZCC minister told me that they also helped members submit claims: they helped fill out forms, took them to the Kganya office, and mediated when benefits led to family conflicts. The minister was very pleased with the funeral scheme and felt that cooperating with Kganya had proved very successful. 
The scheme also had a discretionary fund to help members who missed payments on their insurance plan because they were suffering from a prolonged illness or were hospitalized, and thus unable to make formal insurance claims. The discretionary fund allowed the ZCC to contribute financially to funerals when insurance policies had become invalid.

The ZCC became a model for others in the insurance industry on how to deliver insurance to the African poor. ZCC members voluntarily carried out many administrative and organizational tasks and helped members submit claims, which reduced the insurer's administrative costs and responsibilities. This type of cooperation has been documented in, for example, Alexander's (2009) analysis of Britain's "third sector," which reveals how the state increasingly relies on voluntary labor to carry out its core responsibilities, and how, in the process, it also attempts to gain control over the population. ${ }^{2}$

However, despite this successful and highly praised cooperation between the insurance industry and the ZCC, operational costs remained high. The founder of the scheme explained to me that administration costs still exceeded the risk premium by three to one. The administrative burden was three times greater than the total sum paid out for client claims.

More often, people told me how cooperation with the insurance company led to a wide range of problems. A clear example of the consequences of becoming an insurance intermediary was relayed to me by Mrs. Sitjo, the mother of Sibusiso, the soft-spoken insurance salesman described in the previous chapter. Mrs. Sitjo ran a small undertaking business from her living room in Cape Town's Gugulethu township. Her father had started the funeral business, and when he died a few years before, she and her husband took it over. Until then, she had not been involved in the daily running of the business, and she quickly discovered that her father had incurred considerable debts. Clients had normally paid her father after a funeral, but some paid only a part of the amount that was due, or failed to pay anything at all. When Mrs. Sitjo and her husband took over, they paid the outstanding debts owed to their suppliers and, fearing further deterioration of the financial situation, decided to employ a more personalized mode of operation by establishing a burial society. Every month, Mrs. Sitjo went door-to-door to collect premiums from members. Up-front payments ensured a steady and more reliable income than her father had been able to secure.

Insurance companies began showing an interest in the Sitjo family business in approximately 2004. Sales representatives suddenly began visiting her regularly and asking her to work with them. They promised 
that she could make more profit by sending them the burial society premiums that she collected. Mrs. Sitjo told me she and her husband were hesitant, and it was only after several offers from a number of different companies that they decided to work in cooperation with a Johannesburg-based insurance company. From then on, she deposited the burial society premiums into the insurance company's account and whenever a member of the burial society or one of their dependents died, she submitted a claim. Believing that her clients would not trust the insurance company, Mrs. Sitjo kept the arrangement a secret. Perhaps an additional motivation for her silence was that she wanted to remain in control of the business and did not wish to disclose how much money the insurance company was paying her. Mrs. Sitjo was seemingly unaware of the fact that not being a registered financial service provider or intermediary made her arrangement with the insurance company illegal. As is frequently the case in the world of finance at large, degrees of legality are irrelevant in day-to-day practices.

A few weeks before I met Mrs. Sitjo for the first time, she had received a letter from the insurance company stating that she had submitted too many claims. A few months earlier, Mrs. Sitjo had indeed organized several funerals, which was not unusual seeing as several members of the burial society were of advanced age, and that incidences of road accidents, violence, and diseases such as TB and HIV/AIDS were high in Guguletu. In the letter, however, the insurer did not question the legitimacy of the claims, but simply stated that their corresponding expenses forced them to revise the contract. Mrs. Sitjo would now be required to pay 50 percent more premium per month. If she failed to comply, the insurance company would cancel the contract. Mrs. Sitjo was very upset: "How am I going to explain to people that they have to pay one and a half times as much? How am I going to raise this money? Nobody even knows that I work together with an insurance company." She was suddenly faced with unforeseen financial pressures that threatened the family business and her reputation in the area where she had lived for the last thirty years.

Bongani also felt that an insurance company put her in a predicament. Bongani sells funeral insurance, but does not have the image of a successful entrepreneur. She started in 2002 and runs her business from a small party tent in Khayelitsha that she erected close to the police station. Bongani sits behind a small table across from another chair for potential clients. The smell of grilled intestines and other meat blows over from her neighboring entrepreneur. Bongani apologizes for her unimpressive office and hurries to explain that she has a beautiful work space in the building behind her. The building is being renovated, 
and for now she has to sit here under a tent. But my impression was that she does not have another office and that she is embarrassed about her meager conditions. Bongani is in her tent twice a month on the days that pensioners arrive to receive their pension money and oldage grants in the building that is being renovated. Her hope is to get some of them to buy insurance policies. The premium is Io percent of the old-age grant, which means that the insurance company can legally receive the money directly from the grant, even before it is put in the beneficiary's bank account.

Although Bongani thinks it is dangerous to sell insurance policies from her tent, she is not worried about criminals: "I am not scared because it is opposite the police station and there are a few other business people, but I can't say it is safe." She also goes door-to-door selling policies and distributing pamphlets. On Saturdays she attends funerals where she tries to sell policies. She also helps organize funerals without getting paid hoping that, by helping people, they will purchase a policy from her. She also visits churches for the same reason.

Bongani is not happy with her work and says she is struggling. She finds it difficult to deal with the requests for help that she receives, like filling out forms for people when they submit claims to other companies. Previously, she had worked as an intern for one of South Africa's biggest insurance companies, where the work was a lot better because she had a regular income and good benefits. Now she lives off commissions only, and even then she sometimes does not receive commissions she is entitled to. Additionally, when an insurance company takes longer than expected to pay the bereaved, the clients visit Bongani at her home to complain and demand help. That means she has to take them to the insurance company office, explain the problem, and help solve it.

Mrs. Sitjo and Bongani experienced Janus-faced characteristics in the everyday operation of their business, where insurance can both threaten and benefit relations among neighbors. ${ }^{3}$ Indeed, as Douglas stated in her analysis of risk:

Liberation from the small community also means losing the old protections. The markets suck us (willingly) out of our cosy, dull, local niches and turn us into unencumbered actors, mobile in a world system, but by setting us free they leave us exposed. We feel vulnerable. (1992, I 5)

We have seen that this vulnerability extends even further in that many of the risks inherent to cost-cutting were not covered by the "market" (the insurance company). Instead, they were passed on to the "local 
niche" of the intermediary organization, which was unable to handle them. Cutting operational costs made sense from an actuarial perspective, and was vital to LSM I -5 marketing strategies. But for the brokers working in Cape Town's townships, making insurance affordable meant being deprived of a regular and decent income, often putting the future of their business at risk. For brokers, financial inclusion meant losing their reputation and honor in the neighborhood and feeling exploited by neighbors who placed reciprocal demands on them. These social and organizational dynamics that have such a negative effect on the livelihoods and respectability of brokers demonstrate that the meaning of financial inclusion must be redefined.

\section{Burcaucracies of exclusion}

The vocabulary commonly used in development circles to talk about "providing access" to the poor fails to take essential power inequalities into consideration. The Janus faces of providing insurance for the poor is visible in the amalgamation of networks and bureaucracies that clients are forced to deal with. The social relations that insurance companies draw on to reach clients are often unusable for clients trying to access the security they expected from the insurance company. Brokers and other intermediaries are frequently unable to help clients with their claims to the insurance company. Organizations like the ZCC and Mrs. Sitjo's funeral business provide some assistance in submitting claims, but many clients are often frustrated with their inability to get help. Instead of being able to access the social networks through which they bought their policies, clients must deal with dense bureaucracies and complex procedures that involve being required to fill out forms and call toll-free numbers, often in a language that they have not mastered.

The inequalities in South African society are clearly reflected in insurance company call centers, which are arranged so that important clients that generate more business receive better treatment than clients who purchase small policies. ${ }^{4}$ One of the larger insurance companies had a system set up to distinguish three different tiers, the highest being for the best clients and the lowest for the least important ones. Each tier had its own toll-free number which meant that the call center could immediately recognize the importance of the caller. The call center carefully monitored calls to be sure they were taken within clearly defined time limits, meaning clients in the highest tier were answered much faster than clients in the lowest tier. Additionally, high-tier callers were put through to more experienced and better trained employees. It was 
company policy for new employees to begin with lowest-tier clients, and only after gaining experience and additional training could they take calls from clients in the highest tier.

Less important clients were more likely to be poorer clients, and had to wait much longer for their call to be answered. When they finally got through, they were connected to an employee with relatively little experience and knowledge about the products. In addition, there were language barriers. An employee at the call center explained to me that callers were not always able to express themselves in English. Although it was a national center, there were often not enough employees that were proficient in South Africa's eleven official languages. This meant that calls were conducted in broken English, which could result in numerous misunderstandings that decreased the quality of the service provided by the company. ${ }^{5}$

These inequalities also affected the call center employees. Employees who did not speak an African language more frequently encountered language problems with clients from the lower tier, problems they did not encounter when working with clients from the upper tier. Employees who spoke English well and had a better educational background moved more easily up the tier ladder because it was easier for them to do the additional training required for assisting wealthier clients. Inevitably, the call center's tier system not only gave better service to better clients, but also reproduced South Africa's economic and racial inequalities that financial inclusion was supposed to diminish.

One of the most pressing problems was the deduction of insurance premiums from social grants, which are crucial to the survival of many. Any deductions from these grants have a tremendous impact on the financial situation of the poor. The Social Assistance Act allows for a single Io percent deduction from a social grant for funeral insurance, which must be made before the grant is paid to the beneficiary. All other deductions have to be made after the beneficiary receives the grant. It is clearly more advantageous for the insurance company to have the money deducted before the grant is paid to the beneficiary. Later deductions can be problematic in cases where, for example, there are insufficient funds left in the account.

In 20I4, the Ministerial Task Team revealed to Mrs. Dlamini, the minister of social development, that illegal deductions were being made to pay for financial products and services such as mobile phone airtime and electricity. Debit deductions were also made for water, even though water was free. Apparently, the company responsible for administering the grant payments was selling confidential beneficiary data, including bank account numbers and biometric data. According to the minister of 
social development, this data was used for marketing financial products and other purposes (Dlamini 20I4; GroundUp 2015). The minister stated:

[T] his growing national phenomenon of unlawful and immoral debit deductions is unacceptable in the sense that while some of these deductions may be technically legal, they remain immoral as they serve to rob the poor from the resources that we as South Africans provide for them, to meet their basic needs. (Dlamini 20I4)

It is very difficult for social grant recipients to stop these deductions. The human rights and social justice organization, Black Sash, started a campaign called Hands Off Our Grants and reported hundreds of illegal grant deductions (GroundUp 20I 5). Understanding that grant recipients are fairly defenseless against illegal and immoral deductions, the minister of social development created a Ministerial Task Team (MTT) comprising representatives from government and civil society organizations (Dlamini 20I4). ${ }^{6}$ The Public Protector, the external state institution responsible for investigating misconduct in government affairs, started an investigation in 20I 4 and Black Sash supported grant recipients in a High Court case against NetI, the parent-company of the enterprise responsible for making grant payments (Gontsana 20I6). Consequently, in 2016 these kinds of deductions became illegal, although one year later new legislation was under way to allow companies responsible for paying social grants to once again withhold up to Io percent for funeral insurance (Pilane 2016; Thamm 20I7).

\section{Joyce's insurance claims}

The inability of insurance clients to draw on social networks for help and their frustrating experiences with bureaucracies became particularly evident in Joyce's story. In her late thirties, Joyce had spent thirteen years teaching English to classes of up to seventy students at a secondary school near Nyanga, a township in the Cape Flats.

Joyce's problem began when she had an affair with a married man from her neighborhood. She realized the man's wife had discovered the affair when Joyce received a text message that said: "Tell HIM to stop. It is not good for HIM." Joyce ignored the message, but a few days later three men began hanging around her house. One day, just as Joyce climbed into the back of a colleague's car and they were about to drive away, the three men walked up to the car. One of them took out a gun, 
pointed it at her, and shot several times through the car window. Joyce was hit in the face, chest, arm, and leg. As her colleague sped away with the badly wounded Joyce, the men continued shooting at the car, puncturing a tire. Driving on the flat tire, they pulled into a nearby police station from where Joyce was taken to Groote Schuur Hospital.

Joyce was hospitalized for two months but never fully recovered. I first met Joyce four years after the shooting, and she was still suffering both mentally and physically. Her fractured leg caused her to limp heavily, preventing her from walking for a prolonged time. Another bullet had gone through her jaw and tongue and finally lodged in her cheek. As a result, her jaw was dislocated and some of her teeth had been knocked out. The doctor had mended her jaw with metal pins, which, four years later, still had not been removed. These injuries made it hard for Joyce to chew and talk. It was possible to have a conversation with her in a quiet environment, but she was unable to speak very loudly because of the damage to her mouth. Joyce was certain that the incident had not been a car hijacking, but that her attackers had been sent by her lover's wife. Proof of this was that they had not pointed the gun at her colleague who was driving the car. Joyce's teaching career was clearly over.

Joyce showed me her correspondence with the police, lawyers, her employers, and insurance companies. They showed that she had been forced to stop working because her injuries made it impossible for her to teach a classroom of seventy noisy children. She was medically "boarded," meaning she had been released from work due to poor health. Instead of receiving a salary, her income was reduced to a small disability grant provided by the government.

After the shooting, Joyce stayed with her mother in Langa, also in the Cape Flats. She sold her home in Nyanga because she and her children could not bear to live in that neighborhood anymore. Eventually, Joyce bought her own place close to her mother's house. Her children, who had heard her screams when she was shot in front of their house, were still very worried every time Joyce went out. She had sold her car after the incident, and four years later she was still afraid to sit in one.

The investigation into the case was very disappointing. The police had lost her statement, the bullets, and all other evidence and documents related to the shooting, causing them to eventually close the case. Joyce suspected that the police were hiding something, and that her attackers were responsible for making sure that all the evidence of her case was lost. In an attempt to obtain a prosecution, Joyce wrote a letter to the minister of justice, explaining that her file and evidence had been lost and that the criminals would escape punishment. The ministry 
answered that her case was still being investigated, even though there was nothing left on which to base an investigation. To Joyce's tremendous frustration, no further action was taken.

Joyce became especially distressed when she talked about the problems she had with her health insurance, particularly the fact that the pins in her jaw still needed to be removed. After the shooting, her medical doctor had advised her to cancel her policy and replace it with one from a different company, since the existing one did not cover the surgery required for her jaw and teeth, classifying it as "plastic surgery for beauty enhancement" (cosmetic surgery). She followed his advice and took out a different health policy that cost a monthly premium of R800. However, she later found out that it only covered surgeries after a waiting period of one year or more. To compound matters, she discovered that her previous policy, which she had canceled, had changed its policies and now covered the kind of surgery she needed. Moreover, it would also allow her to pick up prescribed medications at the pharmacy, which could then directly bill the insurance company. Her new insurance policy, in contrast, often fails to pay the pharmacy or pays only after prolonged delays. Consequently, the pharmacy is no longer willing to bill the insurance company directly and instead demands that Joyce pay in cash. The result is that Joyce is forced to go after her insurance company for reimbursement, which is a big financial burden and personal risk.

Joyce also had life and disability insurance, so after the shooting she submitted a claim. Because she was unable to work and was receiving a disability grant from the government, she felt entitled to financial support from her insurance. The company wrote back that in order to process her claim she needed to submit two statements from her doctors. Joyce was able to get these, and the surgeon who had operated on her after the shooting stated clearly that she was in pain, her tongue and teeth were damaged, her jaw had been repaired with metal pins and therefore lacked mobility, and her leg was badly injured. Nonetheless, her claim was denied. The company argued that, because the policy only covered permanent disability, it had to be established whether her disability was permanent, which could only happen after the pins were removed from her jaw. But Joyce could not afford this surgery and her new health insurance would not cover it.

Subsequently, Joyce went to a lawyer in Langa and he wrote several letters to the insurance company objecting to their decision. After prolonged correspondence, the insurance company proposed that Joyce's medical condition be assessed by a speech therapist. They would provide a speech therapist's contact details but Joyce had to pay for the assessment herself. 
Joyce was relieved about this development. The speech therapist was very kind and understanding toward her, making her feel positive about the assessment. However, the therapist's report to the insurance company was not favorable. She wrote that Joyce "claims to be in pain but [I] cannot assess this." She conceded that Joyce had trouble speaking loudly, but was unable to identify any other problem. The assessment report did not mention the context of Joyce's work, nor the fact that she had been on medical leave, was on heavy pain medication, and was receiving a disability grant from the government. Based on the speech therapist's assessment, the insurance company notified Joyce that she was fit to work and that her claim was denied. As Joyce and I went through the paperwork together, it suddenly dawned on her how destructive the speech therapist's assessment had been. She was clearly shocked and puzzled that the therapist had written such a negative report and was convinced that it was because of racism.

As the years passed, Joyce's financial situation became desperate, so to supplement her income she made a claim on her retirement annuity. The policy would mature when Joyce turned fifty-five, at which point she would receive $\mathrm{R}_{2} 85$ per month. But she could not wait that long and notified the company that she wanted to cancel the policy and receive whatever money she was entitled to. The insurance company replied that they needed proof of her situation and requested a statement from the police. So, Joyce went to the police station where one of the officers wrote a brief report for her, which she sent. Yet, once again, the insurance company denied her claim saying that the police statement was too short and did not contain enough details. Looking at the statement myself, I could see that it was indeed very brief and contained barely any details of the shooting, which was probably because the police had lost all the documents and evidence related to the shooting. Joyce's lawyer then wrote a letter to the insurance company objecting to their decision, and the insurer agreed to pay her $\mathrm{R}_{\mathrm{I}}, 330$. Joyce was horrified at the low amount of money, which meant the company had deducted almost ten times that amount $\left(\mathrm{R}_{\left.I_{3}, 000\right)}\right.$ from her retirement

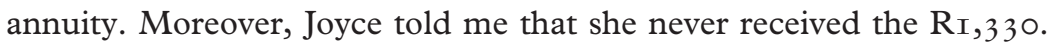
This is possibly because the insurance company did not pay it, or that Joyce, conceivably without realizing it, had signed a paper that entitled her lawyer to a certain amount of money for doing his work.

Joyce was angry and went to the insurance company's headquarters, not far from where she lived. Upon arrival she explained her situation to the woman behind the counter, who asked Joyce for her policy papers and said she would solve the problem and contact her within two weeks. 
But two weeks later there was still no response from the insurance company, so Joyce decided to call their national phone number. The woman at the call center told Joyce that according to their records, she had visited them to cancel her policy, meaning she no longer had a policy. Having never intended to cancel the policy, Joyce was furious and, at the same time, felt extremely powerless. Further enquiries to the insurance company led nowhere. Joyce finally wrote a letter to the Ombudsman for Long-Term Insurance. However, he ruled against her, stating that the insurance company was entitled to withdraw $\mathrm{R}_{I_{3}, 000}$ from her benefits. Joyce was convinced that the Ombudsman was biased and had taken the side of the insurance company.

Although Joyce was well educated, proficient in English, and very persistent, she was unable to successfully submit a claim. Even with all the documentation that Joyce showed me, it was hard to discern exactly what had happened to the money, and whether or not the claims were correct. Nonetheless, the fact that medical reports written by a surgeon were ignored in favor of a report written by a speech therapist of their choice certainly made it look like the insurance company had acted in bad faith. Thus, despite being formally employed for thirteen years, the insurance policies Joyce had purchased failed to provide the risk mitigation she expected.

The problems that clients and brokers experience are not always the responsibility of the insurance company. A man living in Guguletu told me about his predicament after his daughter died. He submitted a claim but the insurance company refused to make the payment he was entitled to as the father. They stated that the daughter's surname on the death certificate did not match their records, supposedly because she had been married. The father was sure this was not the case, so he went to the police station for an affidavit. At the police station, he discovered that apparently his daughter had indeed been married, and her new surname was Nigerian. The police suspected that a Nigerian gang member had bribed a civil servant into forging the marriage records, which would entitle him to a South African residence permit and eventually citizenship. The father was convinced that his daughter never knew about her own marriage. The police also suspected fraud but did not take the case any further. The result was that the insurance company refused to pay him. Even the undertaker thought the insurance company was wrong for declining the father's claim, in spite of the identity documents not being in order. He was convinced that once the insurance company had been informed about the real situation, it should have paid for the funeral costs, and that they had not because they were racist: "She is a black girl, that's why they don't want to pay." 


\section{Reproducing inequality}

Brokers in general are often skilled and successful "translators" between bureaucracies and the diverging social worlds and people that they embody, between the politics of states and the economy of markets (see James 20II; Maurer 1999). However, the insurance brokers in the townships of Cape Town have been unsuccessful in mobilizing their resources and networks. Their position has been closer to the frustrations experienced by French civil servants who, as Bourdieu (I999, 2002) pointed out, had to deal with the provisioning of care as well as disciplining forces: "They [low-ranking civil servants] experience the contradictions of a state whose right hand no longer knows, or worse, no longer wants to know what the left hand is doing, contradictions that take the form of increasingly painful "double constraints" (Bourdieu et al. 2002, I 83).

Janus, the two-faced Roman god of opening and closing gates and doors, is a suitable metaphor for describing the dynamics of social relations and bureaucracies in the insurance market. On the one side, South African insurance companies rely on community relationships to improve social security arrangements and limit operational costs. Thus, social networks are crucial for selling insurance, while bureaucracies remain at the core of processing claims. On the other side, clients like Joyce are unable to draw on those social relationships to successfully submit their claims, and instead face complex and unclear bureaucratic procedures that lead to Kafkaesque situations. The Ombudsman for Long-Term Insurance alluded to the negative reputation of insurance in his speech to the Life Offices Association:

\footnotetext{
Now, one thing you can say about insurers and their marketing material: they convey an impression of help and assistance, of the milk of human kindness flowing freely toward all mankind, especially potential policyholders. But I rather suspect, judging by the stories we get, that beneath that benevolent façade, also beats a heart of stone. (Nienaber 2005, section I3)
}

Yet even ombudsman organizations have been heavily bureaucratized and are difficult to access. For example, the Ombud for Financial Service Providers (FAIS) only accepts complaints written in English. Another ombudsman organization only accepts complaints submitted online through their website. These requirements make it especially difficult for those not proficient in English or who do not have access to the internet, and indeed, most clients in the townships of Cape Town 
were unaware that an ombudsman existed. Ombudsman organizations are not keen to open new cases, since they are already heavily burdened (see Nienaber and Preiss 2006) with, most likely, cases for relatively wealthy and literate clients. It is evident that the taxonomy and bureaucratic procedures of risks bear little resemblance to the risks and adversities that so profoundly impacted Joyce's life.

Contrary to expectations, brokers were not skillful manipulators of ambiguities and constraints and hence were often unable to successfully navigate between the insurance companies and the communities they were expected to represent. Instead, brokers and intermediaries often found themselves in a predicament where their income was not nearly as good as expected, and they were forced into mobilizing their social networks so aggressively that they risked damaging their reputation. They had little choice but to comply with a whole array of time-consuming and expensive social expectations, and often were not able to assist their clients with their claims.

Thus, the inability to "translate" between diverging economic realms reveals some of the ironies of financial inclusion. A close examination of the everyday practices of marketing insurance and handling claims clearly shows that the efforts of insurance companies to reduce what they refer to as operational costs were deeply entangled with the risks to which clients and brokers were exposed. In other words, the measures taken to limit costs meant transferring some of the risks back to their clients. These high costs were partly caused by poor clients who could only afford small policies, which they frequently canceled. However, the strategies insurance companies used to limit these costs served to either increase risks for brokers and intermediaries, or cause clients to get lost in Kafkaesque bureaucracies. The faces of Janus are experienced in the hierarchies of social networks that often made access a one-way street, in the tensions between the social networks used to sell insurance policies and the bureaucracies for submitting claims, and in the problematic way risks were converted into the seemingly neutral category of costs. At least in the short term, these insurance practices reproduce the inequalities that financial inclusion is intended to reduce, especially in a country with one of the highest levels of inequality in the world. 


\section{6 \\ The enchantment of abstract finance}

\section{Introduction: a caring burcauciracy}

There are many stories that circulate in the Cape Flats about the cruelty of insurance companies - people cheated into buying policies they did not need or want, people caught up in impenetrable bureaucracies when submitting claims, people denied compensations they were entitled to, people exploited by the insurance company they worked for.

However, these stories are not enough to prevent many people from taking out insurance policies, particularly life insurance, despite the fact that burial societies already exist to cover funeral costs. Burial societies are voluntary organizations set up by neighbors and fellow Eastern Cape migrants. Society members help organize funerals by pooling money, coordinating wakes and transportation to the Eastern Cape, and providing financial and emotional support to the bereaved. In general, burial societies work well. Although the HIV epidemic is an added burden, they manage it by doing things such as adapting entitlements. For example, when neighbors suspected that a woman from the township of Indawo Yoxolo had died of AIDS, the burial society limited its emotional and financial support. In other words, HIV did not have to mean the collapse of the burial society (Bähre 2007; see also Lee 20I2; Thomson and Posel 2002). So why do people take out life insurance in spite of the many complaints, and given the existence of reasonably well-functioning burial societies? The answer lies in the burden of sociality and the enchantment of bureaucracy and abstract finance - the allure of an idealized world that is stripped of sociality and its moralities, hierarchies, and emotional turmoil.

Weber's (1905) approach to modernity, capitalism, and bureaucracy in The Protestant Ethic and the Spirit of Capitalism is helpful in this attempt to understand why people desire funeral insurance despite already having burial societies, and regardless of the well-known cruelty of the insurance industry. In order to explore the appeal of insurance, it is vital to do away with a common misconception of Weber's analysis of modernity and capitalism. Although it is true that Weber highlights the inhumanity of bureaucracy, likening it to the "polar nights of icy darkness," 1 it would be wrong to say that Weber only addressed the cruel aspects of bureaucracy in modern capitalist society. ${ }^{2}$ Weber's 
metaphor of "iron cage" leaves room for a more ironic understanding of modernity and bureaucracy that, on one hand, is dehumanizing and oppressive, while on the other hand, provides progress and protection. This irony has been lost in the translation from German to English. Thus, reinstating irony to its rightful place can help clarify why Africans living in the townships of Cape Town buy insurance.

The English term "iron cage" is the most common translation for Weber's original German term stahlhartes Gehäuse, which he defines as the central disciplining force of modernity and its bureaucracies. Parsons' now famous use of the English "iron cage" conveys only the dehumanizing and oppressive nature of modern bureaucracy. Baehr pointed out that this translation is hermeneutically superficial (Baehr 200I, I 57) in that it fails to fully capture Weber's argument about capitalism and modernity (see also Kaesler 20I2) and loses the ambiguity comprehended by both stalhart and Gehäuse. Although not completely inaccurate, translating the German word Gehäuse into English as "cage" conjures up images of being involuntarily confined and emphasizes modernity and modern bureaucracy as prisons that rob people of their humanity and freedom. The way Weber used Gehäuse in his work The Protestant Ethic has a more ambiguous meaning such as "casing" or "shell," which denotes confinement more as a form of protection. Furthermore, a shell or a casing can be opened and does not have the significance of being locked in. This ambiguous meaning is highly relevant to Weber's argument. Weber's point is that capitalism and modernity are characterized by people's inability to realize they are in a protective and confining casing. In other words, people do not aspire to escape because they neither recognize nor feel they are locked up (Baehr 200I, I60-I6I).

Additionally, Stahlhart means "hard as steel" and not "iron," which is a significant difference, especially for the time when Weber wrote The Protestant Ethic. Steel, unlike iron, is stronger and does not rust, and has a much closer connection to progress and modernity. Weber used the steel metaphor less than fifty years after the invention of the Bessemer process, which made it possible to make steel at a much lower cost than before (Baehr 200I).

Max Weber and his wife Marianne visited Chicago in 1904 and were both startled by the terrible living conditions and impressed by the steel-framed skyscrapers, which Weber saw as "an expression of economic strength." ${ }^{3}$ Chicago was the first place in the world where steel was at the heart of an architectural revolution. It was used after the Great Fire of I 87I that destroyed large sections of Chicago's business district, killed hundreds of people, and left thousands homeless (Baehr 200I). The tragedy created an opportunity for a new type of 
architecture that designed buildings using a steel frame, which led to the invention of the skyscraper, one of the symbols of American modernity. Chicago's Montauk Block (completed in I882), the Home Insurance Building (completed in I884) and the Reliance Building (completed in I 890) were the world's first steel-framed buildings. ${ }^{4}$ Weber not only saw Chicago as a general metaphor for the horrors and strengths of modern capitalism, but it might have inspired his stahlhartes Gehäuse metaphor, which can be almost exactly translated as "steel-framed building." If one recognizes stahlhartes Gehäuse as an ironic metaphor, what can it tell us about the expectations people have of abstract finance and large-scale bureaucracy?

To understand what finance means in everyday life one must consider the kind of networks that emerge in cities like Cape Town, and how people see insurance in light of these networks. Ethnographic studies have revealed that South African cities are not necessarily places for individualization, but instead are central to the formation of new identities that are intimately connected to new social networks. Earlier studies on networks and identity in South African cities adopted the perspective of migration by asking how socio-economic change affected networks and intersubjectivities. Gluckman and others from the Rhodes Livingstone Institute strongly maintained that so-called modern identities and networks were situational and related to concrete events (Gluckman I940). He pointed out that events in modern life caused networks and identities to be charged with tensions and ambiguities. ${ }^{5}$

Wilson and Mafeje (1963) explored how new networks and identities developed in the Cape Town township of Langa. They carefully examined how kinship networks did not dissolve when living in an apartheid city, but rather led to new forms of cooperation and conflict among kin (Wilson and Mafeje I963, 82-88). They identified that, at least for some, Langa was a place for establishing elaborate new lifestyles, social networks, and identities. Mafeje later criticized the book to which he contributed as a young researcher, for suggesting that a liberal assimilation to Western lifestyles and notions of civilization was the only existing ideology in Langa, pointing out that some residents had markedly different ideologies (Mafeje I998; Sharp 2008).

The study by Philip and Iona Mayer on East London was possibly even more controversial. The researchers found that when rural Xhosa people migrated to the city, they adopted either a "Red" or a "School" identity. The School people embraced the schools, way of dressing, and cultural values that stood for modern urban life, while the Red people resisted modern urban life by rejecting modern institutions, dress, and cultural values (Mayer and Mayer I974). Leslie Bank's (20 I I) 
ethnography of East London carefully dissects this critique and argues that these identities and networks are related to the politics of apartheid and post-apartheid development (Bank 20II, 235-238). Bank uses the notion of fractured urbanism to show how "ordinary people are not simply vectors of larger social and economic processes, but are active agents in their own lives and settlements, claiming and reclaiming control of their homes, yards, streets and neighbourhoods, infusing the city with their narratives, meanings and inscription" (Bank 20II, 24I). Elsewhere (Bähre 2007), I have pointed out how Xhosa migrants developed new networks in the townships of Cape Town, particularly networks among men who identified with one another based on a shared migration history, and networks that were born out of new relations among neighboring women.

This chapter first focuses on what happens to these social networks among neighbors and fellow migrants when the ironic Weberian stahlhartes Gehäuse becomes available through insurance. What happens to the networks where men and women pool money? And how does this differ from the expectations that actuaries have of the "communities" for which they develop insurance policies? I will first present the somewhat romanticized view that actuaries, who are almost exclusively white, have of their predominantly African clients living in the townships of Cape Town. I will show how these views and misconceptions shape actuarial practices. Secondly, this chapter focuses on how African clients experience the social networks that develop between fellow migrants and neighbors in order to help explain why many see largescale bureaucratic insurance as a welcome alternative.

\section{What actuaries think their clients think}

South Africa's actuaries generally feel like they have a clear understanding of the problems confronted by poor South Africans and their reasons for buying insurance products. Racial segregation and sharp economic inequalities confine the knowledge of predominantly white actuaries to statistical data and personal lived experiences. This knowledge is the product of limited and hierarchical interactions that reflect the racial and economic inequalities of the country, which shape how actuaries and other professionals in the insurance sector imagine the world of African clients in what they call the LSM I-5 market.

In order to have a better understanding of how the professional habitus and elite positions of actuaries affect the perspective of actuaries, I complemented ethnographic methods with an online survey. To do 
this, I began with several conversations with members of the Actuarial Society of South Africa to find the most appropriate term for the insurance client target group. I wanted to avoid using "community," even though the marketing discourse included "previously disadvantaged communities" and "group schemes." Furthermore, I did not want to reproduce stereotypes about African collectivity, especially because the survey contained questions about the collective mitigation of risk. Initially, I used "predominantly African poor" but was later asked by the Actuarial Society of South Africa, which would distribute the survey link to its members, to use "LSM I-5." This was seen as a neutral and unambiguous category that avoided uncomfortable references to race and class. However, the neutrality of the term LSM $\mathrm{I}-5$ is problematic because it is the outcome of a discourse that was used to merge and negotiate political and commercial interests, not to mention that referring to people through acronyms and numbers dehumanizes them. Nonetheless, for the survey to work it made sense to use a term with which actuaries were familiar and comfortable.

The actuaries that completed the online survey identified poverty as the most significant problem to affect the sustainability of providing insurance to the LSM I-5 (Figure 6.I). During fieldwork, I was told that poverty made it difficult for clients to buy and continue paying for their insurance products. Poverty meant irregular employment, little education, and family circumstances that made it difficult to afford insurance.

Figure 6.1 - Threats to sustainability of insurance for the poor and lower middle classes (LSM 1-5) according to actuaries (\%)

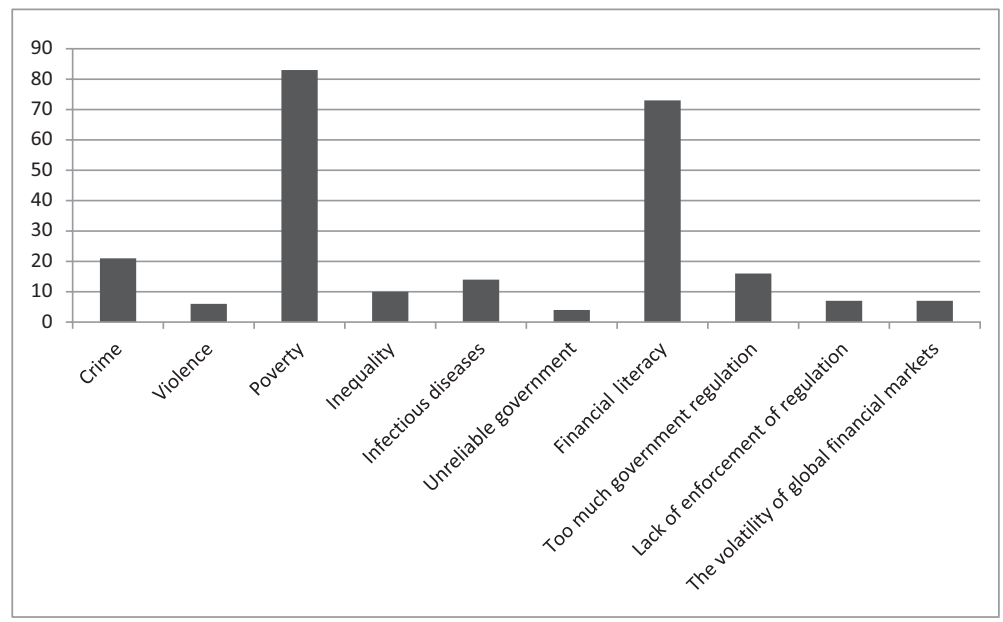


The second biggest threat identified by actuaries was financial literacy. They said the LSM I-5 fail to understand basic concepts like insurance, lack financial skills, and have problems with budgeting and administration. In addition, many have a limited command of English, which actuaries said created numerous misunderstandings. Clients often could not read the policy papers, had trouble filling out forms, and had difficulty with the English-only call centers. It was clear that actuaries believed financial education went far beyond surmounting practical and organizational obstacles. To them, financial education meant building better character. ${ }^{6} \mathrm{~A}$ wide range of programs was created to instill a new "culture of saving" that would teach people to delay gratification rather than live from one day to the next. ${ }^{7}$ The discourse of these programs equated over-indebtedness, bad financial planning, and problematic financial decisions more to personality problems than to structural problems. Initiatives led by the government, such as the National Savings Month held since July 2008, and by NGOs and businesses were told to increase financial education, which they did by emphasizing personal responsibility. James (20I4) examined financial education and its relationship to debt and found that the discourse focused on self-knowledge and skills to withstand personal desires and pressures from kin and society. Financial education, James (2014, 2I6-225) argued, was oriented towards self-improvement and self-transformation.

I found a similar discourse among actuaries. Even though insurance products provide for the future rather than for the instant gratification of desires through credit, the problem of financial literacy was constructed around consumerism and individual responsibility. Peter, a Johannesburg-based actuary specialized in developing products for African clients, explained to me how he saw the problem: "We now live in an entitlement society. There is no sense of delayed gratification by the poor and this results in a big push to get things now. Black society does everything for a great funeral." For Peter, taking out life insurance meant acquiescing to consumerism and instant gratification. $\mathrm{He}$ went on to explain that the South African government strengthened this sense of entitlement, which resulted in insurance becoming less affordable. He explained to me that "black society" does not know how things work, using as an example the fact they consult witchdoctors. This had financial consequences for insurance companies because it meant people waited too long before getting help from a biomedically trained doctor or nurse, making treatment more expensive. For Peter, a lack of financial education meant the inability to delay gratification, a sense of entitlement that was stimulated by the government, and the cultural practices of "black society" like visiting witchdoctors. 
A conversation with two actuaries at their office in Cape Town took a similar turn. One of them explained: "The consumer has a short time horizon. It is better to develop policies that also deliver after five years. A pure risk product is less popular than a product that also has a savings component." The insurance company they worked for tried to solve this problem by developing products that combined savings, where clients would receive a sum of money every two years, and insurance that only reimbursed clients for losses covered by the policies. Both actuaries were convinced that burial societies and other informal financial arrangements only aggravated the problem of poverty and that ministers of churches use the arrangements to steal money from the congregation. Informal arrangements are very difficult. They argued that there is a high risk in community sharing, and that insurance products are a better solution, if only African LSM I- 5 clients could understand how they work. Most actuaries expressed that they had to bridge the gap produced by financial illiteracy. When developing products for African clients, they felt they had to emphasize the collective and the group by including short-term incentives.

In addition to poverty and financial illiteracy, actuaries said that the identity of insurance companies was also a problem. In order to market for African clients, insurance companies had to appear less distant. One actuary explained to me:

This company is seen as a snooty brand. Therefore we work with [name of bank]. We also work with a clothing company that is popular among people with a low income. You have to build on social capital through banks, retailers, and churches.

People working in the insurance industry believed that presenting a more communitarian image would bridge that gap. African and poor clients, they told me, preferred a social image of insurance. Therefore, they expected to overcome the distrust that African and poor clients felt towards their company by adopting a social profile.

In the survey, I asked actuaries to reflect on how they were perceived by the LSM I-5 market. I asked how they thought the LSM I-5 would evaluate the trustworthiness of insurance companies as well as of other institutions and personal relations. The survey asked: "In the eyes of members of low income households (LSM I-5), how trustworthy are ...," which was followed by a list of different institutions and networks. Respondents could answer on a scale from I (extremely untrustworthy) to Io (extremely trustworthy). 
Figure 6.2 - "In the eyes of members of low income households (LSM 1-5), how trustworthy are ..." (1: extremely untrustworthy; 10: extremely trustworthy)

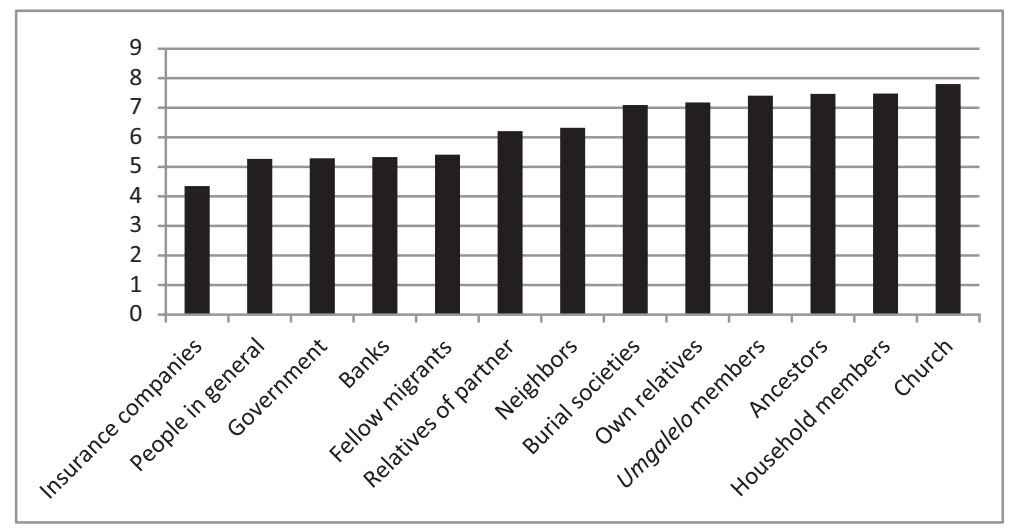

The responses show that actuaries expected their clients to rank insurance companies as the least trustworthy (average of 4.4 ), ${ }^{8}$ followed by other large bureaucracies such as the government and banks (average of 5.3 for both) (Figure 6.2). Actuaries expected low-income clients to place more trust in burial societies (7.I), the umgalelo members (7.4), churches, ancestors, and household members. In other words, the survey results show that actuaries expect the African poor to distrust large institutions involved with money, and to trust personal relationships.

It is worth taking a closer look at the trustworthiness of umgalelo members, which actuaries expected to be very high. The umgalelo is a financial mutual that is typically organized by neighbors and usually has about ten members. The word umgalelo is Xhosa and means "to pour," in the sense that members pour money into a fund. An umgalelo typically meets once a month. The amount of money that is pooled at the meeting can be substantial, with members usually contributing between 20 and 50 percent of their salaries.

Some of the umgalelo organizations immediately give the fund to one of the members in turn. Other umgalelo organizations save the money until the end of the year and sometimes give out loans to its members. Trust among the umgalelo is almost exclusively based on personal relationships (see Bähre 2007). Actuaries believe LSM I-5 clients place much more trust in these personal neighborhood networks than in financial institutions. ${ }^{9}$ 
In order to have a better understanding of how actuaries evaluate trust, I included a question that compared burial societies to funeral insurance. Burial societies and funeral insurance are quite similar in that they support a member/client after the death of a family member. Burial societies are usually organized by neighbors, by networks made up of fellow migrants from the same region in the Eastern Cape, and in some cases by clan members. The burial societies collect money and assist the bereaved family by organizing and paying for funeral costs, giving cash to the bereaved, and providing social and emotional support. Funeral insurance is a much more institutionalized and bureaucratic arrangement, and support is primarily financial.

Nearly two-thirds (65 percent) of the survey respondents expected the LSM I-5 population to prefer burial societies over funeral insurance. When asked why, nearly all (89 percent) said it was an issue of trust.

Actuaries express a distance between their world and that of LSM I-5 clients, who do not like the "snooty" corporate brands and identities of insurance companies. They also point to a distance that is related to education. Uneducated clients are not knowledgeable about financial products, do not speak sufficient English, and are unable to postpone immediate needs and desires. This perspective was expressed in the answers to the survey questions on trust. Actuaries think that LSM I-5's distrust of financial institutions makes marketing more difficult because they prefer financial arrangements based on personal relations that are strongly embedded in kinship and neighborliness.

\section{Escaping burial societics}

The way actuaries expect LSM I -5 clients to think contrasts sharply with what I found during fieldwork in the African townships of Cape Town and in the survey carried out in two of these townships, Indawo Yoxolo and Tembani. Before conducting the actuary survey, my research assistants and I interviewed people that closely resembled what actuaries identified as LSM I-5 on the subject of trust. ${ }^{10}$ We asked them to rate the trustworthiness of organizations and people, also on a scale from extremely untrustworthy (I) to extremely trustworthy (IO).

The findings did not match the expectations of the actuaries at all. These respondents rated the umgalelo members as the least trustworthy (4.9), followed closely by people in general (5.I), and burial societies (6.0), which the actuaries had expected to be identified as more trustworthy than the insurance companies they worked for (Figure 6.3). Household members were regarded as the most trustworthy (9.I), 
slightly higher than banks (8.9). The respondents believed insurance companies to be quite trustworthy (6.8), certainly more than the umgalelo and burial societies they organized themselves.

Actuaries overestimated the trust people placed in personal relationships, especially when they involved money and were not based on kinship, such as the umgalelo and burial societies. Furthermore, actuaries underestimated people's trust in large financial institutions such as insurance companies, especially banks. In fact, the residents of Indawo Yoxolo and Tembani placed significant trust in financial institutions that were predominantly run by a white elite that had had close ties to the apartheid regime, and which offered little space for personal relationships. Understanding this attraction requires a closer examination of how financial mutuals based on personal networks actually function. In other words, the expectations that people have of insurance are closely connected to their experiences with care arrangements based on personal relationships. Thus, the attraction of insurance must be understood from a social perspective by evaluating how people gauge personal and institutional relations.

Mbulelo was born in Encobo, which was part of apartheid Bantustan Transkei until the first democratic elections of I994 led to the end of the Bantustans. Mbulelo moved to the Cape Town township of Langa in I97I and became a member of the newly founded Didi Burial Society. The name of the society derived from the fact that the members were from the area near the village of Didi, located halfway between

Figure 6.3 - Residents of Indawo Yoxolo and Tembani: "How trustworthy do you think are ..." (1: extremely untrustworthy; 10: extremely trustworthy)

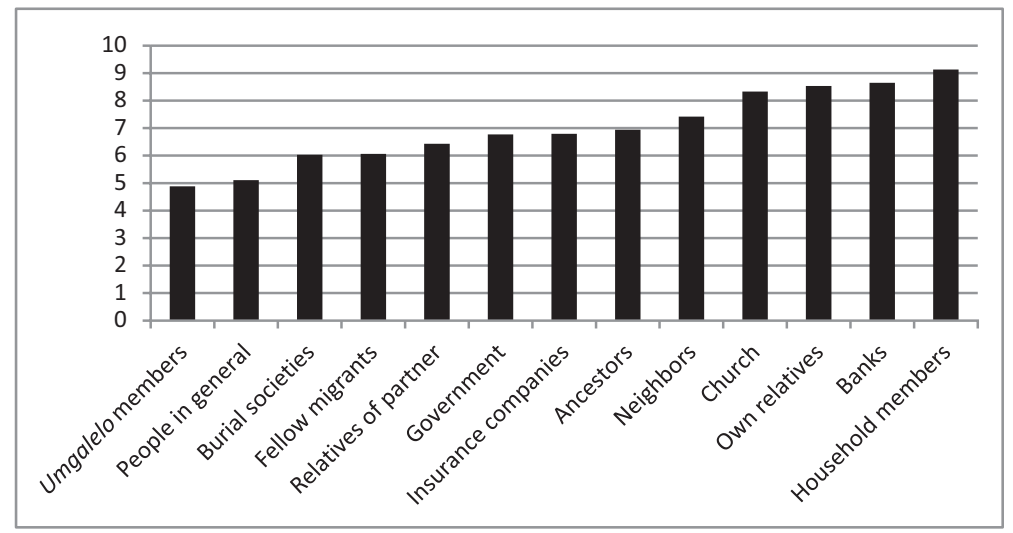


Umtata, the capital of the former Bantustan Transkei, and Port St. Johns. Mbulelo lived in several places in the Cape Flats until settling in Indawo Yoxolo in the mid-I990s, where he ran a small neighborhood spaza shop that sold sugar, eggs, soap, matches, cooking oil, and other daily necessities. Over the years, Mbulelo remained a member of the burial society, although the organization itself had changed due to several conflicts.

These conflicts were closely related to status issues. One started in 1985 when a child died in Cape Town. When the apartheid Bantustans Ciskei and Transkei still existed, children typically stayed with relatives in the Eastern Cape. ${ }^{11}$ This particular child was in Cape Town for a brief family visit when he died unexpectedly. The child's father was a member of the Didi Burial Society, which began collecting money for the funeral. The burial society collected the standard contribution for a child's funeral, as was written in the society's constitution. However, the Didi board decided to go against its constitution and make a much larger contribution. In addition to the money that was collected, they bought a coffin and paid to transport the child's body to the Transkei. Mbulelo was upset that these additional expenses were covered and that the board did not comply with the rules. He believed the board was willing to take on these additional costs because the child's father was wealthy and had a high status in that part of the Transkei. He felt the board was more interested in pleasing the father than in following the rules of the society.

Another controversy emerged a short time later when a member of the Didi Burial Society died. Again, the controversy was about whether the society rules should be strictly applied, or if there were grounds to be more lenient. The deceased had been a member of the society for a long time and had died an elderly man after a long-term illness. However, he had missed his last three payments because he had been too ill to attend the meetings when the money was collected. The rules of the society were very clear: three consecutive missed payments meant being excluded from any assistance. Nonetheless, it was not uncommon to deviate from this rule because of special circumstances. The society often discussed when it was acceptable and morally appropriate to make exceptions. In this case, the board, which had previously deviated from the rules by giving extra support for the funeral of a wealthy man's child, now saw no grounds to provide money or other services to the bereaved of the old man. Mbulelo and other members of Didi strongly disapproved, believing the reason for not helping the old man was his lack of status and marginal position in the community. They were in favor of Didi giving the assistance and thought it was 
unfair to withhold support after the old man had paid his dues for so long. Although the board did not want to help, they realized the old man had to be buried. He had no family in Cape Town who could organize the funeral. The family in Transkei did not have the means to pay for the funeral costs, which meant that, without the society, he would be deprived of a dignified funeral. Finally, the board decided to lend the necessary money to the bereaved family, who accepted the loan, organized the funeral in Transkei, and eventually paid the money back to the Didi Burial Society.

The tensions that surrounded these two deaths caused the Didi society to split into three groups. The members who had been in favor of paying for the old man's funeral formed one group, calling themselves the Maya Burial Society after a small area close to where the old man was from. The second group called themselves Didi Ulahliweyu, which meant "Didi thrown away." Although this group was also made up of members that had supported helping with the old man's funeral, they were not from the Maya area. Mbulelo joined Didi Ulahliweyu. The third group consisted of members who had supported the board's decisions. They decided to rename themselves Masekodube meaning "let's go home," referring to the importance of a dignified funeral at home in Transkei.

The members of Didi Ulahliweyu decided to partner with another nearby burial society called Qinqana. They agreed that one society would contribute R400 towards any funeral covered by the other. This, Mbulelo explained, was an important gesture because it heightened solidarity among migrants in Cape Town and helped them make a concerted effort to maintain kinship relations. Funerals and respect for the ancestors were vital for maintaining respectability in a racist political system that stripped black people of their dignity. Additionally, there was an economic reason. With the $\mathrm{R}_{400}$ contribution came a few seats on the minibus that took the corpse to the Transkei, thus making a family visit more affordable.

People living in the Didi district were not pleased that their migrating men in Cape Town were fighting, which affected the kinship and clan relations in the Transkei. Burial societies are typically set up according to the identification of fellow migrants, or the so-called abakhaya, from one area in the Eastern Cape. In this particular case, many of the Didi members belonged to the same clan. When the larger society split into three societies representing smaller regions in the Eastern Cape, those new divisions cut across clan affiliations. People in Transkei were concerned that tensions between the three burial societies would cause tension inside the clan as a whole. Thus, in order to prevent the Didi 
conflict from causing clan tensions, the three burial societies decided to cooperate again, at least to some extent. They presented themselves to the people in Transkei as a single burial society called Didi, but in fact they continued as three separate societies with separate boards and separate finances. Whenever a member of one of the three groups died, the other two groups each contributed R800 to the funeral costs. In return for the money the donors were each given three seats on the minibus to the Transkei. The cooperation between Qinqana and Didi Ulahliweyu also continued functioning well for about ten years. However, in I996, the death of a poor migrant man that belonged to the Didi Ulahliweyu society caused tensions to resurface. Mbulelo remembered:

We notified the others and all groups contributed [to the funeral expenses] and we hired a minibus to the Transkei [which by then had become part of the Eastern Cape province but which was still spoken of as a Bantustan]. When we returned to Cape Town the minibus broke down and the two other groups pointed the finger at us: "You are responsible," they said. The minibus owner promised to send another vehicle but he did not do so. We were stuck on the road without transport and we had to hire another minibus. The owner of the broken minibus later refused to pay for these additional costs. The two other groups, Maya and Masekodube, refused to contribute to these extra costs and we ended up paying for everything ourselves. That is why we split again.

Maya and Masekodube continued to work together without Didi Ulahliweyu, but a short while later some of their members were returning from the funeral of a Maya member in the Eastern Cape when their minibus broke down. They too had to hire a second minibus in order to get home, but in this case the two societies shared the cost. Although Mbulelo felt vindicated, he was still uncomfortable meeting the members of Maya and Masekodube. Mbulelo also seemed concerned that the Didi Ulahliweyu members would be accused of witchcraft, since "They know that what they did to us now happened to them."

Mbulelo's experience with these financial constraints, complex identity politics, and concerns about morality and respectability is not exceptional. For burial societies to work - and they often work well - members are required to deftly navigate complex relations and identities. In this particular case, this means navigating between loyalties based on being fellow migrants from one district (abakhaya) and loyalties that are based on belonging to the same clan. The conflicts within the burial societies show how new boundaries are established 
over time according to who is abakhaya and who is not. Kinship and fellow clansman loyalties also affect these burial societies. Loyalty and the obligations that came with it were taken into consideration when making decisions about whether to follow the rules and regulations of the burial society, or to make an exception because of loyalty owed to a person, or their socio-economic position (see also Bähre 2007). For Mbulelo and other members of Didi burial societies, the careful and sometimes intense navigation of identities was to some extent rooted in apartheid racial politics.

\section{Aggressive neighbors}

Tensions were not limited to burial societies and other financial mutuals. Contrary to the expectations of actuaries, tensions were also deeply embedded in neighborhood relations. I would argue that these tensions are fundamental to understanding why people living in Indawo Yoxolo or Tembani take out insurance, irrespective of the negative stories and experiences that surround the industry. What follows is an account of one of many conflicts and tensions played out between neighbors.

A married couple had two dogs they could not take care of. They asked their friend, Sandile, and his wife if the dogs could stay with them for a time, to which Sandile gladly agreed. They took the dogs to Sandile's home where they were mostly kept in the yard so they could not run away or attack anyone. One day, however, one of the dogs managed to crawl underneath the fence and into the neighbor's yard, where it chased after his cat and killed it. The neighbor was angry that the dog killed his cat. Sandile then decided it would be better to control the dogs by keeping them on a leash. But the neighbor was so angry that he would throw stones at the dogs, who could not hide because they were tied up. Sandile phoned the couple that owned the dogs to explain what was going on, and asked them to come over. When they arrived at Sandile's home they yelled insults at the neighbor:

A dog is a dog, there is nothing it can do about its behavior. Your cat should know when to run away. Who are you, are you also a dog? You are surely acting like one, throwing stones at our dogs!

The fight escalated and the dog owners started to punch the neighbor. The husband then went into Sandile's house and returned with a large axe threatening to kill the neighbor, who ran away. The husband later told me that he did not really want to kill Sandile's neighbor. He only 
wanted to intimidate him and thought it was very funny that the situation ended so well. He told me: "Nobody touches my dogs, you should let people know that they cannot play with you and you have to make it clear that you will defend yourself." For Sandile and his wife, the whole incident was very unfortunate. Being willing to take care of their friends' dogs led to severe damage in their relationship with their neighbor, who eventually moved away.

Vivian's attitude towards her neighbors is equally revealing. Vivian has lived in a five-room house in Khayelitsha since 1994. Her ninemonth-old daughter, three brothers, and her sister-in-law live with her. That same year, she joined the Universal Church of the Kingdom of God. She explained to me: "God found me. I did nothing for God in return, I joined because God does a lot for me." She is an assistant at the church where she helps with services and visits and prays with hospitalized members of the congregation. She also works for the local government council. When she started in 1986 , she had a standard 8 certificate, and twenty years later she had a Master's degree in public administration from the University of the Western Cape. "I paid for it myself," Vivian proudly stated. It had been very hard for her to study because she was often the only breadwinner in the house.

In the past, Vivian had participated in three burial societies. However, in 1989 , she left the societies organized by fellow migrants from the Eastern Cape and by her fellow clan members, and in 2004, she left her neighborhood society. The church had become more important to her than the societies: "I have to take care of my spiritual life and the people from the burial society did not understand this."

In 2002 and 2003 she left two imigalelo, both of them saving groups. One of the groups met monthly and the money they collected was put into an account, which was to be divided in December 2002. Vivian trusted the members of this group, who were current and former neighbors. The former neighbors were police officers, which she believed only made them more trustworthy. Furthermore, the personal networks and close proximity gave opportunity for oversight. But when the money was divided during a meeting in December, they noticed that a substantial amount was missing. It eventually became clear that the police officers had stolen it. An argument ensued, which ended with the police officers pulling out their guns and holding Vivian and other neighbors at gunpoint. Eventually they left and the money was gone. There was nothing that Vivian could do. The incident caused the group to disintegrate and Vivian decided to join another umgalelo in January 2003. This group was not set up by her neighbors, but by the parents of a friend. Vivian thought she could trust these personal acquaintances. 
She went to the monthly meetings and contributed money to a bank account, from which members could take out loans of RIoo that had to be paid back the following month with 30 percent interest. Although that seemed high, the interest was to be later shared between the members. At the end of the year the plan was to use the fund to buy groceries at a wholesaler and to give cash to the members, who could then use the money as they saw fit. Many hoped to pay for their trip to the Eastern Cape for Christmas holidays and maybe buy a sheep to share with family and neighbors. However, in December when the groceries had been bought and divided, and the cash distributed to the members, Vivian was very disappointed. The groceries were far too little and the cash was not enough for her to buy a sheep. She says that was the last time she would join such a group: "I have no time for them anymore." Today, Vivian no longer trusts neighbors, fellow migrants, or ancestors. She never invites a neighbor into her house for a meal, and they never ask her for a money loan. It seems she has little confidence in reciprocal relations in general, except maybe for those in her household.

Nonetheless, Vivian trusts her church and the insurance companies. Vivian took out five funeral policies with Avbob, Metropolitan, AIG, ABSA, and Standard Bank. She also has a pension fund with Metropolitan, medical insurance with Bonitas, car insurance with Auto \& General, and a provident fund that is part of her employment package. She says she does not have an Unemployment Insurance Fund (UIF), but given her employment status, she might have it without knowing it. ${ }^{12}$ Vivian is much more positive about insurance policies than about reciprocal care arrangements. She feels strongly that insurance policies help her be responsible and take care of herself and others, even though the companies disappoint her at times. For example, in 2004 Vivian's husband got into a fight and was killed. Vivian made a claim with the insurance company, arguing that his death had been accidental. Her policy papers stated that in case of accidental death, Vivian would receive double the benefits she was entitled to. But, seeing as he had been shot twice, the insurance company decided that her husband's death had been the result of a crime, which was not in line with the insurance company's definition of accidental death. Even though Vivian felt the insurance company had let her down, she still preferred insurance over financial mutuals based on personal relationships. ${ }^{13}$

Thus, on one hand, we see that actuaries expect their prospective clients to have little trust in insurance companies, banks, and the government. They expect lower income people, mostly Africans, to have much more trust in neighborhood-based financial mutuals. This perception 
shows how racial and class divisions in South African society can lead actuaries and others in the insurance industry to have a stereotypical image of their prospective clients. Such expectations also inform financial education, which is set up to increase people's financial skills and to transform their norms and values regarding finance and desires (see James 20I4; Van Wyk 20I2).

However, in contrast to the expectations of the insurance industry, residents of Indawo Yoxolo and Tembani place more trust in banks, insurance companies, churches, and the government, and much less trust in a burial society or an umgalelo. They trust banks more than they trust their own ancestors; they place more trust in insurance companies than they do in the mutual aid organizations set up between neighbors.

\section{Alleviating the shackles of sociality}

These contrasting results have important implications for the analysis of institutions and sociality. Apparently insurance companies, as well as other large bureaucratically organized financial institutions, are not seen simply as an iron cage that strips people of their humanity and confines them to ice-cold rationality. Rather, there is an attraction to investing money and care in impersonal and abstract bureaucratic institutions that lends them more trustworthiness than the social relations that make up communities.

This attraction can be better understood when observed through the lens of Weber's stahlhartes Gehäuse metaphor, which in the German original becomes an ironic metaphor that suddenly includes security, confinement, and protection. Because the common English translation of the metaphor of "iron cage" gives no space to imagine modern bureaucracy as anything but dehumanizing and cruel, it fails to encapsulate why African clients in the townships in Cape Town who are burdened by community-based care arrangements are attracted to abstract and impersonal bureaucratic organizations like insurance. The irony of the bureaucratic ideal is that bureaucracy both emancipates people from personal bonds by offering an alternative care arrangement, and dehumanizes them through the abstract and impersonal procedures of that arrangement. While insurance can free people from community conflicts and inequalities, it also produces its own cruelties.

The enchantment of insurance can be attributed, at least partly, to the expectation that it alleviates the strains of care based on personal relationships with neighbors, clan members, and fellow migrants. The 
reason people take out insurance policies, especially funeral policies, is they hope to reduce personal dependencies that are time-consuming and reproduce a wide range of social inequalities that seem primarily related to respectability. In other words, wealth, social status, and gender can increase or decrease respectability, while insurance companies see everyone as the same. Or at least that is what the bureaucratic ideal promises.

The care that Xhosa migrants organize through burial societies is tied to South Africa's troubled labor history. Burial societies were, and still are, typically based on migrant and neighborhood relations shaped by apartheid labor policies that forced Xhosa people to live in designated areas and that decided who was allowed to live in the city and who was forced to live in the Bantustans. An ironic approach to financialization and insurance means extending the analysis to the stahlhartes Gehäuse of relationships with neighbors and fellow migrants. These relationships were largely formed during an exploitative political and economic regime, which opened the door for insurance to ease some of these tensions by offering alternative methods for care. Moreover, as Mauss (1925) and Strathern (1988) and others revealed, personalized and social forms of solidarity and gift-giving are not necessarily the antithesis of care. In the end, the stahlhartes Gehäuse of insurance frees people from the stahlhartes Gehäuse of mutual obligations. ${ }^{14}$

An extensive body of ethnographies on urbanization in South Africa has examined how African migrants developed new social networks and new intersubjectivities. These studies have shown how these networks revolve around new cultural styles that make sense of urban life (Bank 20II; Mayer and Mayer I974; Wilson and Mafeje I963); how labor migration led to networks made up of migrants, and how apartheid, to some extent, forced migrants to depend on those networks for survival (McNamara I980; Ramphele I993); and how strongly gendered these networks were, since men and women had different migratory experiences as well as distinct responsibilities towards kin (Bähre 2007; James I999).

Nevertheless, many Africans living in the townships of Cape Town also leave these networks. Men leave burial societies and women leave financial mutuals when they purchase insurance policies. Just like Van Wyk's (20I4) ethnography on Durban, I found that the tensions and inequalities within these networks make some people opt for a less socially demanding way of organizing security and protection against adversities.

Ethnographies of finance show how new relations and forms of intersubjectivity are built even at the heart of financial markets, even when 
there is no face-to-face contact (Knorr Cetina and Bruegger 2002; Zaloom 2006). But here one also sees a development that goes against Zelizerian expectations of money and finance, at least when it concerns relations among neighbors and fellow migrants. As Hart (2007) and Maurer (2008) pointed out, we need to understand the importance of the abstract side of finance. Part of the attraction of insurance is that it is mediated through largely impersonal institutions and is based on abstract calculations that relieve people of the burden of having to consider their relations with neighbors and fellow migrants. There is an inherently non-social aspect to financial products like insurance that can be a welcome relief to the sometimes unequal and aggressive forms of solidarity that are built on personal networks. 


\section{7 \\ Transforming mutualities in business}

\section{Introduction: breaking associations?}

In addition to individual consumers, insurance companies were also interested in selling policies to the taxi business, which is one of the most important commercial activities in the townships. Every day, millions of people take a minibus taxi or a passenger car taxi to their workplace, to go shopping, to a church service, or to visit friends and family in Cape Town or in the Eastern Cape. South Africa has approximately I 50,000 minibus taxis owned by 20,000 people who employ another 200,000 people. Taxis make up 65 percent of public transportation in South Africa, making it by far the most important mode of public transportation. ${ }^{1}$

Hence, the taxi industry is an extremely valuable market for insurance companies, who offer products to compensate vehicle theft or damage, third party insurance, liability insurance, credit insurance, driver unemployment insurance, and pension provisions. Democratization in 1994 led to the "discovery" of the taxi business as a market of interest for insurance companies.

In order to understand the significance of insurance in this context, it is important to closely examine the history of the taxi industry and the way it is organized. To begin with, operating a taxi requires being a member of a taxi association and paying substantial membership fees. In turn, the associations offer varying forms of mutual support. The taxi associations function as a kind of burial society, offering financial, organizational, and emotional support after the death of a member or a member's relative. In addition to funeral assistance, taxi associations sometimes provide food or money to members and their families when they are in financial difficulties. Members also help one another in confrontations with the police or with rival taxi associations. In this way, taxi associations provide a diverse and fairly extensive form of social, financial, and even physical protection.

This chapter examines how solidarity in taxi associations emerged and how insurance, as well as other forms of financialization, transformed that solidarity. This phenomenon sheds light on how insurance transformed businesses in the townships of Cape Town after I994, and how insurance became part of a wider political and financial 
transformation of industry. How are historically developed forms of solidarity and a strong sense of belonging in businesses affected by financialization?

Taxi associations were, and sometimes still are, associated with South Africa's political parties that were pivotal to the political transformations that began in the I980s. In this chapter I will show how the dynamics of the highly politicized taxi industry affected financialization, and how the government incorporated insurance and other forms of financialization into their strategies as a way to pacify the powerful and often violent taxi associations. I will show how policies such as the Taxi Recapitalization policy, which the government defined as a way to rationalize public transportation, transformed the taxi world by making financial products mandatory. I will show how insurance became part of the government's political-economic agenda to marginalize, "rationalize," and formalize the taxi industry by breaking up the associations.

\section{In and out of control: meeting taxi owners}

Kholiswa is a middle-aged female taxi owner who lives in the township of Old Crossroads. She moved to Old Crossroads in I99I; before that she lived in the Harare shacks, a part of the township Khayelitsha. The house in Old Crossroads was very expensive for her but she could afford the house by using her umgalelo money. The main reason for leaving Harare was the risk of fire that could quickly spread in this densely built area: "Whenever I saw smoke, I thought it was my shack."

Since 200I, Kholiswa has tried to make money by running passenger car taxis. Unlike the minibus taxis, passenger car taxis are only permitted to operate within a township. The Xhosa nickname for these taxis is amaphela, which means cockroaches, because of their shape and how they swerve through the narrow streets of the township, picking up and dropping off passengers, and disobeying most of the traffic rules. Referring to them as amaphela also reflects the messy and dirty living conditions in townships like Old Crossroads. Parallels between insects and people are intended to be dehumanizing and are typically used to refer to other people. However, here "cockroach" is used reflexively to refer to the user's own difficulty of living a respectable life.

Kholiswa does not have a driver's license so she depends on others to operate her taxis. During our conversations, it became clear that a business that had begun fairly well had eventually collapsed. To get started, Kholiswa had wanted to buy a Toyota Cressida, a typical "cockroach" 
sedan for transporting people around the township. But first she had to join a taxi association, so she joined the "cockroaches" in $200 \mathrm{I}$ by paying a RIO,००० membership fee. Because she only had about half of the RI7,000 necessary to buy a Cressida, she decided to buy a Datsun Stanza, which she considered small and ugly. Matters became worse when the Stanza broke down and parts were hard to obtain. Kholiswa told me that she nearly gave up on her taxi business. But then she joined two umgalelo groups and a year later she received RI I,000 from one and $\mathrm{R}_{27,000}$ from the other. This allowed her to buy two Toyota Cressida's (one for RI4,000 and one for RII,000) and get the Stanza repaired. By investing her umgalelo money Kholiswa's business suddenly changed from a broken-down Stanza to three taxis. Nonetheless, this did not mean business went smoothly. Kholiswa's husband was unemployed at the time, which meant that their financial situation was a bit precarious. The situation became more difficult when one of the Cressidas broke down and the other one was hit by a Golden Arrow bus, Cape Town's bus service. Kholiswa blamed the accident on the bus driver and after four months Golden Arrow paid for the damage. Kholiswa had been worried that they would not pay her at all because her driver did not have a driver's license. So after this accident she decided to only have licensed drivers:

From a lady I had bought a Toyota Cressida, but a bad one, it was the Tsolwane (scorpion) model from I980. My drivers did not want to drive it because they were too embarrassed to drive this car. So what should I do with this car? So when I received the new money from the umgalelo I had to get another one. I went myself and saw the car; the ancestors showed it to me. It was R2I,000 and everybody was looking at it. It was meant for me. It took me not even an hour to get a driver, a good driver, although he was drinking. So then I got another driver instead. He was not drinking but he was not a good driver so I got the previous driver back. Things went well. I got a third Toyota Cressida but I also had to sell a car because I could not get a third driver.

For a while Kholiswa was successful in her new taxi business. She had two Toyota sedans and two fairly reliable drivers who were busy picking up and dropping off passengers in and around Old Crossroads, the local bus station, the taxi rank, or the nearby train station. Then Kholiswa set her sights on buying a third car, a Toyota Avanza, which is a multipurpose vehicle (MPV) that had just entered the market and could seat more passengers, and therefore make more money. Once again she tried to use an umgalelo to get the money together. However, despite her 
best efforts to save as much as possible, sometimes even preferring to put money in the umgalelo rather than buying food, she was not able to gather enough to buy the MPV. She tried to get a loan but was told that she could not have one without a driver's license. In the end she was somehow able to get a loan with the help of her daughter. It is not clear to me how they accomplished it, but I think that she took out a more expensive consumer credit rather than a car loan. Kholiswa told the story as follows:

My daughter called me and she said that she talked with a car dealer and they told her that she could buy one and get a loan without a driver's license. I met my daughter in Athlone at the car dealer and bought the Avanza for R90,000. They made sure I got a loan with ABSA bank. But by then I had used part of my umgalelo money and I only had R20,000 left so I had to borrow $\mathrm{R}_{70,000}$ from the bank. I had the car for three days and the driver took the car to George [approximately $400 \mathrm{~km}$ East of Cape Town]. The car broke down. A few days later it was broken again. I brought it back to the dealer and it took them too much time to repair the car and they then gave me another Avanza instead, but I had to pay another R25,000. That second Avanza did not give me problems. Only my driver was drunk and he knocked it twice into another car, one of them was even parked! So the second Avanza that I bought only worked one day. And the driver of another car that I had was drunk and bumped into another car and then ran away. I did not fix it because I had no money, till today I have no money for this. When I thought about fixing it a Somali guy knocked that car again. He knocked the door and the window. The car now has a plastic window. The Somali guy promised to fix my car but when I visited him he was very rude and aggressive. Then when I was recovering from these problems the engine of my Avanza started to make noises again, so we need to fix it. The parts alone cost R6,500. I also had another Avanza, a golden one, but that also is giving me problems. The gearbox needs to be fixed.

By that time, Kholiswa had separated from her husband. "He left me and I had to do this business on my own. I almost gave up but a friend encouraged me to continue."

In another conversation with Kholiswa about her many problems with the vehicles, she pointed out her neighbor Ntokozo, an older woman living opposite her house. Ntokozo spent most of her time at home, frequently sitting behind a table in front of the fenced yard where she would spread out several sweets to sell to neighboring children. 
On another occasion we were at an auto parts shop and Kholiswa accused Ntokozo of being a witch. She said that witches could hear things, which is probably why she was more comfortable expressing her suspicions far away from her neighbor's house. She is convinced that her marital and financial problems started with her. Kholiswa's husband had become a heavy drinker, even drinking during the day when Kholiswa was away for work. He also destroyed one of the cars. He drove to Delft, a development housing area in the Cape Flats, and had a car accident, probably while being drunk. Kholiswa had to use her umgalelo money to get the car fixed.

More problems followed after Ntokozo's sister became ill. Ntokozo asked Kholiswa's husband to take her to the hospital, but he refused, possibly because of the drinking problem. Ntokozo was upset that he did not help her sister and Kholiswa argues that she bewitched her husband:

After that [her husband's refusal to help their neighbor] there was no life. My husband got sick. He started to see people that nobody else could see. He wanted to kill himself. Only my husband and my daughter were in the house and all the neighbors were on the street. The witch said to my husband: "I hope you knock my wall with your car. I hope you have an accident in the car and that they beat you up badly." I can laugh about it today but it was sad. Then Tuesday night my daughter called me while I was at work. My daughter told me on the phone that my husband was drunk and got in the car and then hit a police car. They took him to the police station in Lower Crossroads. I was working at night and could only get home the next morning. I came back home in the morning and my daughter was crying and I tried to be strong. The police brought him home, he was still drunk and rude, and the police wanted an admission of guilt from him. He had to pay a $\mathrm{R}_{3} 00$ fine.

Later there was a court case and he had to pay another RI,500. When my husband was sober he tried to be nice and to stop drinking. He said that he will not drink anymore, except if there are rituals in the Eastern Cape that require him to drink something. He left in 2005 , on the 25 th of May. They [the witch and her family] chased him out of the house.

It was not quite clear how Ntokozo chased Kholiswa's husband away, but she had supposedly resorted to magic. One day, after receiving a mysterious phone call, he packed his belongings and took the only car that was still operating at the time, along with $\mathrm{R}_{22,000}$ that Kholiswa had saved through an umgalelo. All that day, Kholiswa looked for her husband and eventually found him in the car. She walked over to him and said: "When 
do I get my car back?", and he said: "No, I need it to go to work," and kept the car. I said to my husband, "Easy come, easy go." He used the car as a taxi until his driver crashed and totaled the car.

Kholiswa continued: "I told myself, I do not give up. And here I am. I want a bigger one, a Ses'fikile." The Ses'fikile is a Toyota Quantum, South Africa's most popular minibus taxi that came on the market in 2000. However, at the time Kholiswa had only one broken-down passenger car and no money to fix it.

Mr. Bata belongs to the same taxi association as Kholiswa, but unlike her, he owns several minibus taxis and is one of the association's leaders. I met Mr. Bata at the taxi rank that was dominated by his association. I was with my research assistant Edith and Mlaba, who had introduced me to Mr. Bata and set up the meeting. Because the rank was busy and noisy, we decided to drive to another place that offered enough privacy to talk. We all got in my car and I suggested we go to the nearby Kentucky Fried Chicken, which was usually quiet enough to have a conversation and a cold drink. Edith and Mlaba agreed, but Mr. Bata clearly had other plans. From his gestures and the way Mlaba responded to them, I understood that we would not be going to KFC. ${ }^{2}$ Initially I ignored his directions and headed towards KFC. I felt uncomfortable that he had immediately taken charge of the situation and wanted me to go to a place I was unfamiliar with. But Mr. Bata calmly persisted and both Edith and Mlaba explained that it was better to follow his instructions, which I did. We ended up at the most upscale steakhouse in the area.

Mr. Bata decided where we would sit, and once we were at a table in one of the booths, he proceeded to order the largest and most expensive meal on the menu. The rest of us had not planned to eat, so the situation made us feel very uncomfortable. We all ordered a cold drink. I asked Mr. Bata about his involvement in the taxi world and he replied that he did not own taxis, he was merely a consultant for the industry. I was certain that he knew that I knew he was lying, again making his point that he was in charge. He refused to give any details about what this consulting work involved, except that it had something to do with government plans to reform the transportation sector. It was evident that he was not going to say much at all. Mlaba had told me previously that Mr. Bata was very knowledgeable about the history of the taxi associations and the wars that had taken place between rival associations in the I980s and I990s, and was well-informed about recent government policies. But when I asked Mr. Bata about the fights, he said that he did not know much. I asked if he could tell me about specific violent events that were part of the collective memory of people 
working in the taxi world. As one of the leaders of a taxi association, he should know about it. Again, he said that he did not know anything and claimed to have been away from Cape Town at the time. Mlaba was oddly unhelpful.

Eventually the waitress arrived with Mr. Bata's meal. He glanced at it, and without touching it, asked her to wrap it up as takeaway: he was not hungry. When the waitress returned with the parcel, he indicated to me that the interview was over, got up, and walked out of the restaurant carrying the food under his arm. It was obvious that I was supposed to pay the bill. As we drove back to the taxi rank to drop off Mr. Bata and Mlaba, another power display unfolded in the back seat of the car. Mlaba was holding a small box in his hand and Mr. Bata wanted to know what was in it. Mlaba said it was headache medication someone had recommended, which he had just purchased at a nearby pharmacy. Without uttering a word, Mr. Bata took the medication out of Mlaba's hand, and after inspecting the box, put it in his own pocket. Mlaba said nothing.

When I met Mlaba a few days later he apologized for Mr. Bata's rude behavior. He had been shocked that Mr. Bata ordered the most expensive meal and then made me pay for it. He had felt very uncomfortable and embarrassed by the entire situation. Mr. Bata's behavior came across as a warning for me to stop my enquiries into the taxi world. ${ }^{3}$

When examining the taxi associations, it is important to keep in mind that they encompass a wide variety of experiences and socio-economic positions, from aggressive and successful businesspeople with political clout, to people struggling to keep one or two taxis on the road as a way to supplement their income. This variety means that financialization can affect taxi owners in very different ways.

\section{A history of violent solidarity}

Apartheid legislation not only discriminated racial groups, it also separated rural and urban Africans and their taxi associations. The Urban Areas Act of 1923 severely restricted Africans who wanted to remain in or move to South African cities, and the Abolition of Passes and Co-ordination of Documents Act and the Native Laws Amendment Act of 1952 differentiated rural and urban African rights. The so-called Section Io rights (related to the Native Laws Amendment Act) determined that a small group of Africans were allowed to live in the city permanently and gave them some employment advantages. This put the African majority, which did not have Section Io rights, at a disadvantage. For them, 
unemployment meant being forced to leave the city and become even more vulnerable to police harassment and forced removal (see also Ross I999; Lee 2005).

These apartheid laws thus drew a line between a select group of Africans - the "insiders" (Ross I999, I I9) - who had the right to permanently live and work in specific urban townships, and the vast majority of Africans who were denied those rights - the "outsiders." Outsiders were forced to live in Bantustans like Transkei and Ciskei. Some lived in cities illegally for a time, or stayed in appalling government "hostels" (see among others Cole 1987; Ramphele I991). Over a period of three decades, the division between African insiders and outsiders went from a legal distinction to a social and economic reality.

Outsiders traveled hundreds of miles from their Bantustans to informal settlements on the Cape Flats, from where they commuted to their mostly informal jobs. By the I980s, urban African insiders found themselves having to compete with a growing number of illegal outsiders for jobs, housing, and transportation. Insiders had de facto lost the small legal advantages that Section Io rights supposedly gave them, as it became nearly impossible for the apartheid state to enforce them effectively. The increasing presence of outsiders in urban areas in the wake of a collapsing apartheid state led to fierce fighting across the country. These fights often centered on taxi associations, seeing as taxis were the main source of transportation between the Bantustans and the urban areas, and between illegal urban settlements and work places. They also provided important income for owners and drivers. ${ }^{4}$

Bank (I990, 83) gives a vivid description of the fights between rival taxi associations who in order to guarantee victory cooperated with gangsters:

The vehicles of the competing sides would be lined up in formation on a large open field. The leaders of both sides would then distribute weapons - guns, pangas and sticks - and as soon as everyone was prepared the signal would be given to attack. These "battles" always took a heavy toll, leaving dozens of taximen and gangsters either dead or seriously injured. The victors in every case were those who were able to hold their ground the longest.

In the township Soweto, over a decade of sporadic taxi fights erupted into a vicious war in I982. In I987 there were taxi wars in Johannesburg and in the East Rand township of Kathorus, where fifty people were killed and 350 people injured (Khosa I992, 6-7; Bonner and Nieftagodien 200I, I79). 
In Cape Town, the urban insiders had established the Langa, Guguletu, and Nyanga Taxi Association (Lagunya) that monopolized taxi transportation for over thirty years, until some of the rural outsiders began running their own taxis. Several people told me they thought it was unfair for the urban insiders to have such a monopoly on transportation. They complained that urban insiders made money off the back of the marginalized and destitute rural outsiders. In I986, just after the abolishment of the Influx Control Act that separated urban insiders and rural outsiders, the outsiders set up the rivaling Western Cape Black Taxi Association (Webta).

Webta ran taxis to and from the shanty towns where the rural outsiders lived to the center of Cape Town. The police arrested some of these so-called pirates, but with little impact. Around the same time, the Lagunya operators began breaking transport regulations, which led to aggressive fighting between taxi associations, and between them and the police. In I990, the year Nelson Mandela was released from prison, it became clear that the apartheid state was near its end. That same year, there was a violent shoot-out between members of Lagunya and Webta at the Golden Acres, a shopping mall and transportation hub in the center of Cape Town, far removed from residential areas (Dugard 200I, 5 describes this shooting).

By I990, the rivalry between Lagunya and Webta had become a full-blown taxi war. Webta members were afraid that staying in their homes would endanger their families, so for two years they slept underneath or in their vehicles in bush camps they set up near Tafelsig and what is now Mitchells Plain. The camps were also used for planning and launching violent attacks on Lagunya members. Mlaba, who lives in Nyanga, had been a Webta taxi driver and had lived in one of the bush camps.

Mlaba told me that they were only able to survive in the camp because of fellow outsiders who brought them food and drink, often in the middle of the night. Webta members also took care of each other's families, who often had no income because the conflict forced many owners and drivers into hiding, making it impossible for them to earn money. They helped each other with food and emotional support, and organized and financed funerals whenever a fellow member died. The solidarity that emerged among Webta members was thus directly related to the violence imposed by an increasingly weak apartheid state and a rivaling taxi association.

In some ways, the bush camps resembled military strongholds. Mlaba and his fellow Webta members only dared to leave the camps in groups of four or five during the day because they were far more susceptible to 
Lagunya attacks when alone. But at night, they would put on camouflage gear and go out to fight Lagunya.

Kholiswa, who, as we saw earlier, had accused her neighbor of witchcraft, had been a member of Lagunya when she lived in Khayelitsha. She and other Lagunya members were terrified of Webta. According to her, Lagunya always defeated Webta and so they had to be careful when taking a taxi. She would never take a Webta taxi out of fear of being assaulted. She vividly remembers a taxi strike. She had taken a taxi to work when she and the other passengers were stopped by a large crowd of protesters. Because she was a taxi owner they thought she was breaking the strike and were ready to necklace her. This meant shoving a petrol-infused car tire over the body of a person accused of collaborating with the apartheid regime. The tire would be set on fire, causing severe burns or even death. Kholiswa escaped being necklaced that day by lying that she was on her way to see her sick mother. She has strong memories of the violence and says that many people are in wheelchairs today because of those days. At the time, the local taxi rank was nicknamed Kuwait, referring to the iconic images of burning oil fields in Kuwait during the Gulf War.

Another resident of Khayelitsha vividly remembered those I99I/92 fights. Her husband had been a Webta taxi owner and during the fights he did not dare sleep at home. Instead, he would spend the nights in a bush camp, sometimes staying there for months. She and her children had to flee Cape Town because it was too dangerous to stay in the house, with all the neighborhood shootings and retaliations from Lagunya members. They would only return to Cape Town during summer vacations, but even then it had been extremely dangerous. She rarely saw her husband during this period:

He kept in hiding and was too scared to come to our house. Sometimes people knocked on our front door in the middle of the night to check if he was there so they could kill him. It was very bad. Our men were even accused of cannibalism, of eating a taxi owner from Lagunya while they were hiding in the bushes.

The war between Webta and Lagunya fueled further confusion and upheaval about the role of the ANC. Because police did not intervene in the fighting, many believed that the apartheid regime actually encouraged it. Webta was accused of working closely with the "witdoeke," a paramilitary organization set up by the apartheid government as a third force intended to destabilize society and crush liberation movements (see Cole 1987; Cross 2005; and the TRC hearings, see TRC 1998). 
Webta, however, accused the ANC of spreading this rumor and the cannibalism story to discredit them. Mlaba said: "They accused Webta people of eating others. They say that Webta took the liver of someone they captured [a Lagunya member] and barbecued it on a spade." The rumor was well-known and everybody I interviewed had heard about it, many believing it to be true.

In I992, negotiations led to a peace agreement that brought Lagunya and Webta together to form the Congress of Democratic Taxi Associations (Codeta) (see Table 7.I). Two years later a group of former Webta members left Codeta to form the Cape Amalgamated Taxi Association (CATA) because they thought there were not enough Webta people on the governing board and that they did not get a fair share of the routes. Part of the I 992 peace agreement had established that former Webta drivers would take passengers from the townships of Cape Town to the taxi rank of Cape Town's township Nyanga, and former Lagunya members would take them from Nyanga to the city center. But the Webta people wanted to drive their passengers straight to and from the city center. According to Dugard (200I), tensions within Codeta increased when the Independent Electoral Committee issued the association a check of $\mathrm{R}_{4} 8,000$ to transport people to the election polls. Webta people thought that the Lagunya people got too much of that money. Soon after, CATA initiated an aggressive campaign to claim Cape Town's most lucrative taxi routes.

In October 1994, only months after the first democratic elections, CATA was invited to attend an election meeting at the Khayelitsha soccer stadium. Khayelitsha was an important source of business for taxi companies because the township is far from the center of Cape Town,

Table 7.1 - Schematic representation of identities and affiliations of taxi associations

\begin{tabular}{|l|l|l|}
\hline & Urban insiders & Rural outsiders \\
\hline $\begin{array}{l}\text { Legal category during } \\
\text { apartheid }\end{array}$ & Section 10 rights & $\begin{array}{l}\text { Illegal migrants from } \\
\text { Bantustans }\end{array}$ \\
\hline $\begin{array}{l}\text { Name of taxi } \\
\text { association up to 1992 }\end{array}$ & Lagunya & Webta \\
\hline $\begin{array}{l}\text { Political affiliation } \\
\text { during apartheid }\end{array}$ & ANC & $\begin{array}{l}\text { PAC and accusations of } \\
\text { siding with paramilitary } \\
\text { Witdoeke }\end{array}$ \\
\hline $\begin{array}{l}\text { Name of taxi } \\
\text { association after } 1994\end{array}$ & Codeta & CATA \\
\hline
\end{tabular}


thus allowing relatively high fees for the route, and it had played an important part in the taxi war. Initially, CATA (mostly former Webta) members were reluctant to go to the meeting because they were worried it would result in a fight with Codeta (mostly former Lagunya) members. In addition to their rivaling taxi association backgrounds, CATA and Codeta had taken different political sides during the I994 election campaigns. CATA had aligned themselves with the Pan African Congress (PAC), and Codeta had aligned with the victorious ANC. Nevertheless, Codeta leaders convinced CATA that the meeting would be peaceful, saying there would be ample police presence and even soldiers for protection. According to the CATA taxi owners that I spoke to, Codeta had promised to leave their weapons at home. This was to be a festive event celebrating democracy and the victory over apartheid.

Thus, CATA members went to the meeting unarmed, but upon arrival they noticed that the promised soldiers were absent. Some worried when they were seated in a separate section of the stadium, and regretted leaving their guns at home. The meeting started with a speech by Winnie Mandela celebrating the victory of the ANC, after which more speakers followed. According to several eyewitnesses I spoke to, at the end of the meeting Codeta and the ANC made sure that everyone left the stadium except CATA members. Then bullets rained down on them:

We were invited to go to the rally without arms. We saw no need to take guns. This was an ANC rally, but they had planned to massacre us ... the ground was moving from the bullets that hit it. You know how low the taxis were, but people crawled underneath [them] trying to hide.

Releases from the South African Press Association (SAPA) and Reuters confirmed the violent encounter. SAPA reported that the feud between Codeta and CATA had "erupted into open warfare at the weekend when ten people were killed in the Khayelitsha stadium." "That same day, SAPA reported that the police recovered I 62 bullets from the site where ten men had been killed and twenty-three injured: "It now appears that one or two shots were fired inside the stadium as people started to leave, followed by an all-out gunfight ... These were bullets and casings of $\mathrm{AK}_{47}, \mathrm{R}_{4}$ and $9 \mathrm{~mm}$ weapons." Reuters stated that "all but one of the victims belonged to the Cape Amalgamated Taxi Association [CATA] which recently broke away from the Congress of Democratic Taxi Associations [Codeta]."

Although the Khayelitsha massacre features prominently in the oral history of CATA taxi owners, it received surprisingly little attention 
in the media, despite its crucial role in the escalation of violence. All the CATA members I interviewed held the ANC responsible, saying it, along with Codeta and the South African National Civic Organization (SANCO), had organized a trap. For them, the Khayelitsha massacre confirmed that the ANC cared only about the urban insiders, and that they, the rural outsiders, were still not welcome in Cape Town. The fighting escalated into more shootings and petrol bombs being thrown at rival taxi ranks or passenger pickup sites. It was not until years later, in the late I990s, that the taxi associations stopped their violent altercations and more or less agreed to divide their turf along the $\mathrm{R}_{3} 00$ highway. Codeta was allowed to transport people between Khayelitsha and most locations north of the $\mathrm{R}_{300 \text {, while CATA could }}$ operate mostly in the areas south of the $\mathrm{R}_{3} 00$. However, the fighting never stopped completely.

Therefore, we can see how, in the final period of a weakened apartheid state, taxi owners and drivers created a new system of solidarity. They established taxi associations to help them with their businesses, and offered social security as well as physical and emotional support during problematic times. This particular political and economic configuration produced a solidarity that was deeply permeated by violence.

\section{Financialization through the "Recap"}

The post-apartheid government tried to regulate the taxi industry with the Taxi Recapitalization Programme (TRP), ${ }^{7}$ or what taxi owners called simply the Recap. It was introduced in the late I990s, and its implementation was accelerated in the 2000 s as part of the preparations for the 2010 FIFA World Cup (Walters 2008, 102). ${ }^{8}$ The Recap was primarily intended to appease the violent taxi associations and transform a largely informal economy into a formal one that could fit in the financial sector, which meant paying taxes and a strict regime of taxi licensing.

The Recap was part of what government defined as the rationalization of public transport. The Recap would "reduce the taxi vehicles ... from about I 20,000 to 85,000 " (Walters 2008 , I06) in order for the business to become more sustainable and profitable. The government would use the Recap to distribute routes to individual taxi owners through a tendering system, even though similar attempts elsewhere had led to increased transportation costs (Walters 2010, 364). Regulating the industry meant that minibus taxis had to comply with stricter technical 
requirements regarding road safety. Drivers had to pay income taxes, and owners had to pay their drivers proper wages and insure their vehicles (Walters 2008, I05-108). A large sticker would be placed on vehicles to identify them to customers and traffic police as running a licensed route. Police officers had to monitor taxis more closely by conducting traffic stops to check if the vehicles were roadworthy, if the operators had a driver's license, if passenger insurance was paid, if vehicles were not overloaded, if technical requirements were met, and many other regulations.

The taxi Recap was intended to stop illegal practices and make taxi transportation cheaper and safer by implementing a wide range of restrictive measures, as opposed to liberalizing the industry. The Recap undeniably transformed the taxi world into a substantial market for financial loans, insurance policies, and vehicles. For example, the Recap stated that the older Toyota Siyaya models were unsafe, thus it forced owners to replace them with newer, more expensive vehicles. Additionally, the Recap subsidized the scrapping of older vehicles, giving the owners $\mathrm{R}_{45}, 000$ (previously $\mathrm{R}_{5} \mathrm{0}, 000$ ) for every vehicle taken off the road for scrap. The $\mathrm{R}_{45}$, 000 could then be used towards buying a new vehicle. In theory, any vehicle that met a number of standards would suffice, but in practice these rules meant buying either a Toyota model or a much more expensive Mercedes.

In 20I0, the South African Department of Labor conducted a roadshow, visiting taxi ranks to raise awareness among taxi owners and drivers on the need to register for unemployment insurance under the Unemployment Insurance Act (Act 63 of 200I).${ }^{9}$ This opened the door for insurance companies to begin marketing related products.

SA Taxi was established in 2002 and offered financial products such as the Khusela taxi business insurance, which supplies third party coverage, passenger liability, credit insurance for vehicle purchases, and others. ${ }^{10}$ CTU Taxi Insurance, underwritten by Hollard and Hanover $\mathrm{Re}$, offers four different types of comprehensive insurance that includes hijacking, riots, and strikes. ${ }^{11}$ Mobility Insurance, established in 20I3, features an image of Nelson Mandela on its homepage and a quote attributed to him that says, "Money won't create success, the freedom to make it will!" In addition to credit protection, comprehensive taxi insurance, and third party coverage, they cover accidental death and income protection for up to fourteen days. ${ }^{12}$ These are just some of the brands and subsidiaries that insurers created exclusively for the taxi market, which is made up of approximately I20,000 vehicles, I0,000 taxi owners, and even more drivers. 
Many taxi owners were concerned about the financialization of their industry. They maintained that the Recap forced them to buy new and expensive vehicles they did not need. Andries, for example, was a member of CATA and had taken over the family business after his father had died in a car accident. He lives in Crossroads and runs a few taxis, albeit he remains a bit vague about how many. He said the Recap forced him to replace his older Toyota Siyaya model with a Toyota Quantum, because if he did not he would eventually lose his license. The Toyota Quantum model cost R250,000 and a Siyaya only RI 57,000. Andries felt no need to buy a new car, but he had to replace the Siyaya otherwise the government would prevent him from continuing his business. Additionally, because he could not afford it, he had to take out a loan of nearly R200,000. He also had to purchase third party insurance, passenger liability insurance, and comprehensive insurance, all in order to limit the risks of credit default. The comprehensive insurance covered the costs of repairing or replacing the vehicle in case of an accident, and thus would ensure the loan's collateral, i.e. the vehicle. The insurance premiums alone cost Andries RI, 800 a month, which was more than the legal minimum wage at the time. In an attempt to spend less, he bought the insurance policies from the brother of a fellow CATA member, but later found out that it would have been cheaper to buy them directly from the insurance company.

Andries was not sure if the insurance was helpful or not. One month prior to our interview, one of his new taxis had been involved in a car accident. He had to remove the vehicle from service and leave it at a car body repair shop. However, they were not allowed to fix the car because the insurance company required quotes from three different repair shops from their approved list. Andries had no time for this type of bureaucracy in December, the busiest month of the year, meaning he had to keep the car off the roads until January. Andries did not like the fact that he could not choose his own repair shop, and he thought many of the new Toyota Quantum models ended up on the scrapheap because their technology and parts were too complex and expensive to repair, allowing them to be written off quickly.

The formalization of the taxi industry opened the doors to vehiclepurchasing loans, which primarily benefited the financial sector, car manufacturers - especially Toyota - and car dealers. Although these loans were individual, and taxi owners were personally responsible for their vehicles and loans, the taxi association board members were the ones who made the deals. A board member of one taxi association told me that he was engaged in talks with a Toyota dealer in Cape Town, 
ABSA (one of South Africa's largest banks), and the Cape Metropolitan Council about the purchase of I, 500 Toyota vehicles for his association. The negotiation amounted to over R200 million (approximately EUR20 million). Thus, the Recap transformed the taxi associations into powerful and lucrative brokers between taxi owners, car dealers, banks, and government agencies. It enabled the government to create a multibillion-euro industry at the expense of taxi owners and passengers, and there were rumors that taxi association leaders were paid large bribes in return for securing these deals.

Before the Recap, taxi associations had been mutual benefit societies that provided financial, moral, and practical support when members or their relatives died. For example, members of Kiki Murray, a taxi association that was part of CATA, paid Rioo a month into a funeral fund, and an additional RIoo when a member died. This allowed one of their bereaved families to receive approximately R20,000 in cash and goods from the association. ${ }^{13}$ Codeta had membership fees of up to

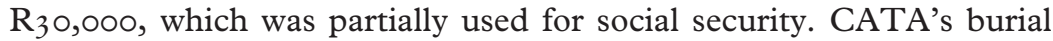
society provided bereaved families $\mathrm{R}_{55}$, 000 when a taxi owner or their spouse died, and RI0,000 when a taxi owner's parent or child died. The introduction of the Recap meant these mutual benefit societies became significant markets for insurance companies. Moreover, the associations provided the insurance companies with new clients and carried out a large part of the administration duties, which reduced the insurer's organizational costs (see Bähre 20I2).

Ingrid's experience shows how insurance can lead to severe financial problems. Ingrid has two minibus taxis that are covered by all the legally required insurance, in addition to theft and robbery coverage. One evening in February 2015 , Ingrid was waiting in her taxi for passengers near the Crossroads taxi terminal. Two men walked up, pointed a gun at her, forced her to get out, and then drove away in her taxi. Ingrid immediately called the police. Although the station was close by, it took them a very long time to arrive on the scene. Ingrid thinks the police officers were scared about confronting the armed robbers, so they took their time. Ingrid's stolen vehicle had a tracking device, so she phoned the security company to ask them to locate it. The police followed the security company's instructions to search for the vehicle, and soon found the tracking device. The robbers had removed it from the vehicle and dumped it in a drain in a nearby street. They never found the vehicle.

Ingrid then submitted a claim to the insurance company, but they refused to compensate her for the loss. Ingrid told me that they initially denied her claim because supposedly the police report was not 
detailed enough. However, the insurance company then accused Ingrid of staging the robbery, believing that her story was impossible. The claims department told her the robbers could not have found the tracking device because they are carefully hidden. The company also informed her that they were going to start an investigation against her for insurance fraud. Ingrid told me that many people know where the tracking device is. She believed that sometimes the mechanics working in the shops that install the tracking devices partner with robbers.

One year later, the insurance company had yet to start an investigation against Ingrid, and even so they refused to compensate her. To her, the threat of an investigation was intended to intimidate her and stop her from pursuing a claim. Yet Ingrid refused to give in and continued fighting the insurance company. She took out legal insurance (R220 a month) to pay for a lawyer. But whenever they were in court, the lawyers representing the insurance company delayed the proceedings. According to Ingrid, the lawyers lied and now the case is postponed with no new court date in sight. Furthermore, her lawyer has moved to another company and she needs to hire a new one. She heard that her minibus had been spotted in Durban, but the police did not impound it. In the meantime, the insurance company continues to charge Ingrid for the credit she took to buy the vehicle, and for credit insurance. Every month she has to pay them RI0,900 for a car she no longer has.

Ingrid also told me about her experiences with stricter government regulations and police control after the Recap. The police could fine taxi owners up to $\mathrm{R}_{5}, 000$ for misdemeanors and, unlike in the past, they quickly impounded non-complying vehicles. One day, her driver told her that the police had impounded her taxi, so she went to the magistrate's court to get it back. Although Ingrid speaks English very well, she expected that the white magistrate would be more likely to return the vehicle if she conformed to the stereotype of a poorly educated, nonEnglish speaking black township woman. She decided to go to the court barefoot and dressed in shabby clothes, acting like she had no idea what had happened. So, in heavily Xhosa-accented English she explained to the magistrate how poor she was and how much she was suffering. "I sufara!" (I suffer!) she cried. Ingrid's husband, who had accompanied her, was very embarrassed but remained quiet. The charade worked. The magistrate was convinced that she had acted in good faith and returned the vehicle without charging a fine.

These types of maneuvers offered only partial relief to a difficult situation. The Recap put financial pressure on taxi owners and affected ties within their associations. Apparently, the Recap strengthened dependence 
on taxi associations and contributed to the criminalization of the industry. In 2005 , an inquiry committee examined the continued taxi violence in Cape Town and reported its findings to the premier (Ntsebeza 2005). They revealed that taxi associations had become more powerful and more unlawful than before, being run like a mafia by warlords. The money they had collected over the previous years for social security had now become a war chest. The warlords used the money to hire hitmen, paying up to RI2,000 for a single contract. They used the money to bribe police officers into making incriminating evidence disappear. They paid for legal fees, ammunition, and spiritual protection provided by traditional healers. Whatever money remained went into their pockets. The inquiry committee also listed a wide range of accusations against the licensing board responsible for providing taxi permits. The board members were accused of accepting bribes and of making personal gains from their close cooperation with the warlords. The taxi associations also formed their own hit squads by recruiting former soldiers. Former ANC soldiers went to work for the ANC-aligned Codeta, and former PAC-aligned soldiers worked for CATA. Furthermore, the warlords demanded money from taxi owners to supplement their war chests. The owners had to pay a "joining fee" of anywhere between RI0,000 and R60,000, plus a monthly fee of RI,000, RI00 every Monday and Wednesday, and a daily fee of Rio. All of these fees had to be paid per vehicle. The inquiry committee uncovered what they described as a "culture of fear." People were reluctant to testify, despite being guaranteed anonymity. One of the men who testified before the committee was murdered soon afterwards, prompting the committee to suggest it was because of his testimony and making people even more reluctant to talk (Ntsebeza 2005). It would be an understatement to say that the Recap did not fulfill its promise. Taxi owners were straddled with heavy financial burdens, and taxi associations had become powerful brokers between financial companies, car dealers, government agencies, and dependent taxi owners.

In 2005 and 2006, several people were killed as the result of a taxi feud in Kraaifontein, and in 2007 there were fights between CATA and Codeta over the Bellville-Kraaifontein route, with the ANC being accused of siding with Codeta (Farber 2007). There was a shoot-out between taxi drivers in Bellville in 2009, and in August 2010 two taxi drivers were murdered in Nyanga. By the end of 2OI3, taxi-related killings had escalated into the temporary closure of the Bellville taxi rank (see Mtyala 20I3; Sibanda 20I3). Although the taxi world today is not as violent as it was in the I990s, there are still regular fights produced 
by the shifting relationships between and within taxi associations, the changing transportation market, and the consequences of new transportation policies introduced by the state.

\section{Making new inequalities}

In 2006, new government policies led to what government referred to as the rationalization of public transport, which further marginalized the taxi industry. The South African National Department of Transport started the Bus Rapid Transit (BRT), a network of bus services that would use major city routes. Once the BRT was implemented, taxis were no longer allowed to drive on highways or other major routes (Schalekamp et al. 20I0; Schalekamp and Behrens 20I0; see also Zuma 2009). This made the BRT a source of severe tensions and violent conflicts in Cape Town. Taxi owners, who had been forced by the Recap to invest in new vehicles and pay substantive costs for insurance and credit products, protested that now their routes were taken away. The ten ensuing years saw numerous violent acts such as damaging buses, sabotaging trains, and intimidating politicians involved in implementing the BRT (see Bähre 2OI4). The BRT also fueled tensions between the taxi associations and among association members. The minibus taxis worried about being barred from the major routes because of the BRT buses, and the "cockroaches" worried about the minibus taxis invading their township routes. In 2013 , several taxi owners were killed in a fight over these routes in Old Crossroads. ${ }^{14}$

The irony of insurance becomes clear when one examines the unintended consequences of financialization in the taxi industry. The government stimulated insurance and credit in order to rationalize the taxi business, break up taxi associations, promote individual entrepreneurship, pacify the industry, make the taxi world more profitable for taxi owners, and formalize the industry in order to have more control. However, the implementation of these policies brought very different results. Rather than breaking up taxi associations, their leadership was strengthened. Instead of the taxi world becoming more peaceful, new financial resources introduced new forms of power and conflict that caused more violence. Instead of having more profit, taxi owners were excessively burdened by debt and the high costs of insurance policies that did not always deliver what they promised. The general impression was that the government was unsuccessful in its quest to regulate the taxi industry. 
In fact, insurance became a risk. The government attempted to gain control over a business sector and forms of solidarity that were deeply rooted in the struggle against apartheid. In the end, their strategies reproduced and continued that same violence. Thus, although financialization reduced some insurance risks, it caused the proliferation of new risks.

The financialization of the taxi industry led to what I call a trickleup economy (Bähre 20I4). Trickle-down economics, also dubbed "Reaganomics," claims that cutting taxes and reducing welfare helps low-income people. In other words, the money of the wealthy eventually trickles down to the poor. I use the concept of trickle-up economics to conceptualize how South African taxi owners find themselves in a reversed situation where they, the poor, support the wealthy. Over the past twenty years, taxi association members have provided substantial economic resources for: the state through taxes, licenses, and fines; for law enforcement officers through bribes; for taxi warlords through membership and protection fees; for banks through forced credit; for insurance companies through obligatory policies; and for car manufacturers and dealers through required vehicle replacement.

The trickle-up economy is an everyday reality in South Africa, not a model like the trickle-down economy. The mutual relations that make up the taxi associations offer free labor - collecting money at taxi ranks, for example - and control the market. It is impossible to run a taxi business without being a member of an association. The so-called "pirates" who try risk being killed. The taxi associations have become aggressive protection rackets mobilized by profit at the expense of drivers and owners.

A trickle-up economy relies on the dialectics of market and community, as well as on hybrid forms of formality and informality (on this point, see Bayart 1993; Hart 1973; Gudeman 2009; Reno I995). It means that formal financial companies and government agencies often cooperate with informal and even criminal associations. ${ }^{15}$ The South African government cooperates with criminal taxi associations sometimes out of convenience, sometimes as part of corruption schemes, and sometimes out of fear. Businesses equally rely on violent association leaders. Banks, insurers, car manufacturers, and car dealers cooperate with untrustworthy taxi association leaders because they want to sell their products to the thousands of members they represent. The fact that formal businesses and government institutions depend on solidarity with informal networks and illegal practices is a key characteristic of trickle-up economics (see also Bähre 20I 2, 20I4). Moreover, 
a trickle-up economy goes hand-in-hand with strong economic interventions imposed by the state. Clearly the government's Recap policies were profitable for the financial sector, car manufacturers, taxi warlords like Mr. Bata, and government revenue. However, they did not pacify the taxi industry as intended. Economic inequality and violence still permeate South African society, forcing taxi owners to make a living in extremely precarious circumstances. Thus, insurance, which should ideally offer security and enable a market that is key to people's livelihoods, in fact introduced new insecurities, supported violent taxi association leaders, and fostered greater economic marginalization. 


\section{8}

\section{Death as moral hazard}

\section{Introduction: care and conflict}

Life insurance is an unusual type of insurance. ${ }^{1}$ Most insurance policies compensate a person that suffers a loss. For example, someone whose insured cell phone is stolen can file a claim with the insurance company, which might then give compensation in cash to purchase another cell phone and thus mitigate the loss. Life insurance works differently. When a claim is made, it means an insured life has ended and, rather than the insurance company transferring money to the policyholder, compensation goes to others, usually family members. Life insurance involves a company that sells policies, policyholders who pay the premiums, insured lives whose deaths will be compensated, and beneficiaries. The fact that a life is insured - rather than an object like a cell phone or car, or a product like debt - makes life insurance a financial product that is intrinsically relational.

This brings specific moral hazards. The Concise Encyclopedia of Economics defines moral hazard as follows:" "Once insured, an individual has less incentive to avoid the risk of a bad outcome." Thus, in the same way life insurance is relational, so is the incentive to avoid certain risks. When life is insured, death seems more likely, which leads to moral hazards. Although insurance policies are intended to compensate risks, a policy can simultaneously become a risk in and of itself. This was a major concern for the clients living in the Cape Flats. For example, when Benjamin died, his family blamed his wife, Linda. They were convinced that she had killed Benjamin to cash in on his life insurance. Benjamin's parents and siblings were angry and did not want Linda to profit from his death. They forced her to go to an ATM and withdraw what they understood to be their money. When she refused to enter her pin code, they beat her until she gave in and withdrew the RIO,००० they demanded (see also Bähre 2007, I64).

Funerals and associated practices such as wakes, mourning rituals, and ancestral rituals are vital to understanding kinship relations. While funerals reflect kinship relations, they also potentially transform them because they confront people with mortality and new cosmological, economic, and emotional challenges. Drawing on Handelman's (I998) work on rituals as models and mirrors, Niehaus (2013a) found 
that funeral rituals in the South African Lowveld presented a model of life that did not reflect how the deceased really lived. The speeches at the wakes and during the funeral, and the expenses that were incurred, established a dignity that had not always been acquired during life. Thus, the model that highlighted the dignity and respectability of the deceased inevitably contrasted sharply with lived life: "This contrast between the manner in which things 'should have been' and the manner in which 'they actually were' generates reflective thought and criticism both about the social structures that constrain people, and also about the moral failings of persons" (Niehaus 20I3a, 200-20I).

In both Cape Town and the Eastern Cape, I found that speeches made during funeral wakes emphasized how things should have been. Speakers went into great detail about the deceased's respectability, elevating them to nearly a saintly status. A method of inquiry that relied solely on speeches would surely convince the observer that the deceased was the most responsible, kind, helpful, and dignified neighbor, relative, or friend. But a more thorough analysis reveals that everyday funeral practices in fact re-enact the tensions that surround the limitations of care and the difficulty of living up to the moralities of everyday life (Bähre 2007, see also Golomski 20I8a).

This chapter explores the contrast between how life should have been and how it actually was in relation to funeral insurance. How do social relations change when insurance becomes part of funerals and funeralrelated events? What is the transformative potential of funeral insurance and how do the events that unfold after someone's death reveal what financialization means in the intimate realm of kinship? Funeral insurance, possibly more than any other type of insurance, highlights how global financial capital is connected to people's private life.

Funeral insurance enables care. The care is apparent when insurance is purchased before death, indicating a sense of responsibility for a future funeral, and after death, when the insurance money and services are used for conducting a dignified funeral. Thus, the care that funeral insurance enables contributes to organizing a funeral model of how life should have been. Golomski (2015, 2016, 2018a) argued along these lines when he examined funeral insurance in Swaziland. According to Golomski (2015), funeral insurance is a "compassion technology" because it facilitates care while simultaneously transforming gender relations among kin. His explorations of how people use funeral insurance in everyday life revealed how it facilitates care in the face of everyday poverty and violence.

In contrast Zelizer's (1978, I995) studies of funeral insurance in nineteenth-century USA and England exposed a different side of 
funeral insurance, namely that it can cause conflicts related to care and suspicions of abuse. Zelizer (1978, I995) showed how life insurance led to vigorous debates about the immorality of pricing life, especially the lives of children. There were theological concerns about equating life with money, in that God decides the value of a life. In addition to the sacrilegious aspect of life insurance, there were widespread rumors that it provided incentive to kill people, or at least neglect them to the point of death. Foster parents were thought to run so-called "baby farms" that purposefully neglected children:

Social critics denounced insurance as a "bounty on neglectual infanticide" ... Baby farmers, for whom the death of one of their children was already a pecuniary gain, made it doubly profitable by insuring the children they "adopted," often in more than one company. (Zelizer I995, II9)

Zelizer shows that people's concerns about life insurance provide a critical reflection and commentary on how capitalism changes values. For example, she states that capitalism changes people's moral perception of childhood by reducing children to a monetary value measured in terms of labor (Zelizer I995). ${ }^{3}$

An alternative to Zelizer's interpretation is that the concern about infanticide might be a moral discourse on how reproduction changes because of financialization. Life insurance was marketed at around the same time as future contracts that function as a kind of crop insurance. Both life insurance and future contracts were made possible because of new ways to statistically analyze risks. Farmers entering into a future contract are guaranteed a fixed price for their crops, irrespective of the actual yield. Hence, in cases of lost crops due to poor weather conditions, farmers are guaranteed a particular price. In other words, future contracts for farmers function as a type of weather insurance. Thus, along those same lines, the moral discourse on farming babies could have possibly been influenced by the introduction of this kind of crop insurance, which equates the financialization of risk with productivity in terms of farming and life itself. ${ }^{4} \mathrm{~A}$ detail that stands out and that points to the importance of reproduction - rather than production - in the moral discourse about life insurance, is that foster parents, not biological parents, were the ones being accused of baby farming. On the one hand, the fear of baby farming might indeed be about labor under capitalism, as Zelizer (I995) argued, but on the other hand, it could also be a discourse about how financialization transforms the reproduction of people, plants, and livestock. 
What does the nexus of life insurance and morality in South Africa look like, and what changed after life insurance became widely available in the townships of Cape Town? ${ }^{5}$ This chapter examines the profound moral impact that life insurance has on kinship relations. I will focus on moral hazards as enacted by clients and their kinship networks by exploring the ironic nature of life insurance. The irony here is that while life insurance facilitates kinship support, it also opens the door to allegations of selfishness and greed. Having life insurance means taking responsibility for providing a respectable funeral as well as leaving benefits for family members to prevent incurring high debts over funeral expenses. I will show that life insurance can also lead to fierce conflicts over perceived selfishness and concerns about insurance murder.

In order to understand the effects of life insurance on kinship, and to examine how life insurance affects kinship morality, I will compare life insurance with burial societies. Although life insurance and burial societies are organized differently, they both provide financial and material support after the death of a family member. Comparing people's experiences with burial societies and life insurance clarifies how kinship morality is changing, and to what extent these changes are the result of life insurance.

The stories, conversations, rumors, and statistical data that I compiled suggest that life insurance has significantly added to concerns about people benefiting from someone's death, commonly known as insurance murder. There are numerous rumors about parents killing their children, especially mothers killing their children. How do these rumors take shape, and what do they look like in concrete events?

\section{Making sure someone dies}

The survey among the residents of Indawo Yoxolo and Tembani included questions about the morality of funerals and death. These questions were to help discern the moral issues involved. Respondents were asked if they had seen someone taking advantage of another's funeral. The questions began with, "Did you see ...," followed by possibilities such as, "... someone pretending that someone is dead in order to get benefits." Rather than using "Have you heard about ..." or "Do you think ...," which would have opened space for rumors and suspicions, the questions were phrased to try to identify the respondents' knowledge of concrete events. Nonetheless, it must be acknowledged that specific wording might not be enough to draw a clear line between actual events and rumors. 
The responses to the survey questions revealed a prevailing concern about immoral behavior at funerals. More than four out of five respondents $(83$ percent $)$ said that they had seen people taking advantage of a funeral. Nearly as many ( 78 percent) said that they had seen this happen more than once a year. Furthermore, the responses indicated that insurance murder is fairly common. Nearly one in five respondents (I9 percent) stated that they had seen someone's death be caused in order to claim benefits, and I 5 percent affirmed that people pretended someone was dead so they could claim benefits. The survey results showed that funeral events are charged with suspicion about some people benefiting at the expense of others, even to the extent of killing someone for material gain. The survey also confirmed the pervasive concern that some individuals take out insurance policies on people that are expected to die soon. Three out of four respondents answered this question affirmatively.

Based on ethnographic evidence, the survey included questions to identify who takes advantage of funerals, distinguishing between the immoral behavior of kin and of strangers. The results showed that most believed a husband's family tried to make money from funerals more often than a wife's family (see Figure 8.I), which is in line with the gendered kinship tensions that have been examined in great detail elsewhere. ${ }^{7}$ The question about strangers gaining financially from funerals was based on a rumor I had heard a few times during fieldwork about

Figure 8.1 - Funerals: advantages taken

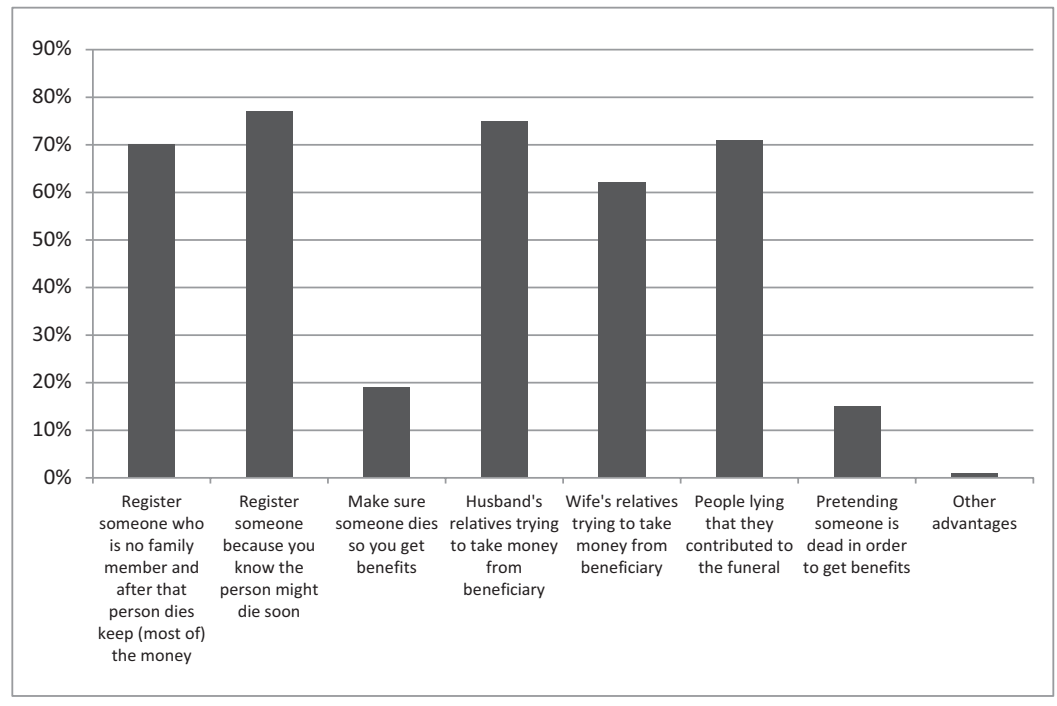


people taking out life insurance on strangers or almost strangers, albeit illegally. The survey revealed that people believe this is common, with 70 percent of the respondents saying that they in fact saw it.

These findings need to be interpreted within the context of everyday life in the townships of Cape Town. A life insurance policy is often worth more than three months' wages for residents of Indawo Yoxolo and Tembani, which at least partially explains the prevalent concerns about abusing death for personal gain. ${ }^{8}$

How does one interpret the responses? One way is to treat the advantages cited by the respondents as rumors that offer a window onto people's understanding of how capitalism, and financialization specifically, affects morality. The responses reveal that concerns about benefiting from funerals are deeply ingrained in kinship relations, and show how people evaluate the behavior of those with whom they have no relationship at all. But before turning to such a discursive approach to financialization and kinship, and in order to fully understand the responses to the survey questions, especially those that involve murder, it is crucial to contextualize a wider topology of violence.

As mentioned previously, the respondents live in one of the worlds' most dangerous places. Most crimes in Cape Town occur in the Cape Flats, in townships like Khayelitsha, Gugulethu, Nyanga, and Mitchells Plain (Manaliyo 2014, 597). According to the Organisation for Economic Co-operation and Development, Khayelitsha is the most dangerous area in South Africa (OECD 2008). In 20I4, a study by an NGO called Citizens' Council for Public Security and Criminal Justice identified Cape Town as the most violent city in Africa and one of the most dangerous places in the world (Everett 20I4). Even so, these statistics must be treated with caution, because not all crimes are recorded properly, and even murders are sometimes not registered in crime statistics.

Therefore, the levels of violence in Indawo Yoxolo and Tembani and the anxieties that violence brings must be taken into consideration to make sense of the survey findings and ethnographic evidence. It is common for people living in the Cape Flats to have known someone who was killed by a family member. Going to funerals of people that had been beaten to death in a bar fight, killed on their way to the local train station or bus stop, or who committed suicide because they could no longer cope with life is a cruel and sad part of their everyday lives. I myself have attended several such funerals.

Most respondents had likely experienced or witnessed some form of assault or murder, some of them even having been perpetrators. When we identify something in a discourse we create an interpretative space 
that suggests what people see, believe, and experience is not reality, or that reality becomes that which people see, believe, and experience, thus implying that there is no objectifiable reality outside the discourse. Such an approach could argue that insurance offers a discursive space for critical comment on the structural violence of global capitalism, even when it is not seen as such. However, a discursive approach has a patronizing side that suggests the anthropologists know better and can either see reality for what it really is, or that it is irrelevant to speak of events in terms of "reality" because they are all discourses. Nonetheless, it would be unwise to take a naïve empiricist position when studying violence. This is why the study of pain and suffering that escapes language - and thus the social constructivist aspect of language as a set of cultural symbols - is so important (see Das I998; Hastrup I993, I995; Samuels 20I 5). ${ }^{9}$ Everyday life in the Cape Flats could very well be like the survey respondents say it is, a situation where "violence becomes so embedded into the fabric of the social that it becomes indistinguishable from the social" (Das 2010, 303).

\section{It's nothing personal}

People are concerned about situations where strangers or distant acquaintances take out life insurance policies on someone, and then kill them or fake their death to benefit from the insurance. This topic came up sporadically during our conversations. Actuaries and other insurance professionals told me that because African clients were poorly educated, they were not aware that it is illegal to take out life insurance on someone in whom there is no vested interest. Thus they took out insurance policies on anyone, including strangers. The insurance professionals realized that it was their responsibility to make sure this did not happen, but blamed the so-called "fly by night" companies that ignored legal limitations.

However, to the African clients the issue was moral rather than legal. My conversations with them clearly showed that they believed it was immoral to buy life insurance policies on strangers, whether they were aware of the law or not. Some people told me they had foreseen this problem. Others told me that even insurance salespeople sometimes took out policies on clients without their knowledge. After selling insurance policies to a client, agents would add another life insurance policy to the paperwork that named themselves as the beneficiary. Then, after a few months, they would kill the client and claim life insurance benefits from the very insurance company for which they worked. Another 
version said that instead of killing the client, the insurance agent would kill a stranger and use the body to claim the life insurance. To ensure that their murder scam was not discovered, perpetrators hid the identity of the corpse by cutting off the hands, making it impossible to get finger prints.

The mutilation of the body and the removal of body parts features strongly in witchcraft discourses (see Niehaus 2000). I had been told that body parts, including hands, were used for witchcraft medicine or charms. A recurring story was about a shop owner who ran a small spaza shop in one of the townships of Cape Town. Business was not going well, so the owner paid a traditional healer (igqirha), who was also a witch, to help him get more customers. To solve the shop owner's problem, the witch needed a carpenter. So he followed one to a tavern, and later, when the drunk carpenter left the tavern, the traditional healer killed him, cut off his hands, and buried them under the shop floor. As a result, the shop became much more profitable and drew large amounts of customers. The explanation for this success was the carpenter's talented hands that were helping the store prosper. In other words, specific body parts are the material manifestations of specific skills and powers.

Stories of strangers committing insurance murder are quite common in South African media. Journalists have reported that insurance companies were forced to scale up their fraud investigation units because of the high insurance murder rates. Peter Kerford, head of investigations at MMI Holdings, a South African financial service provider that works for the insurance companies Momentum and Metropolitan, and is listed on the Johannesburg stock exchange, testified in court: "When I started in the forensics division ten years ago we were four people in my department. I now run a team of eighteen investigators" (Oellermann 20I3).

The media also reported that the police have seen an upsurge in the number of insurance murders: "In just six months, they [the KwaZuluNatal Police] have uncovered thirty-five murders suspected to be linked to insurance fraud" (SABC 20I4). Let us examine a few of the insurance murders that have been reported in the news.

In 201 I, the Cape High Court convicted Vuyisile Ndzumeka and his wife Yalezwa of insurance murder. The couple had taken out life insurance on five people and then ordered a hitman to kill them. Bongani Dingana, one of the five, was shot several times but survived the attack. Later, the hitman tried to kill him again and was successful. The couple paid the hitman and were able to claim RI20,000 from the life insurance company. Vuyisile was the financial administrator of a school in 
New Crossroads, a Cape Flats township. His boss, the school principal, suspected Vuyisile of having committed fraud. So, in an attempt to discover possible financial irregularities, the principal ordered an investigation. To stop the investigation, Vuyisile hired the same hitman to kill his boss. In 20I2, the court sentenced the couple and the hitman to a total of five life sentences (Nombembe 20I 2; Phaliso 20II; SAPA 2OI2). Upon hearing the court's verdict, the school principal's sister inlaw "was shocked that the man [Vuyisile] who conducted the choir at the memorial service had orchestrated the murder" (Nombembe 20I2).

In 20I 5, the Durban Commercial Crime Unit arrested five people for setting up a life insurance scam worth RI million (Hlophe 20I5; Wicks 20I5). Maningi Mkhize had stolen Modnli Dube's identity document and then persuaded an accomplice to phone an insurance company posing as Mr. Dube. They took out a life insurance on $\mathrm{Mr}$. Dube's life with Mrs. Mkhize as the beneficiary. Mrs. Mkhize paid the $\mathrm{R}_{3}$ I9 monthly insurance premium for half a year and then decided she wanted to claim the benefits. But to do so, she needed to prove Mr. Dube was dead. Mrs. Mkhize contacted a woman who worked at the King Edward VIII hospital mortuary to get a corpse that could be identified as Mr. Dube. The woman later testified in court that they used the corpse of an unidentifiable man who had died in a car accident to fake the death. Mrs. Mkhize paid the mortuary employee Rı০,০০০ for her help. However, a death certificate stating that the deceased was Mr. Dube was also needed. So Mrs. Mkhize and a friend, whose surname was also Dube, went to the morgue posing as the deceased's siblings. In return for his help, Mrs. Mkhize promised R200,000, of which she only paid him R20,000. At the morgue, they presented the real Mr. Dube's stolen identity document, and thus were able to identify the body.

Once the body was identified, Mrs. Mkhize and her friend organized a funeral for Mr. Dube. Although cremation is regarded as extremely disrespectful to the deceased and as neglecting familial duties, they cremated the body in the hopes of concealing further evidence of their scam. However, the police were informed before the funeral, and they arrested Mrs. Mkhize and her four accomplices. In court, all five pleaded guilty of fraud and were released on a R2,000 bail (Hlophe 20I 5; Wicks 2015).

What is striking in these cases is the extent to which people go to claim life insurance. This clearly conveys how precarious life can be. It also shows how ruthless and entrepreneurial criminals can be, going to great lengths to mutilate, kill, and deny people a respectable burial for money. These events and stories imply that when there is no relationship between people, even the most fundamental human values can be ignored. 
I would argue that the stories, rumors, and court cases about the ruthlessness of unknown people are a direct consequence of life insurance. Increased life insurance marketing and availability heightens people's fear of strangers, of those with whom they have no personal relationship. Specifically in insurance fraud and murder, there is no significant relationship between the criminal and the victim. Vuyisile, who ordered the killing of his boss, was trying to conceal fraud at work, not claim life insurance.

The impersonal relationship between criminal and victim mirrors the impersonal relations of life insurance, which encompasses the Weberian ideal of bureaucratic and abstract financial arrangements that are neither burdened nor restricted by personal ties. Insurance crimes, both real and imagined, are enabled by the invisibility of money and the abstract relations between beneficiaries and deceased. The importance of impersonality and abstraction becomes particularly clear when contrasting life insurance with burial societies. Burial societies are fairly public social networks that are strongly embedded in neighborhood life. Everyone can see who goes to the burial society, who pays how much money, and who makes which claim. These social relations are both fundamental and burdensome to the functioning of burial societies. In contrast, these forms of social oversight are absent in insurance. Insurance companies do not hold public meetings where people can see who the clients are, how much they pay and claim, and on whose life they take a life insurance policy. Social relations are irrelevant when claiming insurance benefits, and clients usually have to deal with abstract, bureaucratic, and sometimes Kafkaesque procedures. The irony of abstraction and impersonal relations is that, on the one hand it frees people from social obligations, but on the other it enables new forms of crime. Life insurance makes people afraid and suspicious that strangers can benefit financially, sometimes quite significantly, from their death.

One key aspect of life insurance is that while the contract is abstract and impersonal, the product is relational in that it compensates the loss of someone's life. The absence of sociality in the contract is one of the great attractions of life insurance because it is a way to compensate loss without having to rely on reciprocal relations that can be highly unequal, time consuming, and burdensome because of the social dynamics that are involved. Nonetheless, the invisibility of the contract and the fact that it is placed outside social domains is fertile ground for spawning rumors. It creates ample space for speculation about who might have taken out what life insurance on whose life. Who will benefit from someone's death? 


\section{Immoral kin, especially parents}

Tensions in kinship relations are not new and cannot be attributed to life insurance alone. Inheritance issues along with material and financial support from burial societies also generate similar suspicions and accusations, as does the friction over kinship support in everyday life that is unrelated to death. Therefore, in order to understand how life insurance realigns kinship relations, and whether life insurance generates particular tensions over money and care among kin, life insurance must be contextualized within kinship, especially the care arrangements that are mobilized after the death of a family member. It is important to understand that kinship relations are fraught with tensions over care and are rooted in an apartheid history that was significantly transformative and disruptive. ${ }^{10}$

There have been several high-profile insurance murder cases that involve family members. Some insurance murder cases have led to convictions. For example, in 1986, in Guguletu, Cape Town, Lindi Mangaliso hired two assassins to enter her home and kill her husband, a wealthy and abusive business man. Subsequently, Lindi tried to claim $\mathrm{R}_{500,000}$ from the life insurance company, but was discovered and sentenced to twenty years in prison (Marsh I99I). More recently, in 20I4, Fifiso Hlongwane's body was found in a sugarcane field. According to the police, Fifiso's brother and mother had taken out an RII million life insurance policy on Fifiso, with the mother as the beneficiary. The police and the insurance company suspected insurance fraud and possible murder. Phone records showed that the insurance policy had been purchased only two months before Fifiso's death by the brother, who had impersonated Fifiso (Sanpath $2015)$. In 2015 , there was another high-profile insurance murder of a well-known former anti-apartheid activist and businessman. His wife, Thandi Maqubela, had called an insurance company called Liberty Life only a few weeks prior to her husband's death to enquire about the status of his R2O million life insurance policy, of which she was the beneficiary. The court sentenced her to eighteen years in prison for murder (Davis 2015; Nombembe 2015). ${ }^{11}$

In contrast, the clients that I met in the townships of Cape Town were not public figures and rarely took out such large life insurance policies. Their stories and experiences did not make news. More importantly, insurance companies did not investigate or follow up on fraud suspicions or even murder in the townships because, as actuaries told me, the claims were too low and investigations expensive. I was told that 
companies would either grant small claims or simply turn them down, in which case it was up to the claimant to challenge the decision.

However, what insurance companies consider a small amount is a lot of money for Indawo Yoxolo or Tembani clients. For them, a "small" life insurance claim could be equivalent to three months' wages or more. Thus, for them it was a worthwhile endeavor to find out what happened to the money, how it was distributed within kinship networks, and to identify the risks involved in receiving money upon the death of a family member. Below I will examine concrete cases of how life insurance is talked about and experienced within kinship networks after someone's death.

\section{Jama's death}

Grace lived in a small, $3 \times 3$ meter shack in the township Nyanga East with her two children, the oldest already a teenager. She was employed as a domestic worker and told me that the flexible working hours make it easier to take care of her children. Grace had a brother, Jama, from the same mother but different father. Jama lived in Delft where he shared a small house with his girlfriend and their thirteen-year-old son. Although he lived nearby (about Io km), Grace did not know much about Jama's life. She said he was a very quiet man, even secretive. Once a neighbor had asked her what Jama did for a living, and she realized she did not know. Later she found out through another neighbor who had seen him in uniform at The Company's Garden, a park in the city center, that he worked as a security guard.

One day Jama had to be hospitalized because doctors had discovered, according to Grace, that there was something wrong with the blood in his brain. A few days later he died. Grace suspected that her brother's death was not due to natural causes. She thinks that Jama's father and Bonelwa, his sister from the same father, had something to with it. Jama's father lived in the Eastern Cape and when he heard about his son's death he went to Cape Town to claim his son's body and take it to be buried in the Eastern Cape. Grace was very angry about that. She said Jama's father had never looked after his son, and now that he was dead he had suddenly taken an interest. Grace was convinced that Jama's sister Bonelwa had organized this. In spite of Grace's objections, Jama's father took the body to be buried in the Eastern Cape. Initially, Grace did not want to go to the funeral, but eventually she gave in to her family's pressure and went.

According to Grace, the funeral was poorly organized. "Jama did not get the respect that he deserved. His father only wanted to organize 
the funeral so he could claim money from the insurance company and the burial society." It had been difficult for Grace to go to the funeral and contribute financially to the funeral costs. Grace did not have life insurance (although she was considering it) and her burial society membership did not entitle her to money for her brother's funeral. Somehow, which remains unclear to me, she managed to withdraw money from Jama's bank account to pay for her trip to the Eastern Cape and make a substantial contribution to the funeral. Grace did not want to say how much she had withdrawn from Jama's account or how much she had contributed to his funeral.

Grace was also angry that Bonelwa had gone to Jama's home in Delft and told his son he could choose only one item from the house for himself, while she kept the DVD player, television, and stereo set for herself. Additionally, Grace said another of Bonelwa's sisters had evicted Jama's son and girlfriend from the house so she could move in.

Grace was very upset that Jama's girlfriend and son were left with no money from the insurance policy, no home, no furniture, and no cooking utensils. Yet she felt she did nothing wrong when she withdrew money from Jama's bank account. Grace did not want to be involved with family anymore. "Fuck them!" she said aggressively. It was possible that Grace's anger at her family was reinforced by feelings of guilt for not having supported Jama's girlfriend and son, and for having withdrawn Jama's money. She described a recent dream where Jama visited her and reassured her that she was not to blame and that she should not feel guilty because he knew she was not responsible for what had happened. The dream brought Grace a strong sense of relief.

In a patrilineal society, it is expected that a son be buried with his paternal ancestors, thus making it logical for Jama to be buried near his father's house. However, Grace argued that Jama's father could not claim these parental rights because he had failed to take care of his son. Although Grace believed Jama's father had buried him in the Eastern Cape so he could claim Jama's life insurance, the place of burial is not relevant to the issue.

Thus, it would seem that life insurance offers the opportunity to construct a discourse about the immorality of fatherhood without it being the direct cause. Maybe it was more palpable for Grace to use life insurance to tell me about disrupted kinship ties and the inability or unwillingness to care for children and siblings. Although life insurance could not have been the motivation for Jama's father to bury his son in the Eastern Cape, it did feature strongly in her discourse about immorality, even suggesting that it might have caused Jama's death. ${ }^{12}$ While speeches at wakes and funerals depict model lives (how things should 
have been), the practices and conversations that surround life insurance mirror how complex kinship relations actually are.

\section{Mphilo's death: "Why encourage a witch to kill people?"}

Mphilo's death placed concerns about life insurance and insurance claims at the heart of kinship dynamics. It also raised the question of causality. To what extent are the tensions that emerge within kinships related to life insurance marketing? Or should one not be too quick to attribute these tensions to life insurance policies alone? It is theoretically unsound to automatically assume that the kinship tensions that followed Mphilo's death were caused by financialization. It is also possible that the tensions were not caused by insurance alone. To address such issues, a detailed description of the events and rumors that followed Mphilo's death can help contextualize life insurance within the broader dynamics of kinship.

Mphilo and his brother worked and lived at a brick factory in Cape Town. One evening, a fire broke out at the factory. Mphilo's brother managed to escape, but Mphilo did not survive. Rumor had it that Mphilo had been drinking - he was known to have a drinking problem - and had been too drunk to escape.

Yonela, married to Mphilo's son, also lived in Cape Town. Mphilo's sister Nobomi called to tell her about her father-in-law's tragic death. Because Yonela lived close by and had a reputation of being a good organizer, Nobomi asked her to help arrange the funeral.

Yonela agreed reluctantly because she did not get along with her father-in-law's sister, which is a strong feature of the relationship that women generally have with in-laws. ${ }^{13}$ Yonela had also had some bad experiences with Nobomi. A few years before Mphilo died, Nobomi had asked Yonela and her husband to join a burial society that she had set up. Nobomi tried to convince them saying their membership would make the burial society more trustworthy and thus easier to convince other people to join. She also said she regarded Yonela and her husband as her own children and cared deeply for them. They could join the burial society without paying the Rıoo joining fee, a typical single payment (see Bähre 2007). Nobomi even offered to give them money if they joined. However, Yonela and her husband decided not to join the burial society because they were worried that Nobomi might then kill Yonela to cash in on the money, or would take out a life insurance policy on her. Yonela interpreted Nobomi's care as hostile, self-interested, and even life-threatening. The fact that Nobomi said Yonela and her husband were like her own children was understood as a threat rather than a comfort. 
Although they had declined Nobomi's offer, both Yonela and her husband were worried she would enroll them anyway, without their consent. So they went to a meeting of the burial society to find out. Their suspicions were confirmed; Nobomi had indeed registered them as members. In front of about twenty members, Yonela demanded that their names be taken from the society's books. This was highly embarrassing for Nobomi and was a very clear display of distrust in front of other people. She replied saying they had no reason to worry, emphasizing that the burial society was set up to help one another. She wanted Yonela and her husband to join because she cared so much for them and because she had hoped Yonela, who was better educated than her, could help with the bookkeeping.

Yonela did not believe her, and said: "If I find out about my name in the books I will deal with you legally!" Furthermore, Yonela did not like the environment at the meeting because people were drinking alcohol. This was highly unusual and people generally agreed that burial society affairs were too serious for alcohol. After the confrontation between Yonela and Nobomi, several members left the burial society.

Nobomi later paid a visit to Yonela and her husband and told them that she was upset with their behavior. She again emphasized how they needed each other for "when something happens," a clear reference to death. She accused Yonela of being arrogant and of trying to destroy the organization she set up, saying: "You act like white people. Your husband cooks. He bakes in the oven. He eats biscuits!"

After this incident Nobomi kept interfering in Yonela's life. She asked her to help with her daughter's marital problems, and insisted that Yonela and her husband would have an expensive wedding. Yonela and her husband had married under South African law but had never married under customary law and never had a wedding ceremony. Nobomi was upset when she found out that they had opted for a civil marriage that only involved a small ceremony at the offices of the department of home affairs and that did not involve any guests.

In helping with Mphilo's funeral, Yonela contacted his burial society and was told that he had missed some payments. The burial society's rules about this were clear and they refused to assist with the funeral. Yonela relayed this information to Nobomi, who said that she would help solve the problem. She offered a contribution of RI, $\mathrm{R}$ oo and two sheep to be cooked as a meal for the visitors. Yonela didn't believe her donation of two sheep was sincere: "Nobomi knows that we are prohibited from slaughtering sheep at the funeral of someone who died in an accident." She was also suspicions of the $\mathrm{R}_{\mathrm{I}}, 000$ donation, thinking it was too much for Nobomi's income and given the fact that she had 
not been very close to the deceased. Her suspicions deepened when Nobomi asked for a copy of Mphilo's death certificate. Yonela refused to give her a copy and to take the RI, 000 .

Yonela continued helping with the organization of the funeral by collecting money and arranging the transportation of the body from Cape Town to Bedford, a small town on the southern slopes of the Winterberg mountains in the Eastern Cape, about $900 \mathrm{~km}$ from Cape Town. Yonela and her husband attended the funeral and noticed that Nobomi was there as well. Once the funeral rituals were completed, Yonela paid a visit to another of Mphilo's sisters and gave her around $\mathrm{R}_{5} 00$ for the funeral. This sister also gave her a copy of the death certificate. Most family members greatly appreciated Nobomi's help.

However, Yonela continued to interpret Nobomi's help as insincere. She claimed to have heard that Nobomi is normally not generous at all. She also said there were rumors that Nobomi had taken out a life insurance policy on a woman that suffered from mental problems, and after the woman died, Nobomi contributed RI, $\mathrm{R}_{\mathrm{I}}$ to the funeral costs and asked for a copy of the death certificate. Yonela was convinced that she needed the death certificate to claim insurance benefits of RIO,००० or more, and that Nobomi had caused the woman's death by bewitching her.

One year after Mphilo's funeral, Yonela's maternal grandmother died. Nobomi went to see Yonela and offer her condolences. She also said she wanted to contribute R2,000 to the funeral costs. This was an unusually large contribution, when Rıoo or less would have been acceptable. The offer made Yonela suspicious of Nobomi's motives, especially when she asked for a copy of the death certificate. Yonela felt Nobomi's actions were immoral, and so did not accept the money and refused to give her a copy of the death certificate. Yonela explained her decision to me: "Why encourage a witch to kill people? We could do without her help." Yonela had no doubt that Nobomi had taken out an insurance policy on her grandmother's life and was trying to profit from her death.

Although things like that do happen, it seems unlikely that Nobomi would have had access to the personal details of Yonela's grandmother (i.e. Nobomi's brother's son's wife's mother's mother!), which she would have needed in order to purchase a policy. My impression was that other dynamics were at play. Dynamics deeply and structurally rooted in kinship relations that were immoral. Yonela was extremely wary of any form of generosity and support from Nobomi, and made strong allegations against her. She was convinced that her show of support in fact hid personal interests and could not accept that her support 
was possibly genuine. She suspected Nobomi of being a witch and of having killed at least one person through witchcraft.

These affinal tensions are not new and are deeply embedded in patriarchal kinship relations. Therefore, one should be cautious when attributing these tensions to financialization alone, even when insurance policies have an important place. When I did fieldwork in Indawo Yoxolo in the I990s, there were similar tensions between in-laws, yet insurance policies were not readily available (Bähre 2007, 2002). Years later, however, life insurance became part of the explanations for these tensions, featuring prominently in the discourse about what constitutes moral behavior. An important change is that life insurance brings much more cash than other forms of mutual support like burial societies, thus increasing the stakes people have in funerals and kinship relations. The quantity of money matters to how people evaluate relationships and to what extent someone's gift signifies utility or compassion. In other words, the larger the gifts, the more likely the givers are perceived as self-interested and insincere. A RIo० gift is an appropriate expression of care and compassion, while $\mathrm{R} 2,000$ is seen as an aggressive attempt to hide the giver's self-interest. ${ }^{14}$

Equally relevant to these suspicions is the fact that life insurance renders the relationship between the insured and the beneficiary invisible. It is written out in a private contract between policy holder and insurance company, which is not socially embedded. This socially invisible relationship creates a new space for fomenting spectacular rumors and suspicions between already tense kin. Thus, the irony on the one hand is that abstract and impersonal insurance policies free people from pressing social obligations, especially among neighbors, and the money facilitates care of others, especially kin. Yet on the other hand, abstraction and invisibility serve to intensify suspicions and accusations. Life insurance makes it possible to imagine and possess heretofore inconceivable benefits and beneficiaries.

\section{Beauty's stealing daughter}

Life insurance seems to especially affect the dynamics between mothers and daughters. Beauty was Yonela's older sister. When she died, her daughter Mandisa was accused of using life insurance to profit from her mother's death. This goes against the idea that life insurance policies help children finance a decent funeral for their parents. It is equally contrary to the idea that tensions within kinship are primarily affinal, and have no place in the close and caring bond between parents and children, especially mothers and their children. 
Beauty was diagnosed with throat cancer when she was in her late forties. After the diagnosis, she was admitted to the hospital in her hometown of Cathcart in the Eastern Cape Province for surgery. The operation did not successfully remove the cancer, and had been very painful and traumatic for Beauty. She told everyone: "I do not want to go through this hospital experience again. Just let me die." She in fact died not long after, and Yonela and Beauty's four other siblings helped organize the funeral and contributed RI,500 each. They thought it would be a nice gesture to spend the money on a beautiful coffin, so they informed the rest of the family that those costs had been taken care of. Before she left Cape Town for the funeral, Yonela went to the Pick $\mathrm{n}$ Pay supermarket and bought beans, flour, butter, and a large quantity of other produce to prepare the meal for those who would attend the funeral. She bought everything except vegetables and meat, thinking it would be easier and cheaper to buy that in Cathcart.

Yonela also called Beauty's daughter. Mandisa was a young woman in her twenties still living in her mother's home, mostly because of financial constraints that had made it impossible to live on her own. Yonela asked her for Beauty's ID number and explained that she wanted to find out if Beauty had any life insurance policies. She said relatives of the deceased often failed to claim insurance money because they were unaware of existing policies, which Yonela wanted to prevent. Mandisa said she did not have her mother's ID number and had no idea where it was. Yonela did not believe her because they had lived in the same house. Additionally, she knew a doctor had issued a death certificate, which always includes the ID number of the deceased.

Yonela left for Cathcart in the early evening and drove through the night, arriving early the next morning. Before meeting her family, Yonela visited the undertaker in charge of Beauty's funeral and asked whether he knew if Beauty had any life insurance. The undertaker confirmed that indeed there was a policy, and that Yonela need not worry about funeral costs. He had already made the financial arrangements with Mandisa. The policy was worth RIO,००० and the undertaker and Mandisa had agreed to use it to buy a coffin and to cover other minor costs. Whatever was left of the RIo,००० would go into Mandisa's bank account.

The meeting with the undertaker upset Yonela. Mandisa knew that she and her siblings had already collected $R_{7}, 500$ for Beauty's coffin, so there was no reason to use the insurance money for a coffin. Yonela was convinced that Mandisa was trying to hide the fact that the coffin was paid for so she could keep the $\mathrm{R}_{7,500}$ for herself. She was also certain that Mandisa would secretly keep whatever was 
left of the RIo,000 insurance policy. During her time in Cathcart, Yonela stayed in Beauty's house with Mandisa. Yonela unloaded the food she had brought from Cape Town, telling Mandisa she brought it especially for the guests that would attend the meal after Beauty's funeral. Yonela was later horrified when she caught Mandisa stealing parcels of food and hiding them in the small attic of the house. Mandisa told Yonela that she was not stealing the food because she was entitled to it. She did not want to use it for her mother's funeral service: "These people [that attended the funeral] are not worthy of eating all this food."

Beauty's illness and death left Mandisa in a difficult emotional and economic situation. In addition to grieving her mother's death, Mandisa must have felt insecure about the future, since she had depended on Beauty's income, and uncertain whether she could remain in the house now that her mother was gone. It was possible that Mandisa had tried to hide the insurance money and take the food because she did not know how she would survive without employment in one of South Africa's most impoverished regions. At the same time, Yonela accused Mandisa of abusing her mother's funeral. Central to the accusation was the invisibility of the life insurance policy. She had to make an effort to uncover it, which she then believed revealed Mandisa's selfishness and disregard towards her mother and her mother's siblings.

Yonela's cold and unsympathetic stance towards Mandisa and the emotional and financial predicament that Mandisa must have been facing exposes a certain disengagement. In other words, dire economic situations like the ones Mandisa, Yonela, and other family members found themselves in form a barrier to sincere involvement and kindness. Disengagement is one of the characteristics of life insurance in that it is organized bureaucratically and largely outside the social relations that make up care and compassion. Even the intimate bond between mother and child is subjugated to the hidden self-interest of a life insurance payment.

\section{A murdering mother}

More life insurance conflicts connected to Yonela erupted after Zukile died. Zukile's girlfriend, Tembi, was Yonela's great-niece. The couple and their son lived in a small home without electricity. One day, Zukile tried to illegally connect his house to the city's electricity grid and was electrocuted and immediately killed.

Yonela thought his death was suspicious: "He died, but when they examined Zukile's body they did not find any electricity in his blood, they could not find any of it. So how could he have died from electricity? 
It must have been something else." Yonela and others suspected that Zukile's mother, Noluthando, had something to do with it, especially because she had told several people she was unhappy about her son's relationship with Tembi. Some wondered if she had taken out a life insurance policy on her son.

After Zukile's death, Yonela received a phone call from Tembi's mother who lived in the Eastern Cape. She said that although she wanted to come to Cape Town to support her mourning daughter, she could not afford the trip. So she asked if Yonela would help by seeing to Tembi's interests and her consanguinal family. Most likely she was anticipating that Zukile's family would take everything and leave the widow and orphan without financial means. Yonela gladly agreed and went to visit Tembi.

Noluthando traveled from her home in East London to Cape Town to help organize her son's funeral. Zukile's father, who had never married Noluthando, asked his sister Sonia to go to Cape Town and represent his interests. Thus, the three older women, Noluthando, Sonia, and Yonela, met to prepare the wakes and the funeral, and to make various decisions about the estate. They met at Tembi's home where Noluthando and Sonia were hosted for the duration of their time in Cape Town. Although Tembi was also present she was not involved in any arrangements, in keeping with the mourning rituals.

The three women soon began arguing about funeral details. Noluthando insisted that her son be buried close to her home in East London. Sonia insisted that he be buried in Peddie, where his father lived and his paternal ancestors were buried. During the argument, Sonia called her brother who confirmed that the burial was to be in Peddie. Zukile had grown up there and he saw no reason for a funeral in East London.

The argument became more aggressive as Noluthando and Sonia screamed at and punched each other. The fight became so bad that Tembi interrupted her mourning ritual of sitting on a reed mat to stop them. Yonela also tried to stop the fight. She said it was horrible, and that Noluthando was especially rude. Yonela said she was appalled when Noluthando started praying loudly and aggressively:

Oh God, please let this fucking woman [Sonia] out of the house. God, make sure that this horrible woman gets out of the house and that I never see her again. This is my son, I remember how I gave birth to him, how I had to push and push and how my vagina grew really big and how the doctor had to cut me. Here are the scars to prove it. God, help me! 
When the fighting finally stopped Yonela proposed another meeting with the two women. But before they met, she secretly asked Tembi what she preferred. Tembi said that she wanted Zukile to be buried at his father's place in Peddie, with his paternal ancestors. Later, Yonela began the meeting saying: "It is not up to you to decide where Zukile will be buried. Zukile was Tembi's husband and she should make the decision." Initially both women protested, but eventually they agreed to ask Tembi, who repeated what she had told Yonela earlier. In the end, Noluthando gave in and said that she would attend the funeral, even in Peddie.

Zukile's body was taken to Peddie, and Yonela saw that Noluthando kept her promise and went as well. Before the funeral ceremony began, Noluthando showed Yonela a knife that she was carrying. She said: "I am going to be at my son's funeral. They can try and kill me and put me next to him in the grave, but I will not leave and I have this knife to defend myself." Yonela said that the funeral was terrifying. Zukile's father and his family were very hostile and aggressive towards Noluthando. They literally told her to "fuck off" and someone said: "We do not want you here, bitch. We will kill you." They were convinced that Noluthando was a witch and that Zukile had not died from the electric shock, but from his mother's witchcraft. ${ }^{15}$ Accusations of witchcraft do not necessarily deny physical realities such as electric shock, but give a complementary explanation that points to social relations and cosmological interpretations of misfortune. Zukile's paternal family accused Noluthando of taking out a life insurance policy on her son and then using witchcraft to kill him in order to attain the insurance money and have custody over his child.

Yonela said the tensions between Noluthando and Zukile's father and his family became so severe and visible that very few neighbors attended the funeral. This was highly unusual as it is common for around a hundred or more neighbors to pay their respects at a funeral, even when the deceased is relatively unknown. Yonela believed the lack of attendees was because people were afraid of witchcraft and wanted to stay away from the tensions between Zukile's parents.

It is customary to offer food to guests after a funeral. Noluthando, however, did not eat anything she was offered, probably because she was worried it was poisoned or contained substances that would bewitch her.

After the funeral ceremonies were over Noluthando told Tembi that she had an insurance policy on her son's life, which entitled her to $\mathrm{R}_{5}, 000$, plus an additional $\mathrm{R}_{5} 00$ because Zukile had died in an accident. She wanted a copy of the death certificate, and also asked Tembi 
and Yonela for help with submitting the claim because her English was too limited for the complex forms.

Although Tembi had been very upset at Noluthando, she and Yonela helped her with the claim. Noluthando promised she would give Tembi $\mathrm{R}_{500}$ once she received the money. However, Yonela said that Tembi never received anything, and that Noluthando never contacted her or Tembi again. She understood this to mean she must have been successful: "If not, she would have contacted us again asking for help." This was seen as added proof of Noluthando's greediness and ruthlessness.

How much are these accusations against kin, especially against parents, the result of life insurance marketing? Life insurance seems to contribute to tensions that already exist within often volatile kinship relations and care arrangements. These tensions are structural to patriarchal kinship relations as well as the products of poverty and an apartheid legacy that severely disrupted kinship relations. In Cape Town, more so than in the rest of South Africa, apartheid legislation made it virtually impossible for men and women and their children to have a stable household where basic human needs could be met.

Consequently, funerals bring these tensions to the fore. The raw emotions of mourning a loved one, confronting one's own mortality, fearing spiritual contamination, and the cosmological uncertainty about a person who is no longer alive but not yet an ancestor all come together at the funeral events. It could be that life insurance (money) is not the cause, but rather the stage on which these tensions and emotions suddenly and quite dramatically crystallize.

Many of the tensions that were experienced following Zukile's death existed well before life insurance became common among the Xhosa residents of the Cape Flats. Nonetheless, his death shows that life insurance has indeed amplified those tensions and provides fertile ground for speculations about profiting from someone's death because, unlike burial societies, life insurance does not reveal what beneficiaries receive.

What appears to be specific to life insurance tensions is parents being accused of killing their children, specifically mothers of killing their sons. Niehaus (2013a) proffered an explanation for witchcraft accusations against fathers. In the South African Lowveld, the rural resource base collapsed during democracy, which aggravated conflicts over the parental control of cattle and land that were needed for subsistence, marriage, and parental authority over children (Niehaus 20I3a, 206-207). Additionally, Cape Town is witnessing a younger generation whose opportunities for a decent life that includes a stable income, meaningful and enduring relationships, and a home are at odds with the 
freedom that the end of apartheid promised. Cape Town's overly small labor market is aggravated by de-industrialization, racial inequality, and limited education (Crankshaw 20I2). Thus, similar to the Lowveld described by Niehaus (20I3a), life for the younger generation looks bleak, even when compared with the harsh apartheid period. Their parents at least had the hope of improving their lives once apartheid was over. Such moral, economic, and social insecurities have subsequently centered on life insurance.

\section{Moralities of solidarities}

As we have seen in this chapter, the abstract nature of life insurance has fostered concerns about insurance murder. Unlike burial societies that are part of social networks, life insurance is invisible and thus a form of solidarity that is not grounded within the confines of social relations. Life insurance was by far the most popular insurance product sold in the townships of Cape Town. This inserts insurance and financialization into the very core of intimate life and death. Life insurance matters at a moment of cosmological volatility that becomes apparent when people say, "something happened to that person." That phrase is used to avoid referring to the danger and pollution of death. Additionally, death often leads to financial volatility where the bereaved have to deal with funeral costs and often face income insecurities.

Africans living in the townships of Cape Town see taking out life insurance as a form of care, responsibility, and compassion for others, which Golomski (2015, 2018a) also found to be true in Swaziland. However, at the same time they see life insurance as a sign of selfishness. Sometimes the selfishness is very obvious, like when people commit identity or insurance fraud or mutilate bodies. Other times selfishness is more abstract, like when it is cloaked in acts of kindness and support. Hence, the irony of solidarity. Financial help is sometimes seen as a thinly veiled utilitarian desire for personal gain. Thus, it is interpreted as insincere and met with hostility because the benefactor is expected to have an unseen financial interest in the form of an abstract life insurance policy.

In contrast, life insurance relaxes neighborhood relationships. Neighbors are rarely the actors in the rumors about funeral profiting, taking advantage of other's hardships, or other micro-political dynamics that are common to burial societies. Although they continue to help organize and participate in funeral rituals through the burial societies, life insurance does not provide the same stage for rumors and suspicions like it does for kinship relations. 
Gossiping and moral concerns revolve primarily around families, when members profit from or cause the death of a parent, child, or sibling. Life insurance both increases and hides the financial stakes of death, which leads to greater tensions among kin (see also Golomski 201 $8 \mathrm{a}, 96-\mathrm{IO} 2)$. The invisibility of life insurance, meaning that it takes place outside the domain of the social, opens the door to a discursive space for expressing concerns about the limits and constraints of kinship solidarity, especially the consanguinal kinship relations between parents and children. Life insurance inadvertently produces suspicions about immoral behavior where greed and selfishness motivate the exploitation of kin, even of one's own children, which resonates with well-established witchcraft discourses.

I found it very striking that suspicions were directed towards parents who were trying to support their children, especially that mothers seemed to be the target of rumors and gossip. In the past, suspicions of profiting from or causing someone's death were usually directed at affines and part of a discourse in which affinal relations were seen as a threat and a source of immoral accumulation. But here the tensions emerge within consanguinal kinship relations. Niehaus (20I3a) also found that witchcraft accusations emerged within consanguinal relations in the South African Lowveld. Jimmy holds his father responsible for the misfortune in his life and accuses his father of using witchcraft against him. Niehaus (2OI 3 a) convincingly argues that such accusations are related to de-industrialization, a global economic crisis, and joblessness that creates tensions between parents and children. These tensions are fostered when dire economic circumstances cause the future of the younger generation to be bleaker than that of the previous one.

To some extent, the intergenerational tensions explored in this chapter are similar. Cape Town too suffers greatly from de-industrialization and joblessness, and here too the futures of young men and women look desperate, with little hope for improvement. An important difference that I found in the life insurance cases, however, is that it was predominantly the mothers, not the fathers, who were accused of violent and immoral behavior, because they were believed to be profiting from their children. That these accusations were directed specifically at mothers is intriguing. It might have to do with the gendered expectations of parenthood. The role of fathers in child care is focused more on specific ritual moments like marriage and, for men, initiations, which are made possible with money gained in the labor market. The relatively marginal role of fathers in caring for children within a household setting cannot be separated from racist labor policy before and during apartheid. In their search for income, men were forced to leave their households in 
the former Bantustans and work as temporary and often illegal migrants in Cape Town and other cities and industrial areas. The precariousness of fatherhood and paternal rights is deeply rooted in apartheid's history of socio-economic inequalities and the disruption of kinship ties through labor migration policies. ${ }^{16}$ Although fathers were expected to support the household financially and play an important role in rituals, everyday parental care within a household setting was inevitably limited. Unstable fatherhood contributed to what has been identified as the crisis of masculinity in South Africa and tense paternal expectations, which are carefully explored by Niehaus (20I3a).

Although notions of masculinity are changing and the role of fathers in day-to-day care might become more important (Mkhwanazi 20I4), the overall expectation is that fathers are only marginally involved in household affairs and daily care. Such expectations are generally placed on mothers. Life insurance adds a new economic dimension to these care arrangements. The abstract and invisible nature of insurance contracts and financial claims can be particularly hard to reconcile with the selfless, intimate, and unquantifiable ideal of maternal care. For mothers, life insurance symbolically and financially brings together the irreconcilable domains of giving and nourishing life and intimate mother-child relationships with that of receiving financial compensation upon the death of her child. More than anything else, a mother taking out life insurance on her child epitomizes a moral tension that is inherent to money's abstract and social qualities - a tension between the utilitarian dimension of money, which means using it for abstraction, and the social dimension of money, which means supporting life. Mothers with life insurance policies suggest the possibility of profiting from destroying a life they brought into the world. 


\section{9}

\section{Conclusion: ironies of solidarity}

\section{From neoliberalism to irony}

This study has hopefully shown the shortcomings of associating the problem of financialization with neoliberalism and instead made the case for using a new framework that puts the ironies of solidarity at the center of understanding financialization. The shortcomings of the "neoliberal lens" of analysis are both empirical and theoretical. The empirical problem is that post-apartheid South Africa is far from being an example of rising neoliberalism. Instead, the post-apartheid state and its political movements and ideologies played a central role in the marketing of financial products, including insurance. Rather than decreasing government control over the economy, it held a firm grip. Restructuring the economy was pivotal to its strategy of overcoming the racial inequalities of the past. Political change led to greater redistribution in post-apartheid South Africa. The state, led by the ANC, redistributed housing and other services to the predominantly African poor, established a wide range of Black Economic Empowerment programs with strict laws for making businesses racially inclusive, and set up unprecedented social grants schemes to aid the elderly and disabled. The state played a crucial role in developing a racially inclusive financial sector. This meant that financial companies had to transform ownership, employ African staff at different levels, and provide financial services to African clients. The post-apartheid politics of democratization and inclusion made the state pivotal in forming new markets. Accepting, as I suggest, that neoliberalism is not the most appropriate theoretical lens for understanding these changes requires finding other explanations for financialization and the continued violence and inequality in South Africa. I found it more fruitful to explore the financialization of insurance as a kind of solidarity that is interwoven with a wide range of other solidarities, each with its distinct form of care and suffering.

The theoretical problem of using a neoliberal lens for analyses lies in the fact that money is both social and abstract, as existing within personal relations but able to function outside of them. Thus, a neoliberal approach to financialization and power simplifies this duality. It implies that the power of money is due to its abstract characteristic, which leads 
to the conclusion that economies produce inequality, violence, and suffering. One can think of the dual meaning of abstraction in the English language, which refers to a conceptual aspect of leaving concrete things and sociality out, and a material aspect of removing or appropriating something (abstracting from people). Attributing suffering to the abstract side of the economy (for example, by "blaming" neoliberalism for all that is wrong) misses two crucial points. The first is that abstraction can be liberating as it offers people a way out of the shackles of sociality, which can produce its own forms of suffering. I have shown how relations between neighbors are caring and yet simultaneously charged with hierarchies and violence. I have shown how relations between fellow migrants are charged with rivalries regarding status and notions of home. And I have shown how relations of solidarity between "insiders" and "outsiders" during apartheid were central to violent taxi wars. It is clear that kinship is not only a relationship of care, but also a place of complex hierarchies and conflicts. This ethnographic approach shows that one cannot simply attribute suffering to abstraction alone.

Another problem of attributing suffering and violence solely to abstraction is that to do so leads to a nostalgic notion of social relations as inherently good and caring. In other words, they become the antithesis of suffering, inequality, and violence. Arguing that the causes of suffering, inequality, and violence lie outside these relations, somewhere in the abstract dimension of the economy, suggests that social relations are a kind of paradise, were they not "contaminated." For this reason, I find the work of Mauss and Strathern so important, since they both point out the existence of power, aggression, and violence within gift exchanges without connecting them to wider abstract and global political economic forces. Additionally important is Evans-Pritchard's identification of the contradictions in Zande thought and the inherent ironies in how the Zande understand social relations and suffering.

This book analyzes a very different situation from those described by Mauss, Strathern, and Evans-Pritchard. Although the Xhosa residents of Cape Town are integrated into a global political economy, I argue that their suffering within personal relations cannot be blamed on global economic structures alone. Instead, I use an ironic approach to propose a conceptual space for exploring how suffering is at home within social relations, and how this is central to people's interest in the abstract form of solidarity offered by large-scale and bureaucratic companies. Moreover, insurance companies and, to some extent, the state brazenly capitalized on people's intimate suffering and the risks they experienced in everyday life, presuming to offer a win-win situation that was good for business, good for citizenship, and good for African clients. 
I conclude by reflecting on how the ironies of solidarity provide insight on redistribution in the market; how care and conflict are intimately connected; and how methods, as a form of abstraction, can help us to uncover the ironies that underlie solidarity.

\section{Solidarity and redistribution}

Insurance, although provided by commercial companies, can be defined as a kind of distribution-based solidarity. Clients make payments to an insurance company, which pools the resources into a fund from which money is paid back out to compensate specific losses. Fundamental to solidarity is that the one person's loss is compensated by others, which is exactly what insurance purports to do.

This type of solidarity is inherent to both markets and politics. In terms of markets, it means that those who contribute to the funds are clients; the professionals who manage the funds, such as actuaries, receive a salary; the funds are set up and owned by companies who use part of the money to profit shareholders; and the funds are integrated into global financial markets through, for example, re-insurance. In terms of politics, aspects of solidarity are most visible when the South African government urges companies to be racially inclusive; when it creates legislation that forces companies to include the poor; and when the instruments to measure inclusion are the outcome of complex negotiations between government and financial companies. The political aspects of insurance affect the people living in the townships of Cape Town when, for example, insurance contributes to marginalizing taxi associations, or when insurance is deeply entrenched in the micropolitics of kinship relations.

Recognizing commercialized insurance as a kind of solidarity based on redistribution can bring new perspectives to financialization that place ironies at its core. Is it not ironic that financialization, including its many unwanted consequences, occurs inside rather than outside solidarity? A dichotomous approach to financialization by way of insurance and solidarity makes it impossible to conceptualize irony. Thus, an examination of ironies in this context moves away from the analysis that reproduces the dichotomy between market and reciprocity that has governed most of twentieth-century economic anthropology. In this book, I have sought to breach the conceptual boundaries that have dominated anthropology by placing redistribution and solidarity at the core of understanding insurance. Examining insurance as a form of redistribution and solidarity creates a new language through which we can 
better understand how financial products are situated within redistribution as enacted in government policies, neighborhood and community associations, and kinship networks. There are fundamental differences between these forms of redistribution. Thus, highlighting the redistributive characteristics of markets does not downplay the difference between rights and identities based on different forms of redistribution, but rather allows for new forms of comparison.

By conceptualizing insurance as a kind of redistributive solidarity, this study has revealed four salient issues. First, the marketization of insurance is a result of changing notions of citizenship. After the first democratic elections of 1994, black South Africans were "suddenly" seen as potential clients. In the townships of Cape Town, insurance only became commonly available when full citizenship rights were granted to all South Africans irrespective of color, after the fairly comfortable relationship between the financial sector and the apartheid regime ended. Hence, devising and marketing insurance policies for those that suffered from the atrocities of apartheid was part of South Africa's wider national objective of inclusion and citizenship. However, expectations of the rainbow nation, and even of inclusion through financialization, were often too high, possibly naïve, and sometimes conveniently conflated with the interests of financial companies. Some of these forms of inclusion, as this book has shown, actually contributed to inequality or led to new forms of exclusion.

These dynamics would not be fully understood if financialization was defined in neoliberalism terms. The evidence uncovered in this book supports Ganti's (2014) criticism of using neoliberalism as a framework for anthropological understanding. Her literature review shows that the concept forecloses avenues of anthropological inquiry in that it produces a narrative that defines history in terms of before and after neoliberalism, "a contrast that is suffused with moral dichotomies that repeatedly imply that the state is intrinsically superior to the market, and communities to individuals" (Ganti 20I4, 99).

Second, this study has shown that commercial insurance is part of an ontology of redistribution for African clients in the townships of Cape Town. This ontology is central to how people enact the economy, including the narrative that explains why some people are successful in the new South Africa while so many others are not. Redistribution continues to be key in a state that promises, and occasionally provides housing, land, food, and other resources. For poor people, redistribution means depending on social grants. After 1994, South Africa enacted policies that gave unprecedented amounts of social grants to the elderly, mothers, and the disabled. Today, almost half of the population receives 
social grants and even more rely on those received by their relatives. In South Africa, many jobs and business opportunities are framed within a narrative of redistribution. It is understood that accessing these opportunities requires developing relationships with gatekeepers and knowing how to handle the bureaucracies that mobilize state resources. The rise of neo-Pentecostal churches coincides temporally with the proliferation of state redistribution and preaches a theology and a narrative of redistribution that promises vast riches. In the townships of Cape Town, as well as many other places in South Africa, insurance marketing also overlaps with these varying political and religious forms of redistribution. Thus, financialization through insurance has become part of an economic ontology of redistribution through abstract institutions.

Third, I have shown that large-scale redistribution has created new forms of abstraction and embeddedness. In general, these are not specific to redistribution or insurance, but feature in all economic practices. This point is now well established in economic anthropology. ${ }^{1}$ We have seen that solidarity cannot be equated with embeddedness, but rather, as an economic practice grounded in redistribution, it is both embedded and abstract. Underexploring the abstract dimension of solidarity reproduces the problematic twentieth-century dichotomy between abstract, impersonal, and utilitarian economics on the one hand, and embedded, social, and moral economics on the other, placing solidarity in the realm of the latter.

The implication of recognizing that solidarity has both embedded and abstract characteristics is that insurance markets do not erode solidarity, but instead introduce new forms of it. Thus, financialization through insurance presents people with new assemblages of both personal and abstract characteristics that intersect and change pre-existing forms of solidarity.

The dynamics of these personal and impersonal dimensions are apparent in the Janus face of insurance, meaning inclusion is achieved through social networks for sales purposes, which is sometimes followed by exclusion through impersonal bureaucracies when making claims. Both these personal and impersonal dimensions feature strongly in suspicions of wrongdoing, fomenting often spectacular accounts in the news about insurance fraud and even insurance murder by relatives.

Finally, this book has revealed that the economy and all forms of solidarity, including insurance, are made up of both visible and invisible characteristics. People's moral concerns about these different forms of insurance seem to be directed toward the invisibility and intangibility of its redistribution, which facilitates taking care of kin but is simultaneously seen as a threat to kinship because it hides personal interests 
from the scrutiny of neighbors and family members. Whether insurance is interpreted as a responsibility or threat depends on the relationship someone has with the deceased and the person entitled to the insurance payout. This abstraction of insurance redistribution gives ample space for deep-seated antagonisms that are reminiscent of the kinship relations expressed through witchcraft. This shows that the invisibility of redistribution is not confined to abstraction, but also features within personal relationships. ${ }^{2}$

The redistributive characteristic of insurance is fundamental to understanding what insurance is, how it affects cooperation and conflict, and how it leads to both the mitigation and proliferation of risks.

A number of meanings, moralities, desires, and fears can be projected onto insurance money precisely because it is not symbolically or socially determined, because its redistribution has both social and abstract characteristics, and because economies have visible and invisible properties. Hence, a wide range of moralities related to social relations become closely intertwined with insurance. Although some of these characteristics are related to insurance, they also reflect the desires and fears that come from living in one of the world's most unequal and violent societies, where neighborhood ties and kinship relations are full of tensions over rights and responsibilities. Insurance reveals how democratization transformed the relationship between government and the financial sector; how taxi associations changed their stance of solidarity against an oppressive apartheid to became mafia-like organizations; and how solidarity underlies the government's efforts of redistribution to overcome apartheid inequalities, yet also foments the loyalties of a neo-patrimonial state. Insurance offers a space for symbolic labor around which desires, anxieties, and moralities crystallize.

These moralities, desires, and anxieties are first and foremost the result of multiple solidarities that are based on redistribution within kinship, redistribution within neighborhood and other community relations, and redistribution done by a state that promises welfare and prosperity. They are based on the solidarity provided by insurance where clients pool money to compensate specific losses.

\section{Solidarity in care and conflict}

Theorizing the ironies of solidarity is crucial to understanding social change as a contingent process. Once again, Rorty's (I989) understanding of the relationship between solidarity, irony, and contingency proves very helpful for anthropological inquiry. He proposes moving 
from questions regarding truth (e.g. establishing the final vocabulary for defining the world) to questions regarding pain and cruelty. ${ }^{3} \mathrm{He}$ shows that the duality between objectivity and morality is contingent upon specific historical developments and proposes an ironic approach to knowledge. He shows how philosophers like Habermas and writers like Orwell addressed societal issues by appealing to solidarity, and how this produced specific ironies. Rorty identifies ironies in the fact that certain requirements for liberal utopia are irreconcilable. For example, a primary requirement is being ironic in private life, or in other words, having a radical and continuous doubt about the "final vocabulary" for understanding the world. This is irreconcilable with public solidarity because, as Rorty points out, the ironist would have to recognize that solidarity generates cruelty, which is produced in its illiberal form when solidarity suppresses individual liberties by forcing people to conform to the "we." Cruelty emerges because solidarity is only possible through exclusion. In other words, because solidarity is based on the identification of a "we," it automatically requires a "them." Although Rorty recognizes the cruelty of solidarity, he takes a pragmatic approach stating that as long as there is no other vocabulary, we must expand solidarity. We must recognize this inevitable irony and make do with existing vocabulary until another, once again contingent, vocabulary makes it possible to see the world in a different way (Rorty I989).

Rorty's analysis of epistemology and morality offers important insights into the financialization of insurance as a kind of solidarity. According to him, irony is foremost private and personal, a conceptual tool for understanding the world. In this book, I have tried to show how irony can help us understand social phenomena. It is true that an ironist says one thing and means another, meaning irony can also be seen as part of social processes that are intended for one thing but actually achieve another. Put differently, irony means being caught up in a social process that creates uncertainty about what is wanted and what must be achieved, and about what is unwanted and what must be avoided. Irony means being critical of the process in which we are engaged. ${ }^{4}$

Fernandez and Huber (200I, 9) reason that "thinking demands forgetting" and point to the importance of concealing and revealing. They argue that the irony is found in the fact that to think, one inevitably must omit, conceal, forget, and make invisible. They state that remembering everything makes it impossible to generalize or to abstract, and therefore impossible to think (Fernandez and Huber 200I).

The irony of thinking and knowledge was central to the introduction of this book where I follow Rorty's lead in showing that opposing rationality and morality is problematic in Zande thought and rational 
choice theory (RCT). The ironies of these disparate "rationalities" become apparent when fears are attributed to a specific "other": Among the Zande, death and illness are attributed to a witch, and in RCT, the fear of nuclear and collective ideology is attributed to communists. The "other" (the witch or the communists) is placed outside the boundaries of solidarity. In this way, solidarity reveals how rationality and morality are intertwined, and how Zande and RTC thought reveal certain social processes when they conceal others. The ironies of boundary-making (excluding certain people and forms of understanding) are thus central to solidarity as well as thinking.

In the preceding chapters, I have shown that such an approach is not only viable to understanding Zande thought and RCT, but also sheds light on how people think about and act upon the new forms of solidarity introduced by insurance. I examined the ironies found in solidarity by showing how its different forms offer care, belonging, as well as cruelty, and how these aspects (care and cruelty) are connected.

The protection and care offered by solidarity enable people to help one another. Solidarity rests on the kind of redistribution that connects people and highlights the fundamental principle that we are social beings. ${ }^{5}$ In South Africa, the political recognition of all South Africans as fellow human beings preceded the "discovery" of South Africans as potential clients that could be incorporated into the solidarity that insurance offers. Black South Africans were only seriously considered as insurance clients after the racist apartheid regime collapsed and they became citizens of South Africa's rainbow nation. In other words, the solidarity that was made available by insurance markets followed in the footsteps of the state's efforts to expand solidarity to citizens.

The suffering found in solidarity has two causes. First, solidarity inevitably means that people define boundaries and limitations. They identify and act upon who is in and who is out, who belongs and who does not, who is deserving of resources or empathy and who is not. The establishment, maintenance, and alteration of these boundaries is painful and cruel to those who are excluded and identified as outsiders. Second, solidarity requires being subjugated to a collective good and its accompanying ideology. It requires a conformity that, as Rorty pointed out, suppresses individual freedoms and desires. Solidarity predictably produces hierarchies that define responsibilities and entitlements, both of which can be distributed unequally. To paraphrase Orwell (I945), the cruelty of solidarity is that some people are more equal than others. Therefore, solidarity is inexorably oppressive, as experienced on a daily basis by the residents of the townships in Cape Town. The task is, on one hand, to recognize the care found in solidarity 
between neighbors and kin but not forget its cruelties, and on the other hand, to recognize the cruelty found in insurance but not forget that it provides a form of care.

The conflicts that occur within solidarity cause people to navigate between its different forms, each producing its own care and cruelty. An example of this can be seen in Cape Town, when citizenship entitled Africans to social grants, housing, Black Economic Empowerment grants as well as subsidies for purchasing new taxis. Although this inclusion as citizens liberated people from a violent and inhumane apartheid regime, it also created conflicts that centered on the boundaries of the newly formed political solidarities and the hierarchies they produced. Democratization meant that solidarity was expected from the financial sector. The government urged and sometimes forced insurance companies to be inclusive. Although race was central to the transformation of South African society and new forms of inclusion, explicit references to it had to be avoided when calculating risks because it would go directly against a solidarity based on citizenship. Many working in the insurance sector felt that their business was threatened by politicians who adhered to an ideology they considered naïve because it failed to take into account people's self-interest. They saw the ANC as espousing an oppressive socialist ideology of solidarity that was irrational. Some believed this ideology and political appeal to solidarity was an attempt to conceal a new political elite that was enriching itself at the expense of the South African population.

To many insurance clients, the solidarity offered by insurance presented an escape from the solidarity developed among neighbors, such as burial societies and other financial mutuals. The desire to escape those kinds of solidarity was incited by the inequalities and distrust within communities. This becomes even more evident when considering that financial mutuals were set up partly as a defense mechanism against the cruelty of contemporary South Africa and the previous apartheid regime. They were an attempt to restore human dignity, maintain kinship ties that were threatened by apartheid and poverty, and provide a sense of belonging in a violent society. However, the solidarity enabled by financial mutuals often reproduced the inequalities and conflicts that existed within neighborhoods. Thus, for many people, insurance offered a welcome and liberating alternative.

In the case of taxi associations, the approach was quite different. The government wanted financialization to make the taxi industry financially more viable, and at the same time fragment the solidarity between taxi owners. Nonetheless, the results thus far have reinforced that kind of solidarity. Instead of freeing people, financialization has strengthened 
a mafia-type solidarity that is enforced with intimidation and violence. This seems to go along with several recent discourses on state capture and descriptions of contemporary South Africa as a mafia state (BBC 2016; Maharaj 20I7; Masoga 20I7; Strydom 20I7).

Care through insurance is in fact liberating and offers freedom from other forms of solidarity. However, as has been shown here, it also creates its own cruelties when insurance companies distinguish between risks and operational costs. Marketing for what insurers call the LSM I-5 market incurs high costs and reflects South Africa's deep-seated inequalities. In other words, insurance companies limit their operational costs by adapting bureaucracies and social networks, which often reproduces those same inequalities. Consequently, clients living in the townships of Cape Town can get lost in Kafkaesque bureaucracies, and insurance salespeople, brokers, and entrepreneurs are subjected to exploitative labor practices. The intermediary organizations involved with insurance companies sometimes do not receive financial compensation for the work they do and are placed in situations where they risk losing their reputation and financial viability.

The dynamics of care and suffering become particularly clear when examining the nexus of insurance and kinship. Funeral policies are the kind of insurance that many people use to take care of their kin. Death is surrounded by volatility: the grief of family members, the deceased's transition to being an ancestor, and the rituals that are needed to do that successfully. Death also creates financial problems due to the high costs of an honorable funeral. The deceased might not have had a dignified life, but they should certainly be granted a dignified death. Thus, providing life insurance is central to being able to care for one's kin, especially parents and children. Nevertheless, life insurance also exposes the tensions that exist in kinship, and the cruelty among family members. The invisibility of insurance policies amplifies these cruelties and sometimes leads to wild speculations about financial interests in the death of a family member. It seems that the cruelty of death itself is projected onto both real and imagined insurance money.

The fact is that insurance is not intended to reduce inequalities, but to compensate specific losses. Yet in the South African political context it, and financial inclusion in general, was expected to reduce the racial and class inequalities of a colonial and apartheid past. This has indeed occurred for clients in townships like Indawo Yoxolo and Tembani. The racial inequalities of the past that excluded Africans as clients have diminished and insurance companies have made consistent efforts to make their services available to the poor. Nevertheless, insurance has 
also strengthened inequalities by using market segmentation tools that easily fall into racial stereotypes, and by limiting operational costs in ways that augment the vulnerability of clients and brokers. As has been demonstrated in this book, insurance offers an escape from the inequalities of neighborhood relations by providing an alternative to the hierarchies of burial societies and other financial mutuals. Ironically though, insurance also strengthens a trickle up economy in the violent taxi industry. It strengthens inequalities within kinship, particularly gender inequalities in affinal relationships.

The examination of solidarity and redistribution conducted in this study introduces new vantage points for understanding markets, and is a significant departure from the rational choice approach of orthodox economics and an approach that places solidarity outside markets. Additionally, examining redistribution within markets is a departure from earlier approaches that studied it within the politics of kinship, kingship, and statehood. Polanyi (I944), for example, affirmed that redistribution preceded the evolution of a market society. He expected redistribution to return with the rise of socialism, but instead today it is at the heart of global financial markets, enabled by what Polanyi identified as the fictitious commodity of money. Solidarity can only be placed within markets when one recognizes that it is a site of contestation that inescapably leads to exclusion and the establishment of hierarchies.

\section{Solidarity and abstraction}

The solidarity of insurance has both social and abstract sides to it. The dynamics of sociality and abstraction are crucial to understanding what insurance is, why Africans living in the townships of Cape Town buy insurance policies, what they expect from these policies, and how they use these policies to rework their social networks, sometimes successfully, sometimes leading to tensions and conflicts within social networks or with bureaucratic organizations. For the clients, the abstract characteristics of insurance were equally as appealing as the social ones. Abstraction allowed for freedom from social bonds, as well as privacy and even secrecy regarding how money was spent and how it was used to strengthen or weaken social relations among neighbors and kin. Even when clients experienced the oppressive sides of abstraction, like bureaucracy or rumors about hidden financial interests in the death of family members, it unfailingly appealed to a promise of freedom, a promise that was only partially achieved 
with the I994 democratic elections. Because of its abstract dynamics, insurance facilitated a kind of solidarity that struck a chord with people who were looking for a much greater sense of liberation than what was typically defined by politics. Even when insurance created problems and disappointed people, it continued to promise liberation from certain socialities, including inequalities, hierarchies, and its captivating but often depressing social drama.

For actuaries and others in the insurance sector, abstraction was an epistemological and ideological lens through which they envisioned solidarity among African clients. Their knowledge was usually not based on personal contacts with Africans, which were typically charged with the racial inequalities that continue to haunt South Africa. Instead, their knowledge was based on specific abstract LSM and other categories that were used to design solidarities by defining a specific market, setting monthly premiums, defining entitlements and exclusionary clauses, and structures to reduce organizational costs. These technical procedures inevitably also reflected moralities about a democratic and inclusive South Africa and what constitutes rational behavior. However, at the same time, actuaries saw abstraction as an obstacle. They tended to romanticize the Africans' personal bonds of kinship, neighborhood, and community. Some felt that in order to develop the market, they had to mimic these forms of sociality in their advertising and marketing. Those attempts overlooked the abstract and impersonal appeal of insurance and were based on naïve ideas about the dynamics of solidarity within kinship and neighborhood relations. The abstractions that actuaries and others in the industry used had sanitized these relations from their disharmonious qualities.

The dynamics of solidarity and abstraction raise fundamental issues regarding the role of ethnography in the production of anthropological knowledge. Ethnography as a method is social in that its insights hinge on social relations developed during fieldwork and our understanding of the particular in sociality. In anthropology, it is common to associate surveys with problematic abstractions of the world and a form of symbolic violence that can be part of quantitative data collection (see for example Bourdieu 2002 and Bourdieu et al. 2002 on this). Key survey features are based on notions of control where both the questions and the answers are determined to make comparison possible. For surveys, questions related to the representativity of findings are dominant. Surveys and ethnography have somewhat different criteria for including findings into a research project. In general, surveys require a specific writing style and structure that clearly disentangle 
theoretical debates and findings, and the interpretations of those findings. Conversely, ethnographic writing is structured to present arguments that are rooted in ethnographic evidence (ethnography usually does not refer to "facts" or "data") and situated within a theoretical landscape. According to constructivist and reflexive epistemology, the positionality of the researcher is pivotal to ethnographic interpretation, which must then be presented in writing. Surveys, on the other hand, focus on filtering out or minimizing researcher influence, and have a more objectivist approach based on the idea that knowledge can exist outside of language and social relations.

Combining a neighborhood ethnography and an online survey made it possible to more fully comprehend the dynamics of sociality and abstraction. Although anthropological knowledge produces its own theoretical abstractions, it is based on a reflexive approach to social relations and interpretative epistemology. This matters in the way that ethnography offers insights. Survey methods obscure much of what is going on between people and the relationship between the researcher and the people that are being studied. At the same time, however, this more abstract method revealed important insights that I did not find by using ethnography alone. This was particularly poignant when comparing the neighborhood and actuary surveys with the related ethnographic material. During fieldwork, I listened to many stories from people who felt cheated by an insurance company. They showed me in great detail how they did not receive the benefits they had expected, how they ended up paying more premiums than they had anticipated, how insurance forced business owners into a relationship of dependency that threatened their livelihood, and how insurance led to rumors and suspicions about insurance murder. Thus, I was surprised when the neighborhood survey results revealed that those same people trusted insurance companies and banks more than they trusted local financial mutuals organized by neighbors. This unexpected contrast led me to explore more deeply the invisibility and abstraction of different forms of solidarity.

It is worth exploring in greater detail how these methods can be combined and what they mean for the knowledge they produce. This is particularly relevant to economic anthropology and the study of finance. Finance, especially, is charged with abstractions that range from political ideologies that blame neoliberalism and excessively celebrate solidarity within personal relations, to abstract economic indices that assume that the economy is a universal phenomenon that can be studied objectively. Ethnography can help challenge such assumptions and, more importantly, can offer a much more nuanced understanding 
of how people's social relations, experiences, and ways of seeing the world in fact shape finance, solidarity, and the economy in general. But the irony of such an ethnographic approach is that it makes it easier to overlook how attractive abstractions can be; how such abstract qualities create a void that can be filled with people's dreams and hopes for the future. In South Africa, these dreams were often about a liberation that went far deeper than citizenship and national politics, a liberation in ways of relating to other people and in notions of the self. The fact that insurance does not always turn these dreams and hopes into reality does not diminish its attraction. 


\section{Notes}

\section{Introduction}

I I use African to denote the members of Bantu-language groups and colored for people who were thus classified during apartheid and who often still uncomfortably identify themselves as such. I use white for Englishand Afrikaans-speaking South Africans. Here I follow common practice in South Africa while simultaneously recognizing, as this book will show, the problems with these definitions.

2 The Life Offices Association of South Africa (LOA) represented insurance companies and released a press release in 2006 , stating, "The LOA's target for 20I 4 is to increase penetration to I 80 percent of current levels (i.e. to 3.8 million policies)," see press release, LOA, January 27, 2006. On the rise of insurance in South Africa, see Porteous (2005); the 2004 Financial Sector Charter on Black Economic Empowerment, www.atns.net.au/agreement. asp? EntityID $=4500$, accessed October 2I, 20I I. On market expectations see Melzer and Smith (2004); Porteous and Hazelhurst (2004); Porteous (2005). International examples of microfinance can be found at the microfinance gateway website, while in 2005 the World Bank established the Micro Insurance Agency.

3 The attention to financialization has been amplified by the global financial crisis of 2007. For recent studies on the conceptualization of financialization, see among others Davis and Kim (2OI 5); Golomski (20I 5, 20I8b); Palomera (20I4); and Schraten (2OI 5 ).

4 Medical anthropologists have started to examine the role of insurance in health care reform and policy in Africa (Ellison 20I4; Foley 2008; Golomski 2018a; Mariam 2003; Pfeiffer 2003; Wolf 20I2). See also Golomski (20I8b) and Morris (2008) on the HIV/AIDS pandemic and funeral insurance in Southern Africa.

5 Studies on other African countries differ in the weight given to neoliberalism. Elyachar (2002, 2005) argues that new credit markets are a sign of neoliberalism and produce a form of governmentality at the expense of citizenship rights and social justice. Shipton argues that World Bank credit programs and development aid in Kenya "are deeply rooted in colonial and early postcolonial history" (Shipton 20I0, 29). Shipton shows how credit is part of local and international patronage, but also analyzes the emotional and ethical aspects of credit provision. In her review of anthropological and sociological research on financialization in the Global North, van der Zwan (20I4) concludes that everyday financialization is a neoliberal project that politicizes finance as an expression of class and intersubjectivity disciplined through governmentality. 
6 See also Manuel's emphasis on government control in his Budget Speeches of 2007 and 2008 (Manuel 2007, 2008) as well as Reporter (2008).

7 Comaroff and Comaroff (I 999) explore this double meaning in their article "Occult Economies and the Violence of Abstraction: Notes from the South African Postcolony."

8 I found Mary Douglas' (I992) Risk and Blame very valuable in developing these ideas, in that it raises vital questions regarding responsibility and accountability. Academic theory shares some of the traits in this process when it tries to identify causality and develop explanations, which contain dynamics that are similar to blaming or making something or someone responsible.

9 South Africa has been on the world's top ten list of highest intentional murder rates for all but two years since 2000 . Based on statistics provided by the South African Police Service, which can be found online here: www.saps.gov.za/resource_ centre/publications/statistics/ crimestats/20I 5/crime_stats.php, accessed March 26, 2017.

Io Ranking compiled by Mexico's Citizens' Council for Public Security and Criminal Justice, see www.seguridadjusticiaypaz. org. $\mathrm{mx} /$ biblioteca/view. download/5/I77, accessed March 26, 2017. Violence in South Africa is not limited to murder but murder is the most relevant

\section{An ironic analysis}

I Bataille (I99I) and Wolf (I999) further explored the aggressive and destructive potential of giftgiving. Bataille (I99I) took a psychoanalytical approach and Wolf crime in relation to funeral insurance.

I I www.crimestatssa.com/topten. php, accessed June 22, 2015.

The six precincts with the highest murder rates were Nyanga, Harare, Mitchells Plain, Gugulethu, Khayelitsha, Delft. The seven precincts with the highest number of attempted murders were Mitchells Plain, Elsies River, Nyanga, Bishop Lavis, Manenburg, Khayelitsha, Mfuleni.

I 2 In 20I6, Cape Town's Gini coefficient, one of the key measurements of inequality, was 0.6I (Western Cape Government Provincial Treasury 2017, 99).

I3 Statement of Nelson Mandela at his Inauguration as President, May I0, I994, Pretoria. Online: www. anc.org.za/show.php?id=3 I32, accessed March 26, 2017.

I4 See www.vanguardngr. $\mathrm{com} / 20 \mathrm{I}_{4} / 04 /$ disgrace-peoplewent-bed-hungry-tutu, accessed March 26, 2017. On "worse than apartheid," see http://mg.co.za/ article/2OI I-IO-O4-governmentworse-than-apartheid-says-tutu, accessed March 26, 2017.

I 5 I would like to thank Jimmy Pieterse for helping me with the Afrikaans slang.

I 6 Interview by Honeychild, http:// idmmag.com/featured/dookominterview/, accessed March 26, 2017.

I7 Interview, Dookoom 20I4, http:// noisey.vice.com/blog/dookoominterview-20I 4-Larney-Jou-Poes, accessed March 26, 2017.

(I999) used a historical analysis to show how the nineteenth-century Potlatch was transformed by a material and religious crisis caused by an expanding capitalist economy. 
2 Strathern has been criticized for conceptualizing Melanesian society as if it were outside global capitalism and markets (see among others Keesing I992).

3 See for example Amin (2009); Goodman et al. (20I2); Grasseni (20I4); and Rakopoulos (2OI4).

4 In global financial markets, the pool of money is not a physical pool as the premiums that people pay are reinvested into a wide array of financial products. But this does not make the principle of redistribution - pooling money to cover risks collectively - less relevant.

5 See also Seekings and Nattrass (200I); Kerstenetzky (2009); Bähre (2OII); and Ferguson (20I5).

6 See for example Bloch and Parry (I989); Guyer (I995, 2004); and Hutchinson (I996).

7 See for example Ewald (I99I, 2002) on the rise of the precautionary principle; De Swaan (I996) on how actuarial knowledge made the welfare system possible and raised new questions regarding exclusion and respectability; Golomski (201 5 , $2018 \mathrm{a}$ ) on how insurance can be considered a "compassion technology" with far reaching consequences for kinship; and Zelizer (1978, I995) on how insurance raised theological questions on pricing a life and concerns about proper childcare.

8 For these kinds of issues, see also Applbaum (2004). Hart (I973, 20IO) has pointed out that in order to understand economic processes one needs to analyze the interdependency of formal and informal economic arrangements. Popular economic discourses tend to separate economy into formal and informal realms, as if they operate independent of one another. Hart points out that the economy is actually characterized by how formal economic processes are made possible because of informality and vice versa: "The formal and informal aspects of society were always linked; so, the idea of an 'informal economy' is entailed in the institutional effort to organize society along formal lines. The term 'informal sector' (later 'informal economy' and not often just 'informality') arose almost four decades ago to describe the unregulated activities of the Third World urban poor. But the problem of proliferating urban masses, supporting themselves in invisible ways and at some perceived risk to public safety, is an older one" (Hart 2010, I43).

9 On different approaches to irony in anthropology, see among others Fernandez and Huber (200I).

Io This implies the substantivists vs. formalists debate was fairly useless. The debate by Popkin (I975) and Scott (I977) is problematic. Particularly Popkin suggests that rationality and social contexts are exclusive categories.

I I www.rand.org/about/history.html, accessed September 9, 2016.

I 2 See www.rand.org/about/history/ nobel.html, accessed September 9, 20I6. The specificity of this kind of rationality became particularly poignant in the documentary about Donald Rumsfeld, The Unknown Known (2013), which followed his autobiography Known and Unknown: A Memoir (Rumsfeld 20II). Rumsfeld was US Secretary of Defense from I 975 to I977 and from 200 I to 2006 , and was chairman of the Rand Corporation Board of Trustees from I98 I to I986. https://en.wikipedia.org/wiki/ RAND_Corporation, accessed September 9, 2016.

I 3 For a history, see Poundstone (I992) and Amadae (2003), among others. 
I4 For a historical and institutional analysis of game theory, see among others Amadae (2003, 20I6); Cramer (2002); Herfeld (2013); and Mirowski (2005). It appears that this type of analysis is partly inspired by the 9/I I attacks in $200 \mathrm{I}$ that led to a reflexive period about the ability to explain behavior in terms of rationality and irrationality.

I 5 Here I agree with Agar that it is not enough to claim that only emic knowledge exists and that we, while considering the contextuality of knowledge, believe there are universalities because otherwise, translation would be impossible: "Emic and etic are linked, not just in the phonetics and phonemics of a sound system, but in the specificities and generalities of universal human intentionality. Consciousness is about something. What it is about, to some extent, must cover some universal human domains" (2OII, 42).

I6 See also Geertz (I968) on the relationship between morality and understanding: "An assessment of the moral implications of the scientific study of human life which is going to consist of more than elegant sneers or mindless celebrations must begin with

\section{Hope and redistribution}

I On ontological insecurity in South Africa in relation to religion and the occult, see among others Ashforth (2005); Niehaus (20I3a); Van Wyk (20I4); and WilhelmSolomon (2017).

2 The notion of ontology has been developed in science and technology studies in order to rethink the relationship between people and objects (see among others Law and Lien 20I3; M'charek 2000; and Mol I999, an inspection of social scientific research as a variety of moral experience."

I7 The way Sahlins (I985) conceptualizes the transformative potential of rituals and other symbolic events is in some ways similar to Rorty's notion of contingency, even though it is developed in a very different context of transformation.

I 8 “Gluckman's notion of situational analysis had been highly influenced by Evans-Pritchard's ([I937] I976) concept of situational selection, whereby different social logics come into operation relative to the social issue and the kinds of social relations involved" (Kapferer 20I 5, 8).

I9 On the method of the extended case study, see also Burawoy (2009); Meinert and Kapferer (2015); and Evens and Handelman (2006). On the transformative potential of events, see among others Das (I995); Sahlins (I985); and Niehaus (20I3b).

20 See for example Bleek (I987); Bourdieu et al. (2002); Bourdieu and Wacquant (I992); Das (I998); Das et al. (2000); Handler (2013); and Hastrup (I995).

2 I On Indawo Yoxolo, see Bähre (2007).

20I4). Key to these approaches was Latour's work (Latour and Woolgar 1979). For some of the criticism on this approach, see Bessire and Bond (2OI4). The ontological approach to science and technology was a way to escape a positivist-constructivist dilemma. On the one hand, academics can treat objects as real and then develop methods that help them as much as possible to know reality, which is 
a positivist approach to the world. On the other hand, there is the constructivist approach that argues that sciences make objects and realities, however convincing the constructions might seem, to be "only" temporary constructions. But, as Mol writes: "We began to doubt whether 'making' was such a good metaphor, as it gives some 'maker' too much credit; as it suggests a time line with a before and an after; and materials out of which $\mathrm{x}$ or $\mathrm{y}$ might be made. So, we shifted terminology and used words like perform, or do, or enact. Here we widened the idea of the staging social realities (e.g. identities) to that of physical realities" (20I4, I).

3 The wide range of apartheid laws that severely restricted the freedom of Africans to live and work where they chose were known collectively as the passlaws. See Mager (I 999); Bank (20II); Bonner (I995); De Wet and Whisson (I 997); Cole (I987); and Bickford-Smith et al. (I999).

4 On the discrimination of African women during apartheid, see also Bähre (2007, 23-50); OliverEvans (I993); Ramphele (I989); James (I999); Lee (2005); and Ross (20I2).

5 See Ross (I999, I I9); Lee (2005); Bickford-Smith et al. (I999); and Goldin (I987).

6 There were, of course, many other aspects, such as banning political parties, and making marriages between races illegal. See among others Ross (I 999).

7 See among others Sharp and Spiegel (I985) and Bähre (2007).

8 See among others Bank (I999); Bähre (2002); and Jones (I993, I998). In some instances, this gave rise to bilateral kinship, which went against the ideology of paternal rights (Jones I998).
9 Cattle could be replaced by cash earned through migrant labor, but it had major consequences too for people's understanding of kinship rights and obligations. See among others Hunter (I933); HammondTooke (I970); and Comaroff and Comaroff (I990).

Io According to Wilson and Mafeje (1963, 2), in I9I I only I. 5 percent of Cape Town's population were Africans (roughly I,500 people). This increased to 8 percent by I946 (Wilson I972, 70). In I996, the African population was 25 percent, in $200 \mathrm{I} 3 \mathrm{I}$ percent, and in $20 \mathrm{II}$ 39 percent (results from the I996, 200I, and 20I I national population censuses can be found here: www.statssa.gov.za/?page id=993\&id=city-of-cape-townmunicipality, accessed May 30, 2017).

I I Despite the government's determination, these targets were not met. Although one million houses for the poor were built from I 994 to 2003 , during that same period the number of households living in shacks doubled to I. 8 million (Hemson and O'Donovan 2006, I9).

I 2 The RDP was succeeded by Growth, Employment, and Redistribution (GEAR from I 996 to 2005), the Accelerated and Shared Growth Initiative for South Africa (ASGISA from 2005 to 20IO), the New Growth Path (NGP from 2010 to 2013) and the National Development Plan (NDP since 20I3). For an overview see Masilela and Mthiyane (20I4). On development during apartheid see Fischer (I988); McAllister (I989); and De Wet (I989).

I3 In Jain (2010, 33).

I4 These were the Employment Equity Act of 1998, the Promotion of Equality and Prevention of Unfair Discrimination Act of 2000, and the 
Broad Based Black Empowerment

Act of 2003 (Hemson and

O'Donovan 2006, 67). For a

detailed genealogy and debate on

the development of BEE, see Ponte et al. (2007).

I 5 See Thoden van Velzen (I995) on collective fantasies among the Ndjuka in Suriname, and Meyer (2003) on fantasy spaces in Ghanaian cinema. For a philosophical take on this concept of Freudian origin see Lacan (I973) and Žižek (1989).

I 6 South Africa's first social assistance grant was the Children's Protection Act of I9I3, which did not apply to Africans living in rural areas, and was rarely granted to urban Africans (Pauw and Mncube 2007b). The Old Age Pensions Act of I 928 only became available to Africans in I944, with a maximum that reached only a fifth of what whites were entitled to receive (Pauw and Mncube 2007a).

I7 Budget speech by South Africa's Minister of Finance Trevor Manuel, February I 5, 2006, at: www.sarpn.org.za/documents/ dooor 875 /index.php. In 2007 , the number of grant beneficiaries was 50 percent higher than the number of people paying income taxes (Seekings and Nattrass 2005; Pauw and Mncube 2007a).

I 8 On the stigma of HIV infection in South Africa, see among others Niehaus (2007, 20I3a).

I9 On mental health and entitlement of grants, see also MacGregor (2005).

20 From I 997 to 2006 , social grants for foster parents grew 42 percent annually. During the same period, the number of parents receiving a child support grant grew 37 percent annually. Of the total number of social grants that the state distributed in 2006, almost
90 percent were for pensioners (old age grants) and parents (child support grants) (Pauw and Mncube 2007b).

2I Bertrand et al. (2003) appear to be oblivious to the nexus of poverty and household, confusing cause and effect. They argue that the provision of pensions reduces the labor force among Africans. On the contrary, it is the absence of labor that leaves young men and women with little alternative other than to rely on the pensions of their parents and grandparents.

22 In Fort Beaufort, also the Eastern Cape, a woman received an old age pension, at the time just over $\mathrm{R}_{700 \text {, while her son earned a }}$ meagre R200 per month as a fulltime construction worker. Her son was not formally employed and one of the reasons he received such a low salary was that he had mental problems. This situation may be extreme, but when a pensioner's social grant is over three times the salary of a young man, kinship relations are inevitably affected.

23 For a compelling study on individualized explanations for the structural conditions of unemployment in Northern Ireland, see Howe (I998).

24 On the dynamics of sex and money in South Africa, see Bähre (2002, 2007); Niehaus (I995); Jones (I998); and Goldblatt (2003).

25 See Meyer (2004) for an overview of ethnographies and debates on Pentecostalism in Africa.

26 Of the respondents that belonged to a church, I I percent identified as Anglican and 23 percent as Methodist. These are much smaller numbers than were found to belong to those churches in I960. See Wilson and Mafeje (1963).

27 www.assemblies.org.za. 


\section{Penetrating a new market}

I On statistical inventions as a precondition for the establishment of large-scale insurance, see De Swaan (I996). On different ways of controlling people and resources, see Applbaum (2004); Hacking (I990); and Power (I997). On statistics and new ways of seeing the world, see Ewald (I99I, 2002); Hacking (I990); and Hart (2004).

2 See www.saarf.co.za/LSM/lsmpresentations.htm, accessed February 20I 2.

3 See http://go.worldbank.org/ $\mathrm{ON}_{44} \mathrm{~J}_{6} \mathrm{~V}_{3} \mathrm{Ko}$, accessed April I7, 20I7. See Grosh and Glewwe (I995) on the technical development of this measure.

4 See http:/go.worldbank.org/ JUQXBAY6QO, accessed April I7, 2017.

5 See www.saarf.co.za/lsm/lsms.asp, accessed May 23, 2017.

6 For example, Eighty2o. For a quick calculation of your SLM status, see www.eighty20.co.za/databases/ show_db.cgi?db=fulllsmcalculator. See for example Davids and Gaibie (20II); De Jager (2004); Martins (2006); PCAS (2008); Prinsloo (20I0); and Schneider et al. (2009).

7 This is for 20I 2, but the income categories are adjusted regularly. In September 20I 2, the South African Rand was valued at about I 2 US dollar cents or 9 euro cents which means that $R_{I}, 363$ was at the time EURI23.

8 See LSM descriptions 20I2, PowerPoint available on saarf. co.za: thread: SAARF LSM; LSM description slides, accessed February 2012.

9 Rondavels have become popular tourist accommodations in South Africa's game parks.

Io On the way in which language suspends disagreements and tensions, at least temporarily, see also Mosse (2005).
I I See also Prahalad (2004) on this win-win situation.

I 2 Fifteen reasons were listed for belonging to burial societies and fifteen reasons for belonging to stokvels and savings clubs.

I3 See Bleek (I987) for a fascinating account of representing sensitive issues through survey research.

I4 See http://asaba.co.za/about-us/ history.

I 5 Numbers are provided by the South African Actuarial Society, see Harris (20I7). See also Ramaphosa's (20I4) call for more black actuaries.

I6 Section 9(I) of the B-BBEE Act 53,2003 . Act 53 of 2003 .

I7 See www.fscharter.co.za, accessed May 23, 2017.

I 8 The discussions on the NSSF started in 2006. The aim of the program was to ensure that "everyone in employment receives a pension of at least 40 percent of their final salaries at retirement" in "Retirement reform is not a plot to nationalise corporate SA." November 24, 2007, IOL online, www.iol.co.za/personalfinance/retirement-reformis-not-a-plot-to-nationalisecorporate-sa-997082, accessed July 20I7. The NSSF was intended to alleviate poverty and was also seen as a way to "halt the excesses of the financial service industry, which continues to use the retirement savings of ordinary people as an easy source of profits and to pay senior executives extraordinary salaries" (Cameron 2007). Nathea Nicolay, actuary for the Metropolitan insurance company, calculated that many people would not benefit from this provision. "The average life expectancy at birth was $5 \mathrm{I}$, and therefore, she argued, social security systems had to balance 
retirement benefits with death and disability benefits" (SAPA 2008). When asked about the NSSF, 59 percent of the actuaries participating in the survey agreed or strongly agreed that the NSSF would be a threat to Private Retirement Fund Service Providers. Nearly half of the respondents also expected that the unemployed and the poor in general would benefit from the NSSF (both 48 percent).

I9 Government Notice no. 903 in Government Gazette no. 32564 , September I I, 2009.

20 On AIDS denial, see McNeill (2009); Nattrass (2008); and Posel (2005).

\section{The Janus face of inclusion}

I These forms of financialization lead to hierarchies that are both reminiscent of audit culture and patronage (Elyachar 2002; Hull and James 20I 2; Strathern 2000).

2 See also Ferguson's (2005) analysis of state-like business, and Ewald's (2002) thought-provoking view on the development of the precautionary principle in insurance.

3 See also Zelizer (I978) on the rise of insurance in nineteenth-century USA.
2I Estimates according to UNAIDS, see www.unaids.org/ en/regionscountries/countries/ southafrica, accessed April I7, 2017.

22 On this debate see the valuable contributions made by Applbaum (2004); Douglas and Wildavsky (1983); Strathern (2000); Leach (I964); Maurer (2005); Needham (1979); Durkheim and Mauss (I9OI-I9O2); Ericson and Doyle (2004); Beck (I992); and Guyer (2009).

23 On these insecurities and private security policing see Diphoorn (2015) and Comaroff and Comaroff (20I7).

4 See also Golomski (2018a, 9I) on the hierarchy of insurance policies sold in Swaziland.

5 The eleven official languages of South Africa are Afrikaans, English, Ndebele, Northern Sotho, Sotho, Swazi, Tsonga, Tswana, Venda, Xhosa, and Zulu.

6 Representatives are among others the human rights and social justice organization Black Sash, the Association for Community Advice Offices in South Africa (ACAOSA), the Department of Social Development, and the South African Social Security Agency.

\section{The enchantment of abstract finance}

I See Lassman and Speirs (I994).

2 Weber's expectation of bureaucracy as rational and impersonal is problematic. Research has shown that intersubjectivities, personal relationships, and emotions are fundamental to bureaucratic practices (Herzfeld I992; Gupta 2OI2; Terpe 2OI2). However, here I make a different argument.

3 Max Weber quoted in Scaff (2OII, 42).

4 See Jo Ann Rayfield's “Tragedy in the Chicago Fire and Triumph in 
Architectural Response.” Available online: www.lib.niu.edu/I997/

iht4I9734.html, accessed

February 20, 20I 5.

5 See also Ferguson's (I 999)

revisiting of the work by the

Rhodes Livingstone Institute and the critique by Meinert and Kapferer (201 5) on Ferguson's analysis.

6 See also James (20I4).

7 Examples of promoting the culture of saving can be found on: http:// sanews.gov.za/south-africa/youngpeople-introduced-culture-savings and: http://mg.co.za/article/2OI 2०8-०8-turning-south-africa-into-anation-of-savers, accessed July 3, 20I7. On financial education and gambling among South Africa's poor, see Van Wyk (201 2, 45-46). On the morality of financial education related to credit and how this emphasizes personal characteristics above the structural causes of debt, see James (20I4, especially 2I6-224).

8 This can be partly explained because one is most familiar with the shortcomings of the world of which one is a part. These dynamics have been examined in detail by Herzfeld (2005).

9 The position of the church is more ambiguous as some churches are very large and others have congregations of just a few dozen people.

Io The residents of Indawo Yoxolo and Tembani predominantly belong to the LSM I-5 category, but at the same time one needs to be careful in assuming that they are representative for the LSM I-5 population in the whole country.

I I See Sharp and Spiegel (I985).

I 2 UIF premium is automatically deducted by the employee from the employer's salary.

I3 According to Vivian, insurance companies create problems once they become part of social networks, which I will explore in Chapter 8.

I4 Bill Maurer (2008) argued that the plea for a socialization of finance underestimates the complexity of these relations and systematically underestimates the value of calculative rationality.

\section{7 'Transforming mutualities in business}

I www.arrivealive.co.za/MinibusTaxis-and-Road-Safety, accessed January I9, 2017.

2 On the politics of gestures, see Herzfeld (2009).

3 After this meeting, it became clear to me that I was becoming too familiar with a world that was extremely violent and not much later I decided to stop my research on the taxi industry.

4 Dugard (200I, 9) argues that increased taxi violence was due to transport deregulation that took place after the 1987 White Paper on Transport and the I988 Transport Deregulation
Act. However, the taxi wars started in the early I980 and the Transport Deregulation Act commenced only in June I990. I believe that the taxi wars were not a result of taxi deregulation, but of urbanization, political protest, and the breakdown of apartheid legislation.

5 SAPA released several statements on October I9, I994.

6 See also Ntsebeza (2005, section 8).

7 On the TRP policy see Schalekamp et al. (20I0) and Walters (2008).

8 On the legislative process, see Behrens and Wilkinson (2003); 
Schalekamp and Behrens (2010); and Wilkinson (2010).

9 www.labour.gov.za/DOL/mediadesk/media-statements/20Io/ unemployment-insurance-fundputs-taxi-sector-on-the-lens, accessed January 25, 2017.

IO In 20I3, the National Credit Regulator (NCR) issued a Compliance Notice to SA Taxi Securitization for charging their clients too much for credit insurance. See www.ccrworld.net/index. php?option $=\mathrm{com}_{-}$ content\&task $=$ view\&id $={ }_{I} 879 \&$ Ite mid=99999999, accessed January $25,2017$.

I I On these policies, see www. ctu.co.za/insurance-products/ comprehensive-taxi-insurance. html, accessed January 25, 20 I 7.

I 2 See http://mobilityins.co.za, accessed January 25, 2017.

I3 20 IO prices.

I4 For a more detailed account of the BRT-related conflicts, see Bähre (2OI4).

I 5 See also James (20II) on the return of the broker and Niehaus (2006) on neopatrimonialism in South Africa.

\section{Death as moral hazard}

I To highlight this difference the term "life assurance" is often used in the financial sector and legislation.

2 See www.econlib.org/library/Enc/ Insurance.html.

3 See Golomski (2018a, 91-93) on how funeral insurance affects orphanages in Swaziland.

4 On the future contracts and crops, see among others Zaloom (2006, I7-22).

5 African clients mostly saw life insurance and funeral insurance as one and the same thing.

6 Emphasis not in questionnaire, which was read aloud - mostly in Xhosa - to overcome non-response by illiteracy.

7 See among others Bähre (2007); Bank (I 997); Burman and Lembete (I 995); Golomski (2016); Jewkes et al. (2009); Lee (20I2); Mager (I999); Verhoef (200I); Niehaus (20I3a).

8 www.gov.za/new-minimum-wagecontract-cleaning-20 I 5, accessed June 5, 20I7. Estimated on a fortyhour working week and $\operatorname{Ri} 6.98$ minimum hourly wage. There are great differences between the number of hours that cleaners work and not all cleaners receive a minimum wage. Since 2019, South Africa has had a national minimum wage of $\mathrm{R}_{3}, 500$ per month.

9 This is also addressed in the ontological approach by science and technology studies, see for example Mol (1999, 2003) and M'charek et al. (20I6).

Io The effects of apartheid on kinship have been studied in great detail by among others James (I 999); Jones (I993); Mager (I999); Niehaus (2013a); Ramphele (I989); Ross (20I 2); Sharp and Spiegel (I985); Wilson and Mafeje (1963).

I I I would like to thank Anne Mager for pointing me to this case.

I2 See also Niehaus (2013a) and his approach to Handelman (I 998).

I3 Hammond-Tooke (I970) found that most witchcraft accusations occurred between in-laws. See also Bähre (2002) on the tensions between conjugal and affinal relations.

I4 On the aggression of gift-giving, see also the introduction of this 
book; Bähre (2007, 20I 5); and Bataille (I99I).

I 5 Evans-Pritchard ([1937] I976) famously made this point in his study of Zande witchcraft. On witchcraft and misfortune in South Africa see Bähre (2002);
Hammond-Tooke (I970); and Niehaus (1997, 2013a).

I 6 See Bähre (2002); Bank (I999); Mager (I999); McAllister (2005); Niehaus (20I3a); Reid and Walker (2005); and Spiegel (I987).

\section{Conclusion: ironies of solidarity}

I See among others Gudeman (200I); the contributions in Hart and Hann (2009); Hann (I992) on Polanyi (I944); and Maurer (I 999, 2005, 2007, 2008). Knorr Cetina and Bruegger's (2002) approach to global financial markets is of particular relevance. Knorr Cetina and Bruegger undertook an ethnographic study of foreign currency traders and show how the technologies that traders use enable new forms of intersubjectivity.

2 On witchcraft and kinship in South Africa, see among others Bähre (2002, 2007, 2009); HammondTooke (I974); and Niehaus (200I, 20I3a).

3 The importance of suffering has received ample attention in anthropology. See for example Das (I998, 20IO) and Das et al. (2000).
4 According to Fernandez and Huber (200I, I) "'Irony' has come to describe not just a figure of speech, but a questioning attitude and critical stance as well." The ambiguity of irony means that it is unclear what is meant or desired, see also Taylor (200I) on this point.

5 Archbishop Tutu, who headed the Truth and Reconciliation Commission that investigated apartheid atrocities, made a strong case for Ubuntu philosophy, a philosophy that recognized this humanity. For debates and controversies on this notion, see among others Battle (I997); Van Binsbergen (200I); Ramose (I999); and Sindane and Liebenberg (2000). 


\section{Bibliography}

Agar, Michael. 20I I. "Making Sense of One Other for Another: Ethnography as Translation." Language $\mathcal{E}$ Communication 3 I (I): $38-47$.

Alexander, Catherine. 2009. Illusions of Freedom: Polanyi and the Third Sector. In Market and Society: The Great Transformation Today, edited by Keith Hart and Chris M. Hann, 22I-239. Cambridge: Cambridge University Press.

Amadae, Sonja M. 2003. Rationalizing Capitalist Democracy: The Cold War Origins of Rational Choice Liberalism. Chicago: University of Chicago Press.

Amadae, Sonja M. 20I6. Prisoners of Reason: Game Theory and Neoliberal Political Economy. Cambridge: Cambridge University Press.

Amin, Ash. 2009. The Social Economy: International Perspectives on Economic Solidarity. London: Zed Books.

ANC. 1994. The Reconstruction and Development Programme: $A$ Policy Framework. Johannesburg: Umanyano.

Appadurai, Arjun. 20I 5. Banking on Words: The Failure of Language in the Age of Derivative Finance. Chicago: University of Chicago Press.

Applbaum, Kalman. 2004. The Marketing Era: From Professional Practice to Global Provisioning. New York and London: Routledge.

Arya, Bindu, and Balbir Bassi. 20I I. "Corporate Social Responsibility and Broad-based Black Economic Empowerment Legislation in South Africa: Codes of Good Practice." Business \& Society 50 (4): 674-695.
Ashforth, Adam. 2005. Witchcraft, Violence and Democracy in South Africa. Chicago: Chicago University Press.

Baehr, Peter. 200I. "The 'Iron Cage' and the 'Shell as Hard as Steel': Parsons, Weber, and the Stahlhartes Gehäuse Metaphor in the Protestant Ethic and the Spirit of Capitalism." History and Theory 40 (2): I 53-I 69.

Bähre, Erik. 2002. "Witchcraft and the Exchange of Sex, Blood, and Money among Africans in Cape Town, South Africa." Fournal of Religion in Africa 32 (3): 300-334.

Bähre, Erik. 2005. "How to Ignore Corruption: Reporting the Shortcomings of Development in South Africa." Current Anthropology 46 (I): I07-II3, II7-I20.

Bähre, Erik. 2007. Money and Violence: Financial Self-Help Groups in a South African Township. Leiden: Brill.

Bähre, Erik. 2009. Fictive Birthday and Real Debts. Documentary. I 4:40 mins. Leiden University and London School of Economics and Political Sciences.

Bähre, Erik. 20I I. "Liberation and Redistribution: Social Grants, Commercial Insurance, and Religious Riches in South Africa." Comparative Studies in Society and History 53 (2): 37 I-392.

Bähre, Erik. 20I 2. "The Janus Face of Insurance in South Africa: From Costs to Risk, from Networks to Bureaucracies." Africa 82 (I): I 50-I 67.

Bähre, Erik. 20I4. "A Trickle-up Economy: Mutuality, Freedom and Violence in Cape Town's 
Taxi Associations." Africa 84 (4): 576-594.

Bähre, Erik. 20I 5 . "Ethnography's Blind Spot: Intimacy, Violence, and Fieldwork Relations in South Africa." Social Analysis: The International fournal of Social and Cultural Practice 59 (3): I-I6.

Bank, Leslie J. I990. "The Making of the QwaQwa 'Mafia'? Patronage and Protection in the Migrant Taxi Business.” African Studies 49 (I): 70-93.

Bank, Leslie J. 1997. "The Social Life of Paraffin; Gender, Domesticity and the Politics of Value in a South African Township." African Studies 56 (2): I 57-I79.

Bank, Leslie J. I999. "Men with Cookers: Transformations in Migrant Culture, Domesticity and Identity in Duncan Village, East London." Fournal of Southern African Studies 25 (3): 393-4I 6.

Bank, Leslie J. 20I I. Home Spaces, Street Styles: Contesting Power and Identity in a South African City. London: Pluto Press.

Barlow, Sarah. 2003. Donor Innovation in Financial System Development: DFID's Design of FinMark Trust in South Africa. Case Studies in Donor Good Practices 9. CGAP. Accessed July 4, 2017. http://documents.worldbank.org/ curated/en/50872I468305683599/ $\mathrm{pdf} / 764240$ BRI॰CGAPooBox 3743 ${ }_{67}$ BooPUBLICo.pdf.

Bataille, Georges. I99I. The Accursed Share: An Essay on General Economy, Volume I: Consumption. New York: Zone Books.

Battle, Michael. I997. Reconciliation: The Ubuntu Theology of Desmond Tutu. Cleveland: The Pilgrim Press.

Bayart, Jean-François. I993. The State in Africa: The Politics of the Belly. London and New York: Longman.

BBC. 2016. "South Africa Gupta Row: ANC's Mantashe Warns of 'Mafia State'." $B B C$, March I7. www.bbc.co.uk/news/worldafrica-3583 I967.

Beck, Ulrich. I992. Risk Society: Towards a New Modernity. London: Sage.

Behrens, Roger, and Peter Wilkinson. 2003. Metropolitan Transport Planning in Cape Town, South Africa: A Critical Assessment of Key Difficulties. Cape Town: Urban Transport Research Group, Faculty of Engineering and the Built Environment, University of Cape Town.

Bertrand, Marianne, Sendhil Mullainathan, and Douglas Miller. 2003. "Public Policy and Extended Families: Evidence from Pensions in South Africa." The World Bank Economic Review I7 (I): 27-50.

Bessire, Lucas, and David Bond. 20I4. "Ontological Anthropology and the Deferral of Critique." American Ethnologist 4I (3): 440-456.

Bickford-Smith, Vivian, Elizabeth Van Heyningen, and Nigel Worden. I999. Cape Town in the Twentieth Century: An Illustrated Social History. Cape Town: David Philip.

Bleek, Wolf. I987. "Lying Informants: A Fieldwork Experience from Ghana." Population and Development Review I3 (2): 3 I 4-322.

Bloch, Maurice, and Jonathan Parry. I989. Introduction: Money and the Morality of Exchange. In Money and the Morality of Exchange, edited by Maurice Bloch and Jonathan Parry, I-32. Cambridge: Cambridge University Press.

Bond, Patrick. 2000. The Elite Transition: From Apartheid to Neoliberalism in South Africa. London: Pluto Press.

Bond, Patrick. 20I4. Global Financial Governance and the Opening to BRICS Banking. In State of the Nation: South Africa 
I994-20I4: A Twenty-Year Review of Freedom and Democracy, edited by Thenjiwe Meyiwa, Nkodo Muxe, Margaret Chitiga-Mabugu, Moses Sithole, and Francis B. Nyamnjoh, 442-463. Pretoria: HSRC Press.

Bonner, Phillip. I995. "African Urbanisation on the Rand between the I930s and I960s: Its Social Character and Political Consequences." Fournal of Southern African Studies 2I (I): I I 5-I 29.

Bonner, Philip, and Noor Nieftagodien. 200I. The Truth and Reconciliation Commission and the Pursuit of "Social Truth": The Case of Kathorus. In Commissioning the Past: Understanding South Africa's Truth and Reconciliation Commission, edited by Deborah Posel and Graeme Simpson, I73-203. Johannesburg: Witwatersrand University Press.

Botha, Claire, and Michael Hendricks. 2008. Financing South Africa's National Health System through National Health Insurance: Possibilities and Challenges. Pretoria: Human Sciences Research Council.

Bourdieu, Pierre. I999. Acts of Resistance: Against the Tyranny of the Market. New York: New Press.

Bourdieu, Pierre. 2002. Understanding. In The Weight of the World: Social Suffering in Contemporary Society, edited by Pierre Bourdieu, 607-626. Cambridge: Polity.

Bourdieu, Pierre, and Loïc Wacquant. I992. An Invitation to Reflexive Sociology. Chicago: University of Chicago Press.

Bourdieu, Pierre et al. 2002. The Weight of the World: Social Suffering in Contemporary Society. Cambridge: Polity.

Breckenridge, Keith. 20ıо. "The World's First Biometric Money: Ghana's e-Zwich and the Contemporary Influence of South
African Biometrics." Africa 80 (4): 642-662.

Breckenridge, Keith. 20I4. Biometric State. Cambridge: Cambridge University Press.

Burawoy, Michael. 2009. The Extended Case Method: Four Countries, Four Decades, Four Great Transformations, and One Theoretical Tradition. Berkeley: University of California Press.

Burman, Sandra, and Nozipho Lembete. I995. Building New Realities: African Women and ROSCAs in Urban South Africa. In Money-Go-Rounds: The Importance of Rotating Savings and Credit Associations for Women, edited by S. Ardener and S. Burman, 23-47. Oxford: Berg.

Cameron, Bruce. 2007. "Retirement Reform Is Not a Plot to Nationalise Corporate SA." Independent Online, November 24. www. iol.co.za/personal-finance/ retirement-reform-is-not-a-plot-tonationalise-corporate-sa-997082.

Caplovitz, David. 1967. The Poor Pay More: Consumer Practices of LowIncome Families. New York and London: Free Press.

Chan, Cheris Shun-ching. 2012. Marketing Death: Culture and the Making of a Life Insurance Market in China. Oxford: Oxford University Press.

Chander, Ramesh, Christiaan Grootaert, and Graham Pyatt. 1980. Living Standard Surveys in Developing Countries. LSMS Working Paper I. Washington: World Bank.

Cheru, Fantu. 200I. "Overcoming Apartheid's Legacy: The Ascendancy of Neoliberalism in South Africa's Anti-Poverty Strategy." Third World Quarterly 22 (4): 505-527.

Cock, Jacklyn. I980. Maids and Madams: A Study in the Politics of Exploitation. Johannesburg: Ravan Press. 
Cole, Josette. I987. Crossroads: The Politics of Reform and Repression I976/I986. Johannesburg: Ravan Press.

Comaroff, Jean. I985. Body of Power, Spirit of Resistance: The Culture and History of a South African People. Chicago and London: University of Chicago Press.

Comaroff, Jean, and John L. Comaroff. I990. "Goodly Beasts, Beastly Goods: Cattle and Commodities in a South African Context." American Ethnologist I7 (2): 195-2I6.

Comaroff, Jean, and John L. Comaroff. I999. "Occult Economies and the Violence of Abstraction: Notes from the South African Postcolony." American Ethnologist 26 (2): 279-303.

Comaroff, Jean, and John L. Comaroff. 2000. "Millennial Capitalism: First Thoughts on a Second Coming." Public Culture I 2 (2): 29I-343.

Comaroff, Jean, and John L. Comaroff (eds.). 200I. Millennial Capitalism and the Culture of Neoliberalism. Raleigh: Duke University Press.

Comaroff, Jean, and John L. Comaroff. 2017. The Truth about Crime: Sovereignty, Knowledge, Social Order. Chicago: University of Chicago Press.

Cramer, Christopher. 2002. "Homo Economicus Goes to War: Methodological Individualism, Rational Choice and the Political Economy of War." World Development 30 (I I): I 845-I 864 . Crankshaw, Owen. 2012.

"Deindustrialization, Professionalization and Racial Inequality in Cape Town." Urban Affairs Review 48 (6): 836-862.

Cross, Catherine. 2005. "Conflict Re-emerges at Crossroads: New Shacklords Battle the City." HSRC Review 3 (I): 6-7.

Dao, Amy, and Jessica Mulligan. 2016. "Toward an Anthropology of Insurance and Health Reform: An
Introduction to the Special Issue." Medical Anthropology Quarterly 30 (I): 5-I7.

Dao, Amy, and Mark Nichter. 20I6. "The Social Life of Health Insurance in Low- to Middle-Income Countries: An Anthropological Research Agenda." Medical Anthropology Quarterly 30 (I): I 22-I43.

Das, Veena. I995. Critical Events: An Anthropological Perspective on Contemporary India. Delhi: Oxford University Press.

Das, Veena. I998. "Wittgenstein and Anthropology." Annual Review of Anthropology 27: I7 I-I95.

Das, Veena. 2010. "Trauma and Testimony: Implications for Political Community." Anthropological Theory 3 (3): 293-307.

Das, Veena, Arthur Kleinman, Mamphela Ramphele, and Pamela Reynolds. 2000. Violence and Subjectivity. Berkeley: University of California Press.

Datamonitor. 20Io. Industry Profile: Insurance in South Africa. New York: Datamonitor.

Davids, Yul D., and Fairuz Gaibie. 20I I. "Quality of Life in PostApartheid South Africa." Politikon 38 (2): 23 I-256.

Davis, Gerald F, and Suntae Kim. 20I 5. "Financialization of the Economy." Annual Review of Sociology 4I (I): 203-22I.

Davis, Rebecca. 20I 5. "The Black Widow: How Thandi Maqubela Spun Her Web of Lies." Daily Maverick, November 8. www.dailymaverick.co.za/ article/20I3-I I-O8-the-blackwidow-how-thandi-maqubelaspun-her-web-of-lies/\#. WThrB8azhPM.

De Swaan, Abram. 1996. Zorg en de Staat: Welzijn, Onderwijs en Gezondheidszorg in Europa en de Verenigde Staten in de Nieuwe Tijd. Amsterdam: Bert Bakker. 
De Jager, Nedia. 2004. The Living Standards Measure as a Market Segmentation Tool for Selected Retailers. MA thesis. North-West University.

De Wet, Chris. I989. "Betterment Planning in a Rural Village in Keiskammahoek, Ciskei." fournal of Southern African Studies I 5 (2): 326-345.

De Wet, Chris. I996. "Antropologie en die Heropbou- en Ontwikkelingsprogram." South African Fournal of Ethnology I9 (I): 7-II.

De Wet, Chris, and Michael Whisson. I997. From Reserve to Region: Apartheid and Social Change in the Keiskammahoek District of (Former) Ciskei: 1950-I 990. Occasional Paper 35 . Institute for Social and Economic Research, Rhodes University, Grahamstown.

Devereux, George. I967. From Anxiety to Method in the Behavioral Sciences. The Hague and Paris: Mouton \& Co.

Diphoorn, Tessa G. 20I 5. Twilight Policing: Private Security and Violence in Urban South Africa. Berkeley: University of California Press.

Dlamini, Bathabile. 20I4. Media Briefing on Unauthorised Deductions. Black Sash.

Douglas, Mary. 1966. Purity and Danger: An Analysis of Concepts of Pollution and Taboo. London and Boston: Routledge and Kegan Paul.

Douglas, Mary. I992. Risk and Blame: Essays in Cultural Theory. London: Routledge.

Douglas, Mary, and Aaron Wildavsky. I983. Risk and Culture: An Essay on the Selection of Technological and Environmental Dangers. Berkeley: University of California Press.

Dugard, Jackie. 200I. From Low Intensity War to Mafia War: Taxi Violence in South Africa
(1987-2000). Violence and Transition Series 4. Cape Town: Centre for Studies of Violence and Reconciliation.

Durkheim, Emile, and Marcel Mauss. I90I-I902. "De quelques formes de primitives de classification: contribution à l'étude des représentations collectives." Année Sociologique 6: I-72.

Ellison, James. 20I 4. "First-Class Health: Amenity Wards, Health Insurance, and Normalizing Health Care Inequalities in Tanzania." Medical Anthropology Quarterly 28 (2): I 62-I 8I.

Elyachar, Julia. 2002. "Empowerment Money: The World Bank, NonGovernmental Organizations, and the Value of Culture in Egypt." Public Culture I4 (3): 493-5I3. Elyachar, Julia. 2005. Markets of Dispossession: NGOs, Economic Development, and the State in Cairo. Durham: Duke University Press.

Ericson, Richard V., and Aaron Doyle. 2004. "Catastrophe Risk, Insurance and Terrorism." Economy and Society 33 (2): I $35-$ I 73 .

Eriksen, Thomas Hylland, James Laidlaw, Jonathan Mair, Keir Martin, and Soumhya Venkatesan. 20I 5. "The Concept of Neoliberalism Has Become an Obstacle to the Anthropological Understanding of the Twentyfirst Century." Fournal of the Royal Anthropological Institute 2I (4): 9I I-923.

Evans-Pritchard, Edward E. (I937) 1976. Witchcraft, Oracles and Magic among the Azande. Oxford: Oxford University Press.

Evens, Terence M.S., and Don Handelman. 2006. The Manchester School: Practice and Ethnographic Praxis in Anthropology. New York and Oxford: Berghahn.

Everett, Cath. 2014. "Cape Town: Most Violent City in Africa Struggles with Entrenched Gang 
Culture." International Business

Times, November 25. www.ibtimes. co.uk/cape-town-most-violent-cityafrica-struggles-entrenched-gangculture-I 476375 .

Ewald, François. I99I. Insurance and Risk. In The Foucault Effect: Studies in Governmentality with Two Lectures by and an Interview with Michel Foucault, edited by Graham Burchell, Colin Gordon, and Peter Miller, I97-210. London, Singapore, Sydney, Tokyo, and Toronto: Harvester Wheatsheaf.

Ewald, François. 2002. The Return of Descartes's Malicious Demons: An Outline of a Philosophy of Precaution. In Embracing Risk: The Changing Culture of Insurance and Responsibility, edited by Tom Baker and Jonathan Simon, 273-302. Chicago: University of Chicago Press.

Farber, Tanya. 2007. "War over Routes." Mail and Guardian, May I 8. www.pressreader. com/south-africa/mail-guard ian/20070 5 I 8/28 I 732675054984.

Ferguson, James. I999. Expectations of Modernity: Myths and Meanings of Urban Life on the Zambian Copperbelt. Berkeley: University of California Press.

Ferguson, James. 2005. "Seeing Like an Oil Company: Space, Security, and Global Capital in Neoliberal Africa." American Anthropologist I07 (3): 377-382.

Ferguson, James. 2007. "Formalities of Poverty: Thinking about Social Assistance in Neoliberal South Africa." African Studies Review 50 (2): $7 \mathrm{I}-86$.

Ferguson, James. 20I 5. Give a Man a Fish: Reflections on the New Politics of Distribution. Durham: Duke University Press.

Fernandez, James W., and Mary Taylor Huber. 200I. Introduction: The Anthropology of Irony. In Irony in Action: Anthropology, Practice, and the Moral Imagination, edited by J.W. Fernandez and M.T. Huber, I-37. Chicago and London: University of Chicago Press.

FinScope. 2004. FSM: An In Depth Understanding of the Level of Access to Financial Products and Service Usage in South Africa 2003. Johannesburg: FinMark Trust.

Fischer, At. I988. Whose Development? The Politics of Development and the Development of Politics in South Africa. In South African Keywords: The Uses and Abuses of Political Concepts, edited by Emile Boonzaier and John S. Sharp, I 22-I35. Cape Town and Johannesburg: David Philip.

Foley, Ellen E. 2008. "Neoliberal Reform and Health Dilemmas: Illness, Social Hierarchy, and Therapeutic Decision-making in Senegal." Medical Anthropology Quarterly 22 (3): 257-273.

Fournier, Marcel. 2006. Marcel Mauss: A Biography. Princeton: Princeton University Press.

Galtung, Johan. I969. "Violence, Peace, and Peace Research." fournal of Peace Research 6 (3): I67-I9I.

Ganti, Tejaswini. 20I4. "Neoliberalism." Annual Review of Anthropology 43: 89-IO4.

Geertz, Clifford. I968. Thinking as a Moral Act: Ethical Dimensions of Anthropological Fieldwork in the New States. The Antioch Review 28 (3): I39-I 58.

Gluckman, Max. 1940. Analysis of a Social Situation in Modern Zululand. Manchester: Manchester University Press.

Goldblatt, Beth. 2003. "Teen Pregnancy and Abuse of the Child Support Grant: Addressing the Myths and Stereotypes." Agenda: Empowering Women for Gender Equity (56): 78-83.

Goldin, Ian. I987. Making Race: The Politics and Economics of Coloured Identity in South Africa. London and New York: Longman. 
Golomski, Casey. 201 5. "Compassion Technology: Life Insurance and the Remaking of Kinship in Swaziland's Age of HIV." American Ethnologist 42 (I): 8I-96.

Golomski, Casey. 2016. "Outliving Love: Marital Estrangement in an African Insurance Market." Social Dynamics 42 (2): 304-320.

Golomski, Casey. 2018a. Funeral Culture: AIDS, Work, and Cultural Change in an African Kingdom. Bloomington: Indiana University Press.

Golomski, Casey. 2018b. "Elder Care and Private Health Insurance in South Africa: The Pathos of RaceClass." Medical Anthropology 37 (4): 3 I I-326.

Gontsana, Mary-Anne. 2016. "Black Sash Gathers Support for Social Grants Campaign." GroundUp, October I 2. www.groundup.org.za/ article/black-sash-gathers-supportsocial-grants-campaign.

González, Laura López. 2017. "Trade Unions: 'The NHI Is Not Moving Fast Enough'." Bhekisisa: Centre for Health Fournalism, July I. http://bhekisisa.org/ article/20I7-07-OI-cosatu-denosalikely-to-demand-answers-onnational-health-insurance.

Goodman, David, E. Melanie DuPois, and Michael $\mathrm{K}$. Goodman. 2012. Alternative Food Networks: Knowledge, Practice, and Politics. New York: Routledge.

Grasseni, Cristina. 20I4. "Seeds of Trust: Italy's Gruppi di Acquisto Solidale (Solidarity Purchase Groups)." Fournal of Political Ecology 21: I78-192.

Green, Maia. 201 5. "Making Africa Middle Class: From Poverty Reduction to the Production of Inequality in Tanzania." Economic Anthropology 2 (2): 295-309.

Grosh, Margaret E., and Paul Glewwe. I995. A Guide to Living Standard Measurement Study Surveys and Their Data Sets. LSMS Working Paper I 20. World Bank, Washington.
GroundUp. 20I 5. Spotlight on Social Grants: Sassa's Bid to Stop Illegal Deduction. GroundUp, October 7. www.groundup.org.za/article/ spotlight-social-grants-sassas-bidstop-illegal-deductions_3372.

Gudeman, Stephen. 200I. The Anthropology of Economy: Community, Market, and Culture. Malden: Wiley-Blackwell.

Gudeman, Stephen. 2009. Necessity or Contingency: Mutuality and Market. In Market and Society: The Great Transformation Today, edited by Keith Hart, and Christopher M. Hann, I7-37. Cambridge: Cambridge University Press.

Gupta, Akhil. 20I 2. Red Tape: Bureaucracy, Structural Violence, and Poverty in India. Durham and London: Duke University Press.

Guyer, Jane I. I995. Money Matters: Instability, Values and Social Payments in the Modern History of West African Communities. Portsmouth and London: Heinemann and James Currey.

Guyer, Jane I. 2004. Marginal Gains: Monetary Transactions in Atlantic Africa. Chicago and London: University of Chicago Press.

Guyer, Jane I. 2009. Composites, Fictions, and Risk: Toward an Ethnography of Price. In Market and Society: The Great Transformation Today, edited by Keith Hart and Christopher M. Hann, I60-I74. Cambridge: Cambridge University Press.

Hacking, Ian. I990. The Taming of Change. Cambridge: Cambridge University Press.

Hammond-Tooke, David W. I970. "Urbanization and the Interpretation of Misfortune: A Quantitative Analysis." Africa 40 (I): 25-39.

Hammond-Tooke, W.D. I974. "The Cape Nguni Witch Familiar as a Mediatory Construct." Man 9 (9): I28-I36.

Handelman, Don. I998. Models and Mirrors: Towards an Anthropology of Public Events. New York and Oxford: Berghahn. 
Handler, Richard. 2013. The Uses of Incommensurability in Anthropology. In Comparison: Theories, Approaches, Uses, edited by Rita Felski and Susan S. Friedman, 27I-29I. Baltimore: Johns Hopkins University Press.

Hann, Chris M. I992. Radical Functionalism: The Life and Work of Karl Polanyi. Dialectical Anthropology I7 (2): I4I-I 66.

Hann, Chris M. 2009. Embedded Socialism? Land, Labor, and Money in Eastern Xinjiang. In Market and Society: The Great Transformation Today, edited by Keith Hart and Chris M. Hann, 256-27I. Cambridge: Cambridge University Press.

Harris, Roseanne Murphy. 2017. "Number of Qualified African Actuaries Expected to Double over the Next Three Years." FAnews, March 29. www. fanews.co.za/article/peopleand-companies/I 2/news/I I 63/ number-of-qualified-africanactuaries-expected-to-double-overthe-next-three-years/2 I 988.

Hart, Keith. I973. "Informal Income Opportunities and Urban Employment in Ghana." The Fournal of Modern African Studies I I (I): 6I-89.

Hart, Keith. 2004. "From Bell Curve to Power Law." Social Analysis 48 (3): 222-226.

Hart, Keith. 2007. "Money Is Always Personal and Impersonal." Anthropology Today 23 (5): I2-I6.

Hart, Keith. 20I0. Informal Economy. In The Human Economy: $A$ Citizen's Guide, edited by Keith Hart, Jean-Louis Laville, and Antonio Cattani, I42-I 53. Cambridge: Polity.

Hart, Keith (ed.). 20I 5. Economy for and against Democracy. New York and Oxford: Berghahn.

Hart, Keith, and Chris M. Hann (eds.). 2009. Market and Society: The Great Transformation Today. Cambridge: Cambridge University Press.
Hart, Keith, Jean-Louis Laville, and Antonio Cattani. 20I0. Building the Human Economy Together. In The Human Economy: A Citizen's Guide, edited by Keith Hart, JeanLouis Laville, and Antonio Cattani, I-I 7. Cambridge: Polity.

Hastrup, Kirsten. I993. "Hunger and the Hardness of Facts." Man 28 (4): 727-739.

Hastrup, Kirsten. I995. A Passage to Anthropology: Between Experience and Theory. London and New York: Routledge.

Helgesson, Kristina. 2006. "Walking in the Spirit": The Complexity of Belonging in Two Pentecostal Churches in Durban, South Africa. $\mathrm{PhD}$ thesis. Uppsala University.

Hemson, David, and Michael O'Donovan. 2006. Putting Numbers to the Scorecard: Presidential Targets and the State of Delivery. In State of the Nation: South Africa 2005-2006, edited by Sakhela Buhlungu, John K. Daniel, Roger Southall, and Jessica Lutchman, I I-45. Pretoria: HSRC Press.

Herfeld, Catherine. 20I3. The Many Faces of Rational Choice Theory. $\mathrm{PhD}$ thesis. Witten/Herdecke University.

Herzfeld, Michael. I992. The Social Production of Indifference: Exploring the Symbolic Roots of Western Bureaucracy. Chicago: University of Chicago.

Herzfeld, Michael. 2005. Cultural Intimacy: Social Poetics in the Nation State. New York, London: Routledge.

Herzfeld, Michael. 2009. "The Cultural Politics of Gesture: Reflections on the Embodiment of Ethnographic Practice."

Ethnography IO (2): I3 I-I 52.

Hlophe, Nonkululeko. 20I 5. "KZN MEC Welcomes Arrest of Corpse Fraud Suspects." SABC News, March 24. www.sabc.co.za/ news/a/ıc7e3a8047cI 545 ob2odfb9 ob7 I 7e 74I/KZN-MEC-welcomesarrest-of-corpse-fraud-suspects. 
Holmes, Thalia. 20I4. "Social

Grants Beneficiaries More Than

Doubled in Io Years." Mail and Guardian, June I9. https://mg.co. za/article/20I 4-06-I 9-social-grantsbeneficiaries-more-than-double-inIo-years.

Howe, Leo. I998. "Scrounger, Worker, Beggarman, Cheat: The Dynamics of Unemployment and the Politics of Resistance in Belfast." Fournal of the Royal Anthropological Institute 4 (3): $53 \mathrm{I}-550$.

Huchzermeyer, Marie. 200I. "Housing for the Poor? Negotiated Housing Policy in South Africa." Habitat International 25:303-33 I.

Hull, Elizabeth, and Deborah James. 20I 2. "Introduction: Local Economies and Citizen Expectations in South Africa." Africa 82 (I): I-I9.

Hunter, Monica. I933. "The Effects of Contact with Europeans on the Status of Pondo Women." Africa 6 (3): 259-276.

Hutchinson, Sharon E. I996. Nuer Dilemmas: Coping with Money, War, and the State. Berkeley and Los Angeles: University of California Press.

Jain, Hirsch. 20Iо. Community Protest in South Africa: Trends, Analysis and Explanations. Cape Town: Community Law Centre, University of the Western Cape.

James, Deborah. I999. "Bagagsu (Those of My Home): Women Migrants, Ethnicity, and Performance in South Africa." American Ethnologist 26 (I): 69-89. James, Deborah. 20I I. "The Return of the Broker: Consensus, Hierarchy, and Choice in South African Land Reform." Fournal of the Royal Anthropological Institute I7 (2): 3 I 8-338.

James, Deborah. 20I4. Money from Nothing: Indebtedness and Aspiration in South Africa. Palo Alto: Stanford University Press.
Jewkes, Rachel, and Naeema Abrahams. 2002. "The Epidemiology of Rape and Sexual Coercion in South Africa: An Overview." Social Science and Medicine 55 (7): I 23 I-I 244.

Jewkes, Rachel, Yandisa Sikweyiya, Robert Morrell, and Kristin Dunkle. 2009. Understanding Men's Health and Use of Violence: Interface of Rape and HIV in South Africa. Medical Research Council South Africa: MRC Policy Brief, June.

Jones, Sean. I993. Assaulting Childhood: Children's Experiences of Migrancy and Hostel Life in South Africa. Johannesburg: Witwatersrand University Press.

Jones, Sean. I998. Enacted Marriages and Fatherhood without Jural Paternity: Signs of Bilateral Kinship among Xhosa in an Eastern Cape Township. Paper presented at the annual conference of the Association for Anthropology in Southern Africa, University of Stellenbosch.

Kaesler, Dirk. 20I 2. "Ein 'stahlhartes Gehäuse' ist kein 'Iron Cage': Über Forscher, die kein Deutsch können." literaturkritik.de I. http:// literaturkritik.de/public/rezension. php?rez_id= 16239 .

Kapferer, Bruce. 2007. "Anthropology and the Dialectic of Enlightenment: A Discourse on the Definition and Ideals of a Threatened Discipline." The Australian fournal of Anthropology I 8 (I): 72-96.

Kapferer, Bruce. 2015. "Introduction: In the EventToward an Anthropology of Generic Moments." In In the Event: Toward an Anthropology of Generic Moments, edited by Lotte Meinert and Bruce Kapferer, I-28. New York and Oxford: Berghahn.

Keesing, Roger M. I992. "Book Review of Marilyn Strathern, 'The Gender of the Gift: Problems with 
Women and Problems with Society in Melanesia'." Pacific Studies I 5

(I): I 29-I37.

Kerstenetzky, Celia Lessa. 2009.

"Redistribuicao e desenvolvimento? A economia politica do programa bolsa familia." Dados 52 (I): $53-83$.

Khosa, Meshack M. I992. "Routes, Ranks and Rebels: Feuding in the Taxi Revolution." Fournal of Southern African Studies I 8 (I): 232-252.

Kiernan, James P. I974. "Where Zionists Draw the Line: A Study of Religious Exclusiveness in an African Township." African Studies 33 (2): 79-90.

Klein, Naomi. 2008. The Shock Doctrine: The Rise of Disaster Capitalism. New York: Picador.

Knorr Cetina, Karin, and Urs Bruegger. 2002. "Global Microstructures: The Virtual Societies of Financial Markets." American fournal of Sociology I07: 905-950.

Krippner, Greta R. 20I I. Capitalizing on Crisis: The Political Origins of the Rise of Finance. Cambridge: Harvard University Press.

Kusimba, Sibel. 201 8. "It Is Easy for Women to Ask!'”: Gender and Digital Finance in Kenya." Economic Anthropology 5 (2): 247-260.

Kusimba, Sibel, Gabriel Kunyu, and Elizabeth Gross. 201 8. Social Networks of Mobile Money in Kenya. In Money at the Margins: Global Perspectives on Technology, Financial Inclusion, and Design, edited by Bill Maurer, Smoki Musaray and Ivan Small, I79-I99. New York, Oxford: Berghahn.

Lacan, Jacques. [1973] I979. The Four Fundamental Concepts of Psychoanalysis. London: Penguin.

Lassman, Peter, and Ronald Speirs. I994. Weber: Political Writings. Cambridge: Cambridge University Press.
Latour, Bruno, and Steve Woolgar. 1979. Laboratory Life: The Construction of Scientific Facts. Princeton: Princeton University Press.

Law, John, and Marianne Elisabeth Lien. 2013. "Slippery: Field Notes in Empirical Ontology." Social Studies of Science 43 (3): 363-378.

Leach, Edmund. I 964. "Anthropological Aspects of Language: Animal Categories and Verbal Abuse." In New Directions in the Study of Language, edited by Eric H. Lenneberg, 23-63. Cambridge: MIT Press.

Lee, Rebekah. 2005. "Reconstructing 'Home' in Apartheid Cape Town: African Women and the Process of Settlement." Fournal of Southern African Studies 3 I (3): 6I I-630.

Lee, Rebekah. 20I2. "Death in Slow Motion: Funerals, Ritual Practice and Road Danger in South Africa." African Studies 7I (2): I95-2I I.

M'charek, Amade. 2000.

"Technologies of Population: Forensic DNA Testing Practices and the Making of Differences and Similarities." Configurations 8 (I): I 2 I-I 58 .

M'charek, Amade. 20I6. "DataFace and Ontologies of Race." Theorizing the Contemporary, Fieldsights, March 24.

MacGregor, Hayley. 2005. "'The Grant Is What I Eat': The Politics of Social Security and Disability in the Post-Apartheid South African State." Fournal of Biosocial Science 38 (I): 43-55.

Mafeje, Archie. I998. "Anthropology and Independent Africans: Suicide or End of an Era?" African Sociological Review 2 (I): I-43.

Mager, Anne Kelk. I999. Gender and the Making of a South African Bantustan: A Social History of the Ciskei, I945-I959. Oxford, Portsmouth, and Cape Town: Heinemann. 
Maharaj, Brij. 20I7. "South Africa, a Mafia Shadow State?" Daily Maverick, May 2I. www.dailymaverick.co.za/ opinionista/20I 7-05-2 I-southafrica-a-mafia-shadow-state/.

Mahon, Rianne. 2010. "After NeoLiberalism? The OECD, the World Bank and the Child." Global Social Policy IO (2): I72-I92.

Mail and Guardian. 2008. "Reserve Bank: SA Largely Unaffected by Subprime Crisis." Reuters press release, July 8. https://mg.co.za/ article/2008-07-08-reserve-banksa-largely-unaffected-by-subprimecrisis.

Makiwane, Monde, Chris Desmond, Linda Richter, and Eric Udjo. 2006. Is the Child Support Grant Associated with an Increase in Teenage Fertility in South Africa? Evidence from National Surveys and Administrative Data. Pretoria: Human Sciences Research Council, Child, Youth, Family and Social Development.

Malan, Mia. 20I6. "Fed-up NHI Doctors Say They Are Nothing More Than Glorified Nurses." Bhekisisa: Center for Health fournalism, November I 4. http://bhekisisa.org/ article/20I 6-I I-I 4-oo-fed-up-nhidoctors-say-they-are-nothing-morethan-glorified-nurses.

Malinowski, Bronislaw. I922. Argonauts of the Western Pacific. New York: Routledge.

Malinowski, Bronislaw. 1967. A Diary in the Strict Sense of the Term. London: Routledge and Kegan Paul.

Manaliyo, Jean-Claude. 20I4. “Townships as Crime 'Hot-Spot' Areas in Cape Town: Perceived Root Causes of Crime in Site B, Khayelitsha." Mediterranean fournal of Social Sciences 5 (8): 596-603.

Manuel, Trevor A. 2007. Budget Speech 2007. National Treasury, Pretoria.
Manuel, Trevor A. 2008. Budget Speech 2008. National Treasury, Pretoria.

Manuel, Trevor A. 2009. Budget Speech 2009. National Treasury, Pretoria.

Mariam, Damen H. 2003. "Indigenous Social Insurance as an Alternative Financing Mechanism for Health Care in Ethiopia (the Case of Eders)." Social Science \& Medicine 56 (8): I719-I726.

Marsh, Rob. I991. Famous Crimes in South Africa: An Investigation into 26 of South Africa's Most Famous Crimes 1900-1988. Cape Town and Johannesburg: Struik Publishers.

Martins, J.H. 2006. "Household Cash Expenditure by Living Standard Measure Group." fournal of Family Ecology and Consumer Sciences 34: I-9.

Masilela, Temba, and Sihle Mthiyane. 20I4. From the RDP to the National Development Plan: The Mirage of a SuperMinistry. In State of the Nation: South Africa I994-20 I4: A Twenty-Year Review of Freedom and Democracy, edited by Thenjiwe Meyiwa, Muxe Nkondo, Margaret Chitiga-Mabugu, Moses Sithole, and Francis Nyamnjoh, 59-78. Pretoria: HSRC Press.

Masoga, Elvis. 20I7. "South Africa's Become a Mafia State." Independent Online, June I I. www.iol.co.za/ sundayindependent/dispatch/ south-africas-become-a-mafiastate-9725808.

Maurer, Bill. I999. "Forget Locke? From Proprietor to Risk-Bearer in New Logics of Finance." Public Culture I I (2): $365-385$.

Maurer, Bill. 2005. Mutual Life, Limited: Islamic Banking, Alternative Currencies, Lateral Reason. Princeton and Oxford: Princeton University Press.

Maurer, Bill. 2006. "The Anthropology of Money." Annual Review of Anthropology 35: I 5-36. 
Maurer, Bill. 2007. "Incalculable Payments: Money, Scale, and the South African Offshore Grey Money Amnesty." African Studies Review 50 (2): I25-I38.

Maurer, Bill. 2008. "Resocializing Finance? Or Dressing It in Mufti?" Fournal of Cultural Economy I (I): $65-78$.

Mauss, Marcel. [I925] I966. The Gift: Forms and Functions of Exchange in Archaic Societies. London: Cohen.

Mayer, Philip, and Iona Mayer. [I96I] I974. Townsmen or Tribesmen: Conservatism and the Process of Urbanization in a South African City. Edited by P. Mayer, Xhosa in Town: Studies of the Bantu-speaking Population of East London, Cape Province 2. Cape Town, London, New York, and Toronto: Oxford University Press.

McAllister, Patrick A. I989.

'Resistance to 'Betterment' in the Transkei: A Case Study from Willowvale District." Fournal of Southern African Studies I 5 (2): 346-368.

McAllister, Patrick A. 2005. Xhosa Beer Drinking Rituals: Power, Practice, and Performance in the South African Rural Periphery. Durham: Carolina Academic Press.

McNamara, J.K. I980. "Brothers and Work Mates: Home Friends Networks in the Social Life of Black Migrant Workers in a Gold Mine Hostel." In Black Villagers in an Industrial Society: Anthropological Perspectives on Labour Migration in South Africa, edited by Philip Mayer, 305-340. Cape Town: Oxford University Press.

McNeill, Fraser G. 2009. "'Condoms Cause AIDS': Poison, Prevention and Denial in Venda, South Africa." African Affairs I08 (432): 353-370.

Meinert, Lotte, and Bruce Kapferer (eds.). 20I 5. In the Event: Toward an Anthropology of Generic Moments. New York and Oxford: Berghahn.

Melzer, Illana, and Matthew Smith. 2004. Towards a Benchmark for Access to Life Insurance in LSM I-5. Johannesburg: Eighty 20 for FinMark Trust.

Meyer, Birgit. 2003. "Visions of Blood, Sex and Money: Fantasy Spaces in Popular Ghanaian Cinema." Visual Anthropology I 6 (I): I 5-4I.

Meyer, Birgit. 2004. "Christianity in Africa: From African Independent to Pentecostal-Charismatic Churches." Annual Review of Anthropology 33: 447-474.

Miraftab, Faranak. 2004. "Neoliberalism and Casualization of Public Sector Services: The Case of Waste Collection Services in Cape Town, South Africa." International Fournal of Urban and Regional Research 28 (4): 874-892. Mirowski, Philip. 2005. "Sleights of the Invisible Hand: Economists' Interventions in Political Theory." Fournal of the History of Economic Thought 27 (I): 87-99.

Mitchell, Clyde J. I956. The Kalela Dance: Aspects of Social Relationships among Urban Africans in Northern Rhodesia. Manchester: Manchester University Press.

Mkhwanazi, Nolwazi. 20 Iо. "Understanding Teenage Pregnancy in a Post-Apartheid South African Township." Culture, Health \& Sexuality I 2 (4): 347-358.

Mkhwanazi, Nolwazi. 20I4. "Revisiting the Dynamics of Early Childbearing in South African Townships." Culture, Health $\mathcal{E}$ Sexuality I6 (9): I084-I096.

Mol, Annemarie. I999. "Ontological Politics: A Word and Some Questions." The Sociological Review 47 (I): 74-89.

Mol, Annemarie. 2003. The Body Multiple: Ontology in Medical Practice. Durham: Duke University Press. 
Mol, Annemarie. 20I4. "A

Reader's Guide to the

'Ontological Turn' - Part 4."

Somatosphere. http://somatosphere. net/20I 4/o3/a-readers-guide-tothe-ontological-turn-part-4.html.

Morris, Rosalind C. 2008. "Rush/

Panic/Rush: Speculations on the

Value of Life and Death in South

Africa's Age of AIDS." Public

Culture 20 (2): I99-23 I.

Mosse, David. 2005. Cultivating

Development: An Ethnography of Aid

Policy and Practice. London: Pluto Press.

Mtyala, Quinton. 20I3. "Cape

Taxi Rank Faces Shutdown

Over Violence." Times Live,

March 28. www.timeslive.

co.za/thetimes/2OI3/03/28/

Cape-taxi-rank-faces-shutdown-

over-violence I.

Müller, Retief. 20I I. African

Pilgrimage: Ritual Travel in South

Africa's Christianity of Zion.

Farnham: Ashgate.

Nattrass, Nicoli. 2008. "AIDS and the Scientific Governance of Medicine in Post-Apartheid South Africa." African Affairs I07 (427): I $57-$ I 76 .

Needham, Rodham. I979. Symbolic Classification. Santa Monica: Goodyear Publishing.

Niehaus, Isak. I995. "Witches of the Transvaal Lowveld and Their Familiars: Conceptions of Duality, Power and Desire." Cahiers d'Etudes africaines 35 (2-3): 5I3-540.

Niehaus, Isak. I997. "A Witch Has No Horn': The Subjective Reality of Witchcraft in the South African Lowveld." African Studies 56 (2): $25 \mathrm{I}-278$.

Niehaus, Isak. 2000. "Coins for Blood and Blood for Coins: From Sacrifice to Ritual Murder in the South African Lowveld, I9302000." Etnofoor I 3 (2): 3 I-54.

Niehaus, Isak. 200I. Witchcraft, Power and Politics: Exploring the Occult in the South African Lowveld. London and Cape Town: Pluto Press and David Philip.

Niehaus, Isak. 2006. "Doing Politics in Bushbuckridge: Work, Welfare and the South African Elections of 2004." Africa 76 (4): 526-548.

Niehaus, Isak. 2007. "Death before Dying: Understanding AIDS Stigma in the South African Lowveld." Fournal of Southern African Studies 33 (4): 845-860.

Niehaus, Isak. 20I 3 a. Witchcraft and a Life in the New South Africa. Cambridge: Cambridge University Press.

Niehaus, Isak. 2013b. “Confronting Uncertainty: Anthropology and Zones of the Extraordinary." American Ethnologist 40 (4): $65 \mathrm{I}-660$.

Niehaus, Isak, and Gunvor Jonsson. 2005. "Dr. Wouter Basson, Americans, and Wild Beasts: Men's Conspiracy Theories of HIV/AIDS in the South African Lowveld." Medical Anthropology 24 (2): I79-208.

Nienaber, Petrus M. 2005. An Industry under Siege. Speech of the Ombudsman for Longterm Insurance on opening the LOA's Annual General Meeting, November I 8. Ombudsman for Long-term Insurance, Cape Town.

Nienaber, Petrus M., and Jeniffer Preiss. 2006. "Funeral Insurance: A Perception from the Office of the Ombudsman for Long-term Insurance." South African Mercantile Law fournal I 8: 29I-3 I 6.

Niksic, George. 2004. "Difficult but Not Impossible: The ANC's Decentralization Strategy in South Africa." Development and Change 35:353-374.

Nnadozie, Remigius C. 20I3. "Access to Basic Services in PostApartheid South Africa: What Has Changed? Measuring on a Relative Basis." African Statistical fournal I6: 8I-IO3. 
Nombembe, Philani. 201 5. "'Greedy' Widow Thandi Maqubela Jailed for I 8 Years." Times Live, March 3 I.

Ntsebeza, Dumisa. 2005. Committee of Inquiry into the Underlying Causes of Instability and Conflict in the Minibus Taxi Industry in the Cape Metropolitan Area. Cape Town.

OECD. 2008. OECD Territorial Reviews: Cape Town, South Africa 2008. Paris: OECD Publishing.

Oellermann, Ingrid. 20I3. "State Wants Life for Insurance Murders." News 24, November 2I. www.news24.com/Archives/ Witness/State-wants-life-forinsurance-murders-20I 50430.

Oliver-Evans, Ceridwen. I993. Employment and Urbanisation: The Impact of the Abolition of Influx Control in the Western Cape. Cape Town: Southern Africa Labour and Development Research Unit.

Orwell, George. I945. Animal Farm: A Fairy Story. London: Secker and Warburg.

Palomera, Jaime. 20I4. "Reciprocity, Commodification, and Poverty in the Era of Financialization." Current Anthropology 55 (S9): SI05-SII 5 .

Pauw, Kalie, and Liberty Mncube. 2007a. The Impact of Growth and Redistribution on Poverty and Inequality in South Africa. DPRU working paper 07/I 26. Development Policy Research Unit, Cape Town.

Pauw, Kalie, and Liberty Mncube. 2007b. Expanding the Social Security Net in South Africa: Opportunities, Challenges and Constraints. DPRU working paper 07/I 27. Development Policy Research Unit, Cape Town.

PCAS. 2008. Development Indicators 2008. Pretoria: The Presidency, Republic of South Africa.

Pfeiffer, James. 2003. "International NGOs and Primary Health Care in Mozambique: The Need for a New Model of Collaboration."
Social Science E Medicine 56 (4): 725-738.

Phaliso, Sandiso. 20I I, "Insurance Murder Shock." The New Age, September 23.

Pilane, Pontsho. 2016. "Insurance Groups Fight Bid to Halt Social Grant Deductions." Mail and Guardian, May I3-I9.

Polanyi, Karl. 1944. The Great Transformation: The Political and Economic Origins of Our Time. Boston: Beacon Hill.

Ponte, Stefano, Simon Roberts, and Lance van Sittert. 2007. “'Black Economic Empowerment,' Business and the State in South Africa." Development and Change 38 (5): 933-955.

Popkin, Samuel L. I975. The Rational Peasant: The Political Economy of Rural Society in Vietnam. Berkeley: University of California Press.

Porteous, David. 2003. Understanding the (Prototype) Financial Summary Measure (FSM). Mellville:

Finscope.

Porteous, David. 2005. The Access Frontier as an Approach and Tool in Making Markets Work for the Poor. Summerville: Bankable Frontier Associates.

Porteous, David, and Ethel Hazelhurst. 2004. Banking on Change: Democratizing Finance in South Africa I994-2004 and Beyond. Cape Town: Double Storey Books.

Posel, Deborah. 2005. "Sex, Death and the Fate of the Nation: Reflections on the Politicization of Sexuality in Post-Apartheid South." Africa 75 (2): I25-I 53.

Poundstone, William. I992. Prisoner's Dilemma. Ann Arbor: Doubleday.

Power, Michael. I997. The Audit Society: Rituals of Verification. Oxford: Oxford University Press. Prahalad, Coimbatore K. 2004. Fortune at the Bottom of the Pyramid: Eradicating Poverty through Profits. 
Upper Saddle River: Wharton School Publishing.

Prinsloo, Dirk A. 2010. Classification and Hierarchy of Retail Facilities in South Africa. Johannesburg: Urban Studies.

Rakopoulos, Theodoros. 20I4. "The Crisis Seen from Below, Within and Against: From Solidarity Economy to Food Distribution Cooperatives in Greece." Dialectical Anthropology 38: I 89-207.

Ramaphosa, Cyril. 20I4. "SA Needs More than I6\% Black Actuaries Cyril Ramaphosa." City Press, February 2I. www.news24.com/ Archives/City-Press/SA-needsmore-than-I6-black-actuariesCyril-Ramaphosa-20I 50429.

Ramose, Mogobe B. I999. African Philosophy through Ubuntu. Harare: Mond Books.

Ramphele, Mamphela. I989. "The Dynamics of Gender Politics in the Hostels of Cape Town: Another Legacy of the South African Migrant Labour System." Fournal of Southern African Studies I 5 (3): 393-4 I 4 .

Ramphele, Mamphela. I99I. The Politics of Space: Life in the Migrant Labour Hostels of the Western Cape. Doctoral thesis. University of Cape Town.

Ramphele, Mamphela. I993. A Bed Called Home: Life in the Migrant Hostels of Cape Town. Edinburgh: Edinburgh University Press.

Ramphele, Mamphela. 20 I 2. Conversations with My Sons and Daughters. Johannesburg: Penguin Books.

Reid, Graeme, and Liz Walker (eds.). 2005. Men Behaving Differently: South African Men Since I994. Cape Town: Double Storey.

Reno, William. I995. Corruption and State Politics in Sierra Leone. Cambridge: Cambridge University Press.

Reporter. 2008. "Manuel: SA 'Reasonably Insulated' from
Financial Storm." Mail and Guardian, October Io. https:// mg.co.za/article/2008-IO-IOmanuel-sa-reasonably-insulatedfrom-financial-storm.

Roitman, Janet. 2005. Fiscal Disobedience: An Anthropology of Economic Regulation in Central Africa. Princeton and London: Princeton University Press.

Rorty, Richard. [1989] 2007. Contingentie, ironie and solidariteit. Kampen: Ten Have.

Ross, Fiona. 20I 2. "African Women and Apartheid: Migration and Settlement in Urban South Africa." Fournal of Contemporary African Studies 30 (2): 373-375.

Ross, Robert. I999. A Concise History of South Africa. Cambridge: Cambridge University Press.

Rumsfeld, Donald. 20I I. Known and Unknown: A Memoir. New York: Penguin.

SABC. 20I4. "Insurance Fraud on the Rise." $S A B C$, February I2. www.sabc.co.za/news/a/ abf6b9804e $870 a 6 f b 649$ fe 7 da $4 \mathrm{~cd} 6 \mathrm{ad} 7 /$ Insurance-fraud-on-therise.

Sahlins, Marshall. I972. Stone Age Economics. New York: Aldine de Gruyter.

Sahlins, Marshall. I985. Islands of History. Chicago: University of Chicago Press.

Samuels, Annemarie. 20I 5. "Narratives of Uncertainty: The Affective Force of ChildTrafficking Rumors in Postdisaster Aceh, Indonesia." American Anthropologist I I7 (2): 229-24I.

Sanpath, Arthi. 20I 5. "Cases Reveal Insurance Murder Web." Independent Online, February 28. www.iol.co.za/ios/news/ cases-reveal-insurance-murderweb-I 825046 .

SAPA. 2008. "IRF: HIV and Aids Financial Impact Dramatic." Independent Online, August 26. www.iol.co.za/news/south-africa/ 
irf-hiv-and-aids-financial-impactdramatic-4I3905.

SAPA. 20I 2. "Trio Get Five Live Sentences." Independent Online, March 23. www.iol.co.za/news/ crime-courts/trio-get-five-lifesentences-I 26302I.

Sayer, Derek. 1987. The Violence of Abstraction: The Analytic Foundations of Historical Materialism. Oxford: Basil Blackwell.

Scaff, Lawrence A. 20I I. Max Weber in America. Princeton: Princeton University Press.

Schalekamp, Herrie, and Roger Behrens. 20I0. "Engaging Paratransit on Public Transport Reform Initiatives in South Africa: A Critique of Policy and an Investigation of Appropriate Engagement Approaches.” Research in Transport Economics 29: 37I-378.

Schalekamp, Herrie, Roger Behrens, and Peter Wilkinson. 2010.

Regulating Minibus-Taxis: A Critical Review of Progress and a Possible Way Forward. Proceedings of the 29th Southern African Transport Conference (SATC 2010), August I6-I9. Pretoria.

Schneider, Marguerite, Princelle Dasappa, Neloufar Khan, and Azam Khan. 2009. "Measuring Disability in Censuses: The Case of South Africa." ALTER: European Fournal of Disability Research / Revue Européenne de Recherche sur le Handicap 3 (3): 245-265.

Schraten, Jürgen. 20I 5 . Habits of Austerity: Financialization and New Ways of Dealing with Money. In Economy for and against Democracy, edited by K. Hart, I9-38. New York and Oxford: Berghahn.

Scott, James C. I977. The Moral Economy of the Peasant: Rebellion and Subsistence in Southeast Asia. New Haven: Yale University Press.
Seekings, Jeremy, and Nicoli Nattrass. 200I. "Democracy and Distribution in Highly Unequal Economies: The Case of South Africa." Fournal of Modern African Studies 39 (3): 47 I-498.

Seekings, Jeremy, and Nicoli Nattrass. 2005. Race, Class, and Inequality in South Africa. New Haven: Yale University Press.

Sharp, John. 2008. "Mafeje and Langa: The Start of an Intellectual's Journey." Africa Development 33 (4): I 53-I67. Sharp, John S., and Andrew D. Spiegel. I985. "Vulnerability to Impoverishment in South African Rural Areas: The Erosion of Kinship and Neighborhood as Social Resources." Africa 55 (2): I33-I 52 .

Shipton, Parker MacDonald. I989. Bitter Money: Cultural Economy and Some African Meanings of Forbidden Commodities. Washington: American Ethnological Society. Shipton, Parker MacDonald. 2007. The Nature of Entrustment: Intimacy, Exchange, and the Sacred in Africa. New Haven: Yale University Press.

Shipton, Parker MacDonald. 20 Iо. Credit between Cultures: Farmers, Financiers, and Misunderstanding in Africa. New Haven: Yale University Press.

Sibanda, Julia J. 20I3. "Taxi Violence Hits Cape Town." Nerws24, November I 4. www.news24.com/ MyNews24/Taxi-Violence-HitsCape-Town-20I 3 I I I 4 .

Simmel, Georg. [1900] I990. The Philosophy of Money. London and New York: Routledge.

Sindane, Jabu, and Ian Liebenberg. 2000. "Reconstruction and the Reciprocal Other: The Philosophical Practice of Ubuntu and Democracy in African Society." Politeia I9 (3): 3 I-46.

Southall, Roger. 2007. "Ten Propositions about Black Economic Empowerment in South 
Africa." Review of African Political Economy 34 (III): 67-84.

Spiegel, Andrew. I987. Dispersing

Dependants: A Response to the

Exigencies of Labour Migration in Rural Transkei. In Migrants, Workers, and the Social Order, edited by Jeremy Eades. London and New York: Tavistock Publications.

Strathern, Marilyn. I988. The Gender of the Gift: Problems with Women and Problems with Society in Melanesia. Berkeley: University of California Press.

Strathern, Marilyn. 2000. Audit Cultures: Anthropological Studies in Accountability, Ethics, and the Academy. London: Routledge.

Strydom, T.J. 2017. "Churches Warn South Africa Becoming a 'Mafia State'." Reuters, May I9. http:// af.reuters.com/article/topNews/ idAFKCNI $8 \mathrm{~F}_{I} 3$ 8-OZATP?pageN umber ${ }_{\mathrm{I}}$ \& virtualBrand Channel $=0$.

Taylor, Lawrence J. 200I. "'Paddy's Pig': Irony and Self-Irony in Irish Culture." Irony in Action: Anthropology, Practice, and Moral Imagination, edited by J.W.

Fernandez and M.T. Huber, I72-I 87. Chicago and London: University of Chicago Press.

Terpe, Sylvia. 20I 2. "'Mit Gefühl' im Wohlfahrtsstaat: Berechenbarkeit, Gleichbehandlung und Transparenz in der entbürokratisierten Arbeitsverwaltung." Wechselverhältnisse im Wohlfahrtsstaat: Dynamiken gesellschafticher Fustierungsprozesse, edited by M.P.M. Bereswill, C. Figlestahler, L.Y. Haller, and F. Zahradnik, 2I2-232. Münster: Westfälisches Dampfboot.

Thamm, Marianne. 2017. "Parliament: Sassa's Surprise Plan to Deduct I०\% from Grants for Funeral Policies Unearthed." Daily Maverick, June 2.
Thoden van Velzen, Hendrik U.E. I995. "Revenants That Cannot Be Shaken: Collective Fantasies in a Maroon Society." American Anthropologist 97 (4): 722-732.

Thomson, Rob, and Deborah Posel. 2002. "The Management of Risk by Burial Societies in South Africa." South African Actuarial fournal 2: 83-I 27.

TRC. I998. Regional Profile Western Cape. In TRC Final Report, Volume 3, 390-527. Truth and Reconciliation Commission.

Van Binsbergen, Wim. 200I. "Ubuntu and the Globalisation of Southern African Thought and Society." Quest: An African fournal of Philosophy I 5 (I-2): 53-89.

Van der Zwan, Natascha. 20I4. "Making Sense of Financialization." Socio-Economic Review I 2: 99-I 29.

Van Wyk, Ilana. 20I 2. "Tata Ma Chance': On Contingency and the Lottery in Post-Apartheid South Africa." Africa 82 (I): 4I-68.

Van Wyk, Ilana. 20I4. The Universal Church of the Kingdom of God in South Africa: A Church of Strangers. Cambridge: Cambridge University Press.

Verhoef, Grietjie. 200I. "Stokvels and Economic Empowerment: The Case of African Women in South Africa, c.1930-1998." Women and Credit: Researching the Past, Refiguring the Future. edited by B. Lemire, R. Pearson, and G. Campbell, 9I-II4. Oxford and New York: Berg.

Walters, Jackie. 2008. "Overview of Public Transport Policy Developments in South Africa." Research in Transport Economics 22: 98-Iо8.

Walters, Jackie. 20I0. "Is the Bus Transport Contracting System in South Africa Leading to Trusting Relationships between Contracted Parties? An Analysis of Funding 
Issues and the Impact on Relations between Government and Operators." Research in Transport Economics 29: 362-370.

Weber, Max. [1905] 1930. The Protestant Ethic and the Spirit of Capitalism. London and Boston: Unwin Hyman.

Western Cape Government Provincial Treasury. 2017. Municipal Economic Review and Outlook 2017. Cape Town: Western Cape Government Provincial Treasury.

Wicks, Jeff. 201 5. "Body Stolen in Insurance Scam." Nerws24, March 2I. www.news24.com/Archives/ Witness/Body-stolen-in-insurancescam-20I 50430.

Wilhelm-Solomon, Matthew. 2017. "Vital Instability: Ontological Insecurity and African Urbanism." Critical African Studies 9 (2): I4 I-I 5 I.

Wilkinson, Peter. 2010. "The Regulatory Cycle Stalled? An Assessment of Current Institutional Obstacles to Regulatory Reform in the Provision of Road-based Public Transport in Cape Town, South Africa." Research in Transport Economics 29: 387-394.

Wilson, Francis. I972. Migrant Labour. Johannesburg: South African Council of Churches and SPRO-CAS.

Wilson, Monica, and Archie Mafeje. I963. Langa: $A$ Study of Social Groups in an African Township. Cape Town, London and New York: Oxford University Press.
Wolf, Angelika. 20I 2. Health Security on the Move: Biobureaucracy, Solidarity and the Transfer of Health Insurance to Senegal. In Medicine, Mobility, and Power in Global Africa: Transnational Health and Healing, edited by H. Dilger, A. Kane, and S.A. Langwick, 92-I I 4. Bloomington: Indiana University Press.

Wolf, Eric. I999. Envisioning Power: Ideologies of Dominance and Crisis. Los Angeles and London: University of California Press.

Zaloom, Caitlin. 2006. Out of the Pits: Traders and Technology from Chicago to London. Chicago and London: University of Chicago Press.

Zelizer, Viviana A. I978. "Human Values and the Market: The Case of Life Insurance and Death in I9th-Century America." The American Fournal of Sociology 84 (3): 59I-6IO.

Zelizer, Viviana A. I995. Pricing the Priceless Child: The Changing Social Value of Children. Princeton: Princeton University Press.

Zerbst, Fiona. 20I I. "What You Need to Know about Trading Derivatives." Mail and Guardian, March 8. https://mg.co.za/ article/20I I-03-०8-what-you-needto-know-about-derivatives-trading.

Žižek, Slavoj. I 989. The Sublime Object of Ideology. London and New York: Verso.

Zuma, Jacob G. 2009. State of the Nation Address of June 3. Parliamentary Monitoring Group, Cape Town. 



\section{Index}

Note: Page numbers in italic indicate figures or tables; page numbers followed by $n$ indicate an endnote with relevant number.

abstraction: attraction of impersonal nature of insurance, I6, I49; dual meaning, I 5-I6, I66; as freedom, I74-5; LSM and FSM terminology, 77, 80, I04; malign aspects, 9-I 2; social disengagement, I 58 ; and solidarity, I69, I75-8

actuarial knowledge, 24, 57-8; see also classifications

Actuarial Society of South Africa (ASSA), 66, 7 I, IO4 actuaries, 37-8, 65-6; perception of African clients, $\mathrm{IO}_{3}-8, \mathrm{IO}_{4}$, I07, 176

advertising campaigns, 2-3

African identity, I79nI

African Life, 87

AIDS see HIV/AIDS

Alexander, Catherine, 23, 88

ANC (African National Congress):

disillusionment with, I3-I4;

financial inclusion, 2, 67-70, I73; and the insurance industry, $67-8$, $67,68,69-70,72-3$; land and resource redistribution, 42-4, I66, I 68-70; and the taxi industry, I7, I 28-9, I $38-9$

ancestors, 53, 107, 109, III, I 59-60

anthropology, 9-I 2, I76-8

apartheid era, 39, 40-2, I 25-6, I 50, I6I

Applbaum, Kalman, 55, 63

Assemblies of God, 5 I-2
Association of South African Black Actuarial Professionals (ASABA), 66

Azande, Zande thought, 26-8, 30-I, $3 I, 33, I 66, I 72$

baby farms, I42

Bank, Leslie J., IO2-3, I 28

banks and banking: avoidance of 2007 crisis, 9; Mzansi bank accounts, 60, 6I; trustworthiness, I07, I09, II 6

Bantustans, 4O, 4I, I 28

Black Economic Empowerment (BEE), 44-7, 67, 68

Black Sash, 93

Bloch, Maurice, 23

Bolshevik Revolution, I 8

Bond, Patrick, 7

Bourdieu, Pierre, 77-8, 98

bribery, 43, I36

bridewealth (lobola), 49

brokers see insurance brokers

BRT (Bus Rapid Transit), I 37

bureaucracy: in capitalist society, IO०-I; impersonal dimensions, I I6-I7, I 69-70; ombudsman organizations, 98-9; taxi industry claims, I33, I34-5; to avoid health insurance claims, 93-7

burial societies: compared with funeral insurance, I08, I 49; establishment, I 5; HIV adaptations, Ioo; informal businesses, 88-90; missed 
payment rules, I IO-I I, I 54; tensions, I09-I 3 ; trustworthiness, I07, I09, I 53-4; ZCC congregations, 87

Bus Rapid Transit (BRT), I37

call centers, 9I-2, IO5

Campaign of Israel, 52-3

cancellation, insurance policies, $8 \mathrm{I}, 83$

Cape Amalgamated Taxi Association (CATA), I 29-3 I, I34, I 36-7

Cape Flats: crime, I 2; Dookoom anger, I3-I4; fieldwork, 35-8; informal settlements, $42-3$; murder rate, I 2 ; poverty, I 3 ; taxi association violence, I 28-3I; violence, $145^{-6}$

Cape Town: inequality, I2-I3, 40-2; migrant hostels, 40-I; Section IO rights, 40, I 25-6

capitalism, IO०-I

Caplovitz, David, 83

car insurance, 4, I I 5

case studies, 37

CATA (Cape Amalgamated Taxi

Association), I 29-3 I, I 34, I36-7 Chan, Cheris Shun-ching, 55-6

Cheru, Fantu, 7

Chicago, IOI-2

child maintenance grants, $48-50$ church insurance schemes, $87-8$, 106 churches: independent churches, 6I, 86; prosperity churches, 5I-4; trustworthiness, I07, I09; Universal Church of the Kingdom of God (UCKG), 5I, 52-4, I I 4; Zion Christian Church (ZCC), 87-8

citizenship: apartheid era subjugation, 40-2, I 25-6, I6I; and Black Economic Empowerment (BEE), 44-7; financial inclusiveness, 2 , 67-70, 99, I65, I67-8, I73; and prosperity church redistribution, 5 I-4; racial inclusion, 2, 67-70, 99, I65, I67; and redistribution, 39-4I, 42-4, 54-5, I68-70; social grant entitlements, 47-5 I, I68-9

claims: bureaucracy, 93-9, I33,

I 34-5; church help, 87 classifications: abstraction in use of LSM and FSM terminology, 77, 80, I04; for consumer markets, 57; effect on perception of the future, 58-9; frictions over meaning, 66; insurance risks, 57; marketing classifications, 59-65; and race, 60-I, 72, 77; sexuality and gender metaphors, 63, 78; widespread application, 60

Claussen, Alden, 59-60

Codeta (Congress of Democratic Taxi Associations), I 29-3 I, I34, I36-7

Cold War, 28-9

colored people, I79nI

Comaroff, Jean, and John L., 7

commission, insurance brokers, $8 \mathrm{I}$, $83,84,86$

Congress of Democratic Taxi

Associations (Codeta), I 29-3 I, I34, I36-7

consumer statistics: access limitations, 62; closed methods of data collection and analysis, 64-5; FSM (Financial Service Measurement), 59, 6I-5; government use, 72 ; insurance uptake, 4, 37; limited insights, 78; LSM I-5 profiles, 60-I, 72; LSM (Living Standard Measure), 59-60; market segmentation, 57; marketing classifications, 59-65; racial profile neutrality, 60-I, 66; unreliability, 64-5, 70-I

corruption, taxi industry, I 36, I 38 credit, 5, 7 cremation, $\mathrm{I} 48$ 
crime, I04; taxi robbery, I34-5; see also murder; violence

crop insurance, $\mathrm{I}_{42}$

cultural anthropology, 32-4

De Swaan, Abram, 57

death: dignity in, I74; fear of, 30-I; see also burial societies; funeral insurance

Department for International

Development (UK), 62

development, National

Reconstruction and Development

Programme, 42-3, I 83 nI 2

development organizations, 60, 66

Devereux, George, 79

disability insurance, 4, 95-6

Dookoom (music group), I3-I4

Douglas, Mary, 77

Dube, Modnli, I 48

Dugard, Jackie, I 29

economic anthropology, 9-I 2,

$$
\text { 22-3 }
$$

Economic Development and Labor

Council (NEDLAC), 66-7

Edith (research assistant), 35, 36, 64, I 24

education insurance, 4

entrepreneurship, 44-5, 54

ethnography, I76-8

Evans-Pritchard, Edward E., 26-8, 33, I 66

Ewald, François, 27, 58

exclusionary clauses, 75

family see kinship relations

fatherhood, I 5 I-2, I $63-4$

Ferguson, James, 7

Fernandez, James W., I7 I

financial crisis (2007), South Africa's avoidance, 9

financial education, 104 , IO5-6, I I 5

financial inclusion, 2, 67-70, 99, I $65, \mathrm{I} 67, \mathrm{I} 73$ financial literacy, I04, IO5-6, I I 5

financial mutuals see umgalelo

(financial mutual)

Financial Sector Charter (2002), 67

Financial Service Measurement see FSM (Financial Service Measurement)

financialization: in Africa, 4-7; definition, 4-5; taxi industry, I 32-4, I37-9, I73-4; to overcome racial inequalities, 8

FinMark, 62, 7 I

FinScope, 6I-2

foster parenting, I 42

fraud, 97, I46-5I

FSM (Financial Service

Measurement): collection and processing methods concerns, 63-5; data access limitations, 62;

financial behavior and products survey, 6I-3; symbolically "neutral" terminology, 65, 66-7, 77,80, IO4

funeral insurance: advertising, 2; care and responsibility, I4I; compared with burial societies, I08, I49; immoral behavior of kin, I42, I44, I 50-62, I63; immoral behavior of strangers, I43-9, I44; and infanticide, I42; ironic nature, 4, 3I; social grant deductions, 92; suspicions of abuse, I 42 ; taxi industry, I34; uptake, 4, II 5 ; ZCC scheme, 87-8; see also burial societies; life insurance

funerals: place of burial disputes, I 5 I, I 52, I 59-60; tensions, I4 I furniture loan insurance, 4

Galpin, Jacky, 60 game theory, 29-30 Ganti, Tejaswini, I 68 gender: marketing discourse, 63; and migrant networks, II7; see also women 
generational inequalities, $47-5 \mathrm{I}$,

I 6 I-2, I 63

gift-giving, I 8-2I

girls, teen pregnancies, $48-9,50$

Gluckman, Max, 33-4; Analysis of a Social Situation in Modern

Zululand, 34, 102

Golomski, Casey, I 62

government: trustworthiness, I07,

I09; see also ANC (African

National Congress)

Guyer, Jane I., 54

Hacking, Ian, 58

Handelman, Don, I40-I

Hann, Chris M, 23

Hart, Keith, I 2, 58-9

Hastrup, Kirsten, 79-80

health insurance: bureaucratic

exclusions, 95; Joyce's problems,

93-7; National Health Insurance

Scheme (NHI/NHIS), 68-9,

7I-2, 7I, 72; uptake, 4

health service, 6, 69, I05

Historically Disadvantaged

Individuals (HDI), 45-7

HIV/AIDS: and burial societies, Ioo;

deaths, 48, 49, 73; infection risks,

47,73 ; insurance policies, 69;

testing and insurance problems,

74-5; unreliability of government statistics, 7I

households: consequences of apartheid,

$4 \mathrm{I}-2$; trustworthiness, 107

housing, 42-3, 60, 6I

housing loan insurance, 4

Huber, Mary Taylor, I7 I

human economy, I 2

identity: changing nature, $102-3$; problems of definition, I79nI

Indawo Yoxolo: development policies, 42-3; insurance uptake, 4, 37; morality of funerals and death, I43-5; neighborhood tensions, I I $3-\mathrm{I} 4$; redistribution of resources, 42-4; squatter camp, 36-7; trustworthiness, I०8-9; violence, $43-4$

inequality: Cape Town, I 2-I4, 40-2; consequence of credit, 5 ; consumer profiling ambiguity, 60-2; elite/LSM I-5 interactions, 79-80; insurance industry, 9I, I74-5; and insurance sustainability, IO4; intergenerational, 47-5I, I6I-2, I63; language barriers, 92; and neoliberalism, 7-8, II; see also financial inclusion; redistribution infanticide, I 42 informal financial arrangements, $62-3$

insurance: alternative to gift-giving and solidarity systems, $2 \mathrm{I}-2$; collective-private tensions, 26; as redistribution, 22-3

insurance brokers, $82-6$; commission, $8 \mathrm{I}, 83,84,86$; misrepresentation of prospects, $84-5$; social pressures, 82, 85, 91, 98-9; training, 83-4

insurance companies, I4, 7I-2, I06; trustworthiness, I06-7, 107, I09 insurance intermediaries, $8 \mathrm{I}-2$, 88-9I, I 47 insurance murder, I43, I44, I47-9, I 50

insurance penetration: targets, I79n2; uptake statistics, 4, 37 insurance policies: cancellation, $8 \mathrm{I}, 83$; missed payments, 88 ; preferred for impersonal nature, I6, I I6-I7, I I , I 49

insurance professionals: life insurance fraud, I 46-9; worry over violence, 78-9; see also actuaries intermediary organizations, $8 \mathrm{I}-2$, 88-9I, I47 investment fund insurance, 4 
irony: ambiguity, 24, I7I, I89n4; of funeral insurance, $4,3 \mathrm{I}$; and insurance policy purchase, 4,26 , 3 I; "iron cage" (Weber's use), IOI-2, I I 6; of life insurance, I 43; and rationality, 26-8; and research methods, 36-8, I76-8; of solidarity, 3-4, 24-5, I62, I7I; of Zande thought, 26-8, 30-I, 33, I66

James, Deborah, 7, I05

Kalela Dance, 34

Kapferer, Bruce, 34

Kganya Group, 87

Khayelitsha, 37, I 29-30, I 45

Khayelitsha massacre, I29-3 I

Kholiswa (taxi owner), I 20-4, I 28 kinship relations: abstraction of insurance distribution, I69-70; affinal tensions, I 53-6; burial society tensions, I I I-I 3 ; effects of apartheid, I 50, I6I; effects of credit, 5; and gift-giving, 2I; immoral behavior over funeral/life insurance, I 42-5, I44, I 50-62; insurance murder convictions, I 50 ; Jama's death, I 5 I -3 ; loyalty and burial societies, I I $2-\mathrm{I}_{3}$; migration effects of apartheid laws, 40-2; mother-child relations, I 43 , I 56-8; Mphilo's death, I 53-6; rituals, 53, I 40 ; tensions, I $53^{-6}$, I74; trustworthiness, 107, I09; and witchcraft, I70; see also generational inequalities

Klein, Naomi, 7

Krippner, Greta R., 8

Kuju, Mandisa, 35

labor migration, 40-I, I63-4 Lagunya taxi association, I 27-9 Langa township, 2, 40-I, IO2 language barriers, 92, 98, I05 library cleaning contract, 45

life insurance: definition, I 40 ; fraud and bureaucracy, 97; immoral behavior of kin, I42, I44, I 50-62, I 63; immoral behavior of strangers, I 46-9; ironic nature, I43; kinship tensions, I 50-62; LSM I -5 category access target, 67; mixed motives, I 62; moral hazard, I40; moral issues, I46; social disengagement, I 58 ; see also burial societies; funeral insurance living conditions, $42-4$ loans, 4 , III, I 22, I33-4

LSM (Living Standard Measure): background, 59-60; consumer behavior survey, 59; LSM categories I-5, 60-I; symbolically "neutral" terminology, 6I, 66, 77, 80, IO4

Mafeje, Archie, IO2

Malinowski, Bronislaw, 32-3

Manchester School, 33-4

Mandela, Nelson, I3

Manuel, Trevor, 9, 47

Maori society, I 8 marketing classifications, 59-65 marketing strategies: African population, $\mathrm{I}-3$; aggressive sexual language, 63, 78; cultural practices, 56-7; fear of the future, 56; informal methods, 89-90

Maurer, Bill, 9, II, 77

Mauss, Marcel, I66; The Gift, I 8-20, II 7

Mayer, Philip and Iona, IO2

Mbeki, Thabo, 7 I

medical insurance see health insurance

Melanesian society, 20 middle classes, $5,5 \mathrm{I}$ migrant labor, 40-I, I63-4 migrant networks, I $5, \mathrm{IO}_{2}-3$, I I 7 Miraftab, Faranak, 7 
Mitchell, Clyde J., 34

Mkhize, Maningi, I 48

Mlaba (taxi driver), I 24-5, I 27-8

moral hazard, 22, I4O

morality: burial society rulings,

I IO-I 3 ; of insurance sector, 22;

prisoner's dilemma, 29-30, 3I;

public-private divide, $25-6$

mother-child relations, I 56-6I, I 63, I 64

motor insurance, 4 , I I 5

murder: for insurance money, I43,

I44, I 47-9, I 50; statistics, I 2

Mzansi bank accounts, 60, 6I

National Economic Development and Labor Council (NEDLAC), 66-7

National Health Insurance Scheme (NHI/NHIS), 68-9, 7I-2, 7I, 72

National Reconstruction and Development Programme, 42-3, I 83 nI 2

National Social Security Fund (NSSF), 68, I $85 n_{1} 8$

Ndzumeka, Vuyisile and Yalezwa, I47-8, I 49

NEDLAC (Economic Development and Labor Council), 66-7

neighborhood relations: consequences of apartheid, 40-2; and life insurance, I62; savings and credit groups, 62; survey, 36-7; tensions, II3-I4, I 22-3; trustworthiness, 107,109 , II 5-1 6 neoliberalism, 7-I2, I 5, I65-6, I 68 networks see migrant networks; social networks

Niehaus, Isak, I40-I, I6I-2, I63, I 64

Nyanga township, I 2, 40-I, I 27, I 29, I 45

Old Crossroads, I 20-4 Ombudsman for Long-Term Insurance, 97, 98 ombudsmen, 98-9

operational costs, $76-7,8 \mathrm{I}, 88$, 9I, 99

Parry, Jonathan, 23

participant observation, and survey research, 32-4, 36-8

pension funds, 4 , I I 5

Polanyi, Karl, 8, 9, 22-3, I75

poverty, IO4-5, IO4

poverty alleviation, 62 precautionary principle, 58

pricing: for HIV/AIDS uncertainties,

74-5; see also operational costs prisoner's dilemma, 29-30, $3 I$ procurement tenders, $45^{-6}$ prosperity churches, $5 \mathrm{I}-4$ provident funds, 4

racial inclusion, 2, 67-70, 99, I65, I67 racial inequality see Black Economic

Empowerment (BEE); inequality; redistribution

racial profiling neutrality, 60-I, 66 racism, 96, 97; see also apartheid era Ramphele, Mamphela, I3

RAND Corporation, 29

rational choice theory (RCT), 28-3I, $3 I, I 7 I-2$

rationality, 26-8, 70, 72-3

Recap (Taxi Recapitalization

Programme), I 20, I3 I-7

redistribution: and insurance, I $67-8$;

insurance as a form of, 22-3;

ontological change, 39-40; politics of, I 5, 22-3; post-apartheid era citizenship, 39-40, 42-4, 54-5, I66, I68-70; social and abstract characteristics, I68-70; social and moral consequences, 54-5; see also social grants

religion see church insurance schemes; churches

research methods: abstraction versus sociality, I76-8; and anxiety, 79; case study, 33-5, 37; epistemology, I7I, I76-7; irony, 
36-8, I76-8; isolation defence, 79-80; Kalela Dance, 34; mixed methods approach, 34, 37-8; neighborhood survey, 2, 4, 36, 38, I07, IO8-9, I43-5, I44; online survey (actuaries), 37, 38 , 65-6, 67, 68, 7I-2, 7I, 72, I04-5, I04, I06-8, I07; participant observation, 32-4; reflexivity, 25-6, 34-5, I77

retirement annuity bureaucracy, 96-7 risks: actuarial knowledge, 24; classification of risks, 57-9; HIV/ AIDS uncertainties, 74-5; LSM I-5 clients, 73-7; passed to intermediary bodies, 90-I; surveys on consumer perception, 63 ; of violence, 73

rituals, 34, 53, I40

Roitman, Janet, 23

Rorty, Richard, 25-6, I70-I

Rumsfeld, Donald, I 8 InI 2

Sahlins, Marshall, 23

savings groups see umgalelo

(financial mutual)

Section Io rights, 40, I 25-6 sexual violence, 63

Shipton, Parker, 5 singing groups, 2, I 5, 60, 6I social disengagement, $\mathrm{I} 58$ social grants, 47-5 I, 92-3, I68-9 social networks, 2, I 5 social pressures: and gift-giving, 20-I; insurance brokers, 82,85 , 9I, 98-9

social security: beneficiaries, 47; National Social Security Fund (NSSF), 68, I $85 n_{I} 8$

socialism, 70 solidarity: and abstraction, I69, I $75^{-} 8$; as conflict, I 7 I -5 ; cruelty and suffering, I72-3; embedded and abstract characteristics, I69; and immoralities, IO-I2; insurance influences, $6-7$; insurance a type of, 22, I67-70; ironic nature, $3-4,24-5,162$, I $7 \mathrm{I}$; protection and care, I72-4; taxi associations, I 27-8, I3 I, I 34 South African Advertising Research Foundation (SAARF), 60, 7 I stahlhartes Gehäuse, IOI-2, I I6; see also Weber, Max

statistical analysis, 36-8; see also classifications; consumer statistics

Strathern, Marilyn, I66; The Gender of the Gift, 20, I I 7

taxi associations: and the ANC, I7, I 28-9, I38-9; financialization, I 32-4, I37-9, I73-4; identities and affiliations, I29; Khayelitsha massacre, I 29-3 I; politicization, I20, I 29-3 I; social protections, I I9; solidarity, I 27-8, I3 I, I 34 ; violent rivalry, I 28-3 I, I 36-7 taxi industry: aggression, I 24-5; and BRT buses, I37; finance, I20, I2I, I22; importance, I I9; insurance claim bureaucracy, I33, I34-5; insurance schemes, I32; passenger car taxi problems, I 20-4; vehicle purchasing loans, I33-4; vehicle scrapping scheme, I32, I33 Taxi Recapitalization Programme (Recap), I 20, I3 I-7

Tembani, 4, 37, Iо8-9, I I4, I43-5; insurance uptake, 4, 37

Thoden van Velzen, H.U.E., 47 training, for insurance brokers, 83-4 trickle-up economy, I38-9, I75 trustworthiness, 107, 108-9, 109, I I 5-I 6, I 53-4

Tutu, Desmond, I3, I89n5

Ubuntu philosophy, I 89 n 5 umgalelo (financial mutual): disappointments, I I4-I 5 ; membership benefits, 20-I, I 20, I2 I, I22; trustworthiness, I07, I07, 108-9, 109 
unemployment, 36-7, 48, 75

Unemployment Insurance Fund

(UIF), 4, II 5, I32

United Kingdom, Department for International Development

(DFID), 62

Universal Church of the Kingdom of God (UCKG), 5 I, 52-4, I I4

Van Wyk, Ilana, 53

violence: Big Five intimidation, 43-4;

business competition, 46-7; Cape

Flats, I 45-6; fears of insurance

professionals, 78-9; fears of white elite, 79; of gift-giving, I 8-2I; and insurance sustainability, I 04; Joyce's shooting, 93-5; and neoliberalism, 7-8, II; over funeral details, I 59-60; risks, 73; sexual violence, 63; taxi associations, I28-3 I, I36-7

wages, I $88 n 7$; see also insurance brokers, commission wealth, prosperity churches, $5 \mathrm{I}-4$ Weber, Max: stahlhartes Gehäuse (iron cage), IOI-2, II6; The Protestant Ethic and the Spirit of Capitalism, IOO-I
Webta taxi association, I 27-9 welfare, 58

white people, I79nI

Wilson, Monica, IO2

witchcraft: and body parts, I47; cultural practice, I05; involvement in death, I 5 5-6; and kinship relations, I70; and life insurance, I 53-6; suspicions of, 2I, I 23 , I60, I6I; Zande beliefs, 27-8, 33,172

Witdoeke paramilitary, I 28, I 29 women: apartheid era discrimination, 40; dependence on migrant men for survival, 4I; migrant networks, I 5 , I I 7 ; mother-daughter relations, I 5 6-8

World Bank, Living Standard Measure (LSM), 59-60

Xhosa people, 4O, IO3, II 7

Zande thought, 26-8, 30-I, 3I, 33, I66, I72

Zelizer, Viviana A., II 8, I4I-2

Zion Christian Church (ZCC), $87-8$

Zululand, 34

Zuma, Jacob, 44 







